\title{
Esther Vorburger-Bossart
}

Lebensgeschichten

von religiösen Frauen

im 20. Jahrhundert

Eine Analyse

identitätsgeschichtlicher

Themen

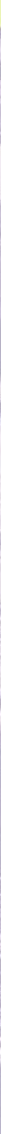



Esther Vorburger-Bossart

Lebensgeschichten von religiösen Frauen im 20. Jahrhundert 

Esther Vorburger-Bossart

\section{Lebensgeschichten \\ von religiösen Frauen \\ im 20. Jahrhundert}

Eine Analyse identitätsgeschichtlicher Themen 
Die Druckvorstufe dieser Publikation wurde vom Schweizerischen Nationalfonds zur Förderung der wissenschaftlichen Forschung unterstützt.

Der Theologische Verlag Zürich wird vom Bundesamt für Kultur mit einem Strukturbeitrag für die Jahre 2019-2020 unterstützt.

Bibliografische Informationen der Deutschen Nationalbibliothek

Die Deutsche Nationalbibliothek verzeichnet diese Publikation in der Deutschen Nationalbibliografie; detaillierte bibliografische Daten sind im Internet über http://dnb.dnb.de abrufbar.

Umschlaggestaltung

Simone Ackermann, Zürich

Unter Verwendung von Fotografien (im Uhrzeigersinn) aus:

Archiv Kloster Weesen; Kloster-archiv Wil; Archiv Kloster Baldegg, Ve/ S-Z; AIM Menzingen, V 1 Diversa, 1886-1992; Lütisburg Kinderdörfli; Archiv Katharinawerk, Basel, St. Gallen - Birnbäumen,

Satz und Layout

Claudia Wild, Konstanz

Druck

ROSCH Buch GmbH, Scheßlitz

ISBN 978-3-290-18344-8 (Print)

ISBN 978-3-290-18345-5 (E-Book: PDF)

https://doi.org/10.34313/978-3-290-18345-5

(C) 2020 Theologischer Verlag Zürich

www.tvz-verlag.ch 


\section{Inhalt}

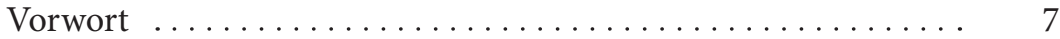

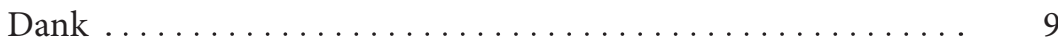

A. Einleitung . . . . . . . . . . . . . . . . 11

1.1 Thematische Einführung: Religiosität als Lebensentwurf in der Erinnerung . . . . . . . . . . . . . . . . 11

$1.2 \quad$ Methodischer Zugriff ................... 16

1.2.1. Forschungsstand ..................... 16

1.2.1.1. Subjektgeschichtlicher Ansatz zu religiösen Frauen in der Schweiz . . . . . . . . . . . . . . . . . . . . . . 17

1.2.1.2. Oral History in der Schweiz zu religiösen Frauengemeinschaften ..................... 18

1.2.1.3. Internationale Projekte zu Oral History und religiösen Frauengemeinschaften ................... 18

1.2.2. Interviewsample, Transkription und Auswertung . . . . . . 23

1.2.3. Erzähltopoi und religiöser Deutungshorizont . . . . . . . . 27

1.2.4. Fragestellungen ... . . . . . . . . . . . . . . . . . . . . . 29

1.2.5. Quellenkorpus, quellenkritische Anmerkungen und These ......................... 31

1.3 Kulturgeschichtlicher Grundriss zur Entstehung schweizerischer religiöser Frauengemeinschaften ..... 33

1.3.1. Kongregationen von Baldegg, Cham, Ilanz, Ingenbohl, Menzingen und Pallottinerinnen . . . . . . . . 33

1.3.1.1. Verberuflichung religiöser Frauen . . . . . . . . . . . . . 33

1.3.1.2. Katholisches Konzept zur sozialen Frage . . . . . . . . . . . 35

1.3.1.3. Katholische Sozialreformer . . . . . . . . . . . . . . . . . . 38

1.3.1.4. Schwestern zur Umsetzung der sozial-karitativen Idee . . . . . 44

1.3.1.5. Skizzen der Gemeinschaftsgründungen im 19. Jahrhundert . . . . . . . . . . . . . . . . . . 47

1.3.2. Religiöser Verein der St. Anna-Schwestern und Säkularinstitut St. Katharina-Werk . . . . . . . . . . . 56 
B. Kollektives Porträt: Lebensgeschichten religiöser Frauen des Katholizismus . . . . . . . . . . . . . . . . . . . . 59

2.1. Sozio-demografischer Rahmen: Familiäre Herkunft . . . . 59

2.1.1. Historischer Kontext: Nachkriegsjahre bis zur Jahrhundertwende ......................... 59

2.1.2. Katholische Familie und Pfarrei als Lebenswelt ....... 61

2.2. Religiöser Rahmen: Klösterliche Gemeinschaft als Wahlfamilie .......................... 64

2.2.1. Kloster als Bezugswelt für sinnstiftenden Lebensentwurf . . . . . . . . . . . . . . . . . . . . . . . . 64

2.2.1.1. Subjektkonstruktion im Spannungsfeld Kollektiv und Individuum . . . . . . . . . . . . . . . . . . . 64

2.2.1.2. Kommunikation, Organisation und Alter im Mutterhaus . . 70

2.2.2. Reguliertes und hierarchisches Klosterleben ......... 80

2.2.2.1 Reguliertes Klosterleben . . . . . . . . . . . . . . . . . $\quad 80$

2.2.2.2. Hierarchisches Klosterleben . . . . . . . . . . . . . . . . 81

2.3. Konfessioneller Rahmen: Katholische Kirche als Konstante ................................ 91

2.3.1. Geistliche und theologische Inhalte . . . . . . . . . . . 91

2.3.2. Frömmigkeit und religiöse Praxis . ............. 93

2.4. Professioneller Rahmen: Berufung und Profession ..... 94

2.4.1. Erzählungen zur Berufung . . . . . . . . . . . . . . . . 94

2.4.2. Berufung als Profession? . . . . . . . . . . . . . . . . 103

2.4.3. Kloster als Bildungsort . . . . . . . . . . . . . . . . . . . 108

2.4.4. Autonome oder regulierte Planung ............. 113

2.5. Erzählstrukturen . . . . . . . . . . . . . . . . . . 117

2.6. Unerzählte Elemente . . . . . . . . . . . . . . . . . . 121

2.7. Fazit . . . ......................... 124

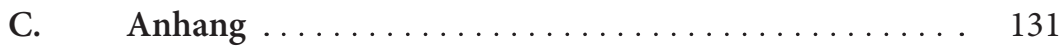

Bildnachweis ......................... 131

Interviews ........................... 131

Biografische und soziodemografische Daten ........ 134

Beispiel einer transkribierten Lebensgeschichte ....... 137

Annexe zur Durchführung der Interviews

(Teil des Samplings) . . . . . . . . . . . . . . . . . . . 162

Abkürzungsverzeichnis ..................... 171

Quellenverzeichnis ....................... 172

Bibliografie .......................... 174 


\section{Vorwort}

Ein zeitgeschichtliches Phänomen, mit dem sich bis in die 1970er Jahre mehrere Tausend von Frauen über gut 150 Jahre auseinandergesetzt haben, ist am Verschwinden. Es handelt sich um die Lebensform religiöser Frauen, die verschiedene Arbeitsbereiche in der Gesellschaft nachhaltig aufbauten und soziale Dienste leisteten. Diesem christlich motivierten Lebensmodell ist diese Arbeit gewidmet.

Das nachfolgende Porträt möchte die Identität geistlicher Schwestern über authentisch erzählte Lebenskonstruktionen nachzeichnen. Es zeigt ein Frauenbild, das erhebliche Leistungen sozialer, gesellschaftlicher und kultureller Art hervorbrachte.

Das durchschnittliche Lebensalter der an Mitgliederzahlen stark zurückgegangenen Kloster- oder Gemeinschaftsangehöriger beträgt um die 75 Jahre. Das Projekt versteht sich als Initialarbeit einer Forschungseinheit, die im kommenden Jahrzehnt die subjekt- und kulturgeschichtlicher Daten von Mitgliedern religiöser Gemeinschaften in der Schweiz sichern soll. Dasselbe hier für Frauengemeinschaften projektierte Konzept lässt sich im Anschluss daran auf die kontemplativen Orden mit denselben Lebensaltersstrukturen anwenden. In einem weiteren Schritt ist unter Berücksichtigung des geschlechtervergleichenden Ansatzes eine Untersuchung für Männerorden geplant. Die angestrebten Forschungsresultate leisten einen Beitrag zur Erweiterung der profanen Frauen- und Männergeschichte und erweitern die allgemeine Katholizismus- und Kirchengeschichte um die Perspektive religiöser Gemeinschaftsmitglieder. Deren vollständige Integration in die kulturgeschichtliche Forschung in diesen Bereichen steht nach wie vor aus.

Zusätzlich wird durch die mentalitätsgeschichtliche Komponente der lebensgeschichtlichen Erzählungen die aktuelle Debatte um die Vorwürfe zu missbräuchlichem Verhalten in kirchlichen Institutionen um die Sichtweise der in diese Vergangenheitsprozesse direkt involvierten Akteurinnen oder Akteure erweitert. 



\section{Dank}

Einen besonderen Dank richte ich an die 53 im Projekt beteiligten Schwestern, die mir ihr uneingeschränktes Vertrauen für die Gesprächsaufnahme schenkten und ihre erzählte Lebensgeschichte für diese Forschung zur Verfügung stellten. Sie verdienen eine grosse Anerkennung. Allen Provinz- und Generaloberinnen sowie weiteren für diese Aufgabe betrauten Schwestern gilt ebenfalls mein herzlicher Dank. Sie haben ihre Mitschwestern zur Teilnahme an diesem Projekt motiviert und dafür gesorgt, dass die interne Organisation und Vernetzung zur Aufnahme der Interviews in den Klöstern und Gemeinschaften reibungslos durchgeführt werden konnte. Namentlich möchte ich für die Ilanzer Dominikanerinnen Sr. Armina Maissen und Sr. Eugenia Jörger, für die Menzinger Schwestern Sr. M. Ursula Niedermann, für die Mitglieder des KatharinaWerks, Basel, Theres Bleisch, für die Ingenbohler Schwestern Sr. Reto Lechmann und Sr. Marie-Marthe Schönenberger, für die Pallottinerinnen Sr. Raphaela Fuchs, für die Chamer Olivetaner-Benediktinerinnen, Heiligkreuz, Sr. Simone Buchs sowie für die St. Anna-Schwestern Sr. Heidi Kälin und Sr. Rosa Scherer nennen. Den zuständigen Archivarinnen der Gemeinschaftsarchive danke ich für Archivierung der mündlichen Quellen und für die Bereitstellung von Akten.

Prof. Dr. Markus Ries möchte ich ebenfalls herzlich für die umsichtige Leitung des Projekts, auch für die anregenden Gespräche und die stets interessierte Begleitung des Forschungsvorhabens danken. Einen weiteren Dank möchte ich meiner Forschungsmitarbeiterin, Martina Blättler, MA, der Bearbeiterin der Lebensgeschichten von Diakonissen für die gute Zusammenarbeit sowie für den wertvollen Austausch interkonfessioneller Aspekte danken. Meinen weiteren Mitarbeitenden, den studentischen Hilfskräften, Samuela Schmid, Valeria Sogne und Pasquale Catena, sei für die Transkription der Interviews gedankt. 



\section{A. Einleitung}

\subsection{Thematische Einführung: Religiosität als Lebensentwurf in der Erinnerung}

Die vorliegende Studie ist Lebensgeschichten von katholischen Ordensschwestern und Mitgliedern religiöser Frauengemeinschaften gewidmet, die in Schweizer Mutterhäusern ihrer Gemeinschaften leben: in Baldegg, Basel, Cham, Ingenbohl, Ilanz, Luzern, Menzingen und Niederuzwil. Ziel ist die Erschliessung alltags- und religionsgeschichtlicher Daten. Mit der Methode «Oral History» sollen Lücken geschlossen werden, die nach Auswertung schriftlicher Quellen zu den Themen «Lebensgeschichten» und «individuelle religiöse Gestaltung des Ordenslebens» geblieben sind, oder die dadurch neu entstanden. Auf diese Weise lassen sich Informationen sichern, die aufgrund des hohen Alters der Gemeinschaftsangehörigen über kurz oder lang der Vergessenheit anheimfallen würden.

Die Ausgangslage ist bestimmt durch die Folgen fortschreitender Entkonfessionalisierung seit Mitte des 20. Jahrhunderts, die auch bei Schwesterngemeinschaften das religiöse Leben «nach innen» verlagerte. Untersucht wird der Zeitraum zwischen dem Zweiten Weltkrieg und dem Ende des 20. Jahrhunderts. Die Forschung des abgeschlossenen Forschungsprojekts «Religiöse Frauengemeinschaften der Ostschweiz im 20. Jahrhundert» ${ }^{1}$, das wie die vorliegende Studie vom Schweizerischen Nationalfonds gefördert wurde, sah die biografische Forschung, die die subjektgeschichtliche Perspektive der Schwester betrifft, nur partiell vor. Bereits diese punktuelle Erhebung hat indessen gezeigt und eine entsprechende Hypothese bestätigt, dass für die Erforschung der subjektiven Kultur- und Alltagsgeschichte von religiösen Frauen wenig schriftliche Quellen vorhanden sind. Die erörterten schriftlichen Materialien erwiesen sich als meist stereotype und standardisierte Dokumente. Die Erhebung inner-

1 Regula Schär, Diakonissen in der Ostschweiz im 20. Jahrhundert, Zürich 2018; Esther Vorburger-Bossart, Ordensschwestern in der Ostschweiz im 20. Jahrhundert, Zürich 2018. 
A. Einleitung

halb dieses Projekts ergab insbesondere für den Analysebereich «Identität», dass sich das Individuum der einzelnen Schwester gegenüber dem weitaus besser dokumentierten Kollektiv der Schwesterngemeinschaft in den schriftlichen Quellen kaum niederschlug. ${ }^{2}$ Die über den bisher angewandten methodischen Zugriff nicht erreichte Subjektforschung muss durch die Methode der Oral History über Interviews mit Schwestern erschlossen werden. Dieses methodische Vorhaben leistet zudem einen Beitrag, das schriftliche Material subjektgeschichtlich zu erhellen bzw. mündliche und schriftliche Quellen zu kombinieren, historiografisch gesehen ein Desiderat.

Das als interkonfessionelles Forschungsprojekt angelegte Vorhaben «Lebensgeschichten von Diakonissen und Ordensschwestern der Schweizer Mutterhäuser» leitet eine Vernetzung nationaler Forschung mit Arbeiten ein, die dieses Gebiet für andere Länder bereits erforscht haben. Bei diesem Vorhaben wurden zwei thematisch und methodisch miteinander verbundene Teilprojekte mit qualitativ-biografischer Methode Lebensgeschichten zugänglich gemacht. Martina Blättler erhob im Teilprojekt «Lebensgeschichten von Diakonissen in Schweizer Mutterhäusern» Daten evangelischer Schwestern; Esther Vorburger-Bossart leistete auf der gleichen Grundlage eine analoge Forschungsarbeit für die katholische Seite. Basis des Projekts bildeten je Konfession ca. 50 bis 60 Interviews. Die Zahl der Interviews wurde nach dem Prinzip des «theoretischen Samplings» im Voraus nur ungefähr festgelegt. Die Ergebnisse werden mit dem vorliegenden Werk in einer konfessionsspezifischen Studie zu den katholischen Ordensschwestern publiziert. ${ }^{3}$ Die Interviews bleiben in den Archiven der betreffenden Gemeinschaften archiviert.

Das Projekt «Religiöse Frauengemeinschaften in der Ostschweiz im 20. Jahrhundert» untersuchte die gesellschaftliche Bedeutung religiöser Frauengemeinschaften und ihrer sozialen Arbeit. Die Tätigkeit von Mitgliedern der Gemeinschaften wurde beschrieben, identitätsgeschichtlich analysiert und einem konfessionellen Vergleich unterzogen.

2 Zur einzelnen Schwester existieren kaum Akten; der entsprechende Nachlass weist in den meisten Fällen etwa eine Identitätskarte und Berufsabschlusszeugnisse auf. Akten, mit denen alltagsgeschichtliche und kulturhistorische Fragen angegangen werden könnten, fehlen weitgehend. Vgl. zum Nachlass der einzelnen Schwester: Esther Vorburger-Bossart, Ordensschwestern in der Ostschweiz im 20. Jahrhundert, Zürich 2018, S. $46 \mathrm{f}$.

3 Esther Vorburger-Bossart, Lebensgeschichten von religiösen Frauen im 20. Jahrhundert, Zürich 2020. 
Im Lauf dieser Arbeit, die sich auf Erhebungen in Dutzenden von Archiven stützt, hat sich, wie oben erwähnt, die für diese Forschung aufgestellte Hypothese bestätigt, dass sowohl auf reformierter wie auf katholischer Seite Selbstzeugnisse von Schwestern und Diakonissen, die einen wichtigen Beitrag zur Subjektforschung leisten könnten, nur in Ansätzen vorhanden sind. Deshalb sind Fragen nach individuellen Gestaltungs-, Wahrnehmungs- und Handlungsmustern in den Lebens-, Dienst- und Arbeitsgemeinschaften kaum zu beantworten. Um das Wissen in diesem Bereich zu erweitern, leisten Befragungen von Zeitzeuginnen einen zentralen Beitrag. Diese Einsicht führte zur Idee, ein weiteres Forschungsprojekt zu lancieren, welches die Fragestellungen des erwähnten Unternehmens mit Methoden der Oral History ergänzen wird.

Die zentrale Quellenbasis für die vorliegende Studie bilden auf katholischer Seite somit 53 Interviews, die zwischen April 2015 und November 2016 in acht verschiedenen religiösen Frauengemeinschaften durchgeführt wurden. Dabei waren die folgenden Kongregationen beteiligt: Menzinger Schwestern, Ingenbohler Schwestern, Baldegger Schwestern, Olivetaner Benediktinerinnen in Cham, Ilanzer Dominikanerinnen und Pallottinerinnen in Niederuzwil und Bernhardzell. Weiter bildeten Mitglieder des religiösen Vereins der St. Anna-Schwestern in Luzern und des Säkularinstituts St. Katharina-Werk in Basel einen weiteren Teil dieser Interviewpartnerinnen. Die Auswahl der Respondentinnen erfolgte erstens - zwangsläufig aus Gründen des hohen Alters der Ordensschwestern - nach dem Prinzip der gesundheitlichen Verfügbarkeit und zweitens nach Kriterien der möglichst differenzierten Wiedergabe der Berufs- und Hierarchiestrukturen der Gemeinschaften. Die Geburtsjahrgänge der Interviewpartnerinnen liegen zwischen 1918 und 1962. Entsprechend kann - mit dem lange Zeit geltenden jungen Eintrittsalter von ca. 20 Jahren - das früheste Professjahr im Jahr 1939 und der späteste Eintritt im Jahr 1999 verzeichnet werden. Die meisten der hier beteiligten Schwestern weisen Jahrgänge zwischen 1930 und 1945 auf. Entsprechend trat diese Gruppe schwerpunktmässig zwischen 1950 und 1965, also noch vor oder während der Konzilsjahre ins Kloster bzw. in die religiöse Gemeinschaft ein. ${ }^{4}$ Die Interviewaufnahmen fanden alle in den Klöstern oder Mutterhäusern der beteiligten Gemeinschaften, meist in für diese Interviews reservierten Gästezimmern statt.

4 Biografische Daten von Schwestern, SNF-Projekt «Lebensgeschichten religiöser Frauen in der Schweiz» 2015-2018. 
Die Rekrutierung der Interviewpartnerinnen erfolgte in den meisten Fällen über die Vermittlung der Provinz- oder Hausoberinnen, in zwei Fällen auch über die der Generaloberin. Diese sprachen ihre Mitschwestern auf das vorliegende Forschungsprojekt an und versuchten, diese von der Beteiligung zu überzeugen. In mehreren Fällen kamen weitere Schwestern, anlässlich einer meiner Aufenthalte in den Gemeinschaften, selber auf mich zu und boten mir ihre Beteiligung an diesem Projekt von sich aus an. Die Interaktionen zwischen den Schwestern und mir als Interviewerin und Historian gestalteten sich ausnahmslos alle freundlich. Die Schwestern brachten mir gegenüber eine herzliche Offenheit auf, obwohl ich nicht allen Schwestern vorher bekannt war. Allen Respondentinnen wurde bereits zum Zeitpunkt der Anfrage zu einem Interview eine weitreichende Anonymisierung der persönlichen Daten bei der Publikation zugesichert. ${ }^{5} \mathrm{Zu}$ Beginn der effektiven Aufzeichnung der Lebenserzählungen wurde diese nochmals in Erinnerung gerufen, um die Interviewpartnerinnen zu möglichst authentischem Erzählen zu animieren. So wurden in der Darstellung der Ergebnisse beispielsweise auch Ortschaften weggelassen, um eine Identifikation der einzelnen Schwester, mindestens für äussere Kreise der Leserschaft, ausschliessen zu können. Diese weitgehende Anonymisierung stützt sich auf Erfahrungen im Umgang mit Schwestern innerhalb früherer Forschungsarbeiten seit 2001. In zahlreichen spontanen Erzählungen von Teilen ihrer Lebensgeschichten während meiner Forschungsaufhalte in den Klosterarchiven hatten sich Schwestern nach Abschluss dieser Sequenzen stets ablehnend gegenüber einer Autorisierung dieser historisch wertvollen Wissensmomente für Forschungszwecke geäussert. Die vorgängig zur Aufnahme des Interviews zugesicherte Anonymisierung persönlicher Daten möchte der Selbstzensur der beteiligten Schwestern wie dem wiederholt geäusserten «aber das erzähle ich Ihnen dann natürlich nicht, wenn das Band läuft» zu kritischen Inhalten des Klosterlebens zuvorkommen.

Die Relevanz des Vorhabens liegt damit einerseits in der Erhebung und Sicherung lebensgeschichtlicher und nicht schriftlich dokumentierter Inhalte zu einem weiblichen religiösen Lebensmodell, das vom Aussterben gekennzeichnet ist. Als zentrales Untersuchungsgebiet ist über den biografischen Oral-History-Zugriff das bisher wenig erforschte Verhältnis von Beruf und Religion ins Blickfeld zu nehmen, das insbesondere

5 Die Belege zu den Interviews in den Anmerkungen enthalten aus diesem Grund nur eine verschlüsselt hinterlegte Nummer. 
für die tätigen Schwesterngemeinschaften ein eigentliches Forschungsdesiderat bildet. Mit diesem Schwerpunkt kann zusätzlich der gesellschaftlich bedeutende sozialökonomische Aspekt beleuchtet werden, der in diversen Gesprächen früherer Forschungen seitens der Schwestern häufig zur Sprache kam, sich aber in den schriftlichen Quellen kaum niederschlug. Neben den kulturellen und sozialen Komponenten vermag dieser Fokus die bisher kaum berücksichtigten wirtschaftlichen Beiträge der Schwesterngemeinschaften im schweizerischen Gesundheitswesen aufzeigen. Dass es sich dabei - in der Leistungserbringung an den Sozialstaat Schweiz als Ergebnis der Verschränkung von Beruf und Religion um ein fast ausschliesslich weibliches Phänomen handelt, hebt zusätzlich den Genderaspekt hervor.

Die Bedeutung der Erhebung entsprechender Daten über die Oral History liegt in der dadurch erreichten diachronen Erfahrungssynthese. ${ }^{6}$ Die daraus zu erschliessende Realität hat eine soziale Bedeutung und ebnet über diesen Zugriff den Weg zur Integration der religiösen Frauengeschichte in die allgemeine sozial- und kulturgeschichtliche Forschung. ${ }^{7}$ Anderseits ermöglicht dieses Projekt die Einordnung von Sichtweisen der einzelnen Schwester auf Forschungsergebnisse und Perspektiven der katholischen bzw. auch der interkonfessionellen Kirchengeschichtsforschung. Steht die subjektive Einschätzung in einem parallelen oder gegenläufigen Verhältnis zur These, dass sich die Ordensgemeinschaften in der zweiten Hälfte des 20. Jahrhunderts von der patriarchalen Familiengemeinschaft zu einer religiösen Lebens- und Dienstgemeinschaft gewandelt haben? ${ }^{8}$ Darüber hinaus geht es wie im jüngst abgeschlossenen Forschungsprojekt zu den religiösen Frauen in der Ostschweiz um eine Verortung im Kontext des christlich ausgerichteten Schwesternwesens, was die religions- und frömmigkeitsgeschichtliche Komponente in den Vordergrund rückt.

6 May M. Broda, Erfahrung, Erinnerungsinterview und Gender. Zur Methode der Oral History, in: Maguérite Bos/Bettina Vincenz u. a. (Hg.), Erfahrung: Alles nur Diskurs? Zur Verwendung des Erfahrungsbegriffes in der Geschlechtergeschichte. Beiträge der 11. Schweizerischen Historikerinnentagung 2002, Zürich 2004, 163.

7 In dem Sinn gesehen, dass subjektive Wahrheit, die soziale Praxis der Menschen bestimmt, siehe: Waltraud Kannonier-Finster/Meinrad Ziegler, Frauen-Leben im Exil. Biographische Fallgeschichten, Wien 1996, 26.

8 Vgl. Ute Gause, Frauen entdecken ihren Auftrag! Neue Erträge diakonischer Frauenforschung, in: Cornelia Coenen-Marx (Hg.), Ökonomie der Hoffnung. Impulse zum 200. Geburtstag von Theodor und Friederike Fliedner, Düsseldorf 2001, 75-92. 
Den Schwerpunkt jedoch bildet die Erhebung und Darstellung der Daten in der vorliegenden Studie. Somit geht es primär um die Sicherung von Quellen der erzählten Lebensgeschichte religiöser Schwestern, welche für die Schweiz in ca. zwanzig bis dreissig Jahren nicht mehr zugänglich sein werden.

\subsection{Methodischer Zugriff}

\subsubsection{Forschungsstand}

Obwohl die deutsche Forschung dieses Gebiet der Oral History insbesondere in der Pflegewissenschaft zu den evangelischen Schwestern bereits gut bearbeitet hat, bestehen für die Schweiz in beiden Konfessionsbereichen Desiderate. Für den Katholizismus ist die Oral-History-Forschung zu Ordensschwestern auch international nur in Ansätzen vernetzt und in der Forschung noch kaum präsent. ${ }^{9}$ Die historische Katholizismusforschung der Schweiz beachtete die kollektive und individuelle Subjektkonstruktion einzelner Schwestern bisher nicht. Für die Schweiz liegt die Studie von Zoe Maria Isenring - selber Ingenbohler Schwester und Historikerin - zur Lebensform weiblicher religiös-tätiger Gemeinschaften vor. ${ }^{10}$ Unzensuriertes autobiografisches Quellenmaterial, das diese Fragenkomplexe erhellen könnte und einen möglichst hohen Authentizitätswert besitzt, ist nicht nur in kontemplativen Frauenklöstern, sondern ebenfalls in weiblichen Kongregationen bis ins 21. Jahrhundert nur spärlich bis kaum vorhanden. ${ }^{11}$

9 Siehe hierzu die Ausführungen unter 1.2.1. Forschungsstand.

10 Zoe Maria Isenring, Die Frau in den apostolisch tätigen Ordensgemeinschaften. Eine Lebensform am Ende oder an der Wende? Freiburg ${ }^{3} 1996$. Siehe für die Schweiz u. a. auch zu weiblichen religiösen Gemeinschaften allgemein: Patrick Braun (Hg.), Die Kongregationen in der Schweiz 19. und 20. Jahrhundert, HS VIII/2, Basel 1998; Patrick Braun (Hg.), Die Kongregationen in der Schweiz 16.-18. Jahrhundert, HS VIII/1, Basel/ Frankfurt a. M. 1994; Cécile Sommer-Ramer (Hg.), Die Beginen und Begarden in der Schweiz, HS XI/2, Basel/Frankfurt a. M. 1995.

11 Vgl. die Quellenedition zu den ersten Schwestern von Menzingen, z. B.: Andreas Sampers (Hg.), Die Briefe der Dienerin Gottes. Frau Mutter Bernarda Heimgartner an ihre Mitschwestern 1851-1863, Menzingen 1972; Vgl. für Ingenbohl die Untersuchung zur Korrespondenz von Sr. Eugenia Welz: Valeria Sievi/Regula Gerspacher, «Hochverehrte liebe theure würdige Mutter!» Sr. Eugenia Welz (1833-1899) von der Kongregation 


\subsubsection{Subjektgeschichtlicher Ansatz zu religiösen Frauen in der Schweiz}

Die Geschichtsschreibung zu Schweizer Diakonissen und Ordensfrauen ist bisher stark ereignis- und kollektivgeschichtlich bestimmt. Das abgeschlossene SNF-Forschungsprojekt «Religiöse Frauen der Ostschweiz im 20. Jahrhundert» ergänzt diese Perspektive um den religions- und kulturgeschichtlichen Aspekt. ${ }^{12}$ Innerhalb der Schweizer Kirchengeschichtsforschung zeigte sich ein Individualansatz zu religiösen Frauen bisher einzig innerhalb von Selbstdarstellungen entsprechender Schwesterngemeinschaften zu Mitgründerinnenbiografien, die meist dem hagiografischen Ansatz verpflichtet sind. ${ }^{13}$ Aus Sicht der Schwesterngemeinschaften erscheint der einzelbiografische Ansatz somit insofern als adäquat, als er für die Erinnerungskultur sowie für Kanonisationsverfahren von den Schwesterngemeinschaften selbst verwendet wird. ${ }^{14}$

Der interkonfessionelle Zugang wurde innerhalb der Subjektforschung bisher nur in Ansätzen umgesetzt. In den Jahren 2003 und 2006 wurden Quellentexte zu Frauen des 16. bis 19. Jahrhunderts ediert. ${ }^{15}$

der Schwestern vom hl. Kreuz, Ingenbohl. Ihr Leben und ihre Briefe während den Sammelreisen in der Schweiz, in Ungarn, Siebenbürgen und Slavonien für das Kreuzspital in Chur, Beiheft Nr. 7 zum Bündner Monatsblatt, Chur 1997.

12 «Religiöse Frauengemeinschaften der Ostschweiz im 20. Jahrhundert», Projekt SNF 100011_134603/1; Laufzeit 2011-2014.

13 Obwohl der diesbezügliche Forschungsbedarf zu Einzel-, Kollektiv- und Gruppenbiografien für evangelische und katholische Schwesterngemeinschaften evident ist, ist dabei dennoch grundsätzlich zu fragen, inwiefern der einzelbiografische Ansatz zur individuellen Subjektkonstruktion von Schwestern in einem vertieften Modus sich mit dem Selbstlosigkeitskonzept des klösterlichen, auch des diakonischen Berufungs- und christlichen Nachfolgevollzugs verträgt. Vgl. dazu die Verbindung des sozialpsychologischen mit dem einzelbiografischen Ansatz: Yvonne Leimgruber, Überlegungen zu einer psychohistorisch-biographischen Lizentiatsarbeit über die Benediktinerin Gertrud Leupi (1825-1904), in: Veronika Aegerter/Nicole Graf/Nathalie Imboden/Thea Rytz/ Rita Stöckli (Hg.), Geschlecht hat Methode. Ansätze und Perspektiven in der Frauenund Geschlechtergeschichte, Beiträge der 9. Schweizerischen Historikerinnentagung 1998, Zürich 1999, 87-97.

14 Siehe unter vielen anderen: Zu Theresia Scherer, Ingenbohl: Clarissa Rutishauser, Mutter M. Theresia Scherer. Neue Strahlen, Freiburg 1946. Zu Bernarda Heimgartner, Menzingen: Hildegardis Jud, Mutter Maria Bernarda Heimgartner 1822 bis 1863, Freiburg 1944.

15 Uta Teresa Fromherz, Maria Carmela Motta (1904-1972). Ermunterungen anlässlich der heiligen Exerzitien (1952), in: Doris Brodbeck (Hg.), Unerhörte Worte. Religiöse Gesellschaftskritik von Frauen im 20. Jahrhundert, Bern 2003, 180-186. Esther 


\subsubsection{Oral History in der Schweiz zu religiösen Frauengemeinschaften}

Die Frauengeschichtsschreibung erforschte bereits ab den 1990er Jahren in mehreren Publikationen die Lebensgeschichten von Frauen über die Oral History. ${ }^{16}$ Darin sind seit Beginn des 21. Jahrhunderts Ansätze biografischer Darstellungen zu Diakonissen und Ordensfrauen eingeflossen, die als Kurz-Porträts publiziert wurden. ${ }^{17}$

\subsubsection{Internationale Projekte zu Oral History und religiösen Frauengemeinschaften}

Eine innerhalb der Katholizismusforschung zentrale Arbeit ging aus der Tätigkeit des «Arbeitskreises 19. und 20. Jahrhundert» hervor, der im Jahr 2000 am Institut für Theologie und Geschichte religiöser Gemeinschaften» in Vallendar entstand. ${ }^{18}$ Weiter liegen seit den späten 1990er Jahren bisher nur einzelne Studien vor, die für die katholische religiöse Frauengeschichte die Oral History als Methode wählten. ${ }^{19}$ Teilweise betreffen sie

Vorburger-Bossart, Opferwille und Hingabe als Lebensinhalt: Schwester Maria Wiborada Zislin Nachruf von Maria Wiborada Treichlingerin von Kempten (1765), in: ders., $152-162$.

16 Siehe zur Absenz religiöser Frauen in der profanen Frauengeschichtsforschung:, in: Esther Vorburger-Bossart, «Was Bedürfnis der Zeit ist ...», Identitäten in der katholischen Frauenbildung, Freiburg 2008, 33-35.

17 Vgl. hier exemplarisch zum einzelbiografischen Ansatz: Diakonissen: Susanne Dschulnigg, Erste Leiterin der Thurgauischen Schule für Krankenpflege: Frieda Uhlmann, in: Verein Thurgauerinnen gestern - heute - morgen (Hg.), Bodenständig und grenzenlos. 200 Jahre Thurgauer Frauengeschichte(n), Frauenfeld/Stuttgart/Wien 1998, 109-111. Ordensschwestern, u. a.: Sr. Columbana Hüppi, in: Elisabeth Bardill, Zwischen Ruhe und Anspannung. Lebensformen von Frauen in Graubünden, Tenna 2007, 51-67. Zum kollektivbiografischen Ansatz: Esther Vorburger-Bossart, Tomasina Färber (18971983), Marina Guntli (geboren 1930), Martina Hässig (1912-1999). Der Posten Sargans, in: Marina Widmer/Heidi Witzig (Hg.), St. Galler Frauen - 200 Porträts. Blütenweiss bis rabenschwarz, Zürich 2003, 119 f. - Vgl. weiter die nicht wissenschaftlichen Standards verpflichteten Monografien: Susann Bosshard/Daniela Schwegler, Unter der Haube. Diakonissen erzählen aus ihrem Leben, Frauenfeld 2011; dies., Im Fahr. Die Klosterfrauen erzählen aus ihrem Leben, Baden 2018.

18 Marjet Derks (Nijmegen), The renewal trap. The dominance of the 1960s perspective in the historical representations of charitable congregations of nuns, Tagungsbericht Arbeitskreis Ordensgeschichte 19./20. Jahrhundert. 05.02.2010-07.02.2010, Vallendar, in: H-Soz-u-Kult, 09.03.2010, http://hsozkult.geschichte.hu-berlin.de/ tagungsberichte/id=3012. [7.6.2013].

19 In Ansätzen: Vera Deissner, Gottes Mägde oder christliche Kommunardinnen? Zum Selbstbild von Frauen im Nonnenkloster, in: Ulrike Krasberg (Hg.), Religion und 
andere Disziplinen wie etwa die Ethnologie oder Medizin. ${ }^{20}$ Martina Gugglberger legte am Beispiel der deutschsprachigen Mariannhiller-Missionsschwestern eine Reihe von Arbeiten vor, denen lebensgeschichtliche Aufzeichnungen zu Ordensschwestern zugrunde liegen. ${ }^{21}$

Auf dem Gebiet der evangelischen religiösen Frauengeschichte sind Oral-History-Forschungsprojekte vorab in Deutschland bearbeitet worden. Im Anschluss an das «Göttinger Frauenforschungsprojekt zur Geschichte der Theologinnen ${ }^{22}$, das erstmals autobiografische Texte und Erinnerungsinterviews von Theologinnen zur Grundlage hatte, entstand die Studie von Heidemarie Lauterer-Pirner zur Geschichte des Kaiserswerther Verbands in den 1930er Jahren, welche auch den Kontext des Nationalsozialismus einbezog. ${ }^{23}$ Aus dem 1999 gegründeten «Netzwerk

weibliche Identität. Interdisziplinäre Perspektiven auf Wirklichkeiten, Marburg 1999, 19-34. Siehe weiter im Sammelband von Lydia Bendel-Maidl (Hg.), Katholikinnen im 20. Jahrhundert. Bilder, Rollen, Aufgaben, Berlin 2007; die beiden einzelbiografischen Beiträge zu Ordensfrauen: Ines Meder/Dietmar Meder, Sr. Dr. Hildegardis Wulff OSB (1896-1961), 131-157; Sr. Basilissa Hürtgen, 261-286.

20 Ethnologie: Gertrud Hüwelmeier, Närrinnen Gottes. Lebenswelten von Ordensfrauen, Münster/New York/München/Berlin 2004. Medizin: Die Münchner Dissertation: Alexa A. Becker, Die Kongregation der Barmherzigen Schwestern vom Heiligen Vinzenz von Paul an den klinischen Einrichtungen der Universität München und ihre Begegnung mit dem Nationalsozialismus, Braubach 2008.

21 Martina Gugglberger, Reguliertes Abenteuer. Missionarinnen in Südafrika nach 1945, L’Homme (22), Wien 2014; dies., «Ich wollte immer nach Afrika». Lebensgeschichten deutschsprachiger Missionsschwestern nach 1945, in: Ingrid Böhler/Eva Pfanzelter u. a. (Hg.), 7. Österreichischer Zeitgeschichtetag 2008, Innsbruck/Wien/Bozen, 551-559; dies., «Ich wollte immer nach Afrika». Lebensgeschichten deutschsprachiger Missionsschwestern nach 1945 (Diss. Uni Salzburg 2009); dies., Abenteuer Mission. Lebensgeschichten von Missionarinnen als Beitrag zur Expatriate-Forschung», in: ÖZG, (2/2013), 139-158. - Siehe dazu ebenfalls eine vergleichbare Arbeit zu amerikanischen Ordensschwestern: Carole G. Rogers, Habits of Change: An Oral History of American Nuns. New York: Oxford University Press, 2011.

22 Frauenforschungsprojekt zur Geschichte der Theologinnen Göttingen (Hg.), Querdenken. Beiträge zur feministisch-befreiungstheologischen Diskussion. Festschrift für Hannelore Erhart zum 65. Geburtstag, Pfaffenweiler 1992; Frauenforschungsprojekt zur Geschichte der Theologinnen Göttingen (Hg.), «Darum wagt es, Schwestern ...». Zur Geschichte evangelischer Theologinnen in Deutschland, Neukirchen/Vluyn 1994.

23 Heidemarie Lauterer-Pirner, Liebestätigkeit für die Volksgemeinschaft. Der Kaiserswerther Verband deutscher Diakonissenmutterhäuser in den ersten Jahren des NS-Regimes, Göttingen 1994. Vgl. hier die später zu diesem Thema im Rahmen des ab 2001 laufenden Kaiserwerther Oral-History-Projekts verfassten Arbeiten, etwa: Uwe Kaminsky, «Frontverkürzung» - Krankenpflege in der Zeit des Nationalsozialismus, in: 
Diakonische Frauenforschung» entwickelte sich unter Leitung der Bochumer Kirchenhistorikerin Ute Gause das Oral-History-Projekt «Kaiserswerther Diakonissen im 20. Jahrhundert». Dazu erschien 2005 die für Diakonissen wegweisende Studie «Kosmos Diakonissenhaus» ${ }^{24}$, welche religionspädagogische und diakoniegeschichtliche Fragen formuliert. ${ }^{25}$ 2010 erschien in einem Sammelband zur deutschen Diakonie ein Beitrag von Cordula Lissner zu Oral History als Forschungsmethode in der Diakoniegeschichte. ${ }^{26}$ Das 2008 beendete Oral-History-Projekt der Henriettenstiftung Hannover wirft eine Perspektive auf transnationale Prozesse der Mission, auf das Konzept von Mütterlichkeit sowie auf die Geschichte der Krankenpflege und der Mutterhausdiakonie. ${ }^{27}$ Zwischen 2005 und 2008 wurden mittels der Oral-History-Methode zahlreiche Interviews mit Diakonissen in Speyer geführt und ausgewertet. ${ }^{28}$ Für die Schweiz fehlt eine biografische Forschung zu religiösen Frauengemeinschaften.

Ute Gause/Cordula Lissner (Hg.), Kosmos Diakonissenmutterhaus. Geschichte und Gedächtnis einer protestantischen Frauengemeinschaft, Leipzig 2005, 217-242.

24 Ute Gause/Cordula Lissner (Hg.), Kosmos Diakonissenmutterhaus. Geschichte und Gedächtnis einer protestantischen Frauengemeinschaft, Leipzig 2005.

25 Zum Beispiel: Birgit Funke, Wahlfamilien - Rekonstruktion der Erinnerung an die Arbeit in Kinderheimen und Kindergärten, 174-195; Cordula Lissner, Migration ohne Migrationserfahrungen? Kaiserswerther Schwestern im Auslandeinsatz, 243-274.

26 Cordula Lissner, «Alles konnten wir Ihnen natürlich nicht erzählen» - Oral History als Forschungsmethode in der Diakoniegeschichte, in: Jochen-Christoph Kaiser/ Rajah Scheepers (Hg.), «Dienerinnen des Herrn». Beiträge zur Weiblichen Diakonie im 19. und 20. Jahrhundert, Leipzig 2010, 83-101.

27 Siehe z.B.: Rajah Scheepers, Die transnationalen Zusammenhänge zwischen Innerer und Äusserer Mission - niedersächsische Kirchengeschichte in Übersee. Die Auslandstationen der Henriettenstiftung im 20. Jahrhundert, in: Jahrbuch der Gesellschaft für niedersächsische Kirchengeschichte 105 (2007), 167-201; dies., Das Jahr 1968 und die Diakonissen. Ein Beitrag zur Geschichte der Inklusion evangelischer Frauen in Kirche und Theologie sowie zur gleichzeitigen Erosion konfessioneller Frauenberufe, in: Heinrich Grosse/Hans Otte/Joachim Perels (Hg.), Erinnerungen an die Zukunft? Die 1960er/70er Jahre und die hannoversche Landeskirche, Hannover 2010. Susanne Kreutzer, Gemeindepflege in Westdeutschland. Alltag und soziale Praxis am Beispiel des Diakonissenmutterhauses der Henriettenstiftung, in: Andrea Thiekötter/u.a. (Hg.), Alltag in der Pflege. Wie machten sich Pflegende bemerkbar? Beiträge des 8. Internationalen Kongresses zur Geschichte der Pflege 2008, Frankfurt a. M. 2009, 161-176.

28 Arnd Götzelmann, Frauendiakonie und Krankenpflege. Im Gespräch mit Diakonissen in Speyer, Heidelberg 2009. 


\section{Qualitative Forschung als methodischer Zugang zu Lebensgeschichten religiöser Frauen}

Die Lebensgeschichten von Diakonissen und Ordensschwestern werden über die Oral History mit qualitativer Methode erschlossen..$^{29}$ Ein offenes Forschungsmuster möchte in Anlehnung an die 1967 entworfene «Grounded Theory» aus der amerikanischen Forschung die Idee der qualitativen Sozialforschung, der Verschränkung von Theorie und Empirie, weiter entwickeln. ${ }^{30}$ Die grundsätzliche Offenheit bei der Wahl der Methode während des Forschungsprozesses entspricht der Charakteristik qualitativer Sozialforschung. Hier wird die prozesshafte methodische Herangehensweise vorgesehen, die sich immer wieder am Frageraster orientiert und gegebenenfalls neu an den Fragestellungen formt. ${ }^{31}$ Durch die Etablierung des methodischen Zugriffs über die Oral History fand diese in vielen Bereichen der historischen Forschung Anwendung, in denen die schriftlichen Quellen keinen oder nur partiellen Zugang gewähren. ${ }^{32}$ Wie Alexander von Plato festgestellt hat, ist Oral History mehr als eine blosse

29 Siehe dazu eine Auswahl aus der allgemeinen Grundlageliteratur zur qualitativen Methode: Lutz Niethammer (Hg.), Lebenserfahrung und kollektives Gedächtnis. Die Praxis der Oral History, Frankfurt a. M. 1985; Gerd Jüttemann/Hans Thomae (Hg.), Biographische Methoden in den Humanwissenschaften, Weinheim/Basel 1999; Thomas Heinze, Qualitative Sozialforschung. Einführung, Methodologie und Forschungspraxis, München/Wien 2001; Ralf Bohnsack/u.a. (Hg.), Hauptbegriffe Qualitativer Sozialforschung, Opladen 2003; Ralf Bohnsack, Rekonstruktive Sozialforschung, Opladen ${ }^{5} 2003$; Siegfried Lamnek, Qualitative Sozialforschung, Weinheim 4/2005; Uwe Flick/u. a. (Hg.), Handbuch qualitative Sozialforschung, Weinheim 3/2012. Siehe zuletzt die Zusammenstellung von in der Forschung in den letzten drei Jahrzehnten seit Lutz Niethammer etablierter Texte: Julia Obertreis (Hg.), Oral History. Basistexte Geschichte, Stuttgart 2012.

30 Barney Glaser/Anselm Strauss, The Discovery of Grounded Theory. Strategies for qualitative research, Chicago 1967/dies., Grounded Theory. Strategien qualitativer Forschung, Bern 1998; Anselm Strauss/Juliet Corbin, Grounded Theory. Grundlagen Qualitativer Sozialforschung, Weinheim 1996.

31 Vgl. diesen Ansatz angewendet in der Dissertation von Martina Gugglberger: Martina Gugglberger, «Ich wollte immer nach Afrika». Lebensgeschichten deutschsprachiger Missionsschwestern nach 1945 (Diss. Uni Salzburg 2009). Vorliegend als Pdf.

32 Alexander von Plato, Erfahrungsgeschichte - von der Etablierung der Oral History, in: Gerd Jüttemann/Hans Thomae (Hg.), Biographische Methoden in den Humanwissenschaften, Weinheim/Basel 1999, 60-74. - Siehe zur internationalen Oral-HistoryForschung etwa: Lynn Abrmas, Oral history theory, New York 2010. - Vgl. zur früheren Kritik an Oral History: U.a.: Alexander von Plato, Oral History als Erfahrungswissenschaft. Zum Stand der mündlichen Geschichte in Deutschland, in: BIOS. Zeitschrift für Biographieforschung und Oral History 1991, Heft 1, $97 \mathrm{ff}$. 
A. Einleitung

Technik der Zeitzeuginnen-Befragung. Sie ermöglicht darüber hinaus einen Perspektivenwechsel, der eine andere Sichtweise aufzeigt. Damit wurde Subjektivität einerseits und die Erfahrung von Subjekten anderseits überhaupt zum Gegenstand der nachkriegsdeutschen Historiografie. ${ }^{33}$ Die Subjektivität soll hier als positiver Inhalt der mündlichen Quellen und als Stimulans für die religiöse Frauengeschichte begriffen werden. ${ }^{34}$

Die Subjektgeschichte bietet durch erzählte Geschichte einen Zugang, der für die Erforschung der weiblichen Geschichte bedeutsam ist, fehlt es doch hier oft an schriftlichen Quellen. ${ }^{35}$ Damit wird die Integration der religiösen Frauengeschichte in die allgemeine Kirchengeschichtsschreibung gefördert. Die mündlich erschlossene und gesicherte Datenbasis bedeutet innerhalb der religiösen Frauengeschichte eine Ergänzung eines bestehenden Quellenbestandes sowie auch die Konstruktion einer eigenen Quellenkategorie. In der befragten Geschichte ist insbesondere die Verknüpfung der Kategorien «Biografie» und «Identität» von Bedeutung. Im mündlichen und autobiografischen Erzählen wird die eigene Lebensgeschichte als historisches Faktum präsentiert und konstruiert, und es wird Identität repräsentiert. ${ }^{36}$ In diesem Sinn werden Interviews als Rekonstruktion eines nachträglich hergestellten Sinnzusammenhangs

33 Alexander von Plato, Erfahrungsgeschichte - von der Etablierung der Oral History, in: Gerd Jüttemann/Hans Thomae (Hg.), Biographische Methoden in den Humanwissenschaften, Weinheim/Basel 1999, 61.

34 Robert Perks/Alistair Thomson (Hg.), The Oral History Reader, London/New York 2000, 3.

35 Siehe u. a.: Susan H. Armitage/Patricia Hart u.a. (Hg.), Women's Oral History. The Frontier's Reader, London 2002; Karen Hagemann, «Ich glaub nicht, dass ich Wichtiges zu erzählen hab ...». Oral History und historische Frauenforschung, in: Herwart Vorländer (Hg.), Oral History. Mündlich erfragte Geschichte, Göttingen 1990, 29-48; Angelika Diezinger (Hg.), Erfahrung mit Methode. Wege sozialwissenschaftlicher Frauenforschung (Forum Frauenforschung), Bd. 8, Freiburg i. Br. 1994; Edith Franke/Gisela Matthiale u.a. (Hg.), Frauen Leben Religion. Ein Handbuch empirischer Forschungsmethoden, Stuttgart 2002. - Zur Oral History in der Diakonieforschung siehe besonders: Cordula Lissner, «Alles konnten wir Ihnen natürlich nicht erzählen» - Oral History als Forschungsmethode in der Diakoniegeschichte, in: Jochen-Christoph Kaiser/Rajah Scheepers (Hg.), «Dienerinnen des Herrn». Beiträge zur Weiblichen Diakonie im 19. und 20. Jahrhundert, Leipzig 2010, 83-101.

36 Michael von Engelhardt, Biographie und Identität. Die Rekonstruktion und Präsentation von Identität im mündlichen und autobiographischen Erzählen, in: Walter Sparn (Hg.), Wer schreibt meine Lebensgeschichte. Biographie, Autobiographie, Hagiographie und ihre Entstehungszusammenhänge, Gütersloh 1990, 197-247. 
vergangener Ereignisse und Erfahrungen begriffen. ${ }^{37}$ In dieser Art interpretiert Oral History Konstruktion und Transformation von Erinnerung als Teil der historischen Wirklichkeit. ${ }^{38}$ Dabei ist das Vergessen und Verdrängen als eigener Prozess und Inhalt der lebensgeschichtlichen Konstruktion der persönlichen Geschichte in Betracht zu ziehen. ${ }^{39}$ Somit sind auch Leerstellen und Lücken interpretierbar und werden zentrale Bestandteile der erzählten Geschichte.

\subsubsection{Interviewsample, Transkription und Auswertung}

Die lebensgeschichtlichen Interviews fanden im konkreten und aktuellen lebensweltlichen Umfeld der Schwestern statt, meist im Mutterhaus oder im zugehörigen Alters- und Pflegeheim. Bei jüngeren Interviewpartnerinnen ab Jahrgang 1950 lagen die Wohnorte punktuell auch anderswo. Die Örtlichkeit zur Durchführung wurde in dem Sinn zum «Gedächtnisoder Erinnerungsort», in dem im Gespräch «Erinnerung aktiviert, vergegenwärtigt und neu arrangiert» wurde. ${ }^{40}$

37 Margrit Reiter, Die Generation danach. Der Nationalsozialismus im Familiengedächtnis, Innsbruck/Wien/Bozen 2006, 39.

38 Siehe zur Bedeutung von Erinnerung u. a.: Karin Hartewig, «Wer sich in Gefahr begibt, kommt [nicht] darin um» - sondern macht eine Erfahrung!», in: Berliner Geschichtswerkstatt (Hg.), Alltagskultur, Subjektivität und Geschichte. Zur Theorie und Praxis von Alltagsgeschichte, Münster 1994, 110-124; Malte Thiessen, Gedächtnisgeschichte. Neue Forschungen zur Entstehung und Tradierung von Erinnerungen, in: Archiv für Sozialgeschichte, 48 (2008), 607-634; Alessandro Portelli, What makes Oral History different, in: Robert Perks/Alistair Thomson (Hg.), The Oral History Reader. Second Edition, London/New York 2006, 32-42; Harald Welzer, Die Medialität des menschlichen Gedächtnisses, in: BIOS. Zeitschrift für Biographieforschung, Oral History und Lebensverlaufsanalysen, 1/2008, 15-27; Harald Welzer, Das kommunikative Gedächtnis. Eine Theorie der Erinnerung, München ${ }^{3} 2011$. - Siehe weiter die Ergebnisse aus der neurowissenschaftlichen Forschung, z. B.: Hans J. Markowitsch/Harald Welzer, Das autobiographische Gedächtnis. Hirnorganische Grundlagen und biosoziale Entwicklung, Stuttgart 2005.

39 Vgl. dazu etwa: Alexander von Plato, «Janus als Zeuge»? Zeitzeugen-Erinnerung und das Problem der «Verdrängung», in: Horch und Guck (2006), Nr. 2, 1-5.

40 Dies insbesondere angeregt durch die mündlich erforschte Geschichte des Nationalsozialismus: Margrit Reiter, Die Generation danach. Der Nationalsozialismus im Familiengedächtnis, Innsbruck/Wien/Bozen 2006, 39. 
Vor dem Interview wurden Angaben erhoben ${ }^{41}$ und eine Einverständniserklärung unterzeichnet ${ }^{42}$; für die Aufzeichnung wurde nach Wunsch ein Pseudonym verwendet. ${ }^{43}$ Die Interviews erfolgten in offener narrativer Form. ${ }^{44}$ Am Anfang stand eine Eingangsfrage, die zu einem offenen, von der erzählenden Schwester autonom strukturierten und selbst beendeten Hauptteil überleitete. In einem zweiten Teil folgten Verständnisfragen zu den Hauptnarrativa.

Im dritten Teil stellte die Interviewerin Bezugsfragen zur Vertiefung und Erweiterung der Gesprächsinhalte, die ihr aufgrund des vorstrukturierten Fragebogens ${ }^{45}$ von weiterem Interesse erschienen. ${ }^{46}$ Aufgrund des Nachfrageteils handelte es sich demnach um teilstrukturierte narrative Interviews. ${ }^{47}$ Dabei standen die Interviewerinnen wie die Respondentin-

41 Siehe den Annex: «Personalblatt befragte Schwester».

42 Siehe den Annex: «Einverständniserklärung».

43 Vgl. Gertrud Hüwelmeier, Närrinnen Gottes. Lebenswelten von Ordensfrauen, Münster 2004, $91 \mathrm{f}$. Hüwelmeier bezeichnet die gemeinsame Wahl eines Pseudonyms für die Interviewpartnerin als wichtigen Prozess ihrer Feldforschung.

44 Fritz Schütze, Technik des narrativen Interviews in Interaktionsfeldstudien, Bielefeld 1977; Fritz Schütze, Biographieforschung und narratives Interview, in: Neue Praxis 13 (1983), 283-292; Fritz Schütze, Kognitive Figuren des autobiographischen Stegreiferzählens, in: Martin Kohli/Günther Robert (Hg.), Biographie und soziale Wirklichkeit. Neue Beiträge und Forschungsperspektiven, Stuttgart 1984, 78-117; Fritz Schütze, Zur Hervorlockung und Analyse von Erzählungen thematisch relevanter Geschichten im Rahmen soziologischer Feldforschung, in: Arbeitsgruppe Bielefelder Soziologen (Hg.), Kommunikative Sozialforschung, München 1976, 159-260; Gabriele Rosenthal, Erlebte und erzählte Lebensgeschichte. Gestalt und Struktur biographischer Selbstbeschreibungen, Frankfurt a. M. 1995, 197-200; Roswitha Breckner, Von den Zeitzeugen zu den Biographen. Methoden der Erhebung und Auswertung lebensgeschichtlicher Interviews, in: Berliner Geschichtswerkstatt (Hg.): Alltagskultur, Subjektivität und Geschichte. Zur Theorie und Praxis von Alltagsgeschichte, Münster 1994, 199-222; Gerhard Riemann, Narratives Interview, in: Ralf Bohnsack/u. a. (Hg.), Hauptbegriffe Qualitativer Sozialforschung, Opladen 2003, 120-122.

45 Siehe den Annex: «Fragebogen».

46 In Anlehnung u. a. an die bereits in Interviews mit Kaiserswerther Diakonissen erprobte Vorgehensweise, in: Cordula Lissner, «Alles konnten wir Ihnen natürlich nicht erzählen» - Oral History als Forschungsmethode in der Diakoniegeschichte, in: JochenChristoph Kaiser/Rajah Scheepers (Hg.), «Dienerinnen des Herrn». Beiträge zur Weiblichen Diakonie im 19. und 20. Jahrhundert, Leipzig 2010, 90.

47 Vgl. Andreas Kruse/Eric Schmitt, Halbstrukturierte Interviews, in: Gerd Jüttemann/Hans Thomae (Hg.), Biographische Methoden in den Humanwissenschaften, Weinheim/Basel 1999, 161-174; Christel Hopf, Qualitative Interviews - ein Überblick, in: Uwe Flick/Ernst von Kardorff u. a. (Hg.), Qualitative Forschung. Ein Handbuch, 
nen in ständiger Interaktion ${ }^{48}$, die die Oral Historian als Teil des Interviews miteinbezog. Beide Personen waren hier einerseits Akteurinnen ihrer Geschichte. ${ }^{49}$

Anderseits wurde dieses interaktive Verhältnis der Interviewpartnerinnen im Gespräch durch Erwartungshaltungen, formale Begebenheiten und sinnstiftende Konstruktionsprozesse bestimmt. ${ }^{50}$ Die Frage der Dis$\operatorname{tanz}$ bzw. Nähe zur Respondentin bildete deshalb ein weiterer Teil im Umfeld der Interviewdurchführung. ${ }^{51}$

Damit eine wissenschaftliche Auswertung möglich wurde, musste im dreistufigen Verfahren von den Primärdaten (Originalgespräch) über die Sekundärdaten (Audioaufnahme) zu den Tertiärdaten (Transkript) der dazu notwendige Prozess der Informationsreduktion und -abstraktion einbezogen werden. ${ }^{52}$ Als technische Hilfsmittel standen pro Gespräch zwei digitale Aufnahmegeräte mit entsprechenden Speichermedien zur Verfügung. Die doppelte Aufnahmesituation sollte gewährleisten, dass mindestens eine der beiden Aufnahmen einer guten Qualität entsprach.

Hamburg ${ }^{4} 2005$, 349-360, 353; Christel Hopf/Elmar Weingarten, Hg.), Qualitative Sozialforschung, Stuttgart 1979; Uwe Flick/u.a. (Hg.), Handbuch qualitative Sozialforschung, Weinheim 3/2012.

48 Vgl. zur Interaktionsanalyse Olaf Jensen/Harald Welzer, Mai 2003: Qualitative Social Research [Online Journal], 4 (2) über: www.qualitative-research.net/fqs/texte/203/0-03jensen-welzer-d.htm.

49 Überblick, in: Manfred Gabriel (Hg.), Paradigmen der akteurszentrierten Soziologie, Wiesbaden 2004; Alf Lüdtke, Geschichte und Eigensinn, in: Berliner Geschichtswerkstatt (Hg.), Alltagskultur, Subjektivität und Geschichte. Zur Theorie und Praxis von Alltagsgeschichte, Münster 1994, 139-153.

50 Siehe die methodischen Überlegungen, hier die Kritik an der Methode der Oral History am Beispiel der Befragung von Ordensschwestern der Mariannhiller Mission: Martina Gugglberger, «Ich wollte immer nach Afrika». Lebensgeschichten deutschsprachiger Missionsschwestern nach 1945 (Diss. Uni Salzburg 2009), 18.

51 Albert Lichtblau, «Keeping Distance», in: Philippe Denis/James Worthington (Hg.), The power of Oral History. Healing and Development, Pieterrmaritzburg 2002, 814-824.

52 Zur Transkription von Gesprächen: Sabine Kowal/Daniel C. O’Connell, Zur Transkription von Gesprächen, in: Uwe Flick/u. a. (Hg.), Handbuch qualitative Sozial-

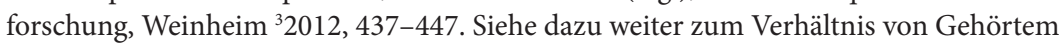
und Transkript: Herwart Vorländer, (Hg.), Oral History, Göttingen 1990, 22-24; Fritz Schütze, Biographieforschung und narratives Interview, in: Julia Obertreis (Hg), Oral History. Basistexte Geschichte, Stuttgart 2012, 101-111. 
A. Einleitung

Formal wurde die verbale Transkription gewählt, die nur besonders auffällige phonetische und nonverbale Äusserungen miteinbezieht. ${ }^{53}$

Für die Auswertung wurde ein qualitatives Analyseverfahren ${ }^{54}$ gewählt, das sich an die induktive und gegenstandsorientierte Theoriebildung der «Grounded Theory» anlehnte. ${ }^{55}$

Die im unmittelbaren Nachfeld der Interviews erstellten Reflexionsnotizen und Tagesprotokolle wurden für die wissenschaftliche Aufbereitung zur Ergänzung herangezogen. Neben der Auswertung qualitativer Daten, der lebensgeschichtlichen Erinnerungen von Schwestern, sollte durch quellengeleitete Interpretation und historische Kontextualisierung entlang der Fragestellungen versucht werden, die mündlich generierten Quellen zu erschliessen..$^{56}$ Dabei wurde davon ausgegangen, dass die erzählte Lebensgeschichte bereits Produkt einer Interpretation durch die erzählende Schwester ist. Bei der Aufbereitung der Daten durch die Historikerinnen handelte es sich um eine Re- oder Sekundär-Interpretation, d. h. um eine Interpretation bereits interpretierter Daten. ${ }^{57}$

53 Vgl. etwa: Fritz Schütze, Biographieforschung und narratives Interview, in: Julia Obertreis (Hg), Oral History. Basistexte Geschichte, Stuttgart 2012, 99-111.

54 Mit in dieses Blickfeld zu nehmen ist hier ebenfalls die computergestützte Analyse; siehe dazu: Udo Kuckartz, Einführung in die computergestützte Analyse qualitativer Daten, Wiesbaden ${ }^{2} 2007$; Philipp Mayring, Qualitative Inhaltsanalyse. Grundlagen und Techniken, Weinheim ${ }^{7} 2000$. Zum Programm: z. B. «Atlas.ti», siehe dazu: Martina Gugglberger, «Ich wollte immer nach Afrika». Lebensgeschichten deutschsprachiger Missionsschwestern nach 1945 (Diss. Uni Salzburg 2009), 21-24, 24.

55 Vgl. dazu die dokumentarische Methode: Ralf Bohnsack, Dokumentarische Methode und die Analyse kollektiver Biographien, in: Gerd Jüttemann/Hans Thomae (Hg.), Biographische Methoden in den Humanwissenschaften, Weinheim/Basel 1999, 213-230 und die objektive Hermeneutik: Ulrich Oevermann, Die objektive Hermeneutik als unverzichtbare methodologische Grundlage für die Analyse von Subjektivität. Zugleich eine Kritik der Tiefenhermeneutik, in: Thomas Jung/Stefan Müller-Doohm (Hg.), Wirklichkeit im Deutungsprozess. Verstehen und Methoden in den Kultur- und Sozialwissenschaften, Frankfurt a. M. 1993, 106-189. Vgl. dazu weiter zur Analyse narrativer Interviews: Gabriele Lucius-Hoene/Arnulf Deppermann, Rekonstruktion narrativer Identität. Ein Arbeitsbuch zur Analyse narrativer Interviews, Opladen 2002; Gabriele Lucius-Hoene, Rekonstruktion narrativer Identität, Wiesbaden 3/2009.

56 Zur Darstellung und Verwendung von Forschung und Ergebnissen vgl. auch: Uwe Flick, Sozialforschung. Methoden und Anwendungen. Ein Überblick für die BAStudiengänge, Reinbeck bei Hamburg 2009, 239-246.

57 Die transkribierten Interviews und die digitalen Tondokumente werden in den entsprechenden Archiven der Mutterhäuser archiviert. 


\subsubsection{Erzähltopoi und religiöser Deutungshorizont}

Die Hauptnarrative der Interviews enthalten die vier übergeordneten lebensgeschichtlichen Erzähl-Bereiche «Herkunft», «Kloster», «Konfessionelle Prägung» und «Beruf». Erwartete Inhalte und Mechanismen waren breite und detailreiche Erzählungen zur Kindheit, aber auch eingehende Schilderungen eher nebensächlicher Vorkommnisse. Es war im Voraus abzusehen, dass die Schwestern eher zurückhaltend vom eigenen Geistes- oder Ereignisleben und intensiver von Erlebnissen und Emotionen, die mit ihrer Berufstätigkeit zusammenhingen, berichten werden. Dazu gehören Ausführungen über Schicksale ehemaliger Patientinnen und Patienten oder betreuter Waisenkinder, die unter dem Aspekt der christlichen Nächstenliebe sowie des dienenden Helfens gedeutet werden könnten. Weiter war vorgängig zu erwarten, dass Ausführungen zu Konflikten oder Brüchen eher «unerzählte` Teile der Darstellung bleiben werden. Dazu waren auch schwierige Situationen im Zusammenleben zu zählen, die sich etwa aufgrund der strengen hierarchischen Strukturen im Kloster ergaben. Persönliche (unerfüllte) Wünsche und Empfindungen wie Zweifel oder Ängste, auch tiefere Schichten der eignen Berufungsgeschichte, sollten voraussichtlich erst ab einem gewissen Vertrautheitsgrad mit der Interviewerin zur Sprache kommen.

Aus Sicht des hier vertretenen Forschungsansatzes interessierten im Interview nicht nur die transformierten Inhalte, sondern auch die Erzählmuster. Es war deshalb bei der Auswertung von Interesse, welche Motive dargelegt wurden und in welchen Erzählfiguren die Lebensgeschichte präsentiert wurde ${ }^{58}$ Dabei geht es um ein Forschungsverständnis, das nicht nur methodisch, sondern auch inhaltlich von einer Rekonstruktion der Lebensgeschichte ausgeht, die zeithistorisch kontextualisiert und interpretativ verdichtet ist. ${ }^{59}$

Die Erfahrung aufgrund früherer Forschungsprojekte ${ }^{60}$ und nicht aufgezeichneter, mehr informativ geführter Gespräche zeigte, dass ein

58 Vgl. u.a. dazu: Gabriele Rosenthal, Erlebte und erzählte Geschichte. Gestalt und Struktur biographischer Selbstbeschreibungen, Frankfurt a. M. 1995.

59 Bettina Dausien, «Biographie» als rekonstruktiver Zugang zu «Geschlecht» Perspektiven der Biographieforschung, in: Doris Lemmermöhle/Dietlind Fischer u.a. (Hg.), Lesarten des Geschlechts. Zur De-Konstruktionsdebatte in der erziehungswissenschaftlichen Geschlechterforschung, Opladen 2000, 96-115.

60 Zuletzt: Esther Vorburger-Bossart, Ordensschwestern in der Ostschweiz im 20. Jahrhundert, Zürich 2018. 
grundsätzliches Erzählmuster mit einer durchwegs positiven Darstellung der Lebensgeschichte überwog. Hindernisse und Hemmungen wurden meist in einem religiösen Deutungshorizont verortet. Diese sinnstiftende Leitlinie machte es möglich, selbst schwierigste Lebenssituationen als aushaltbar oder tragbar zu beschreiben und deren Bewältigung darzustellen. Eine Rolle spielte dafür auf katholischer Seite die Orientierung am Vorbild der Heiligen oder an den ordens- und gemeinschaftseigenen Leitgestalten. ${ }^{61}$ So wurden die vielfach entbehrungsreichen Lebensgeschichten häufig mindestens partiell entlang solcher Muster-Lebensläufe als Erfolgsgeschichten dargestellt. ${ }^{62}$ In einem weiteren ansatzweise eruierten Grundmuster der Erzählung wurde eine autonome Planung des eigenen Lebensentwurfs kaum erzählt, auch als passives Element dargestellt, das sich «einfach ergab» oder «von oben geführt» wurde. Hingegen wurde die Deutung der Lebensgeschichte aus der rückblickenden Perspektive innerhalb eines rekonstruierenden Sinnzusammenhangs aktiv und affirmierend vorgenommen. Ein anderes Grundmuster war im mündlichen Umgang mit der Frömmigkeits- und Religionspraxis innerhalb des Kollektivs sowie mit der persönlichen Religiosität zu erwarten. Dieser Bereich dürfte vorausblickend eine der grossen Leerstellen innerhalb der freien Erzählung wie des stimulierten Gesprächs ausmachen. Erwartete begriffliche Stereotypen oder Erzähltopoi dürften aufgrund der zahlreichen informell geführten Gespräche mit religiösen Frauen durch die Verfasserin ab 2001 unpersönlich formulierte Interpretationen wie «es war einfach so», «man hat es einfach gemacht» oder «man hatte keine andere Wahl» sein.

61 Zur übergeordneten Rolle der «Muttergottes» Maria in Bezug auf Identitäts- und Handlungsmuster der Schwestern siehe: Esther Vorburger-Bossart, «Was Bedürfnis der Zeit ist ...». Identitäten in der katholischen Frauenbildung. Die Innerschweizer Lehrschwesterninstitute Baldegg, Cham, Ingenbohl und Menzingen 1900-1980, Fribourg 2008, 130-142.

62 Die Bedeutung von Nekrologen und ordensinternen hagiografischen Publikationen zu Vorbilder-Figuren werden in der 2014 abgeschlossenen Forschung «Religiöse Frauengemeinschaften der Ostschweiz im 20. Jahrhundert», Projekt SNF 100011_ 134603/1, dargelegt. 


\subsubsection{Fragestellungen}

Im Folgenden wird zur kulturhistorischen Einordnung der Fragenkatalog aufgeführt, nach dem die Interviews analysiert wurden:

\section{A) Subjektkonstruktion im Spannungsfeld Kollektiv und Subjekt}

- Wie ist dieses Spannungsfeld zu beschreiben?

- Welche Eigenheiten kennzeichneten die Subjektkonstruktionen?

- Wie waren individuelle Handlungsspielräume gestaltet?

- Inwiefern unterschieden sich diese von der kollektiven Identitätskonstruktion?

- Zeigten sich Unterschiede zwischen dem subjektiven und dem kollektiven Gedächtnis?

- Lassen sich Ansätze eines individuellen Subsystems innerhalb des Kollektivs wahrnehmen?

- Wie konstruierte die Schwester ihre individuelle Lebensgeschichte in der Erzählung?

B) Beruf und Religion

- Wie verortete die Schwester ihre berufliche Identität?

- Gab es eine gegenseitige Beeinflussung zwischen beiden Feldern?

- Welchen Stellenwert nahm die Seelsorge bei der Betreuung Kranker und Sterbender ein?

- Wie wurde zeitgenössisches pädagogisches oder pflegerisches Wissen von den Mutterhäusern in die Aussenstationen transformiert?

- Wie gestaltete sich die Beziehung zwischen Schwestern und deren Vorgesetzten?

- Welche Rolle übernahmen die Geistlichen im Beziehungsumfeld der Schwestern?

- Welche Handlungsspielräume gab es für Schwestern in den Aussenstationen?

C) Kommunikations- und Konfliktbewältigung

- Wie sah die allgemeine Kommunikation aus; welche Ebenen hatte sie?

- Welche Kanäle der Kommunikation standen den Schwestern im Fall von Konflikten offen?

- Wie gestalteten sich die individuellen Verarbeitungsmechanismen? 
A. Einleitung

D) Gemeinschaft

- Wie wird diese von der Schwester als Individuum vor und nach 1968 wahrgenommen?

- Wie wird die eigene Positionierung in der religiösen Gemeinschaft verortet?

- Wie werden die internen Leitbilder und Satzungen bzw. Statuten wahrgenommen und interpretiert?

E) Beziehung zum Mutterhaus

- Wie gestaltete sich diese allgemein?

- Welchen Einfluss übten die Schwestern auf die Reorganisation der Mutterhausgemeinschaft, die in den 1968er-Jahren ihren Höhepunkt fand, aus?

- Wie wurde die eigene religiöse Sozialisation in Bezug auf die Mutterhausgemeinschaft wahrgenommen?

- Gestalteten sich die Muster sozialer Rollen und Zuschreibungen in externen Arbeitsgebieten anders als im Mutterhaus, oder behielten sie auch ausserhalb der gewohnten Gemeinschaft dieselbe Gültigkeit?

F) Vernetzung

- Wie sah die Vernetzung im religiösen und im weltlichen Umfeld aus?

- Gab es gegenüber dem profanen Lebens- oder Berufsumfeld Ansätze von Abwehr- oder Akklimatisationsmechanismen?

G) Erzählstrategie und -inhalt

- Welche Inhalte wurden erzählt?

- Zeigte sich die Erzählung authentisch oder enthielt sie von aussen beeinflusste Erzählmomente?

- Gab es Leerstellen oder Ausklammerungen bzw. was wurde nicht erzählt?

- Stimmten die erzählten Handlungs- und Deutungsmuster überein?

- Waren dabei die Satzungen bzw. Statuten ein verbindlich-normativer oder ein individuell gestalteter Bezugsrahmen?

- Gab es im Vergleich verschiedener Schwesternerzählungen unterschiedliche Wahrnehmungen gleicher Inhalte?

- Gab es wiederkehrende Muster von Erzählmodi, die in mehreren Erzählungen vorkamen? 


\subsubsection{Quellenkorpus, quellenkritische Anmerkungen und These}

Die Zahl der zu führenden Interviews lässt sich im Voraus nur ungefähr festlegen. Sie ist nach dem Prinzip des theoretischen Samplings dann erreicht, wenn aus weiteren Interviews keine wesentlichen zusätzlichen Erkenntnisse mehr für die Fragestellung zu erwarten sind.

Nach der Methode des theoretischen Samplings soll eine möglichst grosse Varianz an empirischem Material erzeugt werden, ohne einen Anspruch auf Repräsentativität im statistischen Sinn zu erheben. ${ }^{63}$ In Anlehnung an die «Grounded Theory» gilt ein Sampling grundsätzlich als beendet, wenn die theoretische Sättigung erreicht wird, demnach aus zusätzlichen Fällen keine für die Fragestellung relevanten, neuen Erkenntnisse mehr zu erwarten sind. ${ }^{64}$ Es wird hier davon ausgegangen, dass dies bei 30 bis 35 Interviews mit Schwestern der Fall sein wird. Aufgrund des hohen Alters der Schwestern wurde die quantitative Basis des voraussichtlichen Quellenkorpus für dieses Projekt zahlenmässig breiter angelegt. Dieses bestand aus 53 Interviews bzw. erzählten Lebensgeschichten von Schwestern aus unterschiedlichen, eingangs dargelegten katholischen Frauengemeinschaften der Schweiz.

Das qualitative Sampling orientierte sich dabei an folgenden biografischen Kriterien, die bei der Auswahl der Interviewpartnerinnen prioritär waren: Die Schwestern sollten die typischen, in der weiblichen Kongregationsgeschichte hauptsächlich vorgekommenen Berufe der Tätigkeitsbereiche in Schule und Spital abdecken und in ihrer aktiven Zeit unterschiedliche Hierarchiestufen durchlaufen haben. Das Alter der befragten Schwestern sollte nach Möglichkeit über 60 Jahren liegen, um sicherzustellen, dass die in den zwischen 1940 und 1960 liegenden Blütezeiten der Gemeinschaften zum Zug kommen. ${ }^{65}$

63 Barney Glaser/Anselm Strauss, The Discovery of Grounded Theory. Strategies for qualitative research, Chicago 1967/dies., Grounded Theory. Strategien qualitativer Forschung, Bern 1998, 53.

64 Anselm Strauss/Juliet Corbin, Grounded Theory. Grundlagen Qualitativer Sozialforschung, Weinheim 1996, 159.

65 Mutterhäuser der acht beteiligten Gemeinschaften:

- Kongregationen und Ordensgemeinschaften mit Filialstruktur: Baldegg; Cham; Ingenbohl; Menzingen; Dominikanerinnen, Ilanz; Pallottinerinnen, Niederuzwil

- Religiöser Verein: St. Anna-Schwestern, Luzern

- Säkularinstitut: St. Katharina-Werk, Basel. Die Bezeichnung zu dieser Gemeinschaft kommt in schriftlichen Unterlagen in beiden Formen als «St. Katharina-Werk» 
A. Einleitung

Thesen

Innerhalb der kulturhistorischen Einordnung lautet die These in Bezug auf das Verhältnis von Beruf und Religion, dass die einzelne Schwester sich innerhalb des vorgegebenen Rasters der jeweiligen Gemeinschaft nach dessen Vorgaben bewegte. Ebenso geht diese These davon aus, dass eine eigene Subjektkonstruktion grundsätzlich nur in Ansätzen möglich war, ohne dabei individuelle Merkmale zu verlieren. Ein thesenartig entworfenes Gruppenporträt dieser Generation von Schwestern der zweiten Hälfte des 20. Jahrhunderts verdeutlicht, dass die Präsentation der Lebensgeschichte das Resultat von sozio-religiösen Deutungsangeboten und Sinnbildungsprozessen ist. Zur Stützung dieser Thesen diente ein Vergleich mit in der Oral History bereits geleisteten Arbeiten ${ }^{66}$ Weiter wurde diese These gestützt durch Gespräche, die während des erwähnten vorgängigen, regional angelegten Forschungsprojekts, das aus schweizerischer Sicht exemplarisch die Ostschweizer Ordensschwestern untersuchte, geführt wurden.

Aus religionshistorischer Sicht waren die Ordensschwestern Repräsentantinnen praktizierter Religion. Das öffentliche Erscheinungsbild von Religion wurde spätestens ab den 1960er Jahren für grössere Gesellschaftsgruppen immer weniger sicht- und spürbar, zu einem Teil aufgrund der schwindenden Mitgliederzahlen von Ordensgemeinschaften. Damit prägte dieser Prozess einen Teil des hier fokussierten Zeitraums. Parallel dazu setzte die Privatisierung und Individualisierung von Religion ein, die bis heute andauert. Die Kongregationsgemeinschaften bilden einen gegenläufigen Part davon, indem sie diese prozesshafte Entwicklung durch eine moderne Form einer Vergemeinschaftung von Religion begleiten, die das Bedürfnis nach persönlich praktizierter Religiosität des heutigen Menschen integriert.

oder später als «Katharina-Werk» vor. In dieser Publikation wird ausser in LiteraturZitaten die ursprüngliche Form «St. Katharina-Werk» verwendet.

66 Martina Gugglberger, "Ich wollte immer nach Afrika». Lebensgeschichten deutschsprachiger Missionsschwestern nach 1945 (Diss. Uni Salzburg 2009). 


\subsection{Kulturgeschichtlicher Grundriss zur Entstehung schweizerischer religiöser Frauengemeinschaften}

\subsubsection{Kongregationen von Baldegg, Cham, Ilanz, Ingenbohl, Menzingen und Pallottinerinnen ${ }^{67}$}

\subsubsection{Verberuflichung religiöser Frauen}

Seit dem ausgehenden 18. Jahrhundert waren Kirche und Gesellschaft bzw. deren Exponenten und Trägergruppen durch die politischen, sozialökonomischen, religiösen und kulturellen Wandlungen mit diversen veränderten Ausgangslagen konfrontiert, die als strukturelle Modernisierungskrisen nach einer angemessenen Beantwortung durch Staat und Gesellschaft sowie Kirche und Kulturträger verlangten. ${ }^{68}$ Die sich modernisierende Gesellschaft wurde vor grundlegende strukturelle und funktionale Probleme gestellt, die im Zusammenhang mit den Herausforderungen der sozialen Frage, der Frauenfrage, eines kaum zurückgegangenen Analphabetismus und den Unzulänglichkeiten des Bildungssystems, der mangelnden medizinischen Gesundheitsfürsorge sowie mit fehlender wissenschaftlicher Spezialisierung oder multifunktionalem Arbeitshandeln standen.

67 Die Schwesterngemeinschaft der Pallottinerinnen ist eine Missionsgemeinschaft vom katholischen Apostolat, deren Mutterhaus sich seit 1895 im Limburg befindet. Gegründet wurde diese Gemeinschaft von Vinzenz Pallotti (1795-1850). Erste Schwestern dieser Kongregation wurden von Limburg 1932 in die Ostschweiz, zuerst nach Gossau, entsandt, wo sie später v. a. in Niederuzwil und Bernhardzell in Schulen und Spitälern tätig waren: vgl. «Die Sendung der Pallottinerinnen in die Schweiz. Schwierigkeiten und Aufgaben», 1.7.1932; «Das «alte Klösterli in Bernhardzell ist nicht mehr», Akten Gründung Schwesternhaus «St. Wiborad» 1944, o. D. (April 1944). Die Gründungsgeschichte der Pallottinerinnen ist aufgrund ihrer ausländischen Herkunft für die schweizerische religiöse Frauenbewegung des 19. Jahrhundert nicht relevant und wird hier nicht berücksichtigt.

68 Siehe dazu den modernisierungstheoretischen Ansatz, in: Frank-Michael Kuhlemann/Hans-Walter Schmuhl, Einführung. Beruf und Religion im 19. und 20. Jahrhundert, in: dies., (Hg.), Beruf und Religion im 19. und 20. Jahrhundert, Stuttgart 2003, $14 \mathrm{f}$.; Thomas Mergel, Geht es weiterhin voran? Die Modernisierungstheorie auf dem Weg zu einer Theorie der Moderne, in: ders./Thomas Welskopp (Hg.), Geschichte zwischen Kultur und Gesellschaft. Beiträge zur Theoriedebatte, München 1997, 203-232. 
Eine Antwort auf die drängenden Probleme der Modernisierung bot sich mit der Ausdifferenzierung moderner Berufstätigkeit bis hin zur Professionalisierung von Berufsfeldern, die insbesondere Frauen einbezog. ${ }^{69}$

Vor dem Hintergrund der Vielschichtigkeit der sozialen Frage zeichnete sich über die Tendenz zur weiblichen Verberuflichung hinaus auch eine Spezialisierung von Tätigkeitsfeldern ab, die sich parallel zur Entwicklung der Professionalisierung, und damit zur Herausbildung von weiblichen Berufszweigen bewegte. Diese Entwicklung als weiteres Produkt des Modernisierungsprozesses, stellte dem vormodernen multifunktionalen Arbeitsverständnis vor allem der agrarischen Gebiete die spezialisierte Arbeitspraxisentgegen, dieihrerseits aufdieUrbanisierungsprozesse der Moderne wies. ${ }^{70}$

In der Verbesserung von Bildungs- und Pflegeangeboten waren diese Prozesse, in denen die konfessionellen Kirchen und religiösen Vereinsmilieus eine zentrale Funktion einnahmen, konstituierend. ${ }^{71}$ Ein bedeutendes weibliches Potenzial im sozial-karitativen Bereich wurde in neuen Ordensformen mit gelockerten Klausurbedingungen erschlossen. ${ }^{72}$ Diese ordensrechtlichen Mutationen standen in direktem Zusammenhang mit den Modernisierungsprozessen und den sozial-ökonomischen Veränderungen. Mit der im 19. Jahrhundert sich konstituierenden Ordensform der Kongregationen wurden mit keiner bisher vergleichbaren

69 Dies zeigt besonders das weibliche Kongregationsphänomen in der karitativen und in der in dieser Studie untersuchten pädagogischen Ausrichtung des Lehrschwesternzweiges. Siehe zu den weiblichen Kongregationen der Schweiz und Deutschland: Esther Vorburger-Bossart, «Was Bedürfnis der Zeit ist ...». Identitäten in der katholischen Frauenbildung. Die Innerschweizer Lehrschwesterninstitute Baldegg, Cham, Ingenbohl und Menzingen 1900-1980, Fribourg 2008, 76-114; Relinde Meiwes, Arbeiterinnen des Herrn. Katholische Frauenkongregationen im 19. Jahrhundert, Frankfurt a. M. 2000; Zoe Maria Isenring, Die Frau in den apostolisch-tätigen Ordensgemeinschaften. Eine Lebensform am Ende oder an der Wende? Freiburg ${ }^{3} 1996$.

70 Siehe dazu etwa die (interkonfessionell vergleichende) Lokalstudie: Antonius Liedhegener, Christentum und Urbanisierung. Katholiken und Protestanten in Münster und Bochum 1830-1933, Paderborn/München/Wien/Zürich 1997.

71 Frank-Michael Kuhlemann/Hans-Walter Schmuhl, Einführung. Beruf und Religion im 19. und 20. Jahrhundert, in: dies., (Hg.), Beruf und Religion im 19. und 20. Jahrhundert, Stuttgart 2003, 15.

72 Siehe zur ordensrechtlichen Entwicklung der Kongregationen im 19. Jahrhundert: Patrick Braun, Die religiösen Kongregationen im 19. und 20. Jahrhundert (Einleitung), in: ders. (Hg.), Die Kongregationen in der Schweiz 19. und 20. Jahrhundert, HS VIII/2, Basel 1998, 32-36. 
gesellschaftlichen Entwicklung an qualitativem und quantitativem Ausmass Frauen nicht nur religiös, sondern als Novum auch beruflich vergesellschaftet. ${ }^{73}$ Mit der ordensrechtlichen Neudefinition in den Kongregationsgemeinschaften wurde die bisherige weibliche, geistliche Berufung zur Umsetzung einer klausuralen Lebensgestaltung Ausgangslage zur Verberuflichung einer grossen Anzahl von Frauen.

\subsubsection{Katholisches Konzept zur sozialen Frage}

Im schweizerischen Umfeld war es die zunehmende Konfessionalisierung der 1840er Jahre, in welche die konkrete Ideenentwicklung und die Gründungsprozesse, v. a. der Innerschweizer Mutterhäuser weiblicher Kongregationsgemeinschaften, fielen. Der aus der damaligen liberalen Vormachtstellung resultierende katholische Inferioritätsstatus in sozioökonomischer und kultureller Hinsicht dürfte für diese Prozesse eine nicht geringe Rolle gespielt haben. In diesem Sinn rief die gesellschaftliche und ökonomische Moderne von Seiten des Katholizismus sozial-karitatives Handeln hervor, das gleichzeitig einen wesentlichen Beitrag zur Prononcierung, und ferner zur Konfessionalisierung des Katholizismus im schweizerischen liberalen Umfeld leistete. Die Moderne bewirkte besonders auf klerikaler Seite sowie unter Exponenten der apostolisch-tätigen Ordensbewegung eine religiöse oppositionelle Haltung, die sich in teils abwehrenden und teils innovativen Widerstandsformen gegenüber der Verbreitung von liberalen Idealen zeigte und letzteren eine vielgestaltige katholische Alternative entgegenstellte.

Auf der Umsetzungsebene in der Konkretisierung insbesondere der Lehrtätigkeit zeigte sich die Ambivalenz dieses Phänomens insofern, als die Schwestern zwar einerseits aufgrund ihrer klösterlichen Gelübde den für Frauen des 19. Jahrhunderts opportunen Rückzug auf den religiöskirchlichen Raum weit konsequenter als weltliche Frauen realisierten. Anderseits waren es gerade die Schwestern, die durch ihre ausserklausurale Präsenz in Schule und auch Pflege zugleich ein zusätzlich optisch durch ihre augenfällige Ordenstracht verstärktes prominent öffentliches Auftreten vorwiesen. Dies interpretierte die nichtkatholische Gegenseite

73 Die Forschung scheint sich zur Umschreibung dieses Phänomens mehr oder weniger auf den Begriff «Kongregationsfrühling» festgelegt zu haben: Siehe zum weiblichen Kongregationsphänomen vor allem: Relinde Meiwes, Arbeiterinnen des Herrn. Katholische Frauenkongregationen im 19. Jahrhundert, Frankfurt a. M. 2000, 27-113 (siehe dort auch die soziale Frage aus der Geschlechterperspektive, 269-287). 
A. Einleitung

mehrheitlich als provokatives Moment, denn die Kombination von Frau und Konfession gehörte besonders aus bürgerlich-liberaler Sicht in die Nicht-Öffentlichkeit. Das praktizierte Gegenteil im überzeugten Wirken dieser Schwestern, das über dessen religiös-soziale Natur hinaus eine bisher noch kaum etablierte weibliche Profession demonstrierte, musste den politischen Argwohn der Gegnerkreise hervorrufen. Obwohl gerade der von dieser Seite als politische Komponente wahrgenommene Öffentlichkeitsaspekt für die Tätigkeiten der Schwestern grundsätzlich irrelevant war, entwickelten sich die ideellen und personellen Aggregationsprozesse zur Konstitution von Kongregationen insbesondere im Kontext des politischen Umfeldes der Wirren im Sonderbundskrieg. Das konfessionell motivierte Konstrukt der weiblichen tätigen Orden enthielt damit konsistenten politischen Kern mit sozialer Ausrichtung.

Das liberal-radikale Vorgehen gegen Klöster kontemplativer Ausrichtung, wie es insbesondere im Kanton Aargau exemplifiziert wurde, bildete damit aber nur die eine konstituierende Komponente für die tätige Ordensneuausrichtung. Es rief damit innerhalb des katholischen Resistenzverhaltens gleichzeitig das reagierende Element hervor. Die geschlossenen Frauenklöster boten in Reaktion auf die Aufhebungsdrohungen zusätzlich zu ihrer kontemplativen Ausrichtung eine nach liberaler Ansicht allgemein-nützliche Dienstleistung wie die Mädchenerziehung in den zu diesem Zweck neu errichteten, den Klöstern angegliederten Schulen an. Die andere aktive Komponente bildete innerhalb der christlichideologischen Inspiration eine noch dezidiertere weltliche Ausrichtung als die erwähnten - politisch erzwungenen Klosterschulen - der kontemplativen Orden und implizierte eine reflektierte, politisch relevante Konfessionalisierungsidee. Die Idee der im Entstehen begriffenen Professionalisierung der Lehr- und Pflegetätigkeit von geistlichen Frauen zielte somit über den religiösen Gedanken hinaus bewusst auf das säkulare Umfeld, das es aus der Sicht der geistlichen und kirchlichen Promotoren als konfessionell-christlich zu erhalten und wo nötig erneut zu verchristlichen und zu rekatholisieren galt. So firmierte die Verbindung von klösterlich-religiöser Geisteshaltung mit laikaler Verberuflichung von Frauen neben den eigentlichen berufspraktischen Zielen, nämlich den sozialkaritativen oder pädagogischen Tätigkeiten, insbesondere für die gesellschaftliche Präsenz, die Verankerung und auch für die Verbreitung von christlich-katholischem Gedankengut in liberalen, meist antikatholischen Gebieten. Beide Komponenten, die ordensrechtliche Reaktion wie auch die berufspraktisch-ideologische Aktion in der originären Ausgestaltung 
der Kongregationsgemeinschaften, wurden zum katholischen Innovationsmoment.

Die Konstitution dieser schweizerischen katholischen Offensive, die sich grösstenteils in der weiblichen Kongregationsbewegung äusserte, ist einerseits im transnationalen Katholizismuskontext zu sehen, insbesondere unter dem Einfluss ausländischer Beispiele, etwa französischer Kongregationen wie der Spitalschwestern von Besançon, der Vinzentinerinnen oder der Sœurs de la Charité von Besançon. Diese unterhielten auch in der Schweiz Filialniederlassungen und waren zuerst vorwiegend in der Westschweiz und von dort aus ab den 1830er Jahre auch in der Innerschweiz tätig. ${ }^{74}$ Beispielhaft waren in der Schweiz auch die Ursulinen mit ihren Niederlassungen unter anderen in Fribourg, Luzern, Porrentruy, Brig, Sitten und im Tessin, die bereits seit dem 16. Jahrhundert eine Verlagerung vom kontemplativen zum tätigen Ordensideal aufgrund von Impulsen der Regularkleriker, besonders der Jesuiten, vollzogen hatten. ${ }^{75}$ Anderseits ist die Initiierung der kongregationistischen Bewegung vor dem Hintergrund der regionalen, soziodemografischen sowie gleichzeitig basiskatholischen Zusammenhänge zu sehen. Diese Ausrichtungen hingen wiederum eng mit dem organisierten Katholizismus zusammen, der genauso Teil des internationalen katholischen Phänomens der organisierten Massenreligiosität und des Frömmigkeitsverhaltens des 19. Jahrhunderts sowie Teil des katholischen Provinzialismus war und im Widerspruch zum bürgerlich-liberalen Nationalstaat stand. ${ }^{76}$ Die parochiale Struktur des Katholizismus innerhalb der kleinräumigen schweizerischen Verhältnisse verstärkte die Unmittelbarkeit des örtlichen Klerus zur lokalen sozialen Bezugshandlung, durch die der Welt- oder Ordensgeistliche im Dorf nicht nur der Repräsentant der katholischen Kirche war, sondern mit den Sorgen und Einschränkungen, besonders der kinderreichen

74 Patrick Braun, Die religiösen Kongregationen im 19. und 20. Jahrhundert (Einleitung), in: ders. (Hg.), Die Kongregationen in der Schweiz 19. und 20. Jahrhundert, HS VIII/2, Basel 1998, 43.

75 Patrick Braun, Religiöse Männer- und Frauenkongregationen des 16. und 18. Jahrhunderts (Einleitung), in: ders. (Hg.), Die Kongregationen in der Schweiz 16.18. Jahrhundert, HS VIII/1, Basel/Frankfurt a. M. 1994, $21 \mathrm{f}$. Zu den Ursulinen der verschiedenen Schweizer Niederlassungen siehe im selben Band Einführung und Artikel, 42-44, 107-272.

76 Siehe u. a.: Urs Altermatt, Katholizismus und Moderne. Zur Sozial- und Mentalitätsgeschichte der Schweizer Katholiken im 19. und 20. Jahrhundert, Zürich ${ }^{2} 1991$, $67-71$. 
A. Einleitung

Familien in kargen Agrargebieten, vertraut war. Damit eröffnete sich ihm die Möglichkeit, diese wahrzunehmen und sich mit ihnen zu befassen. ${ }^{77}$ Sozial-karitative Gründungsideen und Institutionalisierungen gingen deshalb im 19. und frühen 20. Jahrhundert nicht zuletzt aufgrund dieser unmittelbaren Betroffenheit hauptsächlich auf Geistliche zurück. Ebenfalls prägend dafür dürfte zusätzlich die konfessionell-ultramontane Sozialisation der Priester gewesen sein, die besonders auf die Ausbildungszeit an den reorganisierten und straff strukturierten Ausbildungsstätten zurückging. ${ }^{78}$

\subsubsection{Katholische Sozialreformer}

Verschiedene katholische Geistliche, die mit ihren sozialreformerischen Ideen hervortraten, waren bereits zu Beginn des 19. Jahrhunderts aufgrund ihrer geistlichen wie praktischen Ausrichtung mit den sozial-konfessionellen Nöten der Zeit sensibilisiert. ${ }^{79}$ Für die vorliegende Untersuchung, die hauptsächlich Lebensgeschichten von Schwestern aus den vier grossen Innerschweizer Instituten enthält, sind unter diesen katholischen Geistlichen insbesondere zwei Sozialreformer, Josef Leonz Blum (17861859) und Theodosius Florentini (1808-1865), zu nennen. Für die Gründung einer bündnerischen Niederlassung war der Priester Johann Fidel Depuoz (1817-1875) von Bedeutung. Mit ihrer Konkretisierung weibli-

77 Vgl. zur Rolle des Weltklerus etwa: Irmtraud Götz von Olenhusen, Die Ultramontanisierung des Klerus. Das Beispiel der Erzdiözese Freiburg, in: Loth (Hg.), Deutscher Katholizismus im Umbruch, 46-55; dies., Klerus und abweichendes Verhalten. Zur Sozialgeschichte katholischer Priester im 19. Jahrhundert, Göttingen 1994, 95-117.

78 Siehe zur Sozialisation in den Priesterausbildungsstätten: Götz von Olenhusen, Die Ultramontanisierung des Klerus. Das Beispiel der Erzdiözese Freiburg, in: Wilfried Loth (Hg.), Deutscher Katholizismus im Umbruch zur Moderne, Stuttgart/Berlin/Köln 1991, 46-75; dies., Klerus und abweichendes Verhalten. Zur Sozialgeschichte katholischer Priester im 19. Jahrhundert, Göttingen 1991, 95-142.

79 Siehe im selben Zeitraum die protestantische Entwicklung in Deutschland um Theodor Fliedner (1800-1864) mit der Gründung eines «Diakonissen-Mutterhauses» in Kaiserswerth bei Düsseldorf 1836, in der Fliedner mit seiner ersten Frau Friederike und später mit seiner zweiten Frau Caroline erste Schritt zur Entwicklung einer sozial-religiösen Vergemeinschaftung von protestantischen Frauen einleitete: Martin Gerhardt, Theodor Fliedner. Ein Lebensbild, 2 Bde., Düsseldorf/Kaiserswerth 1933/1937; Anna Sticker, Friederike Fliedner und die Anfänge der Frauendiakonie. Ein Quellenbuch, Neukirchen 1961; Ute Gause, Friederike Fliedner und die 〈Feminisierung des Religiösen` im 19. Jahrhundert, in: Martin Friedrich (Hg.), Sozialer Protestantismus im Vormärz, Münster 2001, 123-13. 
cher Kongregationsformen erbrachten sie die Evidenz für die Zusammenhänge zwischen katholischer Feminisierung und gesellschaftlicher Moderne einerseits sowie anderseits zwischen Religion, Konfession und Profession für die Konsolidierung der katholischen Milieugesellschaft.

Nachfolgend soll exemplarisch den Innerschweizer Gründungen dieser Kongregationen nachgegangen werden. Der Hochdorfer Kaplan und Schüler Johann Michael Sailers (1751-1832), Josef Leonz Blum, gründete auf Anregung des Luzerner Theologieprofessors Josef Widmer (17791844) - auch er ein Sailer-Schüler - 1830 das Schwesterninstitut Baldegg, eine Arbeits-und Erziehungsanstalt für die «Armen Schwestern im Schloss zu Baldegg», im Luzerner Seetal. ${ }^{80}$ Die Entstehung des Instituts Baldegg ist eng mit der wechselvollen politischen Geschichte Luzerns im 19. Jahrhundert verknüpft. Zweck des Instituts war, junge Frauen zu Kost, Erziehung und schulischer Bildung aufzunehmen, um dann die auch schulpädagogisch ausgebildeten Frauen als Lehrerinnen von Mädchenschulen oder Leiterinnen von Armen- und Waisenhäuser einzusetzen. ${ }^{81}$ Diese soziale Institution in Baldegg knüpfte damit als ordensrechtlich noch nicht konsolidierte, aber dennoch religiösen Grundsätzen verpflichtete Schwesterngemeinschaft an den in kontemplativen Orden bereits seit spätestens dem 17. Jahrhundert praktizierten Typus des «Kosttöchterwesens» an. Vorbild zu dieser neu gegründeten Gemeinschaft war die im Elsass ansässige Kongregation der Schwestern der Göttlichen Vorsehung zu Ribeauvillé, einer 1783 gegründeten Gemeinschaft von Schulschwestern, die sich der Kinder- und Mädchenerziehung widmete und sich nach den sozial-karitativen Idealen von Vinzenz von Paul (1576-1660) richtete. Maria Theresia Elmiger (1842-1851) wurde nach ihrer Ausbildung bei den Schwestern in Ribeauvillé von Direktor Blum zur Vorsteherin der Baldegger Gemeinschaft ernannt und ist als Mitgründerin des Instituts Baldegg zu bezeichnen.

Während ihrer Amtszeit begann unter ihrer strukturierenden Führung eine Regulierung des Klosterlebens, zu der ebenfalls die wesentlich teilkonstitutive Institution der Einkleidung gehörte, welche die Verklös-

80 Siehe zu Blum: Josef Strebel, Kaplan Josef Leonz Blum 1786-1859. Gründer des Schwesterninstitutes Baldegg, Hochdorf 1969. Siehe hierzu weiter: Stephan Leimgruber, Theologische Entwicklungslinien in der Schweiz von 1880-1965, in: ZSKG, 86 (1992), 245-268.

81 AB, C VII 2 1/a, Gründungsvertrag des Hilfsvereins 1831. Vgl. für die Anfänge: Matthäa Vock, Das Schwestern-Institut Baldegg, Hochdorf 1930, 3-24. 
terlichung auch nach aussen verdeutlichte und den Ordensstatus öffentlich bezeugte. Die Einkleidungsinitiation der Baldegger Schwestern - darunter ist die Einkleidung Sr. Theresias bezeugt - fand 1841, also noch kurz vor deren Amtsantritt als Vorsteherin während ihrer Ausbildungszeit in Ribeauvillé statt. ${ }^{82} 1844$ erfolgte die Anerkennung des Instituts Baldegg durch den Bischof von Basel. ${ }^{83}$ Die anfänglich noch wenig institutionelle Gemeinschaft wies schon vor Theresia Elmigers Amtszeit durch die von Blum erstmals 1836 verfassten und 1841/44 angepassten Hausregeln im Anschluss an die Statuten der Schwestern von Ribeauvillé erste Anzeichen zu einem regulierten Klosterleben auf, die das soziale und religiöse Gemeinschaftsleben regelten. ${ }^{84}$ Der Regulierungsprozess setzte insbesondere 1839 mit der Unterzeichnung einer Art Dienstvertrags durch die Frauen ein, der sie zu den drei evangelischen Räten verpflichtete und sie mit den zentralen Teilen eines klausuralen Lebens vertraut machte.

Dass das Institut damit Religion mit Arbeit verband, war für die katholische und teils auch säkulare Schweiz ein entscheidender ideeller und praktischer Ausgangspunkt. Dieser diente nicht nur der Verberuflichung von Frauen und der damit verbundenen Professionalisierung neuer Berufszweige, sondern bot die Grundlage zu deren beginnender Ökonomisierung. Dabei spielte der soziodemografische und regionale Faktor zur Rekrutierung und Zusammensetzung dieser und der anderen Innerschweizer religiösen Gemeinschaften eine zentrale Rolle. Die überwiegende Mehrheit der Frauen stammte aus den unteren und mittleren Schichten aus agrar-katholischen Gebieten, welche die kongregationistischen Institute als sozial-tätige Alternative zur bürgerlichen Kleinfamilie ansahen.

Noch dezidierter als Blum verband der Bündner Kapuzinerpater und Sozialreformer Theodosius Florentini die Idee der geistlichen Berufung von Frauen mit der Professionalisierung. ${ }^{85}$ Dabei spielte das theodosiani-

82 AB, EI 1,4, Empfang des Ordenskleides in Ribeauvillé, 23.9.1841.

83 AB, D IV 4,2; Vock, Das Schwestern-Institut Baldegg, 155-158.

$84 \mathrm{AB}, \mathrm{Fc} 36.1$, Fc 36.2, Regeln und Verordnungen für die armen Dienst- und Lehrschwestern von der göttlichen Vorsicht in der Arbeits-Erziehungsanstalt bei St. Jost zu Baldegg, 1836 (Fc 36.1) und 1842/44 (Fc 36.2).

85 Zur Theodosiusforschung siehe eine Auswahl (chronologische Aufzählung in Kurzzitaten): Isenring, P. Theodosius Florentini (1808-1865). «Den Strom nicht stauen, sondern ihm ein Bett anweisen»; Bünter, Wegbereiter aus christlicher Leidenschaft; Rümmer, P. Theodosius Florentini (1808-1865). Ein Mann der Caritas und der sozialen Tat; Stäger, Die pädagogischen Grundsätze des Pater Theodosius Florentini und die Päda- 
sche Ideal einer möglichst weitgehenden Verchristlichung der Gesellschaft vor dem Hintergrund der realen sozial-politischen Situation eine zentrale Rolle. Die Wahrnehmung dieses Kontextes und die pädagogischkonfessionelle Inspiration Theodosius' standen in direkter Relation zum Entschluss zur Gründung religiöser Frauengemeinschaften, der zu einem weiblich-religiösen Vergemeinschaftungskonzept führte und Programm zur konkreten Form der Schwesternkongregationen für Schule und Karitas war. Diese für seine Initiative bestimmende auf religiös-christlicher Grundlage basierender Zweckausrichtung war nicht nur Programm, sondern beeinflusste in den Konsolidierungs- und Approbierungsprozessen bezüglich Rechtsgestalt, Ordenszugehörigkeit und Ausgestaltung der Konstitutionen die entstehenden theodosianischen Kongregationen in entscheidendem Mass. ${ }^{86}$ Ausdifferenzierung und Umsetzung der theodosianischen Idee der katholischen Bekenntnisschule nach christlichen

gogik seiner Zeit, Typoskript; Bünter, Theodosius Florentini (1808-1865). Sozialreformer im Ordensgewand, in: Schweizer Pioniere der Wirtschaft und Technik, 9-36; Grüninger, Mut zum Wagnis. P. Theodosius Florentini als Reformer in Schule, Karitas und Sozialpolitik; Bünter, Die industriellen Unternehmungen von P. Theodosius Florentini. Eine sozial-ethische Studie über Voraussetzungen und Grenzen der Sozialreform; Gadient, Der Caritasapostel Theodosius Florentini; ders., Bewegende Liebe. Die Frömmigkeit im Wirken des Caritasapostels P. Theodosius Florentini ; Frei, Pater Theodosius Florentini und sein Werk; Künzle, P. Theodosius Florentini und die Schule; ders., Gedenkblätter zum 50. Todestag von P. Theodosius Florentini; Steimer, Erziehung und Selbsterziehung von P. Theodosius Florentini; Oesch, Pater Theodosius Florentini, Generalvikar des Bistums Chur. Eine biographische Studie; Krauthahn, Pater Theodosius. Sein Leben, sein Wirken und seine letzten Lebensstunden; Mutter, Kurze Biographie über das Leben und Wirken des Hochwürdigen P. Theososius Florentini, Generalvikar von Chur. - $\mathrm{Zu}$ Theodosius und seine Gründungen in Menzingen bzw. Ingenbohl siehe: Doka, P. Theodosius Florentini. Sein Beitrag zur Gründung der Kongregation der Schwestern vom hl. Kreuz Menzingen; Huber, P. Theodosius Florentini. Seine Stiftung in Ingenbohl; Hättenschwiler, Die Kongregation der Schwestern vom Hl. Kreuze in Ingenbohl und ihr Stifter P. Theodosius Florentini; Fürer, Leben und Wirken des Hochwürdigen Pater Theodosius Florentini, O. Cap., Generalvikar des Bisthums Chur, Gründer und Superior des Institutes der barmherzigen Schwestern von Ingenbohl, Kt. Schwyz. Aus seinen Quellen zusammengestellt; Thaler, P. Theodosius Florentini, Ord. Cap., Generalvikar von Chur, Stifter der Kongregation vom hl. Kreuz in Menzingen und Ingenbohl.

86 Vgl. etwa für das Beispiel der Entwicklung der Ingenbohler Gemeinschaft: Hidburg Baumgartner/Markus Ries/Christian Schweizer u.a. (Hg.), Von der Not der Zeit getrieben. Maria Theresia Scherer - Theodosius Florentini: Briefe und Schriften, HF 45 (2016); Zoe Maria Isenring, P. Theodosius Florentini (1808-1865). «Den Strom nicht stauen, sondern ihm ein Bett anweisen», Fribourg 2016; dies., Franziskanischer Lebens- 
Grundsätzen bildeten sich konkret vor allem im Spannungsfeld der Auseinandersetzungen von Liberalen und Konservativen der 1830er Jahre heraus.$^{87}$ Ein früher theodosianisch pädagogisch-konfessioneller Entwurf einer katholischen Schule für katholische Kinder dieser Zeit nahm die Forderung nach katholisch-konfessionellen Schulen in der Erziehungsenzyklika Pius XI. Divini illius Magistri von 1929 um einige Jahrzehnte vorweg. Besonders während seiner Zeit als Guardian im Kapuzinerkloster in Baden von 1838-1841 konkretisierten sich die pädagogischen Pläne Theodosius', die zur Umsetzung der konfessionellen Erziehungsideale sich nicht nur gegen den Bildungsrationalismus richteten, sondern sich insbesondere auch auf den Faktor Geschlecht fokussierten. ${ }^{88}$ Theodosius definierte, aus Sicht des bürgerlich-dualen Geschlechterverständnisses des 19. Jahrhunderts erstaunlicherweise, aufgrund seiner Ideale hingegen konsequenterweise, den Wirkungskreis für die Frau auch ausserhalb der Familie: «Die Wirksamkeit der Frau erstreckt sich über den Kreis der Familie hinaus ins gesellschaftliche Leben. Wie gross ist nicht hier ihr Einfluss, sei es in Bezug auf Religion und Tugend, wenn sie mit dem Beispiele der Frömmigkeit vorangeht, Liebe und Sanftmut übt, mit Wort und Tat für Glaube und Tugend, für Beobachtung göttlicher und kirchlicher Gebote einsteht.» ${ }^{89}$ Nach den sozial-pädagogischen Vorstellungen von Theodosius sollte einerseits grundsätzlich eine Bildungsmöglichkeit für Mädchen und Frauen institutionalisiert werden, die gleichzeitig die zentrale Bedeutung der konfessionellen Bildungsvermittlung implizierte. Anderseits bezog Theodosius damit ein weiteres Segment von Frauen ein, die insbesondere als zukünftige Lehrerinnen selber höhere oder weiterführende Bildung innerhalb ihrer beruflichen Ausbildung erhielten. Zusätzlich schuf Theodosius mit diesem frauengeschichtlich relevanten Programm die Grundlage zu einem sinnstiftenden Lebensentwurf und

weg für Frauen. Die Zugehörigkeit der Barmherzigen Schwestern vom heiligen Kreuz Ingenbohl zur franziskanischen Ordensfamilie, in: HF, 34/2 (2005), 175-198.

87 Siehe IAI, [Cornelia] Göcking, Canonizationis Servae Dei Mariae Theresiae Scherer positio super virtutibus, 22-33; vgl. weiter: Steimer, Theodosius Florentini, Erziehung und Selbsterziehung, aus seinen Schriften zusammengestellt, 139-170; Gadient, Bewegende Liebe. Die Frömmigkeit im Wirken des Caritasapostels P. Theodosius Florentini.

88 Siehe IAI, [Cornelia] Göcking, Canonizationis Servae Dei Mariae Theresiae Scherer positio super virtutibus, 22-28.

89 Rufin Steimer, Theodosius Florentini, Erziehung und Selbsterziehung, aus seinen Schriften zusammengestellt, Luzern 1911, 509. 
den geistigen Orientierungsrahmen zu einem religiösen Lebensmodell für Hundertschaften von Frauen. Dessen subjekt- und kollektivgeschichtlicher Verlauf im 20. Jahrhundert wird im zweiten Teil dieser Untersuchung anhand der Lebenserzählungen religiöser Frauen dokumentiert.

In der praktischen Umsetzung gründete Theodosius als Vorläuferinstitution zu den späteren Kongregationsinstituten bereits 1840 in Baden im Kapuzinerinnenkloster Mariä Krönung im Kontext der von liberaler Seite geforderten allgemeinen Nützlichkeit von Klöstern ein Pensionat für Mädchen und bestimmte die Oberin des Klosters als Leiterin. ${ }^{90}$ Als zukünftige Lehrerinnen liess er dort drei junge Frauen ausbilden, worunter sich die spätere erste Vorsteherin der Gründung in Menzingen, Maria Bernarda, mit Taufnamen Maria Anna, Heimgartner (1822-1863) befand. 1841 erfuhr mit der Aufhebung aller Klöster im Kanton Aargau auch die theodosianische Badener Institution für Mädchenbildung ein vorläufiges Ende. ${ }^{91}$ Theodosius wurde aufgrund seiner dezidiert konfessionellen Aktivitäten als Ordensmann polizeilich gesucht und musste ins nahe Ausland fliehen. Auf seiner Flucht kam er ebenfalls wie Blum mit der Schwesterngemeinschaft der Göttlichen Vorsehung zu Ribeauvillé im Elsass in Kontakt. Dort sah er seine Idee einer Lehrschwesternkongregation bereits realisiert. Theodosius holte die drei Badener Schülerinnen und mittlerweile Novizinnen zur Vertiefung ihrer religiösen und beruflichen Ausbildung nach Ribeauvillé. Nach Ablauf der Elsässer Ausbildungszeit in Ribeauvillé legten die drei Schwestern ihre Profess als Angehörige des Dritten Ordens des hl. Franziskus 1844 in Altdorf ab. Nach der von Theodosius angeregten und begleiteten Ordens- und Berufsausbildung der ersten Schwestern folgten weiter erste hierarchische und konstituierende Schritte zur Institutionalisierung und Konsolidierung eines Mutterhauses, das seinen Sitz im zugerischen Menzingen nehmen sollte, einer vorerst noch kleinen Schwesterngemeinschaft.

Theodosius stellte seinen praktisch realisierten Institutionalisierungen auch konkrete Richtlinien zur Seite. Er legte besonders mit der Zweckbestimmung des Menzinger Instituts die berufliche Ausgestaltung der Lehrschwestern einerseits und die Konfessionalisierung der Erziehung ander-

90 Siehe zum theodosianischen Schulprojekt im Kloster Mariae Krönung in Baden während der Zeit der radikalen Regierung im Kanton Aargau: IAI, Göcking, Canonizationis Servae Dei Mariae Theresiae Scherer positio super virtutibus, 22-28.

91 Zum folgenden zu Menzingen: Fromherz, Menzinger Schwestern, in: HS VIII/2, 278-281. 
seits schriftlich nieder. ${ }^{92}$ Seine sozial-pädagogischen Ideen bewegten sich ausschliesslich auf religiöser Grundlage und wurden gleichzeitig auf den konfessionellen Boden der katholischen Kirche gestellt. Bereits die von Theodosius 1844 vorgelegten und 1851 bischöflich approbierten Statuten enthielten die programmatische Ausrichtung des Instituts, nämlich an der «Erziehung der weiblichen Jugend mitzuwirken». ${ }^{93}$ Weiter wurde die konfessionell-moralische Prägung des Lehrschwesterninstituts in den Konstitutionen im 4. Kapitel unter «Geist des Instituts» verdeutlicht: Die Schwestern sollten «alles anwenden, um die ihrer Sorgfalt anvertrauten Zöglinge in der Furcht des Herrn und nach den Vorschriften des hl. Evangeliums und der katholischen Kirche zu erziehen, in die Beobachtung der Gebote Gottes und der Kirche durch Übung einführen und dahin zu bewegen, dass sie ihre Unschuld höher schätzen als alle ihre Güter der Erde, die Sünde aber als das grösste Übel meiden.» ${ }^{94}$

\subsubsection{Schwestern zur Umsetzung der sozial-karitativen Idee}

Die Gründungen der Innerschweizer Lehrschwesterninstitute waren wie oben ausgeführt Ausdruck einer katholisch-klerikalen Deutungskultur im Kontext der konfessionellen Abgrenzung. Träger dieser Institutionalisierungs- und Idealisierungsprozesse waren fast ausnahmslos Vertreter des Klerus. Die Konstituierung dieser Institute ging indessen sowohl bereits als gedankliche Konstruktion als auch in der tatsächlichen Realisierung auf die Koexistenz von Geistlichen und geistlichen Frauen zurück. ${ }^{95}$ Entscheidend für die Institutionalisierungsprozesse war somit, dass diesen

92 Siehe die allgemeinen pädagogischen Leitlinien von Theodosius, in: AIM Menzingen, Theodosius Florentini, Schulorganisation um 1853. - Vgl. dazu die kontinuierliche Theodosius-Rezeption, besonders anhand der ideellen Grundlagen in Theodosius' Schriften an die Lehrschwestern: Leben der Heiligen Gottes, Konstitutionen, Schulorganisation, Büchlein für Pädagogik und Unterricht zum Gebrauch der Elementarschulamts-Kandidaten in den Institutszeitschriften der Lehrschwesterninstitute: Magnus Künzle, Das Lehrtestament des P. Theodosius Florentini an seine Lehrschwestern, in: VGMN Menzingen, 1 (1933), 6.

93 AIM Menzingen, Constitutionen des Institutes der Lehrschwestern vom III. Orden des hl. Franziskus von Assis (sic), unter dem besonderen Titel Schwestern vom hl. Kreuze, Menzingen, Einsiedeln 1852.

94 AIM Menzingen, Constitutionen des Institutes der Lehrschwestern vom III ${ }^{\text {ten }}$ Orden des hl. Franciscus von Assisi unter dem besonderen Titel: «Schwestern vom hl. Kreuze», Approbation, Chur, 26.10.1845, I. Abschnitt, 4. Kapitel.

95 Vgl. dazu die Ansätze in der Untersuchung zum Kanton St. Gallen bzw. zur Ostschweiz: Vorburger-Bossart, Die St. Galler Frauenklöster und religiösen Frauengemein- 
Prozessen sowie besonders der strategischen Weiterentwicklung neben den geistlichen Stifterpersönlichkeiten ebenso bedeutende, wenn im Einzelnen nicht noch mehr hervorzuhebende Schwesternpersönlichkeiten vorstanden. Dieser koexistentielle Ansatz revidiert die teilweise etablierte Sicht einer ausschliesslich männlichen Protektorenrolle innerhalb der Gründungsprozesse, ohne die genuin ideellen Pionierleistungen dieser sozial-karitativen Geistlichen zu schmälern.

Um die im zweiten Teil analysierten Lebenserzählungen religiöser Frauen im historisch-biografischen Kontext einordnen zu können, ist es von zentraler Bedeutung, das frauengeschichtliche Profil der Mitgründerinnen dieser Gemeinschaften in Ansätzen innerhalb der Gründungsprozesse nachfolgend darzulegen, das die Verhaltensstruktur ihrer Nachfolgerinnen bis ins 21. Jahrhundert entscheidend prägte. So können die beiden im nachfolgenden Gruppenporträt subjektgeschichtlich erfassten Komponenten eines unbedingten Gehorsams- und Selbstlosigkeitsverständnisses einerseits und eines beruflichen Selbstbewusstseins anderseits vor diesem Hintergrund eingeordnet werden.

Die beiden herausragenden ersten Vorsteherinnen bzw. für Ingenbohl die erste Generaloberin der theodosianischen Kongregationen waren Maria Bernarda Heimgartner (1844-1863) in Menzingen ${ }^{96}$ und Maria Theresia Scherer (1857-1888) in Ingenbohl ${ }^{97}$.

schaften als kultureller und sozialer Faktor, 37-40, 52; dies., Ordensschwestern in der Ostschweiz im 20. Jahrhundert, Zürich 2018.

96 Siehe zu Bernarda Heimgartner (in Kurzzitaten): Binotto, Durch alle Stürme. Bernarda Heimgartner - Ordensgründerin und Kämpferin für die BILDUNG der Frauen; Moos, Zukunft aus dem Glauben. Bernarda Heimgartner und die Gründung des Menzinger Lehrschwesterninstituts im historischen Kontext; Omlin, Bernarda (Maria Anna) Heimgartner (1822-1863). Aufstieg eines Landmädchens zur Ordensmutter, in: Der Kanton Zug zwischen 1798 und 1850. 23 Lebensgeschichten. Alltag und Politik in einer bewegten Zeit, 230-239; Pronzato, La Forza della Debolezza. Bernarda Heimgartner; Egloff/Kälin, In cruce salus. Bernarda Heimgartner 1822-1863; Buono, Die kleine Engelsburg. Kurze Lebensgeschichte von Mutter Bernarda Heimgartner; Duft, Das geglückte Wagnis. Ein Lebensbild von Bernarda Heimgartner; Lüthold-Minder, Sie löschen die Liebe nicht aus. Lebensgeschichte der Mutter Bernarda Heimgartner; Jud, In Memoriam Mutter Maria Bernarda Heimgartner. Mitbegründerin der Lehrschwestern vom Hl. Kreuz in Menzingen (Schweiz); Metzler, Kreuzweg der Pflicht. Lebensbild von Mutter Bernarda Heimgartner, der Mitbegründerin und ersten Oberin der Kongregation der Lehrschwestern vom Heiligen Kreuz in Menzingen; Jud, Mutter Maria Bernarda Heimgartner 1822 bis 1863.

97 Siehe zu Theresia Scherer (in Kurzzitaten): Sprenger Viol, Ein Leben gegen Elend und Unrecht. Weg und Wirken der Schwester Maria Theresia Scherer; Göcking, Cano- 
Die Vorsteherinnen aus den Gründungsjahren der kleineren Institute, Baldegg und Heiligkreuz-Cham, die beide auf die Baldegger Erstgründung von Josef Blum zurückgehen, erreichten wohl nicht dieselbe innerkatholische und internationale Ausstrahlung wie die Gründerinnen von Menzingen und Ingenbohl. Sie sind aufgrund ihrer konstitutiven und mitbegründenden Leistungen ebenfalls namentlich anzuführen: Maria Theresia Elmiger (1842-1851) in Baldegg98, Maria Ottilia Kaufmann (1853-1858) für die Baldegger Exilphase bzw. für die Phase des Doppelinstituts Baldegg-Cham und Maria Aloisia Keiser (1866-1872, 18781889) in Heiligkreuz Cham ${ }^{99}$. Dasselbe gilt für die Mitgründerin des ebenfalls im 19. Jahrhundert errichteten Ilanzer Instituts, Maria Theresia Gasteyer (1835-1892).

Ein zentraler Konsolidierungsfaktor war neben diesen Einzelpersönlichkeiten auch das Kollektiv der gesamten Schwesternschaft, das sich durch die jeweilige lokale Präsenz in Teilschwesterngemeinschaften unter der Bevölkerung durch die Personifizierung von meist pädagogischer und pflegerischer Fachkompetenz einer hohen Akzeptanz erfreute. Aufgrund des Beispielcharakters der bereits bestehenden Schwesterntätigkeiten vor Ort generierten die Institute rasch anwachsende Eintrittszahlen an Kandidatinnen. Allen Schwestern gemeinsam war, dass sie grösstenteils aus gesellschaftlich-ökonomischer Marginalität heraus gesamtgesellschaft-

nizationis Servae Dei Mariae Theresiae Scherer. Confundatricis et primae moderatricis generalis congregationis sororum a chariate s. crucis ab Ingenbohl, e tertio ordine s. Francisci Positio super virtutibus, deutsche Übersetzung Cornelia Göcking; Venzin, Mutter M. Theresia Scherer im Heute; Rutishauser, Mutter M. Theresia Scherer. Leben und Werk; Gadient, Die Dienerin Gottes Mutter M. Theresia Scherer. Darstellung ihres Tugendlebens; Dutli-Rutsihauser, Der Feldzug der Liebe. Roman der Caritas; Rutishauser, Mutter M. Theresia Scherer. Neue Strahlen; Gedenkschrift zum 50. Todestag der Dienerin Gottes, Mutter Maria Theresia Scherer. Mitbegründerin der Kongregation der barmherzigen Schwestern vom heiligen Kreuze, Ingenbohl; von Segesser, Generaloberin Sr. M. Theresia Scherer 1825-1888. Das Lebensbild einer bedeutenden Schweizerfrau; von Liebenau, Die katholische Frau der werktätigen Liebe. Wohlehrwürden Frau Maria Theresia Scherer, die erste Generaloberin von Ingenbohl, in: Villiger-Keller, Die Schweizer Frau, 451-511.

98 MatthäaVock, Das Schwestern-Institut Baldegg 1830-1930, Hochdorf 1930, 25 f.

99 Johannes Invernizzi, 100 Jahre Schwestern-Institut Heiligkreuz Cham, Zug 1962 113-114, 116-121; Patrick Braun, Olivetaner-Benediktinerinnen von Heiligkreiz, Cham, in: ders. (Hg.), Die Kongregationen in der Schweiz 19. und 20. Jahrhundert, HS VIII/2, Basel 1998, $349 \mathrm{f}$. 
lich-sozial bedeutende Beiträge leisteten, die im Kern auf ihre religiöse Daseinsbestimmung zurückgingen.

Aus konfessioneller Sicht leisteten die weiblichen Kongregationen mit der Aggregierung und Vergesellschaftung von religiösen Katholikinnen einen zentralen Beitrag innerhalb der Konfessionalisierungsbestrebungen des katholischen Milieus. Das Kollektiv der Schwesterngemeinschaften erschloss ferner mit den im 19. Jahrhundert gegründeten Frauen- und Mädchenbildungsinstituten einen weiteren Sozialisationskreis von weltlichen Katholikinnen.

\subsubsection{Skizzen der Gemeinschaftsgründungen im 19. Jahrhundert}

\section{Gründung des Instituts von Baldegg 1830}

In Baldegg stellte Kaplan Josef Blum ab 1830 mit der anfänglich aus sieben leiblichen Schwestern bestehenden Gemeinschaft auf Innerschweizer Gebiet der radikalen schulpolitischen Auffassung eine christlich-konfessionelle Bildungsinstitution entgegen, die anfänglich «Arme Schwestern im Schloss zu Baldegg» genannt wurden. ${ }^{100}$ Der Sonderbundskrieg und seine Folgen beeinträchtigten zunächst zunehmend die Entfaltung des Instituts. ${ }^{101}$ Während der Amtszeit von Sr. Theresia Elmiger wurde das Kloster durch die Regierung des Kantons Luzern zweimal, 1848 und 1849, aufgehoben. ${ }^{102}$ Eine dritte Aufhebung fiel in die Amtszeit ihrer Nachfolgerin Maria Ottilia Kaufmann (1851-1858). Der dritte Aufhebungsbeschluss von 1853 verpflichtete das Baldegger Institut nicht nur zur Schliessung der Schule, sondern auch zum Wegzug der Schwesterngemeinschaft. ${ }^{103}$

$100 \mathrm{AB}, \mathrm{Fc} 36$; dort die weitere Entwicklung zur Benennung der heutigen Schwestern von der Göttlichen Vorsehung aus dem Regulierten Orden des hl. Franziskus von Assisi, der Baldegger Schwestern; AB, Entwicklung der Schule Baldegg. Zur Vorgeschichte.

101 Siehe dazu: Borner, Zwischen Sonderbund und Kulturkampf. Zur Lage der Besiegten im Bundesstaat von 1848. Zur Entwicklung des Instituts Baldegg in dieser Zeitphase im Folgenden: Martine Rosenberg, Baldegger Schwestern, in: Patrick Braun (Hg.), Die Kongregationen in der Schweiz 19. und 20. Jahrhundert, HS, VIII/2, Basel 1998, 73-76.

102 AB, A III 2,4; Aufhebungsdekret vom 3.5.1848 (Kopie im AB). AB, III, 2,5; Aufhebungsdekret vom 23. 3.1849 (Kopie im AB).

103 AB, A III 2,5; Aufhebungsdekret vom 8.4.1853 (Kopie im AB). Zum Vollzug des Wegzugs der Schwestern heisst es im 3. Absatz des Aufhebungsdekrets: «Das Polizeidepartement hat dafür zu sorgen, dass die Dienst- und Lehrschwestern sowohl, als auch sämtliche Töchter [...] das Schloss Baldegg räumen.» 
Nach der Luzerner Vertreibung liess sich die Vorsteherin, Sr. Ottilia, in Begleitung einiger Mitschwestern in ihrer Heimatgemeinde im zugerischen Cham nieder. Nur die leiblichen Schwestern, die als erste Schwestern bei der Gründung 1830 die Stammgemeinschaft bildeten, durften in Baldegg bleiben, da sie das Ordenskleid nie trugen und deshalb in ihrem weltlichen Habit dem Vorwurf der Jesuiten-Affiliation, der durch die radikale Regierung erhoben wurde, keinen Vorschub leisteten. Die Gemeinschaft in Cham Heiligkreuz festigte sich in der Folge dank Schwesternzuwachs, bischöflichem geistlichem Beistand sowie der Reorganisation der klösterlichen Gemeinschaft und der Erneuerung der Statuten. ${ }^{104}$ Die Neuordnung zielte darauf hin, Direktor Blum in seinen Kompetenzen zu begrenzen und der Vorsteherin mehr Autoritätsbefugnisse einzuräumen. ${ }^{105}$ Die Nachfolgerin der ersten Vorsteherin in Cham, Maria Jodoka Ruffiuz (1858-1862), wurde aufgrund der in den neuen Satzungen ausgebauten Kompetenzen als erste Frau Mutter der Gemeinschaft gewählt und leitete von Cham aus die Baldegger Gemeinschaft. Zusätzlich konsolidierte sich mit der Wahl von Rätinnen die erste Generalleitung, die den hierarchischen Strukturierungsprozess zu einem ersten Abschluss brachte.

\section{Trennung von Baldegg-Cham und Gründung des Instituts von Heiligkreuz Cham 1862}

Die weitere Ausbaufrage, die eng mit der Standortfrage des in Cham angesiedelten Baldegger Instituts zusammenhing, wurde durch die endgültige Trennung zwischen Baldegg und Cham, die auf Anordnung des Basler

104 AB IV 1,1; Gesuch um Genehmigung des Instituts und um Staatsschutz: Ottilia Kaufmann an Herrn Landammann und Regierungsräte von Zug vom 3.5.1858; Anerkennung des Instituts in Heiligkreuz: Regierungsratsprotokoll vom 13.5.1858 Ziff. 9, Ziff. 12 (Abschrift im AB IV 1,1). Grundzüge der neuen vom Bischöflichen Ordinariate zu beschliessenden Statuten des Lehr- und Waisenschwestern-Institutes von Baldegg-Cham vom 16.10.1858, signiert Bischof Karl Arnold von Basel; Dekan Jakob Buck (am 16.10.1858 von Bischof Karl ernannter geistlicher Vater des Schwesterninstituts BaldeggCham) an Dekan und bischöflichen Kommissar Melchior Schlumpf vom 20.10.1858 (Kommissariatsarchiv Zug; Abschrift im AB C III 2,13).

$105 \mathrm{AB}$, Statuten der Lehr- und Waisenschwestern der göttlichen Vorsehung vom III. Orden des hl. Franciscus v. Assis, Solothurn 1859, 16f. (III. Abschnitt, 2. Kapitel): «Die Vorgesetzten des Institutes sind die Frau Mutter, die Assistentin und drei Ratsschwestern.». In den Statuten von 1867 für Baldegg ist unter den Vorgesetzten des Instituts der Superior wieder vermerkt, und zwar an erster Stelle vor der Frau Mutter (III. Abschnitt). In den Statuten von 1877 wird der Superior unter den Vorgesetzten nicht mehr erwähnt (III. Abschnitt, 2. Kapitel). 
Diözesanbischofs Karl Arnold-Obrist 1862 vollzogen wurde, geklärt. ${ }^{106}$ Die Trennung der beiden Institute, und besonders die für die Baldegger Gemeinschaft im selben Jahr neu verfassten Statuten hatten für die in Baldegg verbliebene Teilschwesternschaft, die in den vorausgegangenen Jahren unter Disziplinschwierigkeiten litt, eine günstige Wirkung. ${ }^{107}$ Eine Weiterführung des Doppelinstituts Baldegg-Cham mit Sitz der Oberinnen in Cham erwies sich auf die Dauer, nicht zuletzt aufgrund der unterschiedlichen Haltung der Regierungen von Luzern und Zug, als unpraktikabel. Somit entstand aus der Blum'schen Gründung von 1830 in Baldegg neben dem 1862 wiederbelebten und neu organisierten Baldegger Institut im Trennungsjahr 1862 mit Heiligkreuz-Cham ein weiteres Institut mit der Zweckausrichtung der katholischen Mädchenerziehung. Mit der Wahl der ersten Frau Mutter von Heiligkreuz, Maria Susanna Füeg (1863-1864) im Jahr 1863, war das Chamer Institut rechtlich konstituiert. ${ }^{108} 1865$ folgte die Anerkennung des Instituts Heiligkreuz durch die Zuger Regierung. Für das Institut in Baldegg genehmigte Bischof Karl Arnold-Obrist 1862 die für Baldegg neu verfassten «Statuten der Armen- und Waisenschwestern der göttlichen Vorsehung zu Baldegg». ${ }^{109}$ Die statutarische Bestimmung des Instituts, die Leitung von Armen- und Waisenhäusern zu übernehmen, wies weiterhin, wie die ursprünglichen Gründungsabsichten Blums gegenüber den zeitüblichen religiös-konfessionellen Schwerpunkten der anderen weiblichen Erziehungsinstitute, wie beispielsweise Menzingen, eine stärkere sozial-ökonomische Komponente auf: «Das Institut Baldegg hat zum Zweck, arme, verwahrloste Mädchen von 6 bis 18 Jahren so zu erziehen, dass sie einstens als tüchtige, getreue und gottesfürchtige Mägde und Haushälterinnen ihr Glück und ehrliches Auskommen fin-

106 AB, A III 1,8 Trennungsurkunde von Bischof Carl Arnold-Obrist vom 24.8.1862. - Vgl. weiter die Verzeichnisse der Schwestern, die sich (1862 anlässlich der Trennung) für Cham, bzw. für Baldegg entschieden, AB EI 1,6.

107 AB, B IV 1,1, 1,4; Vock, Das Schwestern-Institut Baldegg, 126-154.

108 Vgl. die für Cham bis 1892 gültigen Statuten des Doppelinstituts Baldegg-Cham von 1859: Statuten der Lehr- und Waisenschwestern der Göttlichen Vorsehung vom III. Orden des hl. Franziskus von Assisi, Solothurn 1859; vgl. die mit der formellen Aufnahme der Schwestern von Heiligkreuz in den Verband der Benediktinerkongregation von Monte Oliveto von 1892 angepassten Statuten: Statuten für die Schwesterngemeinschaft der Olivetaner-Kongregation OSB von Heiligkreuz bei Cham, Kanton Zug, o. O. 1892.

109 AB, Statuten der Armen- und Waisenhausschwestern der göttlichen Vorsehung zu Baldegg, Baldegg 1862, gedruckt Luzern 1867. 
den.» ${ }^{110} 1863$ bestätigte die Luzerner Regierung die Anerkennung des Instituts. Baldegg konnte sich ab 1866, nach den internen Konsolidierungsprozessen, vor allem auf die Förderung des Schulwesens konzentrieren, das schliesslich mit den 1877 durch Bischof Eugen Lachat approbierten Konstitutionen auch die kirchenrechtliche Anerkennung fand. ${ }^{111}$ Die Konstitutionen bestätigten den Gründungszweck und bekräftigten die Gründeridee von Baldegg, nämlich die Mädchenbildung und Führung von Waisen- und Armenhäusern. ${ }^{112}$

\section{Gründung des Instituts in Menzingen von 1844}

Die ersten Konstitutionen des Lehrschwesterninstituts Menzingen, die am 26. Oktober 1845 wohl aus taktischen bistumspolitischen Gründen von Theodosius in dessen Heimatbistum Chur und nicht in Solothurn approbiert wurden, nennen den Zweck des Instituts: «Das Institut der Schulund Lehrschwestern vom dritten Orden des hl. Franziskus hat den besonderen Zweck, zur Erziehung der weiblichen Jugend mitzuwirken, deshalb sie in der hl. Religion u. den für's Leben nöthigen u. nützlichen Kenntnisse zu unterrichten $\mathrm{u}$. durch Wort, Beispiel u. Uebung zu einem den Lehren der hl. römisch-katholischen Kirche entsprechenden Lebenswandel anzuleiten. Diese Aufgabe sucht es vorzüglich durch Übernahme von Elementar-Schulanstalten in Städten u. auf dem Lande zu lösen.» ${ }^{113}$ Die zweite

110 AB, Statuten der Armen- und Waisenhausschwestern der Göttlichen Vorsehung, Baldegg 1862, gedruckt 1867, I. Abschnitt, Allgemeine Bestimmungen, 3 f. Vgl. die Zweckausrichtung in den allgemeinen Bestimmungen für Menzingen: «[...] zu einem den Lehren der hl. römisch-katholischen Kirche entsprechenden Lebenswandel anzuleiten.», AIM Menzingen/Kantonsarchiv Zug, IV. 1848/74 Th. 58, Constitutionen des Institutes der Lehrschwestern vom III ${ }^{\text {ten }}$ Orden des hl. Franciscus von Assisi unter dem besonderen Titel: «Schwestern vom hl. Kreuze», Approbation, Chur, 26.10.1845, I. Abschnitt, 1. Kapitel.

$111 \mathrm{Vgl}$. die rechtliche Entwicklung des Instituts anhand der Mutationen in den Statuten: AB, Sc 1-Sc 3, Statuten/Konstitutionen von 1859, 1862, 1877; AB, Fc 36, Zur Geschichte unserer Konstitutionen (Generalkapitel 1981).

112 Statuten der Lehr- und Waisenschwestern der göttlichen Vorsehung vom III. Orden des hl. Franziskus v. Assis, Luzern 1877, 3.

113 AIM/Kantonsarchiv Zug, IV. 1848/74 Th. 58, Constitutionen des Institutes der Lehrschwestern vom III ${ }^{\text {ten }}$ Orden des hl. Franciscus von Assisi unter dem besonderen Titel: «Schwestern vom hl. Kreuze», Approbation, Chur, 26.10.1845, I. Abschnitt, 1. Kapitel; vgl. zu den ersten Konstitutionen zu Vorgeschichte, Quellen sowie Analyse: Finbarr Coffey, Geist der Gründung - Auftrag heute. Schwestern vom Hl. Kreuz, Menzingen, Kriens 2003, 142-210. 
Fassung der Menzinger Konstitutionen mit der endgültigen Approbation vom 2. Oktober 1851, nun im für den Zuger Standort des Instituts Menzingen rechtsgültigen Bistum Basel, ergänzte den V. Abschnitt der Konstitutionen von 1845 um den Passus zur Stellung des Superiors innerhalb des Lehrschwesterninstituts, der bisher fehlte. Damit wurde die autoritäre Einflussnahme dieses beigeordneten Geistlichen weder definiert noch auf bestimmte Kompetenzen festlegt oder beschränkt. Gleichzeitig bestärkten die Konstitutionen die Autorität der Oberin, «welcher das Recht und die Pflicht zusteht, $[\ldots]$ alles anzuordnen, was zur Erreichung des Zweckes des Institutes erforderlich und erspriesslich sein wird.» Hingegen war die Stellung des Superiors deutlich als «väterlichen Ratgeber der Schwestern und Obern» umschrieben, und weiter wurde dem Superior ausdrücklich «keine Befugnis zu direkter Leitung des Instituts» zugestanden. ${ }^{114}$ Die Regelung der Kompetenzen, d.h. die Autoritätsübertragung und insbesondere die Autoritätsstärkung der Oberin in der Leitung des Instituts in den endgültig approbierten Konstitutionen von 1851, war im Hinblick auf die später folgenden Divergenzen bezüglich der Zweckausrichtung des Instituts zwischen der Vorsteherin Bernarda Heimgartner und Theodosius Florentini bzw. weiteren geistlichen Beiständen wohl de iure, de facto aber kaum entscheidend.

Einer dieser Geistlichen, der Menzinger Pfarrer Johann Josef Röllin (1814-1873), nahm neben Theodosius zur Konkretisierung des späteren Mutterhaussitzes in Menzingen eine zentrale Rolle ein. Röllin plante, beeinflusst von den Sœurs de la Providence, in Menzingen die Errichtung einer eigenen Mädchenschule. Vom Kapuziner Honorius Elsener (18111890) hörte er 1843 von den drei Novizinnen, die Theodosius in Ribeauvillé ausbilden liess, bereits vor Abschluss ihrer Ausbildung. Im August 1844 trafen sich Theodosius und der Dekan Albrecht von Haller (18081858), Pfarrer in Galgenen, mit Röllin in Menzingen, um die Einführung der Schulschwestern in Menzingen zu besprechen. ${ }^{115}$ Die entsprechende Umsetzung konnte nur dank des Einsatzes von Schwestern und den ihnen

114 AIM Menzingen, Constitutionen des Institutes der Lehrschwestern vom III ${ }^{\text {ten }}$ Orden des hl. Franciscus von Assisi unter dem besonderen Titel: «Schwestern vom hl. Kreuze», Approbation, Solothurn, 2. Oktober 1851, Einsiedeln 1852, V. Abschnitt, 1. Kapitel.

115 AIM, Mappe II, 1. Fasz. 1.1., Protokoll von der heutigen Conferenz zur Einführung der Schulschwestern im Pfarrhaus zu Menzingen. 8.8.1844. 
A. Einleitung

übertragenen Teilkompetenzen geschehen, was der Weitsichtigkeit und dem sachlichen Durchsetzungsvermögen Bernarda Heimgartners zu verdanken ist. Theodosius ernannte kurze Zeit später nach dem Menzinger Gründungstreffen Sr. Bernarda Heimgartner zur Oberin der kleinen Schwesterngemeinschaft.

\section{Gründung des Instituts von Ingenbohl 1856}

Theodosius selber wurde es von seinem Oberen, dem damaligen Provinzial der Kapuziner, entsprechend den Konstitutionen der Kapuziner verboten, sich weiter um das neu gegründete Institut in Menzingen zu kümmern. Die Schwestern erfuhren davon im April 1845. Der Bischof von Basel, Joseph Anton Salzmann (1828-1854), setzte 1846 den Menzinger Pfarrer Röllin zum Vorsteher bzw. geistlichen Vater des Menzinger Instituts ein. ${ }^{116}$ Theodosius entfaltete weitere vielfältige soziale Tätigkeiten, besonders von Chur aus, wo er seit 1845 Pfarrer, Guardian des Kapuzinerklosters und später auch Generalvikar war. Sein sozialreformerisches Wirken dehnte sich in diesen Jahren in mehreren Projekten besonders auf die sozial-karitative Institutionalisierung aus. 1850 errichtete er im Haus Planaterra in Chur ein provisorisches konfessionsübergreifendes Spital. Mit der Übertragung der Leitung an die damalige Menzinger Schwester Maria Theresia Scherer, die spätere Mitgründerin und erste Generaloberin von Ingenbohl, zeichnete sich eine erste Weichenstellung für die weitere Entwicklung der beiden sozialen theodosianischen Wirkungsfelder ab. Theodosius wollte Karitas und Pädagogik, selbst mit der rasanten Ausdehnung der vielfältigen und sich immer mehr differenzierenden Aufgaben, unter dem Dach einer, der Menzinger Kongregation, auch zukünftig vereint wissen. 1856 kam es aufgrund von Differenzen bezüglich Richtungs- und Zweckbestimmungen dennoch zur Trennung der beiden Bereiche, die per bischöflichen Entscheid Grundlage zu zwei selbstständigen Instituten wurden. Die Lehrschwestern hatten weiterhin ihren Sitz in Menzingen, währenddem die aus der Menzinger Gemeinschaft heraus neu ausdifferenzierten Spital- oder Barmherzigen Schwestern ihren Sitz in Ingenbohl nahmen. Theodosius kaufte ein Jahr zuvor mit der Absicht, die vereinigte Kongregation dort anzusiedeln, einen Hof, der nun das Mutterhaus der

116 Uta Teresa Fromherz, Menzinger Schwestern, in: Patrick Braun (Hg.), Die Kongregationen in der Schweiz 19. und 20. Jahrhundert, HS VIII/2, Basel 1998, $279 \mathrm{f}$. 
Ingenbohler Schwestern wurde. ${ }^{117} 1857$ wählte die neue Schwesternschaft, die sich für Ingenbohl entschieden hatten, Maria Theresia Scherer (18571888) zur ersten Generaloberin der Ingenbohler Schwestern.

Bis 1860 galt für Ingenbohl die Druckausgabe der Konstitutionen von 1852, die Theodosius 1845 als Protokonstitutionen auf der Grundlage der Drittordensregel des hl. Franziskus für das Lehrschwesterninstitut Menzingen entworfen hatte. ${ }^{118}$ Die für die karitative Ausrichtung des Instituts Ingenbohl von Theodosius adaptierten Konstitutionen wurden 1860 gedruckt. Nach einer Überarbeitung der Konstitutionen von 1872-1878 wurde die Neufassung 1897 definitiv approbiert. ${ }^{119}$

Die Anfangsjahre der Ingenbohler Schwesterngemeinschaft waren überschattet von einer enorm hohen Schuldenlast, die aus den industriellen Unternehmungen von Theodosius entstanden war. Die Schwestern zeigten sich nach dem Tod von Theodosius im Jahr 1865 durch ausgreifende Sammelreisen im katholischen Europa bereit, diese freiwillig abzutragen. ${ }^{120}$ Somit hatte Theresia Scherer als Mitgründerin des Instituts nicht nur die theodosianischen Institutionalisierungspläne umzusetzen und zu verwirklichen, sondern auch die bedrückenden Schuldenrealitäten des sozialreformerischen Ideologen Theodosius mit ihren Schwestern mühevoll über Jahre abzutragen, was erst 1872 zu einem Abschluss kam. ${ }^{121}$

$117 \mathrm{Zu}$ Ingenbohl: Renata Pia Venzin, Ingenbohler Schwestern, in: Patrick Braun (Hg.), Die Kongregationen in der Schweiz 19. und 20. Jahrhundert, HS VIII/2, Basel 1998, 184-186.

118 IAI, Constitutionen der barmherzigen Schwestern vom heiligen Kreuze aus dem dritten Orden des heiligen Franziskus von Assis, Ingenbohl 1860.

119 Renata Pia Venzin, Ingenbohler Schwestern, in: Patrick Braun (Hg.), Die Kongregationen in der Schweiz 19. und 20. Jahrhundert, HS VIII/2, Basel 1998, 190.

120 «Die Schwestern übernahmen die grosse Schuldenlast so, wie sie vorlag und wie sie nicht vorlag, im Vertrauen auf Gottes Beistand», Cornelia Fürer, Geschichte des Institutes der Barmherzigen Schwestern vom hl. Kreuze in Ingenbohl, Kt. Schwyz, Ingenbohl (1888), 85 .

121 Renata Pia Venzin, Ingenbohler Schwestern, in: Patrick Braun (Hg.), Die Kongregationen in der Schweiz 19. und 20. Jahrhundert, HS VIII/2, Basel 1998, 185 f. Siehe dazu den kulturgeschichtlichen Aspekt anhand von Schwesternselbstzeugnissen, in: Valeris Sievi/Regula Gerspacher, «Hochverehrte liebe theure würdige Mutter!» Sr. Eugenia Welz (1833-1899) von der Kongregation der Schwestern vom hl. Kreuz, Ingenbohl. Ihr Leben und ihre Briefe während den Sammelreisen in der Schweiz, in Ungarn, Siebenbürgen und Slavonien für das Kreuzspital in Chur, Beiheft Nr. 7 zum Bündner Monatsblatt; Regula Gerspacher, Sr. Eugenia Welz (1833-1899) aus Reichenau auf Sammelreisen für das Kreuzspital Chur. Einblicke in das Empfinden und Denken und in die Persön- 
A. Einleitung

\section{Gründung des Instituts in Ilanz 1865}

1865 gründete der Priester Johann Fidel Depouz in Ilanz die «Wohltätige Gesellschaft von der göttlichen Liebe», die er im paritätischen Graubünden aus politischen Gründen auf eine privatrechtliche Grundlage stellte. Unter denselben Vorsichtsmassnahmen nannte er die religiösen Frauen der Gesellschaft nicht «Lehrschwestern». ${ }^{122}$ In der "Grundverfassung» der Gesellschaft ist von der ideologischen Ausrichtung klar die Rede: «Das Ideal, die Richtschnur, die Hauptregel der Gesellschaft ist immer und überall Gott in seiner allwaltenden thätigen Liebe ... Alle sollen sich daher die Worte des Gesetzes der göttlichen Liebe tief ins Herz prägen, sie nie vergessen und ihr ganzes Leben allezeit, überall und allseitig danach einzurichten sich eifrig bemühen: «iebe Gott über Alles und die Menschen wie dich selbst.»» ${ }^{123}$ Die Satzungen, benannt als «Grundverfassung der Gesellschaft von der göttlichen Liebe» gingen 1871 nach Jahren der Zurückhaltung der verantwortlichen kirchlichen Behörden in Druck. ${ }^{124}$

Zunächst führte diese Gesellschaft eine Schule zur Erziehung von Jugendlichen. 1868 wurde Babette Gasteyer, die zuvor zwei Jahre als Lehrerin in dieser Schule wirkte, als «Mutter Maria Theresia» zur Generaloberin der Gesellschaft ernannt. Im gleichen Jahr eröffnete die Gesellschaft in Ilanz ein Spital. Damit wurde das grundlegende Ziel von Depuoz, für die wirtschaftlich wenig entwickelte Surselva einen Grundstein zu einer professionell geführten pädagogischen und gesundheitlichen Versorgung der Bevölkerung zu legen, erfüllt. 1894 schloss sich die Kongregation der Ilanzer Schwestern zwei Jahre nach dem Tod der ersten Generaloberin dem Dominikanerorden an. ${ }^{125}$

\section{Konsolidierung der religiösen Frauengemeinschaften}

Die hierarchische Unterordnung religiöser Frauen gegenüber geistlichen Autoritäten bildete neben den reellen und ideellen Leistungen der Schwestern nicht nur einen zentralen, sondern einen geradezu konstitutiven Bestandteil innerhalb der Kohäsions- und Konstituierungsprozesse der neu gegründeten Institute. Die Schwestern gaben intellektuell, physisch,

lichkeit einer jungen Bündner Ordensfrau anhand deren Briefe, in: HF 27/2 (1998), 323-331.

122 Magna Monssen, Die Ilanzer Schwesternkongregation, Ilanz 1950, 96.

123 Klosterarchiv Ilanz, Grundverfassung, 5.

124 Magna Monssen, Die Ilanzer Schwesternkongregation, Ilanz 1950, 97.

125 Magna Monssen, Die Ilanzer Schwesternkongregation, Ilanz 1950, 163-179. 
und nicht zuletzt emotional ihren vollsten Einsatz zugunsten des Aufbaus und der Konsolidierung der Schwesterninstitute. Diese Haltung unter den Schwestern ist über weite Strecken auch im 20. Jahrhundert bis in die Gegenwart hinein in zentraler Weise spürbar. Ihre Loyalitätsempfindung und -verpflichtung gegenüber den ihnen zugeordneten Geistlichen brachte sie immer wieder in starke innere Gewissensnöte sowie in äussere Zielkonflikte. Die Strapazierung dieser weiblich-kollektiven Loyalitätszusicherungen an geistliche Einzelfiguren betraf ebenso die von den Schwestern abgelegten Gehorsamsgelübde sowie deren Autoritäts- und Gehorsamsverständnis. Die sozialreformerische Idee wurde besonders bei Theodosius durch religiösen Eifer ideell überhöht und überforderte damit die realitätsgebundenen Kräfte der Schwestern, denen die Konkretisierung und Realisierung der theodosianischen Idee oblag.

Vor dem Hintergrund der lebensgeschichtlichen Bedeutung des Gehorsamsgelübdes in den durch Oral History erschlossenen Erzählungen der Schwestern ist hier im kulturgeschichtlichen Abriss zur Gründungszeit nach den Mechanismen zwischen den Loyalitätsbezeugungen der Schwestern und dem autoritären Verhalten der Geistlichen gegenüber den ihnen hierarchisch unterstellten Schwestern zu fragen. Inwiefern stellte sich innerhalb dieser Mechanismen ein Legitimierungsprozess für patriarchales Verhalten ein und inwiefern wurde ein allfälliger Legitimierungszustand zur Norm? Eine Würdigung der Leistungen dieser Schwestern darf darüber hinaus nicht ausser Acht lassen, was es für geistliche Frauen unter Gehorsamsgelübde bedeutete, im ausgehenden 19. Jahrhundert sowie in etwas weniger dezidiert auch im 20. Jahrhundert vor dem Hintergrund eines Katholizismus, für den die Klerikalisierung immer mehr zum Konstituens wurde, sich einem Geistlichen zu widersetzen. Es ist deshalb dem doppelten Durchhaltevermögen der Schwestern aller fünf vor dem Hintergrund der Industrialisierung gegründeten Schwesterninstitute zu verdanken, dass die Aufbauarbeiten trotz ärmlichsten ökonomischen Verhältnissen einerseits und nicht selten einer personell-geistlichen Schieflage anderseits über die Klippen der Anfangsschwierigkeiten hinweg kamen und zu blühenden Institutionen im 20. Jahrhundert führten. ${ }^{126}$ Nicht selten mussten sich die ersten Schwestern Oberinnen aufgrund

126 Zur weiblichen Konsolidierungsleistung innerhalb des Bildungsprozesses im internationalen Vergleich siehe: Juliane Jacobi, Religiosität und Mädchenbildung im 19. Jahrhundert, in: Margret Kraul/Christoph Lüth (Hg.), Erziehung der Menschengeschlechter, Weinheim 1996, 101-119. 
einer Zukunft gerichteten Entwicklung der Gemeinschaften gegenüber den Vollmachtbestrebungen der Instituts-Geistlichen unter grössten Schwierigkeiten durchsetzen.

Neben der konstituierenden Vernunft und Weitsicht der Schwestern spielte im Kern gerade bei den hochkomplexen Realisierungsvorgängen von Bildungs- und Berufsangeboten für katholische Frauen die tiefe Religiosität und das Vertrauen der Schwestern auf die göttliche Führung eine zentrale Rolle. Die anfangs des 21. Jahrhunderts erfassten Lebensgeschichten von nachfolgenden Generationen dieser Schwestern der Gründungszeit zeugen immer noch von diesem identitätstiftenden Vorsehungsverständnis. Damit verbunden war das Ideal der dienenden Selbstlosigkeit geistlicher Schwestern, das die Lebensverläufe im gesamten 20. Jahrhundert in persönlicher, und damit in ökonomischer und gesellschaftlicher Hinsicht entscheidend prägte.

\subsubsection{Religiöser Verein der St. Anna-Schwestern und Säkularinstitut St. Katharina-Werk}

Die Gemeinschaft der St. Anna-Schwestern ist eine Gründung des frühen 20. Jahrhunderts und setzt sich sowohl inhaltlich wie organisatorisch von den Kongregationsgemeinschaften des 19. Jahrhunderts ab. 1909 gründete der Luzerner Regens Wilhelm Meyer (1870-1912) die Gemeinschaft der St. Anna-Schwestern in Luzern als religiös-sozialer Verein. ${ }^{127}$ Meyer orientierte sich für die geistlichen Richtlinien an der Volksfrömmigkeit der Zeit. ${ }^{128}$ Mit seiner regen Tätigkeit an Vereinsgründungen im sozialkaritativen Bereich im ausgehenden 19. und beginnenden 20. Jahrhundert war er mit dem noch nicht institutionell gedeckten Bedarf an sozialen Einrichtungen besonders für ärmere Bevölkerungsschichten befasst. Obwohl die zu Beginn des 20. Jahrhunderts zunehmend professionell ausgebaute Gesundheitsfürsorge der bestehenden religiösen Spitalschwestern weitgehende Bedürfnisse abdeckte, bestand ein Mangel im Angebot der Geburtshilfe und der Wöchnerinnenpflege. Aus religiösen Gründen durften die Schwestern als Angehörige von Kongregationsgemeinschaften mit

127 Raymund Netzhammer, Regens Wilhelm Meyer. Lebensbild des Gründers der St. Anna-Schwestern 1870-1912, Stans 1930, 203-224.

128 Archiv St. Anna-Schwestern E2/6, Gedruckte Briefe des Stifters an die St. AnnaSchwestern, Brief «An die Mitglieder des St. Anna-Vereins!», 1. November 1910. 1. 
reguliertem Klosterleben und Gelübden diese Bereiche im medizinischen Betreuungssystem nicht abdecken. Mit dem St. Anna-Verein entstand eine neue rechtliche Form einer Frauengemeinschaft, die auf diese Lücken mit der Konstituierung der Wöchnerinnen- und Säuglings- sowie ambulanten Familienpflege reagierte. ${ }^{129}$

Aus ähnlichen Gründen eines sozial-strukturellen Defizits in der Zeit vor dem Ersten Weltkrieg entstand das Säkularinstitut St. KatharinaWerk in Basel. Das Netz der katholischen Sozialfürsorge sah bislang keine spezialisierte Betreuung innerhalb der weiblichen Unter- und Mittelschichten, besonders im städtischen Umfeld, vor. Der eigentlichen Bildung einer «Gemeinschaft zur Erziehung und Berufsbildung» schulentlassener Mädchen von 1913 ging 1910 die Gründung eines «katholischen Sühnevereins» voran. Die Gründerin des späteren St. KatharinaWerks, Marie Frieda Albiez (1876-1922), rief diesen Verein aus religiös-moralischen Gründen ins Leben, die gleichzeitig die ideelle Basis für den 1913 gegründeten «Verein des Schweizerischen katholischen Rettungsheimes St. Katharina in Basel» bildeten. ${ }^{130}$

129 Gemeinschaft der St. Anna-Schwestern, Luzern, (Hg.), Weltoffen, weitblickend und nahe bei den Menschen. 100 Jahre Gemeinschaft der St. Anna-Schwestern 19092009, Baar/Luzern 2009, 4-11.

130 Katharina-Werk, Basel, (Hg.), Mut zum Wandel. 100 Jahre Katharina-Werk, 76. 



\section{B. Kollektives Porträt: Lebensgeschichten religiöser Frauen des Katholizismus}

\subsection{Sozio-demografischer Rahmen: Familiäre Herkunft}

\subsubsection{Historischer Kontext: Nachkriegsjahre bis zur Jahrhundertwende}

Die Schwestern der Jahrgänge um 1920 erlebten mit einem Eintrittsalter zwischen 20 und 25 Jahren ihre frühe Klosterzeit im Umfeld der letzten Kriegsjahre oder unmittelbar danach. In diesem Kontext war das Kloster nach wie vor ein attraktives Angebot für junge Frauen, denen auf diese Weise eine fundierte Ausbildung und ein sinnstiftender Lebensentwurf gesichert waren. Für Schwestern mit Jahrgängen um 1930 war die Kombination eines sinnvollen beruflichen Engagements mit der Zugehörigkeit $\mathrm{zu}$ einer religiösen Gemeinschaft attraktiv. Katholikinnen dieser Jahrgänge waren geprägt durch die Kindheitserlebnisse des religiösen Aufbruchs, den die Pius-Päpste nach 1920 gefordert hatten. ${ }^{131}$ Die zwischen 1940 und 1950 Geborenen waren demgegenüber vom Zweiten Vatikanischen Konzil geprägt. Generell spielte stets die konfessionell-katholische Sozialisierung in der Herkunftsfamilie und in der Pfarrei mit ihrem milieu-spezifisch geprägten Vereins- und Bildungssystem eine bedeutende Rolle für die Herausbildung einer konfessionsspezifischen Frömmigkeit. ${ }^{132}$ Die agrarische Lebenswelt, denen die meisten der hier beteiligten Schwestern entstammen, stand den religiösen Abläufen des

131 Siehe u.a. zum Schweizer Katholizismus allgemein: Urs Altermatt (Hg.), Schweizer Katholizismus im Umbruch 1945-1990, Freiburg 1993; ders. (Hg.), Schweizer Katholizismus zwischen den Weltkriegen 1920-1940, Freiburg 1994; Franz Xaver Bischof/Markus Ries (Hg.), Kirche zwischen Aufbruch und Verweigerung. Ausgewählte Beiträge zur Kirchen- und Theologiegeschichte des 19. und 20. Jahrhunderts. Festgabe für Manfred Weitlauff zum 65. Geburtstag, Stuttgart 2001.

132 Vgl. u. a.: Norbert Busch, Die Feminisierung der ultramontanen Frömmigkeit, in: Irmtraud Götz von Olenhusen (Hg.), Wunderbare Erscheinungen. Frauen und katholische Frömmigkeit im 19. und 20. Jahrhundert, Paderborn/München/Wien/Zürich 1995, 203-219. 
Kirchenjahres nahe und unterstützte so die kirchliche Assoziierung der jungen Frauen. Im Hinblick auf einen möglichen Klostereintritt war darüber hinaus, besonders neben der zentralen Rolle der Priester, der Einfluss der katholischen Mädcheninstitute von Gewicht - insbesondere in der Zentral- und Westschweiz. Die klosternahe Gestaltung des Alltagslebens in diesen Institutionen übte bis in die 1960er Jahre eine grosse Ausstrahlung auf junge Katholikinnen aus.

Der identitätsprägende Bezugsrahmen zur Gestaltung des eigenen Lebensentwurfs lag damit bei den Ordensschwestern innerhalb von Kirche, Religion und konfessionsgeprägter Frömmigkeit - nur zu einem unwesentlichen Teil war zu Beginn des Projekts eine gesellschaftspolitische Verankerung zu erwarten gewesen. ${ }^{133}$ Grosse Teile der untersuchten Schwesterngenerationen erlebten die Auswirkungen der Umbrüche der 1968er-Bewegung, die flachere Hierarchien und einen stärker kommunikativen Umgang mit sich brachten sowie die Veränderungen im Verständnis für das Gehorsams- und Armutsgelübde in entsprechenden Anpassungsprozessen der Konstitutionen einleiteten. ${ }^{134}$ Zusätzlich war die Zeit nach 1960 durch den allgemeinen wirtschaftlichen Aufschwung geprägt, der gerade für Frauen zunehmend ökonomische und berufliche Unabhängigkeit mit sich brachte. In Bezug auf die Klostereintritte wirkte sich diese Entwicklung mit markant rückläufigen Zahlen aus und führte zu zahlreichen Austritten. ${ }^{135}$ In der gleichen Zeit erlebten die Schwestern durch die zunehmende Verberuflichung von weltlichen Frauen die Integration von Laienkräften in die klosterinternen Institutionen, welche seit 1970 verstärkt ins Gewicht fiel. Dies war besonders in der Krankenpflege und im Bildungswesen der Fall - in Berufsfeldern, welche zuvor von geistlichen Schwestern dominiert wurden. ${ }^{136}$

133 Vgl. u. a.: Ute Gause, Dienst und Demut. Diakoniegeschichte als Geschichte christlicher Frauenleitbilder, in: Siri Fuhrmann/Irmgard Pahl/Erich Geldbach (Hg.), Soziale Rollen von Frauen in Religionsgemeinschaften, Münster 2003, 65-83.

134 Vgl. Zoe Maria Isenring, Die Frau in den apostolisch tätigen Ordensgemeinschaften. Eine Lebensform am Ende oder an der Wende? Freiburg ${ }^{3} 1996$.

135 Vgl. u. a.: Maria E. Gründig, Weibliche Ordensgemeinschaften an der Schwelle zum 21. Jahrhundert. Herausforderungen - Chancen - Perspektiven. Ergebnisse der Podiumsdiskussion, in: Rottenburger Jahrbuch für Kirchengeschichte, Bd. 27 (2008), $239 \mathrm{f}$.

136 Vgl. u. a.: Ruth Felgentreff, Die Diakonissen. Beruf und Religion im 19. und 20. Jahrhundert, in: Frank-Michael Kuhlemann/Hans-Walter Schmuhl (Hg.), Beruf und Religion im 19. und 20. Jahrhundert, Stuttgart 2003, 195-209; Walburga Hoff, «Kirche ... ist irgendwo so ein geschützter Raum». Weiblichkeitskonstruktionen in den Berufsstruk- 


\subsubsection{Katholische Familie und Pfarrei als Lebenswelt}

Wie sah die religiöse Sozialisation der Schwestern in Kindheit und Jugend aus? Die Narrative zur Kindheit wurden in den meisten Interviews äusserst detailreich ausgestaltet und nehmen innerhalb des Erzählstrangs quantitativ einen grossen Teil ein. ${ }^{137}$ Dabei sind die Wahrnehmung des allgemeinen konfessionellen Umfelds und die oft bereits in früher Kindheit einsetzenden «Berufungserlebnisse` nicht immer klar zu trennen. Die religiöse Ausrichtung durchzieht die Lebensberichte bereits von Beginn weg und gibt praktisch immer den Lebenssinn und auch die Erzählstruktur vor. Etwa, wenn eine Schwester erzählt, dass sie so schnell als möglich habe getauft werden müssen, denn man habe nicht gewusst, ob sie eine Lebenschance gehabt hätte, aber «der Herrgott habe schon eine Aufgabe für sie bereitgehalten». ${ }^{138}$

Allgemein beschreiben fast ausnahmslos alle Schwestern ihre Kindheit als geglückt oder als eine «sehr schöne Zeit». Dabei erzählen sie meist begeistert und lebendig vom katholischen und ländlichen Elternhaus, auch von den für die Blütezeit des Milieukatholizismus typischen Grossanlässen wie von Katholikentagen oder Wallfahrten. ${ }^{139}$ Die Mehrheit der Schwestern erzählte von der «streng katholischen Familie», wo durch die Eltern initiierte religiöse Elemente wie das Rosenkranzgebet, das während der Wintermonate tagtäglich in der Familie gebetet wurde, den Alltag strukturierten. ${ }^{140}$ Die Schwestern führen weiter das reich gestaltete Kirchenjahr an. Sie erwähnen dazu die einfachen, aber schönen Feste. Immer wieder wird von der prägenden Rolle der Priester und des Pfarreilebens erzählt. ${ }^{141}$

Dabei stufen sie die durchwegs bescheidenen ökonomischen Verhältnisse im Elternhaus nicht als entbehrungsreich oder beschwerlich ein, vielfach werden sie gar nicht genannt. Auch der nicht selten auftauchende

turen der katholischen Kirche, in: Ingrid Lukatis/Regina Sommer/Christof Wolf (Hg.), Religion und Geschlechterverhältnis, Opladen 2000, 181-192.

137 Vgl. zu den Diakonissen dieselben Beobachtungen: Cordula Lissner, «Alles konnten wir Ihnen natürlich nicht erzählen», in: Jochen-Christoph Kaiser/Rajah Scheepers (Hg.), Dienerinnen des Herrn. Beiträge zur weiblichen Diakonie im 19. und 20. Jahrhundert, Leipzig 2010, $96 \mathrm{f}$.

138 Interview 015, Z. 42-50.

139 Interview 031, Z. 1-167.

140 Interviews 051, Z. 23-30; 040, Z. 10 f.

141 Zum Beispiel: Interview 020, Z. 9 f. 
Kindstod eines oder mehrerer Geschwister in den oft kinderreichen Familien erwähnen sie kaum. Das gehörte einfach dazu. Sie betonen vielmehr den guten familiären Zusammenhalt und die elterliche Fürsorge als beglückende Momente der Kindheit. Selbst, wenn in Einzelfällen eine Schwester die Kindheit nicht zu Hause, sondern beispielsweise in einem Kinderheim mit von aussen gesehen weniger glücklichen Umständen verbringen musste, stellt sie diesen Lebensabschnitt als positiv dar. ${ }^{142}$ Viele Schwestern berichten dagegen, dass sie trotz materieller Armut reich an Geborgenheit und elterlicher Zuneigung aufwachsen durften. ${ }^{143}$

Die Schulzeit endete in den meisten Fällen mit der Primar-, allenfalls mit der Oberstufe, da für die schulische und berufliche Bildung entweder die Mittel fehlten oder viele Kinder im elterlichen Bauern- oder Gewerbebetrieb mithelfen mussten. ${ }^{144}$ Auch wurden dem damaligen Kontext gemäss in diesen kinderreichen Familien die Knaben oft ausbildungsmässig bevorzugt. ${ }^{145}$ Später in der Erzählung erwähnen einige Schwestern in Bezug auf die Lebensgestaltung, dass sie aus der Familie wegkommen wollten, um ins Kloster eintreten zu können. Bei den deutschen Schwestern war es die Notsituation des Zweiten Weltkriegs, die eine Flucht in ein Kloster in der Schweiz, weg aus kriegsversehrten Gegenden, auslösen konnte. ${ }^{146}$ Dort gestalten sich die Schilderungen zum Fluchterlebnis meist noch ausführlicher als dies bei den Schweizer Schwestern zu deren Kindheitserlebnissen der Fall ist. Etwa, wenn eine Schwester aus der unmittelbaren Nachkriegszeit von ihrer Flucht aus Oberschlesien über Ostberlin nach Westdeutschland berichtete, um dort ins Noviziat eintreten zu können. ${ }^{147}$ Eher selten gaben leidvolle Erfahrungen in der Kindheit den Ausschlag zu einem späteren Klostereintritt. Eine Schwester erzählte in diesem Zusammenhang von ihrer Familie mit mehr als einem Dutzend Kindern in einem ländlichen Gebiet, der die Behörden die Kinder weggenommen hatten und in Kinderheime oder in andere Familien fremdplatzierten. ${ }^{148}$

142 Interview 047, Z. 4-70.

143 Zum Beispiel: Interview 012, 30-32.

144 Interview 010, Z. 7-15.

145 Interview 014, Z. $18 \mathrm{f}$.

146 Zum Beispiel: Interview 039, Z. 10-55.

147 Interview 048, Z. 17-105.

148 Interview 047, Z. 4-30. 
Inwiefern stellten die Schwestern ihre Kindheit aus der Retrospektive im Hinblick auf den späteren Lebensweg im Kloster dar? ${ }^{249}$ Wie zeigte sich hier die Rolle von Eltern, Priestern oder ortsansässigen bzw. auch verwandten Ordensschwestern?

Die Beeinflussung während der Kindheitsjahre zu einem späteren Klosterentscheid geschah fast ausschliesslich im engeren sozialen Umfeld, denn es war nicht immer von Grund weg der eigene Wunsch eines jungen Mädchens, in ein Kloster einzutreten: «Mein Wunsch ist es gewesen, nicht Ordensschwester primär zu werden. Bin aber natürlich von der Familie her schon ein wenig beeinflusst worden, weil sie ist sehr religiös gewesen [...]. Man hat in der Familie noch eine alte Tante gehabt. Die ist bei uns gewesen bis sie gestorben ist. Und die ist sehr fromm gewesen.» ${ }^{150}$ Eine andere Schwester erzählt von ihrem Ortspfarrer, der den Mädchen vom Besuch der örtlichen Sekundarschule abriet und ihnen stattdessen ein Klosterinstitut empfahl. ${ }^{151}$ Andere Lebensgeschichten von Schwestern beinhalten als Beeinflussung zu einem Klostereintritt die «sehr religiösen Eltern». Man sei in einem guten christlichen Umfeld aufgewachsen, was für die Berufung prägend war. Weiter gibt diese Schwester dazu an: «Und zwar haben wir gebetet am Abend, am Morgen. Wir haben bei Tisch gebetet. Wir sind in die Kirche gegangen. In der Primarschule haben wir im Religionsunterricht dafür gebetet, dass eine von uns ins Kloster gehe. Das hat dann unbewusst innerlich weitergewirkt.» ${ }^{152}$

Andere Schwestern wurden als Kinder über eine längere Krankheitsund Genesungszeit, die sie in von Schwestern geführten Spitälern oder Kurhäusern verbrachten, für ein mögliches Leben im Kloster sozialisiert. ${ }^{153}$ In diesem Zusammenhang, bei der Schilderung der Kindheit, gaben sie dies aber noch nicht als eigentlichen Grund zu einer späteren Berufung für einen Klostereintritt an. ${ }^{154}$

149 Gemeinschaftsarchive von Baldegg, Basel, Cham, Ilanz, Ingenbohl, Luzern, Menzingen, Niederuzwil, Biografische Daten von Schwestern, SNF-Projekt «Lebensgeschichten religiöser Frauen in der Schweiz» 2015-2018.

150 Interview 013 , Z. 23-27.

151 Interview 015, Z. 61-63.

152 Interview 024, Z. 19-24.

153 Interview 044, Z. 16-104.

154 Vgl. Die eigentlichen Berufungsgeschichten unter 2.4.1. 


\subsection{Religiöser Rahmen: Klösterliche Gemeinschaft als Wahlfamilie}

\subsubsection{Kloster als Bezugswelt für sinnstiftenden Lebensentwurf}

\subsubsection{Subjektkonstruktion im Spannungsfeld Kollektiv und Individuum}

Welche Eigenheiten kennzeichneten die Subjektkonstruktionen im Lebensverlauf von Ordensschwestern? Wie wurden individuelle Handlungsspielräume gestaltet bzw. inwiefern unterschieden sich diese von der kollektiven Identitätskonstruktion der Klostergemeinschaft? Lassen sich Ansätze eines individuellen Subsystems innerhalb des Kollektivs der Schwestern wahrnehmen?

Zunächst soll dieses Spannungsfeld zwischen der Klostergemeinschaft als Kollektiv und der einzelnen Schwester als Individuum beschrieben werden. In den Erzählungen bildet dieser Beschäftigungskreis ein viel erzähltes Thema.

Es gibt keine Erzählung, die nicht eine zentrale Bezugnahme oder die Einbettung der eigenen Person in das Kollektiv der Klostergemeinschaft enthält. Jede erzählte Lebensgeschichte lebt vom Spanungsfeld zwischen Kollektiv und Individuum. Ausgangspunkt, Optik und Inhalt der Erzählungen der «typischen Schwestern〉 mit Jahrgängen um 1940 ist dennoch die einzelne Schwester, die sich einerseits, wie oben dargelegt, in einer dichten Erzählung der eigenen Kindheit zeigt. Gleichzeitig wird der Lebensrückblick anderseits ausschliesslich auf das Leben in der Klostergemeinschaft fokussiert, von diesem her aufgerollt und an diesem festgemacht. Somit gibt es für diese Schwesterngruppe, die die Mehrheit aller Interviews ausmacht, keine Erzählung, die den eigenen Lebensverlauf nicht als durchwegs prägende Einheit oder als Verflechtung mit dem der Klostergemeinschaft darstellte. Bei den jüngeren Schwestern mit Klostereintritten ab den 1970er Jahren ist oft eine andere Position auszumachen. Hier ist die komplette Identifikation mit dem Kollektiv aufgelöst. Der eigene Standpunkt und persönliche Aktivitäten werden stärker gewichtet. Die Bleibe im Kloster wird öfter optional interpretiert. ${ }^{155}$

Die Frage, wie die eigene Positionierung in der religiösen Gemeinschaft verortet wird, ist demnach eng mit jener nach der Konstruktion der individuellen Lebensgeschichte verknüpft. Die ‘typische Schwester〉

155 Zum Beispiel: Interview 043. 
stellt ihre Lebensgeschichte anhand der drei Orientierungspunkte «eigene Person», «Gott» und «Gemeinschaft» dar. So ordnen diese Schwestern «alles», was ihnen im Leben begegnete in die göttliche Fügung ein, auch schwierige Situationen, die beispielsweise durch ein Verfehlen der Vorgesetzten ausgelöst wurden. ${ }^{156}$ Die noch älteren Schwestern mit Jahrgängen um 1930 bewegten sich ohne den Einbezug des eigenen Ichs zwischen den beiden Eckpunkten Frömmigkeit und Arbeit bzw. dem Leben im Kloster. Sie stellen ihr Leben als eines ohne Ansprüche auf Selbstverwirklichung und ohne die Nennung eigener Gefühle, Wünsche oder Leistungen dar. ${ }^{157}$ Diese Lebenserzählungen beinhalten noch zentraler die «Geführtheit durch Gott», die sämtliche widrigen Umstände annehmbar oder ertragbar machte. ${ }^{158}$

Gibt es aufgrund der hohen Identifikation mit der Gemeinschaft ein Kollektiv oder zerfällt es durch die Erzählungen einzelner Lebensgeschichten in seine Individuen, aus denen es sich zusammensetzt? Oder trifft das umgekehrte Szenario eher zu, nachdem sich in der Klostergemeinschaft, wo geistliche Werte gemeinsam gelebt werden, individuelle Merkmale und Charakteren von Mitgliedern verlieren? ${ }^{159}$

Viele gemeinsame Lebensgewohnheiten waren bereits bei Klostereintritt der Schwestern vorhanden und verbindend, da die jungen Katholikinnen aus demselben Milieu mit denselben Lebens- und Denkgewohnheiten stammten. Weiter stellen viele Schwestern eine beinahe bedingungslose Loyalität gegenüber ihrer Gemeinschaft ${ }^{160}$ in den Vordergrund, und damit die Zugehörigkeit zur Gemeinschaft als letztlich überwiegend positiv dar. Vor dem Hintergrund des fortgeschrittenen Alters der Mehrheit der Respondentinnen wird die Zugehörigkeit zu einer Gemeinschaft besonders hoch eingeschätzt. Es sei das «Gemeinsame», das «jetzt bis ins Alter trage». ${ }^{161}$

Dennoch zeigt sich in den Lebenserzählungen die Individualität teilweise prononciert und in verschiedenen Facetten. Beispielsweise jene

156 Zum Beispiel: Interview 044, Z. 177-188.

157 Zum Beispiel: Interview 045.

158 Zum Beispiel: Interview 048.

159 Gabriele Rosenthal, Erlebte und erzählte Lebensgeschichte. Gestalt und Struktur biografischer Selbstbeschreibungen, Frankfurt a. M./New York 1995, 109.

160 Vgl. zu den Diakonissen: Cordula Lissner, «Alles konnten wir Ihnen natürlich nicht erzählen», in: Jochen-Christoph Kaiser/Rajah Scheepers (Hg.), Dienerinnen des Herrn. Beiträge zur weiblichen Diakonie im 19. und 20. Jahrhundert, Leipzig 2010, 99.

161 Interview 030, Z. 160-171. 
Individualtität, die durch Krankheiten oder persönliche Lebenskrisen erzeugt wurde, so dass es für die betreffenden Schwestern dauerhaft nicht möglich war, regelmässig am gemeinschaftsstiftenden Stundengebet teilzunehmen. Dies «stosse bei den Mitschwestern mitunter auf Unverständnis». ${ }^{162}$ Andere Schwestern nahmen sich selber aufgrund von Minderwertigkeitsgefühlen, die beispielsweise auf eine mangelnde Schulbildung zurückgehen konnte, innerlich aus dem Kollektiv heraus. ${ }^{163}$ Individualität wird in den Berichten weiter durch Beschreibung von persönlichen Leiden innerhalb der Gemeinschaft markiert. Nicht selten geben die betreffenden Schwestern dazu an, dass die dazu notwendige Hilfe zur Überbrückung oder Heilung von persönlichen Defiziten von ausserhalb des Klosters gekommen sei. Unter Umständen konnte diese Lebenssituation einen grossen Teil der Klosterzeit ausmachen. ${ }^{164}$ Im Übrigen sprechen die Schwestern selten das Einzelne oder Individuelle in Abgrenzung zum Gemeinsamen an. Auch Regelverstösse tauchen in den Erzählungen kaum auf, um das Individuelle hervorheben zu können.

Hingegen weisen fast sämtliche Lebensgeschichten von jüngeren oder spätberufenen Schwestern mit Eintritten ab den 1980er Jahren eine Erzähloptik auf, die sich hauptsächlich mit dem Ich und den verbundenen persönlichen Entfaltungsmöglichkeiten innerhalb der Gemeinschaft beschäftigt. So wird die erzählte Individualität zur Generationenfrage.

Zusätzlich kommt in den Erzählungen älterer Schwestern eine zeitbedingte Konstruktion von Individualität zum Vorschein. Während des Zweiten Weltkriegs und in der unmittelbaren Nachkriegszeit nahmen die grösseren Gemeinschaften vermehrt deutsche Schwestern auf, die aus Gründern von Vertreibung und Flucht in schweizerische Klöster kamen. Die Lebenserzählungen dieser deutschen Schwestern zeigten durchwegs Elemente des Fremdseins, auch Erfahrungen von Zurückweisung oder Ablehnung, die ihnen im Schwesternkonvent nach eigener Darstellung widerfuhren. Die deutschen Schwestern rechneten diese subjektiven Erfahrungen der Exklusion ausschliesslich ihrer deutschen Identität zu. ${ }^{165}$ Aus der Perspektive der Schweizer Schwestern wird das Verhältnis zu den deutschen Schwestern nur ein paar Mal aktiv in eine Lebenserzählung

162 Interview 026, Z. 82-84.

163 Interview 044, Z. 13-20.

164 Interview 044, Z. 194-211; 593-794.

165 Zum Beispiel: Interview 012, durchzieht die ganze Erzählung; Interview 037, Z. 1-9. 
integriert, Dabei wird die von deutscher Seite her beschriebene Spannung innerhalb der Konvente nicht unterstützt. Eine Einteilung oder eine Separation unter den nationalen Herkunftsländern wurde nicht vorgenommen. Es sei «normalerweise gut gegangen», wenn auch erwähnt wird, dass es «deutsche Schwestern gab, die einfach dann so ein bisschen, so ein bisschen dominante Frauen waren, dann mussten wir einfach einen Weg finden. Aber es gibt nicht «die Schweizer» und 〈die Deutschen»». ${ }^{166}$

Mit den oben angeführten Respondentinnen jüngeren Alters oder erst später Eingetretenen handelt es sich meistens um gut gebildete Frauen, die bereits vor dem Klostereintritt Bildung erworben und teilweise selbstständig im Berufsleben gestanden hatten. Die entsprechenden Lebenserzählungen werden zum grossen Teil über die Berufsfunktion konstruiert. ${ }^{167}$ Diese Schwestern definierten sich bedeutend weniger stark über den klösterlichen Gemeinschaftsgedanken, sondern über die Selbstverwirklichung innerhalb einer religiösen Frauengemeinschaft. Vor diesem Hintergrund beobachten ältere Schwestern, dass die daraus resultierende subjektbezogene Ausrichtung dieser Schwestern der Gemeinschaft geschadet habe, denn es seien statt der gemeinsamen viele einzelne Projekte entstanden. ${ }^{168}$ So veränderte sich der Begriff von subjektiver Gestaltung und Individualität innerhalb des Kollektivs in dem Sinn, als Individualisierung ab den 1980er Jahren laut den Beobachtungen der betagten Schwestern zugenommen habe. Dies zeige sich auch in der ab diesem Zeitraum auftauchenden subjektiven Formulierungen «ich habe gearbeitet, so habe ich das Recht auf etwas [...]», was unter älteren Schwestern weder als persönlicher Anspruch existierte noch zum Sprachgebrauch gehörte. ${ }^{169}$ Bei den nach 1980 in eine religiöse Gemeinschaft eingetretenen Schwestern gehörte die aufgrund dieser Aussagen bis nach dem Konzil gängige ausnahmslose Orientierung an vorgegebenen bzw. gemeinschaftsinternen Rollen und Lebensmustern nicht mehr zum Selbstverständnis einer religiösen Gemeinschaftsangehörigen.

Gab es diese individuellen Handlungsspielräume auch bei den «typischen Schwestern', die in dieser Untersuchung die Mehrheit bilden? Das Individuelle bei dieser Schwesterngruppe löste sich in den entsprechenden Erzählungen in kollektiven Tätigkeiten, etwa in Erziehungsheimen

166 Interview 045, Z. 304-308.

167 Interview 035.

168 Interview 034, Z. 326, 699-718.

169 Interview 043, Z. 143-145. 
und Säuglingsabteilungen auf, wo die Respondentinnen dank des damals üblichen Identität prägenden Rollenmusters einer «geistlichen Mutterschaft in der Mutterersatzrolle ${ }^{170}$ oder in Berufen mit Dienstcharakter wie z. B. jener der Krankenschwester, die sie selber wählen durften, aufgingen. Hier war das Selbst oder die eigene Person gewissermassen «in Gottes Hand» aufgehoben, da dieses Lebensmoment als Geschenk oder Fügung Gottes angesehen wurde. ${ }^{171}$ Dazu gehören ebenfalls Berichte, die sich auf die persönliche, meist aktuelle Alltagsgestaltung beziehen, etwa zu Fragen «wie gestalte ich als Schwester den Tag glücklich». Hier handelt es sich nicht um die Erzählperspektive, die eine individuelle Innensicht wiedergeben möchte, sondern mit den Inhalten «Dankbarkeit» und «Achtsamkeit» den kollektiven Nutzen anstreben möchte. ${ }^{172}$

Kleine individuelle Tätigkeiten, wie einen Teil des Klostergartens pflegen oder ein Inventar zu den gemeinschaftsintern vorhandenen Heiligenstatuen zu erheben, schufen sich diese Schwestern ebenfalls, deren Produkte oder Ergebnisse indessen wenn immer möglich der Gemeinschaft zugutekamen. ${ }^{173}$ Dazu gehörten auf geistiger Ebene in Einzelfällen auch kleine Abweichungen zur gemeinschaftlich praktizierten Religiosität, etwa wenn die Oberin einer einzelnen Schwester aufgrund von persönlichen Gründen für die private Gebetszeit eine andere Gebetsform erlaubte. ${ }^{174}$ Insofern unterscheiden sich die individuellen Alltagsgestaltungen dieser Schwestern von der kollektiven Identitätskonstruktion kaum. Ansätze eines individuellen Subsystems innerhalb des Kollektivs lassen sich für diese Schwesterngruppe nicht wesentlich, für die jüngeren Jahrgänge hingegen fast durchwegs aufgrund deren höherer Bildung wahrnehmen. Bei dieser Subjektkonstruktion handelt es sich vor allem um Vorhaben zum Ausbau von Führungspositionen oder neuen internen Bildungsangeboten, welche die Äusserung von Individualität in den Erzählungen kennzeichnen. ${ }^{175}$ So bewegen sich die Eigenheiten der älteren Schwestern in den Subjektkonstruktionen innerhalb der Verklammerung von Frömmigkeit und Alltag, die eine weitgehende Prägung durch

170 Interviews 033, 036, 037.

171 Interview 030.

172 Interview 026, Z. 267-314.

173 Interview 030.

174 Interview 022, Z. 325-335.

175 Interviews 035, 049, 043, 038, 034. 
den Dienstgedanken aufwies. ${ }^{176}$ Das Konzept, das diesem Lebensentwurf zugrunde liegt, beruhte auf der geistlichen Orientierung «sein eigenes Leben in die Hand Gottes zu geben». Es handelte sich hier um eine Orientierung an vorgegebenen bzw. gemeinschaftsintern tradierten Rollen.

Das Spannungsfeld von Individuum und Kollektiv wurde weiter durch die jeweilige Dynamik aufgrund von Austritten von Mitschwestern aus der Klostergemeinschaft herausgefordert. Diese Situation betraf vor allem die Phase nach dem Konzil, in der es zu gehäuften Austritten kam. Ein Teil der in diesem Zeitabschnitt im Kloster verbliebenen Schwestern erzählte wie folgt von der inneren Auseinandersetzung, die diese Vorgänge in ihnen auslösten: "Wenn eben erst neueingetretene oder auch langjährige Mitschwestern das Kloster wieder verliessen, forderte das immer auch einen selber heraus, den eigenen Weg neu auszuloten; bin ich hier noch richtig?» ${ }^{177}$

Für die im Kloster verbliebenen wenigen, nach 1980 eingetretenen und damit tendenziell eher jüngeren Schwestern waren die nach kurzer Zeit stattgefundenen Austritte von eben eingetretenen Mitschwestern gleichen Alters schwierig zu verarbeiten. Es sei das Gefühl in einem entstanden, man bleibe als Einzige übrig unter den Jüngeren, es komme keine Mitschwester nach dem eigenen Eintritt mehr nach. ${ }^{178}$ Klosteraustritte und der fehlende Nachwuchs ab den 1980er Jahren beschäftigte vorab die jüngere Generation, da diese Schwestern angaben, keine Schwestern im gleichen Alter zum Austausch zu haben. ${ }^{179}$ Vergleichsweise zeigte sich die ältere Generation mit je nach Grösse der Klostergemeinschaft Dutzenden von gleichaltrigen Mitschwestern von dieser Frage weniger betroffen, obwohl sie dieser Entwicklung nicht indifferent gegenüberstanden und die Austritte von auch älteren Mitschwestern ebenfalls verhalten thematisierten. ${ }^{180}$

Dem gegenüber betraf ein in jüngerer Zeit eher selten gewordener Klostereintritt auf der anderen Seite ebenfalls das Kollektiv und die einzelne Schwester. Erzählt wurden diese Prozesse hingegen ausschliesslich

176 Vgl. zu den Diakonissen: Ute Gause, Kirchengeschichte und Genderforschung, Eine Einführung aus protestantischer Perspektive, Tübingen 2006, 219.

177 Interview 043, Z. 44-49.

178 Interview 028, Z. 92-103.

179 Interview 018, Z. 635-656.

180 Interview 001, Z. 1142-1152.; Z. 1168-1276. 
von den jüngeren Schwestern. Demnach wurde ein Neueintritt und der Entscheid, als jüngere Schwestern zu bleiben, ab den 1980er Jahren verstärkt sowohl von der betreffenden Schwester selber als auch von der Gemeinschaft her als eine unter mehreren gangbaren Lebenslinien verortet. Die Argumentation zum Verbleib in der gewählten Gemeinschaft beinhaltete somit vielfach gleichzeitig den Gedanken an die Möglichkeit, auch ausserhalb des Klosters leben zu können. In diesem Sinn führten die jüngeren Schwestern ihre Gedankengänge zur Legitimationsfrage für den Verbleib im Kloster wie folgt aus: «Was war es, das einen im Kloster hielt? Oder solange kein konkretes Leben ausserhalb da war, blieb einem alternativ das Kloster übrig.» ${ }^{181}$ Dieses Narrativ einer optionalen Optik, welches das Leben in der Klostergemeinschaft als eines unter anderen möglichen Lebensgestaltungen für die eigene Person darstellt, kam in den Lebenszählungen der ‘typischen Schwestern` kaum vor. Gleichzeitig wurden Sinnfragen in jeder Generation von Schwestern durch die in allen Gemeinschaften ab den 1970er Jahren einsetzenden Erodierungsprozesse der beiden Konfessionen geprägt. ${ }^{182}$ Besonders die nach 1975 eingetretenen Schwestern erlebten die in ihrer frühen Klosterzeit bereits sichtbaren, v. a. personellen und institutionellen Auflösungs- und Orientierungsprozesse sowie die damit verbundene Suche nach neuen Identitäten innerhalb der Gemeinschaft als einschneidend. In ihren Erzählungen beschreiben sie diese als zusätzliche persönliche Herausforderung. ${ }^{183}$

Entgegen diesen Tendenzen fiel für die Schwestern älterer Jahrgänge diese klosterinterne Phase mit der Beendigung der Berufstätigkeit und meistens mit der Rückkehr ins Mutterhaus zusammen. Vor diesem Hintergrund musste sich diese Generation an Schwestern weniger mit der Identifikation mit neuen Modellen auseinandersetzen.

\subsubsection{Kommunikation, Organisation und Alter im Mutterhaus}

Wurden Kommunikationsstrukturen innerhalb der Gemeinschaften in die Erzählungen einbezogen? Und wie sah die allgemeine Kommunikation aus? Welche Ebenen hatte sie?

181 Interview 043, Z. 75-96.

182 Siehe beispielsweise: Wilhelm Damberg, Abschied vom Milieu? Katholizismus im Bistum Münster und in den Niederlanden 1945-1980, Paderborn/München/Wien/ Zürich 1997; Urs Hofmann, Innenansichten eines Niedergangs. Das protestantische Milieu in Basel im 20. Jahrhundert, Basel 2011.

183 Interview 018, Z. 247-249. 
Allgemein betrachtet thematisierten die Schwestern die Kommunikationskultur, die ohne Konflikte ablief, selten. Vermutlich spielte hier die Grundhaltung mit, dass das konfliktfreie Zusammenleben als selbstverständlich vorausgesetzt wurde und die einzelne Schwester in der Konstruktion ihres Lebensrückblicks nicht in zentraler Weise beschäftigte, da es aus der Erzählperspektive als ereignislos eingestuft wurde.

Dennoch nannten die Schwestern immer wieder angenehme oder konstruktiv-dialogische Gesprächskulturen, die sie mit leitenden Schwestern erfuhren. So berichteten sie etwa von Änderungswünschen innerhalb ihres beruflichen Umfelds, die sie mit der Oberin besprachen und auf Verständnis gestossen seien. ${ }^{184}$ In diesem Zusammenhang erzählten die Schwestern, dass sie ab den 1970er Jahren mit der einsetzenden Abflachung des Autoritätsverständnisses innerhalb der zuvor herrschenden Führungsmodellen den Mut gehabt hätten, ein persönliches Anliegen ihrer Oberin gegenüber vorzubringen. Dieses sei dann auch gutgeheissen worden. Es habe «eine gute Kommunikation auf gleicher Ebene» stattgefunden. So wurde «ein Anliegen, das eine Bitte um Erholung oder ein längeres Verbleiben am bisherigen Arbeitsort, wo es einem sehr gut gefallen habe», beinhaltete, in neuerer Zeit in der Regel bewilligt. ${ }^{185}$

Häufiger und emotional bewegender tauchen in den Erzählungen verschiedene Konflikte auf, die vorab zwischen Basis- und Ratsschwestern als deren Vorgesetzte einsetzten. Insofern war die Konfliktkultur eng mit der Konstruktion eines Schwesternbildes verbunden, dessen Identität auf der weiter unten ausgeführten Umsetzung des Gelübdes zum Gehorsam basierte. Welcher Art zeigen sich Beschreibungen zu Konflikten? Es ging hier innerhalb des bis gegen Ende des 20. Jahrhunderts hierarchisch angelegten Beziehungsgeflechts zwischen untergebenen und leitenden Schwestern um die Kollision von eigenen Vorstellungen mit den normierten kollektiven Vorgaben, die durch die Oberinnen vertreten wurden. Als zentralen Ansatz, die vielen damit verbundenen Konflikte und Schwierigkeiten zu umgehen, nennen die Schwestern, «einfach den Gehorsam zu leben, auch wenn die Anweisungen der Oberen widersinnig waren». ${ }^{186}$

In der wiedergegebenen Wahrnehmung der Schwestern gehören diese Kommunikationsstrukturen als selbstverständliches, durch die Satzungen geregeltes Element zur Gemeinschaftsgestaltung dazu, obwohl sie als

184 Interview 040, Z. 386-391.

185 Interview 001, Z. 178-115; 602-612.

186 Interview 044, Z. 191-193. 
schwierige Erfahrungen sehr häufig in die Erzählungen integriert wurden. Entsprechend wurde innerhalb dieses Themenfeldes nur einmal von «Machtstrukturen ${ }^{187}$ oder von «Mobbing» ${ }^{188}$ durch eine Vorgesetzte gesprochen. Hingegen wurden tradierte und gängige interne Kommunikationsformen von Schwestern aller Generationen hinterfragt. ${ }^{189}$

Welche Kanäle der Kommunikation standen den Schwestern im Fall von Konflikten offen?

Verhältnismässig wenige Schwestern gaben hier als Instrumente klärende Gespräche mit den zuständigen Ratsschwestern oder die Vermittlung durch die zum Kloster gehörenden Geistlichen an. ${ }^{190}$ Gegen Ende des 20. Jahrhunderts konnten die Schwestern in vielen Gemeinschaften bei auftauchenden zwischenmenschlichen Konflikten oder bei psychischen Schwierigkeiten entweder eine externe geistliche Begleitung oder eine Fachperson beiziehen. ${ }^{191}$ Eine offene Kommunikationsform entwickelte sich in späteren Jahren, wie von jüngeren Schwestern erwähnt wurde, innerhalb der es auch zu direkten Auseinandersetzungen kommen konnte, wenn Meinungsverschiedenheiten auftauchten. ${ }^{192}$

Bei Schwierigkeiten, die das Kollektiv der Schwestern betrafen, wurde mit einem ausserordentlich einberufenen Konvent ebenfalls ein offenes Gefäss für Diskurse und Aussprache eingerichtet. ${ }^{193}$

Wie gestalteten sich die individuellen Verarbeitungsmechanismen? Hier erwähnten die Schwestern eigene Konflikte, die etwa aus einer Krankheit oder aus einer Situation innerhalb der Gemeinschaft heraus entstanden. Daraus konnten in gewissen Lebensverläufen eher jüngerer Schwestern Erwägungen zu einem Austritt aus der Klostergemeinschaft entstehen. In Einzelfällen wurde ein u. U. geplanter nur vorübergehender Austritt realisiert. Durch die dadurch gewonnene Distanz konnte es durchaus nach ein paar Jahren zu einem Wiedereintritt in dieselbe Gemeinschaft kommen, der durch leitende Schwestern begleitet wurde. ${ }^{194}$ In anderen Fällen, die Austrittsgedanken aufgrund von Schwierigkeiten

187 Interview 023, Z. 286-289.

188 Interview 023, Z. 327-329.

189 Zum Beispiel: Interview 018, Z. 359 f.

190 Interviews 004, Z. 154-159; 029, Z. 191-196.

191 Interview 044, Z. 191-193.

192 Interview 035, Z. 182-190.

193 Interviews 014, Z. 441-462; 001, Z. 91-98; Z. 232-239.

194 Zum Beispiel: Interview 032, Z. 65-94. 
mit Mitschwestern betrafen, versuchten die verantwortlichen Oberinnen oder der Spiritual zu vermitteln. ${ }^{195}$

Weiter konnten schwierige Beziehungen von Schwestern untereinander, die sich mitunter über Jahre hinzogen, noch über den Tod einer involvierten Mitschwester hinaus innere Verarbeitungsstränge einfordern. In positiv verlaufenen Fällen kam es noch vor dem Tod zu einer Aussöhnung: «Sie ist gestorben und wir haben uns schon vorher ausversöhnt. Sie ist glücklich gestorben und ich war auch glücklich, dass wir beide im Frieden verbleiben konnten. [...] und sie hilft mir jetzt auch. Wir mussten einander gegenseitig verzeihen. Ich hab auch meine Fehler eingesehen.» ${ }^{196}$

Die Schwestern nennen verschiedene Strategien, um bei zwischenmenschlichen Schwierigkeiten «Kraft zu schöpfen» oder «durchzuhalten». So ist es vielfach das gemeinsame Gebet oder ausgewählte geistliche Literatur, die als Kraftquelle oder als «Boden zum Durchhalten» genannt werden. ${ }^{197}$ Weiter führten hier die Schwestern die Eucharistie, aber auch den «Halt in der Familie» an. ${ }^{198}$ Es konnte auch vorkommen, dass Schwierigkeiten im Umgang unter Mitschwestern innerhalb eines Konvents einer Aussenstation auftauchten. Nicht immer konnten diese von den Schwestern selbst gelöst werden: «Dann haben wir alle zusammen im Mutterhaus um Hilfe nachgesucht.» ${ }^{199}$ Vielfach geben die Schwestern an, dass sie versucht hätten, immer wieder zu verzeihen, wenn sie unter einer Mitschwester oder vorgesetzten Schwester gelitten hätten. Dazu brauchten sie Formulierungen wie die folgende: «Ich habe viel gelitten unter dieser Oberin, dann habe ich gleichzeitig ihr verziehen. Der Herrgott muss ihr schon gnädig sein». ${ }^{200}$

Die Erzählungen zu Kommunikationsstrukturen wurden ferner nicht selten unter dem Gesichtspunkt der offiziell kommunizierten Vorgaben zur Identität der «typischen Schwester〉 konstruiert. Wie war das Schwesternbild und was war der Identitätsmassstab? Dazu gibt es zwar nur wenige direkte Erzählungen. Meistens bildet diese Frage aber als geistliche Richtlinie auf der Metaebene den Hintergrund der Erzählungen. Eine Schwester führte konkret aus, was es ausmacht, «eine gute Schwester» zu

195 Interview 018, Z. 292-468.

196 Interview 008, Z. 1010-1015.

197 Interviews 003, Z. 99-102; 021, Z. 427-473.

198 Interview 018, Z. 681-685; Z. 691-706.

199 Interviews 020, Z. 191 f.; 010, Z. 273-277.

200 Interview 025, Z. 338-341. 
sein: «So mit den Jahren und auch später dann habe ich schon auch gemerkt, dass über viele, viele Jahre, wenn nicht sogar zu sagen Jahrzehnte, war das einfach so. Wenn du viel arbeiten konntest und gut gearbeitet hast, nie krank warst und immer am Morgen in der Kirche warst, dann warst du eine gute Schwester. Das war einfach der Massstab.» ${ }^{201}$

$\mathrm{Zu}$ Themenkreisen, die inhaltliche und organisatorische bzw. strukturelle Belange des Mutterhauses betrafen, erzählten die Schwestern wenig. Dazu gehören die zentralen Diskurse, die das Gemeinschaftsleben und die darauf einwirkenden kirchlichen Prozesse betreffen. Darin wurden insbesondere kollektive Inhalte wie die zeitbedingte Anpassung des Ordenskleides und religiöser Formen, Gelübde, Entscheide der Oberinnen, Umgang mit schwierigen Geistlichen, Auflösung des Noviziats, Leitungspersonen und -funktionen oder auch Seligsprechungsprozesse angesprochen. Entsprechende Forschungen haben gezeigt, dass dies Diskurse sind, die in den Gemeinschaften ab den 1960er Jahren unter Umständen bis zur Gegenwart teils rege geführt wurden. ${ }^{202}$ In den selbststrukturierten Erzählungen der Lebensgeschichten der Schwestern tauchen diese Elemente hingegen kaum auf. Sie entsprachen offenbar nicht der Perspektive der einzelnen Schwester, die sie für ihre Lebenserzählung wählte. Sprach die Interviewerin diese Themenbereiche nach Beendigung der durch die Schwester frei strukturierten Erzählung an, so folgte eine Bestätigung des Vorkommens dieser Themen oder eine kurze Ausführung dazu. Zur Reorganisation der Strukturen im jeweiligen Mutterhaus, die allgemein nach 1968 einsetzten, erzählten die Schwestern ab und zu über die zahlreichen Prozesse im Zusammenhang mit Schliessungen und Überführungen von klostereigenen Institutionen in andere Trägerschaften. Ebenfalls selten griffen etwa ehemalige Oberinnen emotional bewegende Diskurse mindestens der letzten beiden Jahrzehnte des 20. Jahrhunderts auf, welche die Gemeinschaften stark in deren innerster Substanz herausforderten. Hier führte eine Oberin einerseits ihre strategischen Überlegungen an, die sie bei heiklen Abstimmungen im Provinzkapitel, etwa zur Frage der Anpassung des Ordenskleids, angewendet hatte. ${ }^{203}$ Anderseits sprach die betreffende Oberin das Verhältnis der Gemeinschaft zu ihren ausgetretenen ehemaligen Schwestern an. Es sei ihr aufgefallen, dass hier eine hilf-

201 Interview 040, Z. 226-230.

202 Esther Vorburger-Bossart, Ordensschwestern in der Ostschweiz im 20. Jahrhundert, Zürich 2018, 23-324.

203 Interview 051, Z. 181-211. 
reiche Struktur zur Kontaktpflege fehle. So habe sie angefangen, Adressen dieser ehemaligen Schwestern zu sammeln und habe wiederkehrende Gefässe der Begegnung geschaffen, was unter den Ehemaligen wie auch unter grossen Teilen der bestehenden Schwesterngemeinschaft auf "grosses positives Echo» gestossen sei. ${ }^{204}$ Ein weiteres Thema aus Sicht der leitenden Schwestern betraf die Reorganisation des internen Personalwesens. Dies zeigte sich vor allem innerhalb der Schwesterngemeinschaften in der Umstrukturierung des über Jahrzehnte gängigen Berufungsmodells, nach dem bis ca. 1980 möglichst gut qualifizierte Schwestern für die Klosterleitungen vorgesehen wurden. Aus Gründen des sich mehr und mehr abzeichnenden Mangels an Schwestern standen indessen immer weniger fähige und jüngere Schwestern zur Verfügung, die sich in sozialer und fachlicher Hinsicht für Führungsaufgaben auf oberster Stufe eigneten. So mussten dafür vereinzelt entweder weniger geeignete Schwestern eingesetzt oder Schwestern gegen deren Willen mit Führungsaufgaben betraut werden. ${ }^{205}$

Diese Fragen konnten im Zusammenhang mit allgemeinen Zukunftsüberlegungen zur Entwicklung der eigenen Gemeinschaft, die vereinzelt auch als «aussterbende» Gemeinschaft empfunden werden konnte, stehen. «Man konnte zufrieden sein, wenn man noch gute Persönlichkeiten für Leitungsfunktionen finden konnte. Hier sind wir am Aussterben, dafür haben wir in unseren ehemaligen Missionsgebieten sehr viele Eintritte. ${ }^{206} \mathrm{Zu}$ den bereits seit drei Jahrzehnten in allen grösseren Gemeinschaften für Leitungs- und Verwaltungsaufgaben eingesetzten Laien oder klosterexternen Fachkräften machten die Schwestern keine Angaben.

Dem gegenüber kommt der von aussen wahrnehmbare Wandel, der sich in den betreffenden Institutionen ab den 1970er Jahren markant abzeichnete, relativ häufig zur Sprache. Es gibt hierzu Erzählungen, die ihren ganzen Fokus auf Veränderungen von institutionellen, personellen und baulichen Belangen richteten. ${ }^{207}$ Diese Perspektive hätte innerhalb der verschiedenen Auflösungs- und Umstrukturierungsprozesse in den Erzählungen v. a. die häufige Nennung des sich immer deutlicher abzeichnenden Schwesternrückgangs beinhalten können, der sich zur grossen Bautätigkeit noch in den 1970er Jahren und zur damals vorherrschenden

204 Interview 051, Z. 347-359.

205 Interview 018, Z. 180-189.

206 Interview 019, Z. 471-477.

207 Zum Beispiel: Interview 041. 
Planung des Ausbaus von Schwesternwerken in entgegengesetzter Richtung bewegte. ${ }^{208}$ Demgegenüber taucht diese Frage in den Lebensgeschichten relative selten auf. Hingegen wurde die explizite Thematisierung der Überführung von traditionellen klostereigenen Institutionen in weltliche Trägerschaften immer wieder in die persönliche Erzählung einbezogen. ${ }^{209}$ Dabei kam meist der Blickwinkel aus Sicht der Gemeinschaft zum Tragen. ${ }^{210}$ Dabei erzählten die Schwestern nur selten von persönlichen Gefühlen, die sie anlässlich etwa einer Schliessung eines Heimes empfunden hätten, im dem sie mehrere Jahre arbeiteten. ${ }^{211}$ Vereinzelt wurden hier, beispielsweise nach dem Verkauf eines Altersheims an die betreffende Gemeinde, Reorganisationselemente innerhalb der Kommunität genannt, die das religiöse Leben betrafen. So erzählte eine Schwester, dass es selbstverständlich gewesen sei, dass ihre Schwesternkommunität eines der Zimmer der nach dem Verkauf der vorher auch als Schwesternunterkunft genutzten Liegenschaft neubezogenen Wohnung als Kapelle eingerichtet habe. ${ }^{212}$

Diese äusseren Wandelerscheinungen in Gemeinschaft und Beruf mit den nötigen Umstrukturierungen wurden aus der ereignisgeschichtlichen und berichterstattenden Sicht explizit und eingehend von älteren Schwestern genannt. Dem gegenüber liessen sie - anders als die jüngeren Schwestern, die eher von eigenen Gefühlen berichteten - in ihren Lebensdarstellungen Erzählelemente, die Veränderungen im eigenen inneren oder geistlichen Leben, auch in der äusserlichen Erscheinung zum Ordensgewand betrafen, weg. ${ }^{213}$ Wurden von Schwestern dieser Generation dennoch äusserliche Elemente wie Details zur Bekleidung genannt, dann wurden sie ausschliesslich religiös kontextualisiert. Beispielsweise, wenn eine Schwester anlässlich der Verleihung des Krankenschwesterndiploms den Unterschied zwischen weltlichen, sogenannten «freien Schwestern» und eingekleideten (Ordens-)Schwestern erklärte und dazu ausführte, dass nur die «freien», d.h. die weltlichen Schwestern eine Brosche verliehen bekamen. ${ }^{214}$

208 Interview 026, Z. 154-180.

209 Zum Beispiel: Interview 001, Z. 509-601.

210 Interview 003, Z. 363-393.

211 Interview 045, Z. 204-206.

212 Interview 048, Z. 208-216.

213 Zum Beispiel: Interview 048.

214 Interview 040, Z. 164-172. 
Nur einmal erwähnte Themen betrafen Nennungen zu spezifischen nicht-alltäglichen Bereichen im Klosterleben, die in der Regel mit Änderungen im Gemeinschaftswesen verbunden waren. Auch hier dominierte die kollektive Sicht auf die persönliche Konstruktion der eigenen Lebensgeschichte. Eine Schwester erzählte, sie habe anfangs des 21. Jahrhunderts in ihrer Gemeinschaft die Erstellung eines Kulturgüterinventars angeregt. Es sei ihr ausgehend von den Schliessungen vieler Schwesternwerke im Zusammenhang mit der Reflexion über die Geschichte der Gemeinschaft aufgefallen, wie viele Güter ihre Gemeinschaft besitze, die bisher in keinem Inventar erfasst worden seien. ${ }^{215}$ Eine weitere Schwester beschrieb Prozesse, die sich rund um die Frage von Tod und Bestattung im Gemeinschaftswesen bewegten. Beispielsweise sei gemeinschaftsintern anfangs des 21. Jahrhunderts eine Kremation möglich geworden. Neu eingeführt wurden im selben Zeitraum auch das eigenständige, und damit vorzeitige Verfassen des eigenen Nekrologs. Zuvor war für die Gestaltung von Nekrologen ihrer Mitschwestern die zuständige Oberin zuständig. ${ }^{216}$

Wie gestaltete sich in den Erzählungen die Beziehung der einzelnen, meist auf Aussenstationen lebenden Schwester zur Mutterhausgemeinschaft? Obwohl diese Beziehungsstruktur den grössten Teil des Arbeitslebens der meisten Schwestern prägte, wurde sie in den frei gestalteten Erzählungen wenig thematisiert und wohl als selbstverständlich vorausgesetzt. Einzelne diesbezügliche Aussagen betreffen Erzählmuster wie «wir haben verschiedene Treffen gehabt im Mutterhaus, aber sonst ist ja das Mutterhaus eigentlich weit weg gewesen, das muss ich sagen. $\gg^{217}$ Aus dieser Erzählperspektive lassen sie darauf schliessen, dass die Einrichtung eines weitverzweigten Filialnetzes den auf Aussenstationen arbeitenden Schwestern gewisse Möglichkeiten der freien Arbeitsgestaltung eröffneten. Diese Interpretationsrichtung, die implizit Möglichkeiten von gewissen Freiheiten innerhalb des regulierten Klosterlebens eröffnete, wird unterstützt durch die zahlreichen Schilderungen von älteren Schwestern, welche die mitunter zwar als «Heimkommen» benannte alters- oder strukturbedingte Rückkehr ins Mutterhaus anführen. ${ }^{218}$ Nicht selten wird dieser Rückführungsprozess von über Jahrzehnte auf externen Niederlassungen tätig gewesenen Schwestern demzufolge als eher schwierig

215 Interview 021, Z. 569-688.

216 Interview 051, Z. 290-311.

217 Zum Beispiel: Interviews 003, Z. 347 f.; 001, Z. 1114-1117.

218 Zum Beispiel: Interview 001, Z. 626-631. 
beschrieben. Sich nach so langer Zeit des Aufenthalts «draussen» mit den teils in Ansätzen individuell gestalteten Alltagsmustern wieder in die Restgemeinschaft im Mutterhaus eingliedern zu müssen, konnte als mühsam erlebt werden. ${ }^{219}$ Dass diese Thematik relativ häufig Gegenstand der Erzählungen war, wurde mit grosser Wahrscheinlichkeit neben des emotional relativ hohen Betroffenheitscharakters ebenfalls vom Umstand der zum Zeitpunkt der Interviewaufnahme aktuellen Lebensphase der Respondentinnen im Pensionsalter geprägt.

Grundsätzlich wurde das Alter, das aufgrund der hohen Aktualität unter den teilweise hoch betagten Respondentinnen als eigenständigen Themenkreis hätte erwartet werden können, analog zu weiteren bereits angeführten Themen v.a. unter dem organisatorischen oder gemeinschaftsinternen Blickwinkel betrachtet. So fehlen etwa allgemeine Beschreibungen zu auftretenden Beschwerden, die mit nachlassenden Kräften oder Krankheiten im Alter vermehrt auftauchen können, fast ganz. Die Erzählungen richten sich auf die nach dem beendeten Berufsleben neu entstandenen Möglichkeiten. Man sei «auch in der Pensionierung noch breit tätig». So besinne man sich in der Gemeinschaft beispielsweise «wieder neu auf den «Gründergeist` und lote aus, was in diesem Sinn mit einer kleiner werdenden Gemeinschaft noch möglich sei». ${ }^{220}$ Eine Schwester machte eine Aussage zum religiösen Angebot, das im Mutterhaus den betagten Schwestern zur Verfügung stehe. ${ }^{221}$

Das Alter oder auch eine Krankheit thematisieren die Schwestern nur am Rande als gegebenen Rahmen, der Neuorientierungen im Leben zur Folge haben kann, so beispielsweise als Anlass, eine externe Tätigkeit aufgeben zu müssen, um ins Mutterhaus zurückzukehren: «Im achtzigsten Lebensjahr wurde ich krank. So musste ich dann alles aufgeben und ins Mutterhaus umsiedeln».222

Wie beschrieben die Schwestern nebst dem Mutterhaus das Leben auf den Aussenstationen? Gestalteten sich hier die Muster sozialer Rollen und Zuschreibungen in externen Arbeitsgebieten anders als im Mutterhaus, oder behielten sie auch ausserhalb der gewohnten Gemeinschaft dieselbe Gültigkeit? Welche Handlungsspielräume gab es für Schwestern in den Aussenstationen?

219 Interview 029, Z. 293 f.; Z. 315-330.

220 Interview 051, Z. 534-613.

221 Interview 039, Z. 244-249.

222 Interview 009, Z. 156-167. 
Erwähnungen zu Rollen und Handlungsspielräumen bilden nicht die hauptsächlichen Erzählinhalte innerhalb dieser Thematik. Die Schwestern greifen eher den sozialen Aspekt in dem Sinn auf, dass sie es «als Glück» empfanden, nie allein auf einer Aussenstation leben zu müssen und in eine kleine Kommunität eingegliedert zu sein. Dabei stellten sie den Bezugsrahmen zur grossen Mutterhausgemeinschaft her und erwähnten, dass man mit dieser Konventstruktur auf den Aussenstationen «nicht so allein draussen» war. ${ }^{223}$ Religiös gesehen war man näher an der liturgischen Verantwortung als im grossen Schwesternkreis im Mutterhaus, was als positive Erscheinung beschrieben wurde. ${ }^{224}$ Der gewöhnliche Alltag auf den Aussenstationen wurde selten dargelegt. Eine Schwester gab detaillierte Schilderung zum Alltagsleben an, das sie mit einer älteren Schwester teilte und bezog die Alltagsgestaltung auf die Generationenfrage. ${ }^{225}$

Hingegen erwähnten die Schwestern auch in Bezug auf die Aussenstationen immer wieder die dort im Lauf der Zeit notwendig gewordenen Umstrukturierungen, die vor den 1980er Jahren als bauliche Erweiterungen und in jüngerer Zeit als Auflösungen von Schwesternwerken zu bewältigen waren. Selten erzählten sie Elemente zur Beziehungspflege zum Mutterhaus wie es im folgenden Beispiel vereinzelt wiedergegeben wurde: «Um die Beziehungen zum Mutterhaus zu fördern, entschloss ich mich, alle vierzehn Tage ins Mutterhaus zu fahren.» ${ }^{226}$ Wie wurde die eigene religiöse und gesellschaftliche Sozialisation in Bezug auf die Mutterhausgemeinschaft wahrgenommen? Diese wurde über besondere religiöse Ereignisse wie das Noviziat und die Profess, auch über Feste in der Gemeinschaft im folgenden Erzählmodus beschrieben: «Es war vor der Ewigen Profess. Ich war dann den ganzen Sommer oben und durfte dann am 10. November ins Mutterhaus und am 7. März habe ich dann Ewige Profess gemacht.» ${ }^{227}$ Weiter erwähnten einzelne Schwestern die gemeinsam gefeierten Feste wie besonders die aufwändig gestalteten Fastnachtsfeierlichkeiten. Diese wurden als sehr ausgelassenen und wichtigen gemeinschaftsstiftenden Teil, nebst der gemeinsam gepflegten Spiritualität, nachgezeichnet. ${ }^{228}$

223 Interview 001, Z. 663-675.

224 Interviews 026, Z. 14-16, 006, Z. 70-79.

225 Interview 020, Z. 111-135.

226 Interview 009, Z. 156-167.

227 Interview 008, Z. 552-555.

228 Interview 034, Z. 180-201. 


\subsubsection{Reguliertes und hierarchisches Klosterleben}

\subsubsection{Reguliertes Klosterleben}

Im Verhältnis zur häufig thematisierten, unten ausgeführten, hierarchischen Organisation der Gemeinschaften griffen die Schwestern nur selten Themen zum regulierten Klosterleben auf. Diese betrafen etwa Beobachtungen zur gemeinsam gelebten Religiosität, die hie und da nach dem Konzil etwas verloren gegangen sei. Hier benannten die Schwestern entweder nur diesen Umstand oder suchten nach entsprechenden Gründen. Einzelne Schwestern erwähnten in diesem Zusammenhang, «dass manchmal vielleicht eine etwas straffere Führung in der religiösen Praxis nötig gewesen wäre». ${ }^{229}$ Mehrheitlich beschäftigte hier die Frage, weshalb «man denn im Kloster sei». ${ }^{230}$ Gemeint war damit der Wunsch, dass das gemeinschaftliche Gebetsleben ab den 1970er Jahren wieder etwas mehr hätte gepflegt werden sollen. Vor diesem Hintergrund taucht immer wieder das nicht als ideal empfundene Verhältnis zwischen Arbeit und Religiosität in dem Sinn auf, dass die Schwestern vielfach vor allem für die Phase der Berufsausübung den Wunsch formulierten, «die Berufung, das Gebet mehr leben zu dürfen, als es in der Realität vorkommt». ${ }^{231}$

Zum Inhalt der praktizierten Religiosität selber kommen - vermutlich wiederum aufgrund der Selbstverständlichkeit - nur wenige Passagen vor, etwa zu den alltäglich in allen Gemeinschaften gelebten Gebetszeiten: «Es ist ganz klar. Wir beten am Morgen, am Mittag, am Abend miteinander und jede nimmt sich diese Zeit.» ${ }^{232}$

Weiter wurde wenige Male, abgesehen zur breit unten angeführten Thematik der Ereignisse um die Berufung zu einem klösterlichen Leben, die «Vorsehung Gottes» erwähnt: «Und so denke ich, dass Gott weiterschaut für das, was wir in nächster Zeit brauchen.» ${ }^{233}$

Die geistliche Betreuung durch den klostereigenen Spiritual, und damit die persönlich reflektierte Religiosität, erwähnten die Schwestern in der inhaltlichen Ausführung nicht, sondern nur hin und wieder als institutionelles Gefäss. Einmal gab eine Schwester an, «eigentlich keine

229 Interview 039, Z. 179-183.

230 Interview 033, Z. 357-363.

231 Interview 001, Z. 55-60.

232 Interview 003, Z. 229-230.

233 Zum Beispiel: Interview 006, Z. 130-132. 
solche geistliche Begleitung gehabt zu haben als Einzelbetreuung». «Ich wurde irgendwie anders geführt.» ${ }^{234}$

Die «Gegenwart Gottes` integrierten die Schwestern in Ausdrücken wie «durch die Führung Gottes» relativ häufig in die verschiedenen Erzählthemen. Diese Wendungen waren hier nicht kollektiv gemeint, sondern wurden als subjektive Strukturelemente im persönlichen Glaubensleben verwendet. Damit hoben die Schwestern den persönlichen Vollzug einer gemeinschaftlich ausgeübten Religiosität hervor: «Und in all dem immer auch das Religiöse zu finden» ${ }^{235}$ oder «das Gefühl, dass ich Gott gefunden und mich geführt gefühlt habe». ${ }^{236}$

Das Noviziat oder entsprechende Erinnerungen zur eigenen Noviziatsausbildung gehörten ebenfalls zu den selten angesprochenen Themen. Einmal wurde diese in dem Sinn kritisch beleuchtet, dass «theologisch keine Inhalte im Noviziat vermittelt wurden, sondern fast nur Tugendund Anstandslehre». ${ }^{237}$ Eine weitere Schwester ging auf Neuerungen ein, die im Noviziat eingeführt wurden. Es sei dort «mit der Zeit ein freier Tag und das Ausschlafen an einem der Wochentage eingeführt» worden, «was bei älteren Schwestern nicht unbedingt auf Verständnis gestossen» sei. ${ }^{238}$

\subsubsection{Hierarchisches Klosterleben}

In der hier untersuchten Zeitspanne bis gegen Ende des 20. Jahrhunderts herrschte ein weitgehend traditionelles Autoritätsverständnis vor, das auf entsprechenden hierarchisch angelegten Organisationsstrukturen beruhte. Die «Frau Mutter» als Generaloberin galt an der Spitze der Klostergemeinschaft als eine sowohl in Ansehen als auch in sozialer, religiöser und fachlicher Kompetenz unantastbare Person bis mindestens in die 1980er Jahre hinein. Dieses Führungsmodell prägte das Autoritätsbild und das soziale Verhalten unter den Schwestern ungemein. Die Generaloberin war für die Schwestern als ihre Töchter darüber hinaus nicht nur Vorsteherin, sondern gleichzeitig auch wie eine Mutter. In dieser Rolle prägte sie gewissermassen das «private und berufliche`, aber auch das soziale Leben der ihr untergebenen Schwestern. Wurden beispielsweise

234 Interview 039, Z. 280-287.

235 Interview 003, Z. 224-226.

236 Interview 033, Z. 389-395.

237 Interview 014, Z. 496-533.

238 Interview 051, Z. 75-106. 
einzelne Schwestern von der Frau Mutter eingeladen, mit ihr die Ferien $\mathrm{zu}$ verbringen, so wurde dies als Privileg empfunden und konnte unter den übrigen Schwestern der Gemeinschaft Gefühle von Neid hervorrufen. Teilweise zeigte sich dies auch über das Dienstverhältnis. So registrierten die Mitschwestern, wenn die eine oder andere Schwester häufig bei leitenden Schwestern oder gar bei der Frau Mutter «ein und aus» ging, d. h. von dieser ausserhalb von offiziellen Dienstwegen gerufen wurde, um diverse Dienstleistungen zu erbringen. Weiter zeigten sich hierarchische Verhältnisse über eine Zweiteilung der Gemeinschaften mindestens in Ansätzen durch den Bildungsgrad, den die Schwestern entweder bei Klostereintritt bereits mitbrachten oder bei entsprechender intellektueller Fähigkeit nach dem Eintritt erwerben durften. Bei der ältesten, noch lebenden Generation von Schwestern blieb es tendenziell am häufigsten beim ungelernten oder angelernten beruflichen Status. Diese Schwestern verrichteten zeitlebens strenge körperliche Arbeiten in Küche, Haus, Garten oder Landwirtschaft. Dies betraf ide Mehrheit der Schwestern mit Jahrgängen um 1920 bis ca. 1940, die grösstenteils aus einfachen ökonomischen Verhältnissen stammte. ${ }^{239}$

Die meisten interviewten «typischen Schwestern〉 erlebten den grössten Teil ihres Klosterlebens praktisch ausschliesslich das hierarchisch aufgebaute Führungsmodell. Dies betraf alle Schwestern, da die jeweiligen Oberinnen gemäss den Satzungen nur für eine bestimmte Zeitspanne zur Amtsausübung in eine leitende Stellung gewählt wurden. Nach Ablauf dieser Amtszeiten waren diese abgetretenen Rätinnen wieder «normale` Schwestern. Nach gemeinschaftsinternen Beratungen und Diskussionen in den 1970er Jahren wurden ab den 1980er Jahre über breit angelegte organisatorische Umstrukturierungsprozesse demokratischere Leitungsstrukturen spürbar, durch die das hierarchische Verständnis mit der Zeit eingeebnet wurde.

\section{Die Perspektive der Schwestern in Führungspositionen vor 1980}

Mehrere Schwestern in ehemals leitenden Funktionen gaben an, spätestens ab den 1990er Jahren auf allen Ebenen basis-demokratische Führungsmodelle eingeführt zu haben. So hätten sie als Rätinnen einmal im

239 Gemeinschaftsarchive von Baldegg, Basel, Cham, Ilanz, Ingenbohl, Luzern, Menzingen, Niederuzwil, Biografische Daten von Schwestern, SNF-Projekt «Lebensgeschichten religiöser Frauen in der Schweiz» 2015-2018. 
Jahr mit jeder einzelnen Schwester ein Gespräch geführt. Für diese neuen Aufgaben der Gesprächsführung seien sie ausgebildet worden. ${ }^{240}$ Einer anderen Schwester war in derselben Zeitspanne die kommunikative und konstruktive Art des Zusammenlebens, die sie als Rätin versucht hatte zu fördern, wichtig. Auch konnte sie neue Themen, etwa die Frage der Gestaltung des Klosterlebens mit immer mehr älter werdenden Schwestern, einbringen. ${ }^{241}$ Die Befähigung von Schwestern für Leitungsaufgaben wurde unter den älteren Schwestern nur sehr selten in die Erzählungen einbezogen. Eine der leitenden Schwestern gab an, dass sie nur gelernt hätten, wie man mit den Schwestern im allgemeinen zwischenmenschlichen Bereich umgeht. Von «Führungsfunktionen haben wir früher keine Ahnung gehabt». ${ }^{242}$ Eine andere Schwester erzählte, dass sie in der Generalleitung viel gelernt habe, was Management anbelangte. Sie habe einen Weitblick erhalten, insbesondere, wenn es um Schliessungen von klostereigenen Heimbetrieben ging. ${ }^{243}$ Eine ehemalige Generaloberin berichtete von einem «enormen Druck», der auf den leitenden Schwestern lastete. Es sei hier auch um kircheninterne und öffentliche Erwartungen gegangen. Die Geistlichen hätten im 19. Jahrhundert eine Idee für ein neues soziales Werk gehabt und dieses gegründet. «Und wer hat diese Gründung durchgezogen? Klosterfrauen! ${ }^{244}$ Obwohl man früher oft keine Ausbildung hatte, musste man schauen, dass die Führungsarbeit eine gute Qualität gehabt habe. So habe man «bis zum Umfallen gearbeitet, dass man sich ja nicht blamieren musste». Sie erwähnte weiter, dass man als leitende Schwester zusätzlich derart unter öffentlichem Leistungsdruck stand, die zahlreichen, der Kongregation angeschlossenen Betriebe effizient und ökonomisch erfolgreich zu führen. Insofern blieb den leitenden Schwestern oft keine andere Wahl, als «die eigenen kostengünstigen Arbeitskräfte, die Schwestern, nicht nur manchmal gegen deren Willen, sondern auch über deren Leistungsvermögen hinaus einzusetzen». ${ }^{245}$

240 Interview 051, Z. 163-179.

241 Interview 051, Z. 121-142.

242 Interview 017, Z. 589-591.

243 Interview 002, Z. 160-176.

244 Interview 017, Z. $308 \mathrm{f}$.

245 Interview 017, Z. $308 \mathrm{f}$. 
Schwestern in Führungspositionen in der Perspektive ihrer Mitschwestern Wie nahmen umgekehrt die Schwestern der Basis in Bezug auf ihre Vorgesetzten deren Führungsumgang wahr bzw. was erzählten sie zum Verhältnis zwischen Ratsschwestern und «gewöhnlichen` Schwester? Allgemein gesehen erwähnen sie mehrmals, dass die Gemeinschaft gut geleitet wurde und man in neuerer Zeit gewisse Themen auch besprechen konnte, ohne sie nur angeordnet erhalten zu haben. ${ }^{246}$

Grundsätzlich gestaltete sich die Wahrnehmung der Beziehungsstrukturen zwischen Schwestern und deren Vorgesetzten während Jahrzehnten über berufliche Abläufe, v. a. über Fragen zur Aus- und Weiterbildung sowie über die Kommunikationskanäle zur Versetzung der Schwestern «von einer Niederlassung zur anderen». ${ }^{247}$ Die Schwestern erwähnten kritische Punkte zum Gemeinschaftsleben denn auch häufig nur über strukturelle Mängel, die neben den unten ausgeführten Mutationen innerhalb der Arbeitsstellen den Mangel an Schwestern als Arbeitskräfte und die vielen Personalausfälle durch Krankheiten betrafen. ${ }^{248}$ Dabei fehlte es in den Erzählungen der Schwestern oft nicht an Verständnis, grösstenteils auch nicht an Akzeptanz, für diese organisatorischen Umstände: «Damit der Betrieb aufrecht erhalten werden konnte, haben wir halt einfach spuren müssen.» ${ }^{249}$

Konnten die Schwestern hingegen bestimmte Weisungen der Oberinnen weder als sinnvoll noch als notwendig einstufen, so gaben sie an, dass sie in diesen Situationen als mögliches Erklärungsmodell das Gelübde des Gehorsams vor Augen hatten. Unter dieser Verpflichtung, mit der sich die einzelne Schwester nebst den zentralen religiösen Inhalten gegenüber dem Kollektiv verantwortete, gelang es ihr über weite Strecken, sich für die Umsetzung einer solchen Anordnung zu motivieren. Dabei konnte die einzelne Schwester nicht geltend machen, ob ihr der Gehorsamsvollzug persönlich zum Vorteil gereichte oder nicht. Dieser Mechanismus trug zusammen mit einem bis in die 1980er Jahre ausgeprägten Gemeinschaftssinn - erheblich zum Erfolg des Kongregationsmodells, insbesondere aber zur erfolgreichen Betriebsführung der zahlreichen Sozial- und Bildungsinstitutionen bei. Die quantitativ und qualitativ gesehen äusserst intensive Beschäftigung der Schwestern in ihren Erzählungen mit der zu

246 Interview 001, Z. 603-613.

247 Interview 050, Z. 161-251.

248 Zum Beispiel: Interview 011, Z. 108-133.

249 Zum Beispiel: Interview 011, Z. 155. 
beruflichen Zwecken bedingten Versetzung von einem Ort zum anderen und den damit verbundenen Unannehmlichkeiten, zeigt welche zentrale Rolle das Gelübde des Gehorsams innerhalb der Kloster- und Betriebsführung spielte.

Erzählungen zu inneren Emotionen und Gedankenabläufen von Schwestern dazu zeigen einerseits die Konfrontation mit subjektiven Vorstellungen und anderseits die Einsicht und Aufgabe eigener Wünsche zugunsten des Kollektivs auf: «Sie [die Oberin] hätte mich ja von da her nicht zwingen können, aber ich bin noch von dieser Generation, haben wir ja diesen Gehorsam dann ja auch irgendwo gelobt und man hat ja mit uns geredet, nicht Gehorsam in dem Sinn, nicht einen Kadavergehorsam, aber zu sagen: ja, gut, also wenn es der ganzen Sache noch ein Dienst ist, und dann mache ich es auch.» ${ }^{250}$ Eine andere Form einer Gehorsamsäusserung, eine Sache einfach zu akzeptieren, ohne den Sinnzusammenhang nachvollziehen zu können, taucht in den Erzählungen immer wieder auf: «Ja, gut. Dann habe ich halt dann nur gesagt: 〈Ja, ja〉.» ${ }^{251}$

Eine Schwester führte den ebenfalls häufig erwähnten «Sinn für die Gemeinschaft» in ihren Erzählungen aus dieser Sicht an, dass sich innerhalb ihrer Klostergemeinschaft die Auslegung des Dienstverständnisses einer Schwester in der neusten Zeit verändert habe hin zu einer individuelleren Interpretation. Die jüngeren Schwestern hätten in dieser Hinsicht ein «Recht auf etwas», also subjektive Erwartungen an die Klostergemeinschaft formuliert, die etwas anderes meinten, als das, «dass ich [als Schwester und Angehörige einer religiösen Frauengemeinschaft] alles in die Gemeinschaft hineingebe und mich selber zurücknehme.» ${ }^{252}$ Diese Beobachtung zeugt von oben bereits ausgeführten zeitbedingten unterschiedlichen Subjektkonstruktionen, die gegen Ende des 20. Jahrhunderts auf ein grundsätzliches Spannungsverhältnis zwischen der einzelnen Schwester und dem Kollektiv hinweisen.

Zur Pflicht der kontinuierlich geltenden unbedingten Gehorsamsleistung gehörte anderseits die Auflösung subjektiver Lebensentwürfe, die eine grössere, meist lebenslange Tragweite haben konnte. Dies konnte Berufswünsche betreffen, die bereits vor dem Klostereintritt Motivation $\mathrm{zu}$ einem geistlichen Leben sowie Bestand einer Lebensplanung waren

250 Interview 018, Z. 137-241.

251 Interview 010, Z. 187.

252 Interview 028, Z. 143-147. 
und vielfach das Berufsfeld der Mission betrafen. ${ }^{253}$ Nicht immer konnten die leitenden Schwestern diesen Vorstellungen der Schwestern entsprechen, was zu persönlichen Enttäuschungen führen konnte. In diesem Zusammenhang wurde in den Erzählungen hin und wieder eine persönliche Vorstellung eines Lebens im Kloster als zu idealisiert aufgegriffen, die in der Wahrnehmung mit dem Anforderungsprofil einer Ordensschwester kollidierten. Vor allem betraf dies als häufig dargestelltes Thema bei einem grossen Anteil der Lebenserzählungen die enorme Arbeitsbelastung, die den Ordensschwestern aus den oben angeführten betriebswirtschaftlichen Gründen zugemutet werden musste. Entsprechend eingehend erwähnten die Interviewpartnerinnen im frei gestalteten Teil ihrer Erzählungen auch unter diesem Aspekt, wie «viel und hart» sie als Schwestern arbeiten mussten. ${ }^{254}$ Die unter religiösen Voraussetzungen geleistete Treue zeigte in der Umsetzung des Gehorsams für viele Schwestern die in der folgenden Äusserung zu Tage getretene alltägliche Komponente: «Da ist man ja nicht mehr Ordensschwester, sondern man arbeitet ja nur.» ${ }^{255}$ Damit sprachen die Schwestern das Thema der steten Arbeitsüberlastung nicht nur aus Sicht des dadurch zurückgedrängten religiösen Lebens an, sondern auch aus der Perspektive des geleisteten Gehorsamsgelübdes.

Die Umsetzung des Gehorsams bedeutete für die Schwestern im Alltag insbesondere, den Weisungen der leitenden Schwestern nach Versetzungen an andere Wirkungsorte nachzukommen. Die von den Kongregationsgemeinschaften teilweise in der ganzen Schweiz bis in die letzten Jahrzehnte des 20. Jahrhunderts hinein unterhaltenen, weitverzweigten Filialstrukturen erforderten teilweise einen häufig wechselnden Arbeitseinsatz von Ordensschwestern, um die dortigen Niederlassungen oder sozialen Institutionen unterhalten zu können. ${ }^{256}$ Dabei fühlten sich die Generaloberinnen verpflichtet, den steten, oft eindringlichen und wiederholt geäusserten Forderungen von Geistlichen, Behördenmitgliedern oder leitenden Ärzten nach weiteren leistungsfähigen Ordensschwestern

253 Interview 015, Z. 448.

254 Zum Beispiel: Interview 011 weist zu grossen Teilen Erzählungen über das viele Arbeiten auf.

255 Interview 011, Z. $1056 \mathrm{f}$.

256 Vgl. hierzu das Verzeichnis der zahlreichen Niederlassungen von schweizerischen Kongregationen exemplarisch für die Ostschweiz, in: Esther Vorburger-Bossart, Ordensschwestern in der Ostschweiz im 20. Jahrhundert, Zürich 2018, 423-471. 
für einen Einsatz an die diversen Arbeitsorte nachzukommen. ${ }^{257}$ Diesen Umstand der personellen Versetzung erwähnten die Schwestern in ihren Lebenserzählungen beinahe am häufigsten. ${ }^{258}$ Darunter wurden - zwar unter steter Bezeugung des Verständnisses gegenüber den zuständigen Oberinnen für diese personelle Mutationspraxis - auch systemkritische Bemerkungen angeführt, wie: «Eine sogenannte Anfrage für einen Postenwechsel [Wechsel des Arbeitsortes] war eigentlich keine freie Wahl: «Nein, nein. Sie kommen in die andere Abteilung. Sagen sie doch ja, hat sie [die Oberin] gesagt. Hat ein bisschen gebettelt, ich solle ja sagen. Und dann hab ich halt ja gesagt.» ${ }^{259}$ So gaben viele Schwestern an, über das oft kurzfristig angekündigte oder wiederholt angebrachte «Geheiss» der Generaloberin zur Versetzung, «zwar verwundert» gewesen zu sein, aber sie hätten gehorcht und dem Auftrag Folge geleistet. ${ }^{260}$

Schwestern, die von ihren Vorgesetzten für Leitungsaufgaben bestimmt wurden, gaben immer wieder an, dass sie eigentlich lieber abgelehnt hätten, diese Verantwortung zu übernehmen. Sie hätten aber der Anfrage der Oberin entsprochen und «nicht aus Bequemlichkeit» die Anfrage der Oberin zur Übernahme eines Amtes mit leitender Funktion abgelehnt. ${ }^{261}$ Manchmal kam es anlässlich von personellen Notsituationen zu einer abrupten Ankündigung eines Wechsels mittels Anweisungen, die unter Umständen vor dem versammelten Plenum der Schwestern, beispielsweise während des Mittagessens, auch öffentlich erfolgen konnten. Eine Schwester erzählte dazu, dass die Oberin die für ein neues Amt vorgesehene Schwestern wie nachfolgend anwies: «Setzten Sie sich bitte jetzt oben an den Tisch, ab heute sind Sie Oberin». ${ }^{262}$

Oft war eine gewisse Selbstverständlichkeit in den Erzählungen zu spüren, auch bei unvermittelten Versetzungen, die manchmal innert weniger Stunden einen Arbeitsortwechsel für Schwestern bedeuteten. ${ }^{263}$ Dennoch bereitete das unvermittelte Versetzen von Schwestern an andere Einsatzorte Mühe und ist in der Erinnerung vielfach präsent. ${ }^{264}$ Tenden-

257 Vgl. hierzu die Korrespondenzen der Generaloberinnen, in: Esther VorburgerBossart, Ordensschwestern in der Ostschweiz im 20. Jahrhundert, Zürich 2018, 146-163.

258 Interview 001, Z. 282-288; Z. 326 f.

259 Interview 008, Z. 839-841.

260 Zum Beispiel: Interviews 046, Z. 18-22; 023, Z. 13-37.

261 Interview 049, Z. 157-161.

262 Interview 044, Z. 167-170.

263 Interview 037, Z. 53-61.

264 Zum Beispiel: Interview 011, Z. 87-89. 
ziell erwähnten dennoch nur vereinzelte und jüngere Schwestern mit Jahrgängen nach 1950 explizit, in welch emotionale Schwierigkeiten sie dadurch gekommen seien, auch im Umgang mit dem in der Regel wenig partizipativen Versetzungsmodus der verantwortlichen Oberinnen. ${ }^{265} \mathrm{Bei}$ Schwestern der älteren Jahrgänge herrschte auch hier der Erzähltopos vor, dass man «es einfach gemacht habe». ${ }^{266}$ Diese Schwestern gaben mehrheitlich an, dass sie den Anfragen der Oberinnen nach Mutationen des Wirkungsortes stets nachgekommen seien. ${ }^{267}$ Innerhalb dieser Prozesse kam es auch vor, dass eine von der Oberin angeordnete Versetzung aufgrund von persönlichen Umständen wie Krankheiten oder starke Heimweh-Gefühle, etwa nach Versetzungen ins nahe Ausland, rückgängig gemacht werden musste. ${ }^{268}$

In seltenen Fällen traute sich eine Schwester bereits vor der Einführung von flacheren Führungsstrukturen ab den 1970er Jahren, die geltende Hierarchieordnung zu durchbrechen und der Oberin Vorschläge zu machen bezüglich einer anderen Lösung beim Versetzen von Schwestern. Sie begründete dies mit strukturellen Umständen. Durch die Versetzung von Personal würde dies in der betreffenden sozialen Institution einen Mangel an Arbeitskräften auslösen. ${ }^{269}$ Dies konnte den Vorschlag einer praxisorientierten Lösung betreffen, wenn beispielsweise kurz vor Beginn der Winter- und damit Hochsaison an einem Wintersportort eine leitende Schwester abberufen werden sollte oder ein Oberinnenwechsel geplant war, den die zuständige Schwester aus betrieblichen Gründen gegenüber der Klosterleitung als nicht sinnvoll verantworten musste. Diese Erzählsequenzen wurden indessen stets mit einer Bezeugung des Gehorsams beispielsweise wie folgt abgeschlossen: «Aber da war der Gehorsam, auch wenn sie [die leitenden Ratsschwestern] dann einsahen, dass das nicht gut war, $[\ldots] . »^{270}$ Eine weitere Schwester in leitender Stellung auf einem Aussenposten bat ihre Vorgesetzte im Mutterhaus um mehr Personal. Sie begründete dies mit dem Umstand, dass die Schwestern auf diesem Posten «gar nie frei» hätten. Da habe die Frau Mutter entgegnet, dass «das

265 U.v. a.: Interviews 020, Z. 81-103; 031, Z. 402 f.

266 Interview 004, Z. 209.

267 Interview 001, Z. 75-160.

268 Interview 047, Z. 115-128.

269 Interview 011, Z. 74-88.

270 Interview 029, Z. 182-188. 
nicht nötig» sei und angefügt habe, dass «die Schwestern unterdessen modern» würden und immer mehr eigene Wünsche hätten. ${ }^{271}$

Im Zusammenhang mit dem üblichen Versetzungsmodus erwähnten die Schwestern häufig den Mut, den sie aufbringen mussten, um die Oberin um einen anderen Posten zu bitten, der etwa der körperlichen Konstitution besser entsprach. Eine Schwester gab an, in der klosterinternen Metzgerei sehr hart gearbeitet zu haben. Sie erzählte von ihrer Erfahrung, dass sie merkte, diese Arbeit aus körperlichen Gründen nicht mehr länger ausführen zu können. Weiter führte sie von ihren Gewissensnöten aus im Zusammenhang mit ihrem bewusst aus spirituellen Gründen gewählten klösterlichen Lebensentwurf: «Bin ich eigentlich für das ins Kloster? Ist das mein Weg? Und dann haben sie mich versetzt.» ${ }^{272}$

In späteren Jahren, nach 1970, als die bislang geltenden hierarchischen Leitungsstrukturen gelockert wurden, fiel es den Schwestern leichter, die Artikulation innerer Widerstände oder gar eigener Wünsche gegenüber ihren Oberinnen vorzubringen. So erzählte eine Schwester, dass sie nach vielen Ortswechseln in ihrem Ordensleben angesichts einer neuen diesbezüglichen Anfrage im fortgeschrittenen Alter das Gefühl gehabt habe, nicht noch einmal einen Wechsel verkraften zu können. Dazu führte sie wie zur Rechtfertigung ihres Entscheids an, dass sie den häufigen Anfragen der jeweiligen Leitungen nach Wechsel stets positiv gegenüber gestanden sei und diese bisher nie zurückgewiesen habe. ${ }^{273}$

Die unbedingte Gehorsamsleistung wurde somit selten infrage gestellt, wenn es äussere Fakten gab, weshalb zum gefragten Zeitpunkt ein Wechsel aus innerbetrieblichen Gründen angezeigt war. ${ }^{274}$ Manchmal äusserten einzelne Schwestern bei der Erzählung von Situationen zur Gehorsamsleistung vorsichtig ihre damals nach innen ausgetragenen Widerstandsgefühle. Etwa, dass man, wenn eine Versetzung gegen den eigenen Willen vorlag und man eine geliebte Stelle verlassen musste, dies «zuerst als Schlag» empfunden hatte. Als Abschluss dieses Topos hängten die Schwestern auch hier Verarbeitungsmechanismen an wie: «Aber dann habe ich das unter das Motto gestellt, wenn ich damit etwas für die Gemeinschaft tun kann, dann mache ich das.» ${ }^{275}$

271 Interview 010, Z. 253-269.

272 Interview 015, Z. 174-177.

273 Interview 001, Z. $268 \mathrm{f}$.

274 Zum Beispiel: Interview 044, Z. 175-188.

275 Interview 051, Z. 69-75. 
In seltenen Fällen kam es vor, dass eine Schwester wie nachfolgend ihre Oberin nach dem Klostereintritt um eine andere Ausbildungsmöglichkeit als die für sie vorgesehene bat. Diese offenbar unter grossen Gewissensnöten vorgetragene Bitte schilderte sie im Interview noch aus der Erinnerung heraus in der damals üblichen Höflichkeitsformel der Frau Mutter gegenüber: «Ach, liebe ehrwürdige Mutter, also mir ist es so schwer. Ich kann fast nicht mehr essen und nicht mehr fröhlich sein. Haben Sie nicht eine andere Arbeit. Aber Lehrerin werden, nein, also das liegt mir nicht, [...]. Dann hat sie [die Oberin] gesagt: «Was? Also das gibt es nicht. Man wirft die Flinte nicht so schnell ins Korn.${ }^{276}$

Den Weisungen der Frau Mutter etwas zu entgegnen kostete auch Mut, selbst, wenn ein ärztliches Zeugnis vorlag, das beispielsweise eine Arbeitsunfähigkeit bezeugte. Eine Schwester erzählte dazu, dass sie «allen Mut» zusammengenommen habe, um die Oberin anlässlich deren Arbeitsanweisung trotz Genesungsbedarf nochmals auf das vorliegende ärztliche Zeugnis aufmerksam zu machen: «Ja, aber der Arzt hat gesagt, ich dürfe noch nicht schaffen, ich müsse zuerst kuren gehen». ${ }^{277}$

Gehorsam leisteten die Schwestern auch bei klosterinternen, meist traditionell bedingten Ritualen oder Gepflogenheiten, die durchwegs als «wenig einsichtig» eingestuft wurden, wie insbesondere die «Culpa». Dieses Gefäss des öffentlichen Schuldeingeständnisses diente der Schwesterngemeinschaft als wöchentlich wiederkehrende Möglichkeit, das eigene Verhalten $\mathrm{zu}$ reflektieren und das begangene Unrecht vor dem Kollektiv der Schwesterngemeinschaft darzulegen. Da die Schwestern in der Regel keine grossen Verfehlungen aufzuweisen hatten, mussten sie nach denkbaren Motiven suchen, die sie bei der «Culpa〉 vorbringen konnten. ${ }^{278}$ Sie orientierten sich hier an den Satzungen, die sie hier als Norm einbezogen. In den Erzählungen ist dies der einzige Zusammenhang, in dem sie auf diesen normierten Rahmen Bezug nehmen. Am Schluss des unten exemplarisch aufgeführten Zitats nennt diese Schwester den grundsätzlichen Sinn der 〈Culpa〉, die das gute oder zumindest verträgliche Zusammenleben fördern sollte. Es war somit die Form dieser Einrichtung, die die Schwestern mit Überlegungen wie «ich habe den Wunsch gehabt, Gott ganz zu gehören, sonst hätte man diese «Culpa〉 nicht mitmachen können» überwinden mussten oder infrage stellten. Ein Schuld-

276 Interview 008, Z. 262-266.

277 Interview 010, Z. $146 \mathrm{f}$.

278 Zum Beispiel: Interview 014, Z. 470-473. 
eingeständnis anlässlich einer «Culpa〉 konnte wie das folgende lauten: «Ich habe drei Tritte die Stiege hinaufgenommen oder zwei Tritte, das durfte man nicht. Oder ich bin zu schnell gelaufen. Oder ich habe gelacht. Oder ich habe geschwatzt, als man nicht sollte, und so weiter. Einfach solche Sachen. Und das hat man dann angeklagt. Das war die sogenannte «Culpa». Und als ich Schwester im Beruf war, hatte ich jeweils nicht viel Zeit, mich darauf vorzubereiten und wusste auch nicht was. Dann hörte ich einfach den anderen zu und dachte jeweils «ja, das könnte ich auch noch aufschreiben, das habe ich eigentlich auch gemacht. Das waren Oberflächlichkeiten. Diese Culpa ging dann langsam unter. Mit den Konzilien hat sich vieles geändert und das war gut. Gut, wir wurden zu «Gehorsam» erzogen. Wichtig war, dass man gut arbeitete, dass man sich gut miteinander verstand.» ${ }^{279}$ Bei materiellen Schäden, die während der Arbeitsprozesse auftreten konnten, mussten die Schwestern sich bei der Oberin melden und den Schadensvorgang erzählen: «[...] und dann hat es Scherben gegeben. Man musste halt wieder um Vergebung bitten, bei der höheren Oberin, ich habe Scherben gemacht, obwohl wir ja auch nichts dafür konnten. Aber in Gottes Namen, man hat alles gemacht, alles treu gemacht. $\gg^{280}$

\subsection{Konfessioneller Rahmen: Katholische Kirche als Konstante}

\subsubsection{Geistliche und theologische Inhalte}

Die Institution der katholischen Kirche schienen die Schwestern in Bezug auf die Gesprächsgestaltung als selbstverständlichen Rahmen, in dem sie sich tagtäglich bewegten, vorauszusetzen, ohne diesen in die Erzählungen explizit einzubeziehen. ${ }^{281}$

279 Interview 042, Z. 284-304; Z. 288-298.

280 Interview 046, Z. 47-52.

281 Frühere Forschungen in den Gemeinschaftsarchiven zeigten eine intensive Auseinandersetzung der Gemeinschaften mit den Weisungen des Zweiten Vatikanischen Konzils: Esther Vorburger-Bossart, Ordensschwestern in der Ostschweiz im 20. Jahrhundert, Zürich 2018, 286-316. 
Gesamtkirchliche Ereignisse wie namentlich das Zweite Vatikanische Konzil erwähnten die Schwestern selten. Wenn es in den Erzählungen auftaucht, dann als zeitliche Orientierungsangabe oder als Referenz zur Einschätzung wie «fortschrittlich» in Bezug auf kirchliche Neuerungen entweder man selber oder die einzelne Mitschwester dachte. ${ }^{282}$

Entsprechende Themen, die zentral zum Schnittfeld «klösterliches Leben` und «katholische Kirche` gehören, wie insbesondere die Rolle von Geistlichen bzw. Spiritualen, die Gestaltung von Eucharistiefeiern oder die geistliche Begleitung, sprachen die Schwestern in der freien Erzählung selten an. Auch laufende oder abgeschlossene Seligsprechungsprozesse, der persönliche oder kollektive Umgang mit Priestern oder Bischöfen, auch mit deren Weisungen, sind nur in Einzelfällen Gegenstand der Lebenserzählungen. ${ }^{283}$

Wenige Male berichteten Schwestern im Zusammenhang mit der Berufsausübung als Krankenschwestern über kirchliche Richtlinien, die in der Spitalpraxis bei damals sogenannten «Sterilisationen» oder Unterbindungen für religiöse Schwestern zur Anwendung kamen. Als Ordensschwestern hätten sie klare Weisungen von der Ordensleitung gehabt, bei einer Sterilisation nicht assistieren zu dürfen. «Man hat uns gesagt, wenn sterilisiert wird, dann müssen Sie alles hinschmeissen und vom OP-Tisch weglaufen.» Eine Schwester erzählte, dass sie dadurch in Gewissensnot und in einen Loyalitätskonflikt gegenüber ihren beiden Vorgesetzten geraten sei und sich deswegen an den Bischof wandte. Später sei die Assistenz bei Sterilisationsvorgängen erlaubt gewesen, auch sei man als Schwester von den Ärzten besser in diese Thematik eingeführt worden. Damit hätten sich die eigenen Zwiespälte verringert. ${ }^{284}$

Eine einzelne Schwester nahm das Thema des Priestermangels auch in den Klostergemeinschaften auf und sprach in diesem Zusammenhang über die künftige Situation. Bei diesem Szenario müsse die religiöse Versorgung aus der Klostergemeinschaft heraus selber gewährleistet werden, auch wenn unter Umständen nicht nur wenige, sondern eventuell gar keine Priester mehr da sein werden. ${ }^{285}$

282 Interview 014, Z. 617-629.

283 Interview 051, Z. 211-289.

284 Interview 045, Z. 75-86.

285 Interview 043, Z. 479-489. 


\subsubsection{Frömmigkeit und religiöse Praxis}

Analog zur Frage, wie Religiosität innerhalb des regulierten und gemeinschaftlichen Lebens gestaltet wurde, gibt es auch zur persönlich gelebten Frömmigkeit oder zum Gebrauch religiöser Symbole kaum Ausführungen in den Erzählungen. So führte eine einzelne Schwester den persönlichen Bezug zur Religiosität explizit aus: «Das Religiöse, das machte mir Freude und im Kloster hat mir vor allem so der Umgang mit der Bibel, mit dem Franziskanischen entsprochen. Das waren für mich grosse Entdeckungen.» ${ }^{286}$

Eine weitere Schilderung zu diesem Thema betraf die Nachkriegszeit und gibt Einblick in das Bedürfnis einer Schwester, «ein bisschen fromm sein zu dürfen». Sie erzählt davon, «wie glücklich» sie aus grösster materieller Not heraus im Noviziat mit anderen Novizinnen zusammen war. Als Novizinnen hätten sie sich auf dem Estrich getroffen und dort mit einem kleinem Taschentuch und einem Maiskolben anstelle von Altartuch und Kerzen Andachtsfrömmigkeit gelebt. ${ }^{287}$

Eine zweite Schwester berichtete vom Erlebnis der «Ewigen Andacht» zu Beginn ihres Noviziats. "Als ich im Kloster war, hat es mich immer wieder in die Kirche gezogen, immer wieder. Zu meinem «Gspane` habe ich gesagt: $\backslash \mathrm{Du}$, ich möchte so gerne auch in der Nacht in die Anbetungsstundes. Damals hatten sie noch in der Nacht Anbetungsstunde, die ganze Nacht durch. Wir mussten dann allerdings schon um 21.00 Uhr in die Anbetungsstunde, also nicht später, nicht in der Nacht. Aber trotzdem, es gefiel uns einfach. Und dann gingen dann jeweils so ein paar Schülerinnen miteinander in diese Anbetungsstunden. Auf alle Fälle zog es mich enorm an.»288

Erzählpassagen zu religiös motivierten Handlungen aus jüngster Zeit gibt es ebenfalls selten. Eine einzelne diesbezügliche Erzählung widmet sich einem Türmchen eines früher von Schwestern geführten Kindergartens, dessen Glocke seit 1944 dreimal pro Tag das Angelus-Gebet läutete. Beim Abbruch des Kindergartens vor ein paar Jahren habe die Schwesterngemeinschaft das Türmchen heruntergeholt und in andere Bestimmung überführt. ${ }^{289}$

286 Interview 051, Z. 43-46.

287 Interview 048, Z. 111-127.

288 Interview 042, Z. 131-140.

289 Interview 047, Z. 267-277. 
Eine weitere Schwester machte sich darüber Gedanken, «wohin heute die religiöse Ausstrahlung nach aussen durch die immer kleiner werdende Gemeinschaft noch gehen könne?» Sie ist der Überzeugung, dass «es trotz der verkleinerten Gemeinschaft und trotz veränderter Auffassung von Frömmigkeit möglich sein sollte, den «Gründergeist` [die geistlich-religiöse Ausrichtung des Gründers der Gemeinschaft] auch heute weiterzugeben». ${ }^{290}$

\subsection{Professioneller Rahmen: Berufung und Profession}

\subsubsection{Erzählungen zur Berufung}

Die Berufung, ins Kloster oder in eine klösterliche Gemeinschaft einzutreten und damit in der Nachfolge Christi zu leben, hatte für Schwestern der Blütezeit der Kongregationsgemeinschaften zwischen 1940 und 1965 eng mit beruflichen Vorstellungen zu tun. Da es sich bei den untersuchten Frauengemeinschaften um tätige Orden oder um religiöse Vereine mit definierten beruflichen Tätigkeitsfeldern handelte, stand bei den hier eingetretenen Schwestern der Wunsch, eine Tätigkeit im sozialen Bereich zu erfüllen oft im Vordergrund, um so «Gott und den Menschen» zu dienen. Die Verbindung eines karitativen Berufsauftrags mit dem Leben in einer religiösen Gemeinschaft empfanden viele als sinnvoll. Der Impuls in ein Kloster einzutreten, trat für Schwestern dieser Generation oft über den Vorbildstatus geistlicher Schwestern aus ihrem verwandtschaftlichen oder ersten geografischen Umfeld heraus an sie heran. Entsprechend setzen die meisten Respondentinnen den Zeitpunkt ihrer Entscheidung zum Klostereintritt in der Kindheit oder frühen Adoleszenzphase an. Die Eintritte in die religiösen Gemeinschaften erfolgten dementsprechend in dieser Zeitspanne in der Regel fast gleichzeitig oder wenige Jahre nach dem Entscheid für ein klösterliches Leben im frühesten Erwachsenenalter. Somit traten Frauen bis zur Mitte des 20. Jahrhunderts in sehr jungen Jahren in die Klostergemeinschaften ein. Nicht selten bedeutete der Eintritt ins Kloster gleichzeitig den nahtlosen Übertritt von der Herkunftsfamilie in 
die Klostergemeinschaft. Das Eintrittsalter war bei den um 1940 bis 1950 eingetretenen Frauen mit durchschnittlich 18 Jahren sehr tief. ${ }^{291}$

Die Schwestern beschreiben nach dem Aufkommen solcher Absichten eines Kloster-Eintritts vielfach die Reaktion der Eltern, die häufig verhalten bis abwehrend war. Die Eltern rieten der Tochter, den Klosterwunsch nochmals gut zu überlegen. ${ }^{292}$ Auch solle sie zuvor einen Aufenthalt «in der Welt draussen machen». ${ }^{293}$ Mehrere Schwestern erzählten, dass sie selber genau gewusst hätten, entgegen dem Willen der Eltern, dass sie ins Kloster eintreten wollten. ${ }^{294}$ Aus familiären Gründen, etwa anlässlich des Todesfalls eines Elternteils kurz vor dem geplanten Klostereintritt, sah sich die eine oder andere Schwester veranlasst, den Klostereintritt zu verschieben, ohne den Entschluss zu einem Klostereintritt deswegen zu ändern. Innerhalb der Familie wurde in diesen Fällen der jungen Frau mitunter angeraten, die Stelle des verstorbenen Elternteils zu übernehmen, was aber keine der erzählenden Schwestern auf Dauer beherzigte: «Wenn das in der Familie wieder in Ordnung kommt, gehe ich dann ins Kloster». ${ }^{295}$

Eine weitere, eher selten erzählte Hürde, die es vor einem eigentlich bereits geplanten Klostereintritt zu überwinden galt, war eine sogenannte «Bekanntschaft», die sich in den Erzählungen ausschliesslich von Seiten der jungen Männer anbahnte. Im Gebet, in dem die angehenden Schwestern um den richtigen Weg beteten, spürten sie jedoch klare Zeichen, dass der «Herrgott» sie «nicht in der Ehe, sondern im Kloster wollte». ${ }^{296}$ Eine Schwester berichtete von einem jungen Mann aus ihrem damaligen sozialen Umfeld, der «um eine gute Frau» betete. Seine Wahl fiel im Anschluss daran auf die Erzählerin, die hingegen bereits fest entschlossen war, ins Kloster einzutreten. ${ }^{297}$

Ein Erzähltopos um die Berufung zu einem Klostereintritt, der praktisch in allen hier aufgenommenen Erzählungen vorkommt, wurde meis-

291 Gemeinschaftsarchive von Baldegg, Basel, Cham, Ilanz, Ingenbohl, Luzern, Menzingen, Niederuzwil, Biografische Daten von Schwestern, SNF-Projekt «Lebensgeschichten religiöser Frauen in der Schweiz» 2015-2018.

292 Zum Beispiel: Interview 013, Z. 83-85; Interview 006, Z. 40-45.

293 Zum Beispiel: Interview 010, Z. 34-41.

294 Zum Beispiel: Interview 050, Z. 52-70.

295 Interview 014, $34 \mathrm{f}$.

296 Zum Beispiel: Interviews 025, Z. 194-196; Interview 010, Z. 59-63; Interview 016, Z. 74-79.

297 Interview 046, Z. 6-14. 
tens als eigentliches «Berufungserlebnis» bezeichnet, obwohl es sich bei den vor 1965 Eingetretenen in den Lebensschilderungen oft nicht ausschliesslich um einen tieferen spirituellen Verlauf handelte. Inwiefern ging es bei einem sognannten «Berufungserlebnis» um den eigenen aktiv erzeugten Wunsch und inwiefern war es die 〈Stimme Gottes〉, welche die Schwester hörte oder als solche interpretierte? Wenige Schwestern erwähnten von sich aus, dass es sich mit diesem Zugang zu einem klösterlichen Leben um «keine eigentlichen Berufungsgeschichten», sondern um einen durch «eine katholisch geprägte Kindheit vorgezeichneten Weg» handelte..$^{298}$

Die Ausstrahlung eines Lebens als tätige Ordensfrau, die insbesondere durch das gesellschaftliche Ansehen und die Bedeutung der religiösen Frauengemeinschaften zu einer positiven Identität führte, übte einen grossen Einfluss aus auf die jungen Mädchen. Ein zentraler Faktor innerhalb der Entscheide zu einem tätigen Ordensleben war die Möglichkeit einer Berufsausbildung, die sich den jungen Frauen aus ländlichen Gebieten meist ausschliesslich im Kloster bot. Oft hatten diese vor dem Klostereintritt nur die Primarschule absolvieren können. ${ }^{299}$ In diesem Sinn beschrieben viele Schwestern ihren Eintritt in eine religiöse Gemeinschaft im Zusammenhang mit dem Motiv der Berufssuche in allen Details. ${ }^{300}$

Die Zugänge in diesen erzählten «Berufungsgeschichten` für ein Leben im Kloster oder in einer religiösen Gemeinschaft vor 1965 lassen sich grundsätzlich in drei Gruppen einteilen:

Nebst der konstant in allen Erzählungen konstruierten Koppelung des Berufswunsches mit dem Klostereintritt, bildete das erwähnte positive Vorbild von bereits aus dem Umfeld bekannten eingekleideten Schwestern die weitaus häufigste erwähnte Motivation. Die Werbung für ein Leben im Kloster über verwandtschaftlich verbundene oder ortsansässige Geistliche wurde in den Erzählungen dagegen selten erwähnt. In nur wenigen Fällen stiessen die hier befragten Schwestern über eine Empfehlung eines Inserats in einschlägigen katholischen Zeitschriften auf eine Klostergemeinschaft.

298 Zum Beispiel: Interviews 052, Z. 68-84; 037, Z. 16-18.

299 Gemeinschaftsarchive von Baldegg, Basel, Cham, Ilanz, Ingenbohl, Luzern, Menzingen, Niederuzwil, Biografische Daten von Schwestern, SNF-Projekt «Lebensgeschichten religiöser Frauen in der Schweiz» 2015-2018.

300 Zum Beispiel: Interview 040, Z. 110-172. 
Wie gestaltete sich der Zugang über die Vorbildfunktion bereits eingekleideter Schwestern? Die meisten Erzählungen handeln vom damals üblichen sozialen engeren Umfeld in Kirche, Familie und Pfarrei, wo geistliche Schwestern den Mädchen oder jungen Frauen in verschiedenen Funktionen begegneten: «Schon [...] in der Pfarrei habe ich mehrere Bänke Klosterfrauen gesehen [...] Mir hat das sehr Eindruck gemacht, miteinander, in einer Gemeinschaft für ein gemeinsames Werk zu arbeiten. ${ }^{301}$ Oder man war als junge Frau beeindruckt, wie Schwestern am Wohnort gemeinsam gebetet hatten. Dadurch wurde der eigene Lebensweg massgeblich vorgezeichnet. ${ }^{302}$ Eine andere Schwester hatte als Kind in der Nähe eines Klosters gewohnt und erzählte, dass sie durch eine bekannte Schwester ermuntert worden sei, «doch ins Kloster zu kommen». ${ }^{303}$ Auch kamen über bereits bestehende Kontakte aktive Werbungen durch die «Schwester Oberin» vor, welche die Erzählerin «durch mehrere Zuschriften ermunterte, in das Kloster einzutreten». ${ }^{304}$

Eine weitere Schwester durfte als Kind bei der nahegelegenen Schwesterngemeinschaft Brot holen und sei von daher mit dem Alltag der Schwestern schon in der Kindheit vertraut gewesen. ${ }^{305}$

In den meisten Familien der erzählenden Schwestern hatte es unter den männlichen Verwandten Priester oder Patres sowie unter den weiblichen Familienmitgliedern eine oder mehrere Ordensschwestern, die einen möglichen Klostereintritt beeinflussen konnten. ${ }^{306}$ Ein weiterer Zugang gestaltete sich über verschiedene Kontakte der Eltern zu Klostergemeinschaften, etwa über Unterstützungsleistungen an Missionsgesellschaften. ${ }^{307}$

Mehrere Zugänge zum Klosterleben eröffneten sich den jungen Frauen, wenn sie Ordensfrauen an deren Wirkungsstätten während der Ausübung ihrer Berufstätigkeiten erlebten, v.a. als Lehr- oder Spitalschwestern. ${ }^{308}$ Im Lehrerinnenseminar imponierte den Seminaristinnen, wie die Schwestern zusammen arbeiteten. Nicht selten liess diese beruf-

301 Interview 020, Z. 23-31.

302 Interview 045 , Z. 15-19.

303 U.v. a.: Interviews 008, Z. 120-125; 013, Z. 80-83; 032, Z. 26-28. Interview 032, Z. 26-28.

304 Interview 039, Z. 62-75.

305 Interviews 033, Z. 94-100; 046, Z. 16-19.

306 Zum Beispiel: Interview 025, Z. 155-160.

307 Interview 013, Z. $15 \mathrm{f}$.

308 Interview 010, Z. 16-30. 
liche Vorbildfunktion in den jungen Frauen den Entschluss reifen, auch Schwester zu werden. ${ }^{309}$ Immer wieder erzählten Schwestern von «Schwärmereien», die sie für ihre Lehrschwestern während der Seminarzeit empfunden hätten. Sie fühlten sich vom Vorbild der Schwestern angezogen. Es habe ihnen damit «den Ärmel hineingenommen», um selber Lehrschwester zu werden. ${ }^{310}$ Als Gründe hierzu nennen die Respondentinnen die vorgelebte tiefe Religiosität unter den Lehrschwestern, die in ihnen den Wunsch wach werden liess, selber ähnliche, über den gewöhnlichen Gottesdienstbesuch hinaus gehende religiöse Elemente in ihren Alltag einzubauen, wie die nächtliche Anbetungsstunde. ${ }^{311}$ Die Schilderungen zu dieser durch Schwestern gestalteten Religiosität konnten eine ähnliche Intensität annehmen wie die Motivdarlegungen zum Berufswunsch: «Dann war ich das erste Mal in dieser Klosterkirche und anschliessend gingen wir noch auf den Friedhof und so. Und dann in diesen Exerzitien wurde mir klar, das ist dein Weg. Und auch klar hier, und nicht an einem anderen Ort». ${ }^{312}$ Dieses Zitat zeigt, dass neben der praktizierten Frömmigkeit der Schwestern auch die Wahl des Klosterortes vielfach mit den persönlichen Erlebnissen in der Kindheit oder Jugendzeit verbunden war. Die aktive Werbung seitens der Lehrschwestern im Seminar kam vor 1965 noch öfter und aufgrund des damals noch offener praktizierten religiösen Lebens offensiver vor: «[...] und dann im dritten Jahr vom Seminar, und auch die Schwestern, die warben damals noch für Nachwuchs. Nachher ging das einfach auch langsam zurück. Sie warben weniger, eigenartig. Und dann sagten die auch immer wieder «Du wärst jetzt eine für das Kloster. Du würdest für das Kloster passen, komm zu uns ins Kloster >.» ${ }^{313}$

Eine weitere Gruppe von Lebenserzählungen enthält das Motiv zum Entschluss eines Klostereintritts, das als eigentliches «Berufungsereignis〉 bezeichnet werden kann. In diesen Narrativen war weder ein Vorbild noch eine aktive Werbung von aussen, auch nicht der eigene Wunsch $\mathrm{zu}$ einem klösterlichen Leben entscheidend, sondern der «Ruf oder die Anfrage Gottes»: Diese «Berufungsereignisse` durch Gott gaben die Respondentinnen wie folgt wieder: «Der Ruf Gottes liess mich nicht mehr

309 Interview 051, Z. 15-18.

310 Interview 037, Z. 14-18.

311 Zum Beispiel: Interviews 027, Z. 134-140; 001, Z. 21-23.

312 Interview 031, Z. 189-192.

313 Interview 042, Z. 168-171. 
los.» ${ }^{314}$, «Ich habe gespürt, dass da eine Anfrage von Gott ist, dieser wollte ich entsprechen». ${ }^{315}$ Weitere Erzählungen enthalten zusätzlich die Angabe des religiösen Ortes, an dem die 〈Berufung〉 erfolgte: «Ich bin nach Lourdes gegangen und habe nicht gewusst, ob ich ins Kloster soll, doch dann kam die Eingebung Gottes.» ${ }^{316}$ "Als Praktikantin arbeitete ich in einem Schwestern-Betrieb. In der Kapelle habe ich den Ruf Gottes gehört.» ${ }^{317}$ Die tiefe Gottesbeziehung der Kindheit wurde in weiteren Narrativen auch aus der Retrospektive im Alter mitunter noch als inniges kindliches religiöses Erlebnis für den Zugang zu einem Leben im Kloster erzählt: «Das ist bei mir bei der Erstkommunion klar gewesen, ich will etwas Schönes tun für «de Liebgott». ${ }^{318}$ Der klösterliche Lebensentwurf bot für Schwestern dieser Generation mit Klostereintritten vor 1965 auch Projektionsflächen und Sublimierungsmöglichkeiten, die parallele Entwürfe zu einem weltlichen Leben boten: «Ich bin mit sehr viel Freude eingetreten. das ist für mich wirklich, ja ist ein wenig Hochzeit gewesen. Ich hätte nicht auf die Profess warten müssen. Es ist für mich klar gewesen, dahin gehöre ich und das ist mein Lebensweg.»119

Diese beinahe durchwegs als positive Erlebnisse begeistert und emphatisch erzählten Zugänge zu einem klösterlichen Lebensentwurf, die eine klare Absicht beinhalten, ins Kloster eintreten zu wollen, wurden als narrative Einheit und als linearen Lebensabschnitt dargelegt. Meist waren sie an den wiederkehrenden Erzähltopos gekoppelt, «bereits schon früh gewusst zu haben, ins Kloster eintreten zu wollen». ${ }^{320}$ In manchen Fällen gaben die Schwestern den genauen Zeitpunkt an, der ihnen den Weg ins Kloster wies: «Ich habe klar gewusst, ich möchte ins Kloster, seit ich 17 war.» ${ }^{321}$

Daneben kamen unter diesen Erzählfeldern in einzelnen Fällen auch nicht lineare Zugänge vor, die entweder einen aufgekommenen Klosterwunsch wieder zurücktreten liessen oder vorübergehende Zweifel am Vorhaben eines Klostereintritts aufzeigen. ${ }^{322}$ In diesen Erzählungen leg-

314 Interview 012, Z. 226.

315 Interview 021, Z. 236-240; Z. 261-263.

316 Interview 004, Z. 74-82.

317 Interview 005, Z. 16-27.

318 Interview 003, Z. $19 \mathrm{f}$.

319 Interview 003, Z. 69-72.

320 Zum Beispiel: Interview 029, Z. 31-35.

321 Interview 011, Z. 17-20.

322 Interview 014, Z. 46-64. 
ten die Schwestern den Zugang zum Kloster nicht als eigentliches kompaktes und vorgezeichnetes «Berufungsereignis» dar, sondern als Prozess, der Ungewissheit und Unklarheiten beinhaltete, die dennoch positiv konnotiert waren: «[...] hat es andere gehabt, die auch so ein wenig spekuliert haben, da einmal in ein Kloster zu gehen und wir sind so vier gewesen, die uns immer so ein wenig, aber nicht, dass ich so eine Berufung gehabt hätte oder ich hätte sagen können.» ${ }^{323}$ Einzelne Schwestern erzählten, dass sie viele Klostergemeinschaften aufgesucht hätten, bis sie die richtige gefunden hätten. ${ }^{324}$ In anderen, ebenfalls selten erzählten Fällen konnte es ein «schlechtes Vorbild einer Schwester» sein, das davon abgehalten hatte, in dasselbe Kloster, sondern in ein andere Gemeinschaft einzutreten: «Denn ich hatte von dort eine Klassenlehrerin gar nicht eine Gute gehabt [...].»25

Nur in Ansätzen kamen in einzelnen Erzählungen kritische Äusserungen vor: «Meine Mutter hatte eine Schwester, die auch Ordensfrau war. [...] Und von daher haben wir gewusst, dass es, dass es auch menschlich zu und her geht, [...], doch habe ich gespürt und vor allem auch in der Pfarrei drinnen, ich habe gespürt, ich muss zuerst meiner Sache ganz sicher sein. $\gg^{326}$ Ein weiteres Zitat illustriert den im letzten Teil des vorangehenden Zitats geäusserten Findungsprozess. Es handelt sich hier um einen Erzählpassus, der innerhalb des Klosterwunsches wohl klare Absichten impliziert, aber die Umsetzung dieses Vorhabens noch nicht konkret geäussert wird: «So eine möcht ich auch noch werden. Und die hat von einem lieben Gott erzählt. So eine möchte ich werden. Und dann ist das aber verflogen. Dann habe ich irgendwie ja nichts mehr gewusst vom dem. Oder man vergisst. Und dann ist bei der Erstkommunion, also als wir dann Kommunion gehabt haben, dann ist mir wieder der Gedanke, der Kloster-Gedanke gekommen». ${ }^{327}$

Vereinzelte Schwestern erzählen vom Mut, den sie vor dem Klostereintritt gebraucht hätten. Zentral war bei diesen Zugängen das diese Entscheidungsfindung begleitende Gebet: «Ein Unfall hat mich vier Wochen ins Spital gebracht. Dort hatte ich viele Kontakte mit den pflegenden Schwestern des benachbarten Klosters. Ist das ein Zeichen? «Der Geist,

323 Interview 018, Z. 82-85.

324 Interview 013, Z. $71 \mathrm{f}$.

325 Interview 025, Z. 262-268.

326 Interview 006, Z. 7-14.

327 Interview 015, Z. 106-111. 
der in euch wirkt, ist mächtiger, als der Geist, der die Welt regiert, Johannes 4). Mit viel Gebet und Muttergottesbesuchen bei der Grotte bekam ich den Mut, mich an der Klosterpforte zu melden.» ${ }^{328}$

$\mathrm{Zu}$ diesen personell und institutionell geprägten Zugängen gehörte auch die Empfehlung des klösterlichen Lebensentwurfs durch Geistliche, die in den hier untersuchten Lebenserzählungen entgegen der aufgrund hierarchischer Strukturen anderslautenden Annahmen relativ selten zum Zug kam. Es liegen nur wenige Berichte von Schwestern zur aktiven Werbung des Ortspfarrers unter jungen Mädchen der Heimatpfarrei vor. ${ }^{329}$ In diesen Narrativen wird der Zugang über einen Priester als positive Begleitung umschrieben. ${ }^{330}$

Der dritte, ebenfalls nur selten erwähnte Zugang zu einem Leben im Kloster geschah über Inserate in einschlägigen Zeitschriften, die in katholischen Institutionen auflagen oder vielfach als Abonnemente in den katholischen Familien zirkulierten. Die Zeitschrift «Unsere Führerin» war zwischen 1945 und 1964 als Organ der Marianischen Jungfrauen-Kongregationen die prägende Zeitschrift für junge katholische Frauen. Dort erschienen regelmässig Anzeigen verschiedener Klostergemeinschaften, die für ein Leben im Kloster warben. Hin und wieder half diese Zeitschrift, sich nach dem Entschluss für ein Leben in einem Kloster, für eine bestimmte Gemeinschaft zu entscheiden. So habe man die «Führerin» durchgeblättert und sich aufgrund eines ansprechenden Inserats für einen bestimmten Klosterort entscheiden können. ${ }^{331}$

Ausführungen zur Gewissheit, nach der «Berufung» mit dem vollzogenen Klostereintritt das «Richtige» getan zu haben, erfolgen in nahezu allen Lebenserzählungen dieser Gruppe von Schwestern mit Jahrgängen zwischen 1925 und 1950. Entsprechende Erzähltopoi wie «man würde diesen Weg nochmals wählen» kommen ebenfalls sehr häufig vor. Entsprechend zahlreich sind Äusserungen wie die folgenden, die eventuelle Zweifel ausser Acht lassen und stattdessen Geborgenheits- oder Heimatgefühle beinhalten: «Ich habe keinen Moment gedacht, als ich eingetreten war, es sei der falsche Weg». ${ }^{332}$ «Und als ich über die Klosterschwelle getre-

328 Interview 009, Z. 17-24.

329 Zum Beispiel: Interview 011, 15-20.

330 Interview 030, Z. 55-65.

331 Zum Beispiel: Interviews 003, Z. 55 f.; 014, Z. 85 f.

332 Interview 029, Z. $103 \mathrm{f}$. 
ten bin, habe ich den Eindruck gehabt, jetzt bin daheim». ${ }^{333}$ Das begeisterte Moment des im frühen Lebensalter getroffenen Entscheids zu einem Klostereintritt schwang beinahe in sämtlichen Lebenserzählungen der Respondentinnen noch im Alter oben auf.

In diesem Erzählfeld zur Erörterung der Richtigkeit des Klosterentscheids in jungen Jahren wird die Frage nach der Absicherung des Lebensunterhalts besonders in der aktuellen Situation des letzten Lebensabschnitts geäussert. Die Schwestern erzählen in diesem Zusammenhang nur nebenbei oder hin und wieder, dass es zwar innerhalb einer Gemeinschaft auch zwischenmenschliche Schwierigkeiten gebe, dass aber das soziale und materielle Sicherheitsgefühl, das die Klostergemeinschaft vermittle, weitaus überwiege. Dabei kommt die für diese Schwesterngeneration typische Ausrichtung auf das kollektive Leben zum Tragen, die grundlegend für die Funktionsfähigkeit des kongregationellen Schwesternmodells war. ${ }^{334}$ Dass die «Berufung als Wandel, für die man sich immer wieder neu entscheiden muss» ${ }^{335}$ begriffen wird, kommt in den Erzählungen eher selten vor.

Im Vergleich mit den Narrativen nachfolgender Generationen zeigt diese Analyse aus quantitativer und qualitativer Sicht, dass die Motivation zu einem Klostereintritt durch das religiöse Verständnis des jeweiligen Zeitabschnitts geprägt wurde. Die Frage eines Klosterentscheids wird damit zur Generationenfrage. In Bezug auf die Zugänge nach dem Konzil kann aufgrund der Erzählungen von Schwestern, die nach 1965 eingetreten sind, zusammengefasst gesagt werden, dass diese Entscheidungen nicht mehr massgeblich aus beruflichen, sondern mehrheitlich aus spirituellen Gründen erfolgten. Diese jüngeren Schwestern mit Jahrgängen nach 1950 brachten bei Klostereintritt bereits eine berufliche Ausbildung mit. Sie entschieden sich kaum mehr aufgrund von vorbildlichen Personen oder Institutionen für ein gemeinschaftliches religiöses Leben, sondern wegen der spirituellen Lebensausrichtung oder der persönlichen 〈Gottsuche〉. Diese war neu stärker an die Sinnfrage gekoppelt: «Weshalb bin ich im Kloster, wieweit hängt das von Personen ab? Oder bin ich wegen eines grösseren Ganzen da?» ${ }^{336}$ So sprachen Schwestern dieser Generation nicht mehr von «Frömmigkeit» bzw. 〈Religiosität` oder vom

333 Interview 016, Z. 112-114.

334 Interview 014, Z. 535-548.

335 Interview 001, Z. 462-467.

336 Interview 028, Z. 106-113. 
gemeinsamen Stundengebet als zentrale Inhalte eines klösterlichen Lebens, sondern von 〈Spiritualität), die sie bewusst in einer religiösen Frauengemeinschaft suchten. ${ }^{337}$ In diesen Lebensentwürfen legten die Schwestern die Inhalte einer in beiden Generationen vorkommenden «Sehnsucht nach Gott» nun konkret dar bzw. benannten diese explizit. Manchmal wurden diese von den jüngeren Schwestern auch breiter ausgefaltet. «Ich hatte Sehnsucht nach einem religiösen Leben, das ich aber nicht allein in der Welt führen kann, wo ich eine Gemeinschaft brauche. Und ich hatte auch den Wunsch, etwas mehr für die Kirche zu tun. Und das aber eben auf der spirituellen Ebene.» ${ }^{338}$

\subsubsection{Berufung als Profession?}

Die Verbindung von Beruf und Religion brachte dank den weiblichen Kongregationsgemeinschaften für die Zeit ab Ende des 19. Jahrhunderts bis in die 1990er Jahre hinein ungewöhnliche weibliche Karriereverläufe mit sich. Die nicht wegen Mutterschaft unterbrochenen und oft auch nicht im Pensionsalter beendeten beruflichen Lebensläufe von geistlichen Schwestern, die somit über fünfzig bis sechzig Jahre dauern konnten, unterscheiden sich stark von den damals üblichen weiblichen Biografien, wo in der Regel die Berufstätigkeit nur über wenige Jahre wahrgenommen wurde. ${ }^{339}$ Ferner wurde die Aneignung von Professionalität grundsätzlich von der Klostergemeinschaft gewährleistet, dies ebenfalls oft im Unterschied zu den Bildungsmöglichkeiten für Frauen ausserhalb der Klöster während den ersten Zweidritteln des 20. Jahrhunderts. Für die Mehrheit der Schwestern, die vor dem Konzil eintraten, war die Ausübung eines Berufs ein wichtiger Teil ihrer «Berufung〉, wofür die tätigen religiösen Gemeinschaften in dieser für Frauen im weltlichen Bereich eher bildungsfeindlichen Zeit einen idealen Rahmen boten. Darüber hinaus konnte die Zugehörigkeit zu einer Klostergemeinschaft für Katholikinnen - auch für Frauen aus materiell ärmlichen oder bildungsfernen Verhältnissen - für

337 Interview 035, Z. 30-32.

338 Interview 002, Z. 61-67.

339 Dies analog zu den Diakonissen: Cordula Lissner, «Alles konnten wir Ihnen natürlich nicht erzählen», in: Jochen-Christoph Kaiser/Rajah Scheepers (Hg.), Dienerinnen des Herrn. Beiträge zur weiblichen Diakonie im 19. und 20. Jahrhundert, Leipzig 2010, $98 \mathrm{f}$. 
diese Zeit ungewohnte Berufs- und Führungschancen eröffnen. So erzählten Schwestern in ihren Lebensdarstellungen von Aufstiegsmöglichkeiten, die sich ihnen, mitunter auch als angelernte Hilfskräfte im Kloster boten, obwohl man sich eine höhere Bildung, etwa das Lehrerinnenseminar zu absolvieren, «fast nicht zugetraut» habe. ${ }^{340}$ Eine weitere Schwester spricht davon, dass sie über ihre 〈Berufung〉 in verschiedene verantwortungsvolle Ämter bis zur Generaloberin «hineingerutscht» sei, obwohl sie ohne Sekundarschulbildung ins Kloster eingetreten sei. ${ }^{341}$ Eine Generaloberin einer weiblichen Kongregation war eine Managerin eines Grossbetriebs und hatte je nach Grösse der Klostergemeinschaft die spirituelle, strukturelle und personelle Verantwortung über bis zu mehreren Hundert Schwestern zu tragen.

Entsprechend diesen häufig vorkommenden bildungsferneren Voraussetzungen im soziodemografischen Umfeld der jungen Katholikinnen vor deren Klostereintritt konnten diese Schwestern indessen seltener mit verantwortungsvollen Leitungsfunktionen innerhalb der Gemeinschaft betraut werden. Erst die zugespitzte Personalknappheit ab den 1970er Jahren öffnete diese Zweiteilung, indem Posten mit kleineren Führungsverantwortlichkeiten auch Schwestern übertragen wurden, die keine Möglichkeit einer höheren Bildung erhalten hatten oder deren persönliche Voraussetzungen sich nicht für die klösterlichen Führungsebenen eignete.

Einzelne Schwestern bezeichneten diese Prozesse, insbesondere in vorkonziliarer Zeit, bewusst als «Frauenförderung, die man selber erlebt habe». Die entsprechende Wahrnehmung lautete dahingehend, dass «jemand anders sich das fast hätte erkämpfen müssen und im Kloster habe sich das ergeben». Das sei der «Verbindung von Ordensleben und Beruf und umgekehrt zu verdanken». ${ }^{342}$

Wie verortete die durchschnittliche Schwester ihre berufliche Identität als Mitglied einer religiösen Gemeinschaft? Gab es eine gegenseitige Beeinflussung zwischen den beiden Feldern?

Zur Verbindung oder auch zur gegenseitigen Beeinflussung von Religion und Beruf, die sich zunächst augenfällig in zahlreichen von Schwestern initiierten Ritualen zeigte, erzählten die Schwestern nicht von sich aus, erst auf Nachfrage der Interviewerin im dritten Teil der narrativen Interviews. So nannten sie zu diesem Thema etwa das durch die Schwes-

340 Interview 008, Z. 242 f.

341 Interview 014, Z. 239-250.

342 Interview 002, Z. 112-119. 
tern mitgestaltete Taufritual von Neugeborenen direkt im Spital, unmittelbar nach der Geburt, oder das sogenannte «Aussegnen der Mütter» nach Ende des Wochenbettes, um nach religiöser Auffassung den «Reinheitszustand der Wöchnerin» wiederherzustellen. Eine weitere religiöse Handlung betraf die Vorbereitung der katholischen Patientinnen und Patienten für die Verteilung zur Verteilung der täglichen heiligen Kommunion durch den Spital-Geistlichen oder die Pflege der Weihwassergefässe, die in jedem Spitalzimmer beim Eingang angebracht waren. ${ }^{343}$ Eine Lehrschwester erzählte, dass sie jeweils während der schriftlichen Prüfungen für ihre Schülerinnen gebetet habe. ${ }^{344}$ Eine weitere Beeinflussung von Religion auf die Berufstätigkeit zeigte sich vorab in der Spitalpraxis, wenn es um die in einem anderen Zusammenhang bereits erwähnte Verhütungspraxis ging. Als Angehörige einer religiösen Schwesterngemeinschaft durften die Schwestern keiner Sterilisation assistieren. Es wurde ihnen aufgetragen, bei einer anstehenden Unterbindung, «den Operationstisch umgehend zu verlassen», was mehreren Schwestern während des Erzählvorgangs in detailreicher Erinnerung präsent war. ${ }^{345}$

Von sich aus äusserten die Schwestern zu diesem Themenfeld hauptsächlich eher ihre (unerfüllten) Erwartungen an das Kloster, das sie neben der beruflichen Seite auch als religiöse Gemeinschaft wählten. Vielfach wurde hier angeführt, dass der Schwesternalltag mehr Zeit für das regelmässige Gebetsleben hätte bereithalten müssen, was wegen der häufig sehr strengen und langen Arbeitszeiten, besonders in der Heimerziehung und im Gesundheitswesen nicht immer möglich war. ${ }^{346}$ Immer wieder ist gar von einer «sehr hohen Arbeitsbelastung» in den Spitälern die Rede. Das religiöse Gemeinschaftsleben habe oft darunter gelitten. ${ }^{347}$ Viele Beschreibungen lauten dahingehend, wie sehr intensiv und strapazierend die Arbeit als Krankenschwester war, mit zusätzlichen Diensten in der Nacht, der dazugehörigen ständigen Abrufbereitschaft und unregelmässigem Essen. Auch der Tagesbetrieb begann im Spitalalltag für die Schwestern nicht selten bereits um fünf Uhr, da die Schwestern vor Arbeitsbeginn «die heilige Messe besuchten sowie die Laudes beteten und die

343 Interview 045, Z. 310-406.

344 Interview 025, Z. 426-431.

345 Interview 046, Z. 76-85.

346 Interview 001, Z. $55 \mathrm{f}$.

347 Interview 001, Z. $69 \mathrm{f}$. 
Betrachtung absolvierten». ${ }^{348}$ Diese Erzählsequenzen zur körperlich und auch emotional fordernden Arbeit schlossen die betreffenden Schwestern stets mit einer Äusserung der Zufriedenheit ab, dass man «trotzdem diese Arbeit sehr gerne gemacht habe» und diese Beanspruchung «dem Herrgott» oder «Gott zu lieb» getragen werden konnte. ${ }^{349}$ Dass die berufliche Beanspruchung der im Pflegebereich arbeitenden Schwestern das geistliche Gemeinschaftsleben dominieren konnte, wurde in diesen Erzähltypen dennoch übergeordnet als nicht dem vorgestellten religiösen Ideal entsprechend dargestellt. Das galt ebenfalls für die zweite grössere Berufsgruppe, für die Lehrschwestern, die nebst einem vollen Lehrpensum das reguläre Stundengebet ebenfalls nicht immer zufriedenstellend bewältigen konnten. ${ }^{350}$

Geregelte Arbeitszeiten mit zugesagten freien Tagen und Ferien existierten für geistliche Schwestern bis in die 1970er Jahre, bis zur Anstellung von «Laien» bzw. weltlichen Arbeitskräften in den Schwesternbetrieben oder bis zur Übernahme dieser Betriebe durch die öffentliche Hand oder durch Stiftungen, auch ansatzweise nicht. ${ }^{351}$ Die zunehmende Integration dieser weltlichen Arbeitskräfte habe einige strukturelle Anpassungen gebracht. So erzählten die Schwestern von der Einführung einer Pensionskasse, von Arbeitseinsatzplänen, von Diskussionen zur Berufskleidung oder von einer flacheren Hierarchie bzw. einer basisorientierten Gesprächskultur, die als neue Elemente das Arbeitsleben bestimmten. ${ }^{352}$

Im selben Restrukturierungsprozess von ausserklösterlichen Arbeitskräften wurden ab den 1980er Jahren die Löhne der Schwestern geregelt und teils massiv erhöht bzw. an die Normen der weltlichen Arbeitskräfte angeglichen. Ordensintern wurden nebst den Ferien- und Freizeiten auch die Exerzitien neu geregelt und in den Satzungen verankert. Dass die Arbeitsleistung einer religiösen Schwester der älteren an dieser Untersuchung teilnehmenden Generation kaum oder nur schlecht entschädigt wurde, war ganz selten Gegenstand der Lebenserzählungen. Es gehörte zum Selbstverständnis und zur Identität der tätigen Frauengemeinschaften, für einen «Gotteslohn» zu dienen.

348 Interview 031, Z. 377-380.

349 Interview 040, Z. 231-243.

350 Interview 023, Z. 147-159.

351 Interview 031, Z. $265 \mathrm{f}$.

352 Interview 045, Z. 135-142. 
Die gewünschte Arbeitsverminderung durch die Einführung von ein bis zwei arbeitsfreien Tagen in der Woche konnten weite Kreise der Schwestern nicht ganz einfach umsetzen. Der Umstellungsprozess von einer Siebentagewoche auf einen Wochenablauf mit offiziell kommunizierten arbeitsfreien Tagen konnte Probleme für Schwestern mit sich bringen, die sich gewohnt waren, praktisch lebenslang sieben Tage die Woche zu arbeiten. Diese Schwestern erzählten, dass sie sich lange nicht trauten, sich an den wohl zugesprochenen freien Tagen einfach hinzusetzen und sich auszuruhen. Das widersprach dem Ideal der stets dienstfertigen religiösen Schwester. In diesem Zusammenhang gaben die Schwestern an, noch über Jahre, auch an den arbeitsfreien Tagen, die weisse «Spitalschürze» oder eine sonstige Arbeitsschürze getragen zu haben, die sie sonst nur während der Arbeitszeiten als Arbeitstracht trugen. ${ }^{353}$

Gewisse Arbeitseinheiten wurden bewusst unter dem karitativen Gedanken ausgeführt bzw. in den Lebenserzählungen unter diesem Aspekt hervorgehoben. So konnte die eigene religiöse Haltung etwa die Gestaltung des Spitalalltags über die geregelten Arbeitsleistungen hinaus beeinflussen. In diesem Sinn erzählte eine Schwester, sie habe während ihrer Dienstzeit als Krankenschwester einem mittellosen zugelaufenen Mann erlaubt, sich im Badezimmer des Spitals einmal im Monat ein Bad nehmen zu dürfen. Ebenso luden die Schwestern diesen obdachlosen Mann ein, mit ihnen Weihnachten auf der Abteilung mitzufeiern. Aus ethischen Gründen stellten die Schwestern auch behinderte Menschen in den eigenen Betrieben ein oder boten diesen geeignete Ausbildungsplätze an. In den zahlreichen von Schwestern geführten Alters- oder Pflegeheimen kümmerten sich die Schwestern über die offiziellen Pflegeleistungen hinaus um die älteren oder zu pflegenden Leute, indem sie mit ihnen spielten oder ihnen zuhörten und so manchmal fast buchstäblich «rund um die Uhr» für die Patientinnen da waren. Oft verteilten sie den Pensionären in den Heimen kleine Ämtli oder Arbeiten und integrierten sie so sinnvoll ins Alltagsgeschehen. Die Schwestern legen diese Arbeitshaltung in den Erzählungen als «praktizierte christliche Nächstenliebe» aus. ${ }^{354}$ In diesem Zusammenhang weisen viele Lebenserzählungen von Schwestern eingehende Sequenzen auf, die von der Beziehung der in Kinderheimen tätigen Schwestern zu den ehemaligen betreuten Kindern handeln. Diese «Ehemaligen» hätten sich in vielen Fällen noch nach Jahren regelmässig bei

353 Interview 045, Z. 161-179.

354 Interview 047, Z. 138-209. 
den sie ehemals betreuenden Schwestern gemeldet und so den Kontakt von sich aus gepflegt. Die Schwestern gaben an, dass sie ihrerseits «ihre ehemaligen Kinder» aus den Kinderheimen mit durchwegs sozial ungünstigen Lebenschancen noch lange Zeit nach deren Austritt aus den Heimen, teilweise aber bis heute, begleiteten. ${ }^{355}$

\subsubsection{Kloster als Bildungsort}

Erwähnungen zur eigentlichen Klosterausbildung, die im Noviziat gemacht wurde, kommen in den entsprechenden Erzählsequenzen nur marginal vor oder werden gar nicht erwähnt. Wenn das Noviziat bzw. die eigene klösterliche Einführungs- und Ausbildungszeit genannt wird, dann oft nur in einem Nebensatz, etwa wenn im Erzählfluss nach einer chronologischen Einordnung eines anderen Ereignisses, meist eines mit beruflichem Erzählinhalt gesucht wird, wie «bis zur Einkleidung» oder «nach dem Noviziat kam ich an diese Stelle». ${ }^{356}$ Dies zeigt nochmals die hauptsächliche Ausrichtung des Verständnisses einer beruflich orientierten Identität, wonach Kongregationsgemeinschaften und religiöse Vereine Orte der Vermittlung von Professionalität an Frauen galten, in einer Zeit, da deren Bildungs- und Berufsausübungsmöglichkeiten ausserhalb der Klostergemeinschaften sehr gering waren.

Unterschiede innerhalb der Bildungsauffassung unter den Ordensgemeinschaften wirkten sich im Untersuchungsraum des 20. Jahrhunderts nur noch berufsspezifisch aus und sind allenfalls historisch aus ordensinternen Gründen zwischen den Klöstern zu orten. So sind etwa Dominikanerinnen traditionell eher der theoretischen Bildung und theologischen Auseinandersetzung zugewandt. Die im 19. Jahrhundert gegründeten tätigen Kongregationsgemeinschaften, die u. a. Lehrerinnenseminarien und Gymnasien unterhielten wie Menzingen, Ingenbohl, Baldegg oder Cham, wiesen in der Regel einen höheren Anteil an Schwestern mit Mittel- oder Hochschulbildungen auf. In Gemeinschaften, die für Wöchnerinnen und für private Pflegeeinsätze, auch zur Führung von Heimen gegründet worden waren, wurde den Schwestern schwerpunktmässig medizinische oder erzieherische Ausbildung vermittelt.

355 Zum Beispiel: Interview 048, Z. 235-243.

356 Beispiel einer kurzen Schilderung des Noviziats: Interview 012, 279-285. 
Welche Bildungsmöglichkeiten boten die Gemeinschaften den Schwestern? Für die ersten Zweidrittel des 20. Jahrhunderts war es üblich, den in die jeweiligen Gemeinschaften eingetretenen Schwestern eine Grundausbildung - meistens im pädagogischen oder pflegerischen Bereich - zu ermöglichen. Mit den entsprechenden beruflichen Abschlüssen waren die Schwestern anschliessend befähigt, innerhalb des weitverzweigten Filialnetzes mit klostereigenen Institutionen wie Schulen, Spitäler, ambulante Krankenpflegestationen oder Heime, eine der Stellen zu besetzen. Wurde eine geeignete Schwester nach der Erstausbildung für eine andere Stelle vorgesehen, für die sie weitere Qualifikationen benötigte, wurde sie von den Klosterleitungen an weiterführende Schulen geschickt. Dies war häufig der Fall für Schwestern mit einer Primarschullehrerinnenausbildung, die vom Kloster aus die Gelegenheit erhielten, anschliessend die Sekundarlehrerinnenausbildung zu absolvieren. ${ }^{357}$ Auch für Schwestern anderer Berufssparten waren aufgrund struktureller Veränderungen teilweise zwei Ausbildungen möglich. ${ }^{358}$

Aus Sicht vieler Schwestern wurde im letzten Drittel des 20. Jahrhunderts grundsätzlich dem Bedürfnis nach einer Weiterbildung entsprochen, die nicht immer beruflich oder zweckorientiert ausgerichtet sein musste. Dies war insbesondere der Fall, wenn die Initiative von der Schwester selber kam, unter Umständen waren auch mehrere Weiterbildungen möglich. ${ }^{359}$ Später waren auch sogenannte Auszeiten möglich, besonders nach langen Abschnitten in verantwortungsvollen Leistungsfunktionen, was oft vor der Rückkehr von externen Niederlassungen ins Mutterhaus der Fall war. ${ }^{360}$ Ebenfalls wurden in dieser Zeit vermehrt zusätzliche Ausbildungen seitens der Klosterleitungen bewilligt, etwa wenn eine Schwester für eine bestimmte innerbetriebliche Stelle als geeignet eingestuft wurde wie beispielsweise für die Pflegedienstleitung. ${ }^{361}$ Die Schwestern äussern in den Lebenserzählungen in Bezug auf ihre Bildungsmöglichkeiten Dankbarkeit der Klostergemeinschaft gegenüber. Es sei beachtlich, dass man - vielfach ohne Schulbildung vor dem Klostereintritt - eine solche berufliche Entwicklung habe machen dürfen. Anderseits stuften die Schwestern auch in neuerer Zeit eine Weiterbildung als

357 Interview 050, Z. 75-79.

358 Interview 001, Z. 772-778.

359 Interview 001, Z. 682-709.

360 Interview 026, Z. 204-206.

361 Interview 018, Z. 177. 
nicht selbstverständlich ein oder äusserten sich insbesondere bezüglich Wissensvermehrung im informationstechnologischen Bereich dankbar gegenüber Mitschwestern, die einem gezeigt hätten, wie diese oder jene Fertigkeit zu bewerkstelligen oder die neuen Apparate zu bedienen seien.» ${ }^{362}$ Einzelne jüngere Schwestern hätten sich eine externe Berufsberatung gewünscht. ${ }^{363}$

Die andere Seite ist in den Lebenserzählungen ebenso vertreten. Es gab in allen Gemeinschaften immer wieder Situationen, wo der einzelnen Schwester entweder die gewünschte oder die notwendige Bildung nicht vermittelt werden konnte. Davon zeugen die unerfüllten Berufswünsche, von denen Schwestern erzählen. Schätzungsweise dürften sich diese mit den von den Klöstern ermöglichten Ausbildungen die Waage gehalten haben. Gleichzeitig berichten diese Schwestern vom Verständnis, das sie dieser strukturellen Sachlage gegenüber aufbrachten. Denn aus planerischen oder organisatorischen Gründen konnten die Oberinnen den individuellen Vorstellungen einer einzelnen Schwester nicht immer nachkommen, was wiederum dem kollektiven Grundverständnis der religiösen Gemeinschaften entsprach. Als Hauptgrund muss hier die ununterbrochene externe Nachfrage nach ausgebildeten und einsatzfähigen Schwestern genannt werden, die schweizweit seitens der Behörden oder der Verantwortlichen von sozialen Institutionen für diverse Stellen in Schulen, Heimen, Spitälern oder Pflegeabteilungen an die Generalleitungen traten. ${ }^{364}$ In diesem Sinn war der Mangel an Schwestern wie von aussen wahrnehmbar nicht eine Erscheinung, die erst ab den 1970er Jahren augenfällig wurde, sondern bereits in den sogenannten «Blütezeiten` der tätigen Ordensgemeinschaften in Bezug auf die erwähnte Nachfrage nach Schwestern als Arbeitskräfte allgegenwärtig. ${ }^{365}$

Nicht selten mussten daher die Oberinnen ihre Mitschwestern entweder ohne geeignete Ausbildung oder aus dem noch nicht abgeschlossenen Lehrgang heraus an diverse Aussenstationen schicken, um den teils energisch vorgebrachten Forderungen nach Arbeitskräften - getreu dem allgegenwärtigen Dienstverständnis geistlicher Schwestern - entsprechen

362 Interview 045, Z. 37-40.

363 Interview 019, Z. 148-167.

364 Esther Vorburger-Bossart, Ordensschwestern in der Ostschweiz im 20. Jahrhundert, Zürich 2018, $252 \mathrm{f}$.

365 Esther Vorburger-Bossart, Ordensschwestern in der Ostschweiz im 20. Jahrhundert, Zürich 2018, $252 \mathrm{f}$. 
zu können. ${ }^{366}$ Diese Vorgänge kamen in allen Berufsausrichtungen vor. Die Schwestern erzählten, dass sie bei diesen Entscheidungen nicht gefragt wurden. ${ }^{367}$

Auch war die Professionalisierung der Berufsausbildungen bis nach Mitte des 20. Jahrhunderts in vielen Sparten noch nicht vorangeschritten. In diesem Sinn war es üblich, eine Tätigkeit entweder nach Gutdünken und bestem Wissen oder gestützt auf einzelne Kurse auszuführen. Manche Schwestern erzählen davon über einen unkomplizierten Zugang, wobei der Erzähltopos «man hat es einfach gemacht» überwiegt: «Da hiess es auch, ja die Kindergärtnerin ist die Katechetin von der ersten und der dritten Klasse. Gut, dann hat man das auch gemacht so gut es ging. Also gut, man hatte natürlich schon ein wenig Ausbildung, aber nicht wie heute. Es fragte niemand nach einer katechetischen Ausbildung, wie man sie heute macht. Das hat man einfach gemacht.» ${ }^{368}$ Die entsprechende interne Kommunikation, um Schwestern Mutationen für diese oder jene Stelle mitzuteilen, verlief meistens einfach und direkt. Manchmal wurden bevorstehende Stellenwechsel auch kurzfristig anberaumt bzw. der betreffenden Schwester mitgeteilt: «Dann hat die Oberin gesagt, ja Sie wir brauchen einfach jemanden für die Hausorganisation. Dann war ich eine Art Hausbeamtin von einem Tag auf den andern ..., aber ich machte schon Kurse. ${ }^{369}$ In diesem Zusammenhang geben Schwestern immer wieder an, wegen der Berufsausbildung und auch Berufsausübung ins Kloster gekommen zu sein. Man habe die Ausbildung erst im Kloster erhalten, beispielsweise als Operationsschwester. ${ }^{370}$ Manche Schwestern erzählen bei nicht eingetretener Ausbildungsmöglichkeit, «einfach gearbeitet $\mathrm{zu}$ haben, ohne Ausbildung, und da und dort etwas dazu gelernt zu haben». Manchmal konnten die Oberinnen ein Versprechen in Bezug auf einen bestimmten Ausbildungslehrgang an ihre Mitschwestern nicht einlösen. Unter Umständen gab es über lange Zeit für eine dafür vorgesehene Schwester keine Möglichkeit, etwa eine pädagogische Ausbildung in einem Lehrerinnenseminar zu absolvieren. Die entsprechende Schwester gab an, zwar lange auf diese Ausbildung gehofft zu haben, aber dennoch

366 Vgl. zu den externen Forderungen die entsprechenden Korrespondenzen der Generaloberinnen, in: Esther Vorburger-Bossart, Ordensschwestern in der Ostschweiz im 20. Jahrhundert, Zürich 2018, 146-158.

367 Interview 047, Z. 128-135.

368 U.v. a.: Interviews 041, Z. 17-22; 026, Z. 19 f.

369 Interview 041, Z. 67-69.

370 Interview 001, Z. 35-42. 
gern als Hilfslehrerin gearbeitet zu haben. ${ }^{371}$ Andere Schwestern haben unter der mangelnden Ausbildung gelitten. ${ }^{372}$ Dennoch herrschte dahingehend die allgemeine Wahrnehmung vor, dass die Mehrheit der Schwestern die Ausbildung im Kloster machen konnte. ${ }^{373}$ Unter den Schwestern war das Bewusstsein, eine Ausbildung zu haben oder nicht in vielen Fällen vorhanden und wurde als teilweise detailreich erzählwürdig eingestuft: «Ich habe keinen Abschluss in Pflege und eigentlich auch vom Labor her nicht, also einen Arztgehilfinnen-Abschluss habe ich». ${ }^{374}$ Viele Schwestern wiederum erzählen ohne Wertung oder Einordnung ihres persönlichen beruflichen Werdegangs chronologisch die Abläufe ihrer Ausbildung oder ihrer Tätigkeiten. ${ }^{375}$

Überblicksmässig kann gesagt werden, dass je älter die Jahrgänge der Schwestern waren desto mehr war einerseits das Gebets- und Klosterleben geregelt. Im Gegenzug war es anderseits dafür die Ausbildungs- und Karriereplanung nicht. Beispielsweise gaben betagte Schwestern mit Jahrgängen um 1918 bis 1925 an, keine Ausbildung weder vor noch nach dem Klostereintritt gemacht zu haben. Sie seien dort eingesetzt worden, wo man sie brauchte. ${ }^{376}$ Diese Generation von Schwestern lebte in Bezug auf die nichtprofessionalisierte berufliche Tätigkeit nach dem Verständnis der Selbstaufgabe oder des Selbstlosigkeitsideals, dem das klösterliche Gehorsamsgelübde zugrunde lag. Dadurch habe man «vieles gemeistert und den lieben Gott um Hilfe gebeten und Hilfe von Mitschwestern erhalten». Dank dieser der damaligen Zeit entsprechenden Haltung, den Gehorsam zugunsten der Gemeinschaft zu leben, gelang es über mehrere Jahrzehnte, die Fülle der Aufgaben mit sehr hoher Arbeitsbelastung zu bewältigen.

Das fortgeschrittene 20. Jahrhundert wies innerhalb des Professionalisierungsprozesses eine gegenläufige Entwicklung auf. Um den ständig steigenden Anforderungen der Zeit genügen zu können, passten die Klöster ihre arbeitstechnischen Strukturen und Ausbildungsmodule sowie die entsprechenden Planungen an. Die von Schwestern geleiteten Institutionen gewannen somit an Format und Konturen, dafür nahm die Regulie-

371 Interview 010, Z. 376-402.

372 Interview 020, Z. $60 \mathrm{f}$.

373 Gemeinschaftsarchive von Baldegg, Basel, Cham, Ilanz, Ingenbohl, Luzern, Menzingen, Niederuzwil, Biografische Daten von Schwestern, SNF-Projekt «Lebensgeschichten religiöser Frauen in der Schweiz» 2015-2018; Interview 001 Z. 36-80.

374 Interview 045, Z. 45-50.

375 Interview 040, Z. 199-220.

376 Interview 010, Z. 173-183. 
rung des internen Gemeinschafts- und Gebetslebens ab. Personell gesehen wirkten sich diese Zeiterscheinungen ebenfalls aus. So kann aus generationenspezifischer Sicht gesagt werden, dass je jünger die Jahrgänge der Schwestern waren, desto mehr stand der Zeit entsprechend die religiöse und berufliche Selbstverwirklichung im Vordergrund. Diese Generation an Schwestern, die nach 1970 eingetreten war, fügte sich auch aus Sicht des beruflichen Verständnisses tendenziell weniger in das zuvor geltende Identitätsverständnis ein, nach dem das Individuum bedingungslos für die Gemeinschaft aus religiöser und beruflicher Sicht einstand und sich gleichzeitig als Person zurücknahm. Das klösterliche Selbstlosigkeitsideal von tätigen religiösen Frauengemeinschaften, das eigene Lebenswerk "Gott und den Menschen zu lieb» auszurichten, musste deshalb ab den 1980er Jahren bezüglich der über hundert Jahre erfolgreichen Verbindung von Religion und Beruf neu interpretiert oder mit angepassten Inhalten gefüllt werden.

Der gesellschaftliche und ökonomische Erfolg dieses Modells hing somit nebst der religiösen Prägung ab den Gründerjahren Mitte des 19. Jahrhunderts in direkter Weise mit dem Selbstlosigkeitsideal, das auf der Zusage von Gelübden basierte, zusammen. Um Schwesterngemeinschaften in Form von Kongregationen mit ihren zahlreichen sozialen Dienstleistungsbetrieben überhaupt führen zu können, brauchte es ein internes Organisationssystem, das auf hierarchischen Strukturen aufgebaut war. Inhaltlich gründete dies auf dem klösterlichen Versprechen des Gehorsams. Der Erfolg des Kollektivs im Kongregationsmodell, der bis in die 1970er Jahre verzeichnet werden konnte, hing demnach direkt von der einzelnen Schwester ab.

\subsubsection{Autonome oder regulierte Planung}

Erzählmuster zum eigenen Lebensentwurf, zur aktiv vorgenommenen biografischen Planung, sind sich für die noch stark regulierten Klosterjahre in den Jahrzehnten vor 1960 ziemlich ähnlich. Demnach war es für ältere Schwestern mit Jahrgängen zwischen 1920 bis 1940 entweder nicht üblich, eigene Lebenspläne zu entwerfen oder sie erklärten die vom Kloster her gegebenen Entwürfe als die eigenen. Auch hier gaben sie auffällig häufig an, damit zufrieden gewesen zu sein oder sich angepasst zu haben. Allfällig aufgetretene persönliche Wünsche formulierten die Schwestern nicht, oder die eigenen kollidierten nicht mit denen der Klosterleitungen. 
In dem Sinn wies diese Gruppe von Schwestern grösstenteils kontinuierliche Lebensläufe auf, wie sie als Selbstverständnis für eine religiöse Schwester von der Tradition der jeweiligen Gemeinschaft vorgegeben waren. Eine der wesentlichen Grundlagen zu dieser Linearität bildete die Bereitschaft der Schwester, geistliche und arbeitstechnische Strukturen zu akzeptieren und in die eigene Subjektkonstruktion zu integrieren, die von ihren Oberinnen vorgegeben wurden. ${ }^{377}$

Der äussere Lebensverlauf war in der Erinnerung dieser Schwestern als Mitglied einer geistlichen Gemeinschaft mit Gehorsamsgelübden bestimmt durch die Anweisungen der Oberinnen, von Station zu Station geschickt zu werden. In der Regel fügten sich die Schwestern in diese Verordnungen und waren dabei zumindest nicht unglücklich. ${ }^{378}$ Die Zeit vor dem Konzil erlaubte wie bereits dargelegt keine Nachfrage oder gar eine Wiederrede gegenüber den Plänen der vorgesetzten Schwestern. Es gab ausser in Krankheitsfällen grundsätzlich nur den Weg der Fügung, wie das folgende Zitat verdeutlicht: «Nur einmal habe ich gesagt, dass diese Arbeit nichts für mich ist; da habe man gesagt, dass es jetzt nichts Anderes gebe, da bin ich halt dahin gegangen.» ${ }^{379}$

Jüngere Schwestern, die nach ca. 1965 ins Kloster eintraten, benennen in ihren Erzählungen die Schwierigkeiten, die ihnen berufliche Zuweisungen bereiteten. Eine dieser Schwestern berichtete, dass sie «kränklich» gewesen sei und deswegen nicht habe leisten können wie die anderen Schwestern. Offenbar wurde dieser Zustand nur stillschweigend geduldet, wenn sie dazu erzählte, «es habe sie gestört, dass nicht offen darüber geredet wurde.» ${ }^{30}$ Eine andere Schwester erzählte, dass sie «einfach mitgemacht habe, obwohl für sie Schwieriges dabei war. Das habe sie aber nicht so genommen, denn sonst hätte sie Angst haben müssen, aus dem Kloster entlassen zu werden.» ${ }^{381}$

Eine im Rahmen einer selbstgewählten Klostergemeinschaft mit Gelübden auch nur teilweise selbstbestimmte Planung des Lebensentwurfs war erst in der Zeit nach 1970 oder 1980 praktikabel. So erzählten Schwestern bezüglich ihrer Bildungswünsche, dass sie bei der Klosterleitung «nicht locker gelassen hätten», bis ihnen eine Zweitausbildung nach

377 Interview 039, Z. 77-120.

378 Interview 053, Z. 17-162.

379 Interview 053, Z. 137-139.

380 Interview 029, Z. 262-275.

381 Interview 014, Z. $539 \mathrm{f}$. 
ihren Wünschen erlaubt worden war.» ${ }^{382}$ oder «bis man ihr entgegen des üblichen Weges einer Klosterfrau erlaubt habe, Theologie zu studieren.» ${ }^{383}$ Vereinzelte Lebensläufe weisen für Schwestern, die tendenziell nicht aus dem üblichen agrarischen Umfeld kamen, ein dezidiertes Streben nach höherer Bildung auf, das oft mit der Äusserung nach mehr Selbstbestimmung einherging. ${ }^{384}$

Wenige Schwestern suchten auf spiritueller Ebene ihren eigenen Weg gehen zu können und konnten dies meist nach langen Prozessen nur über einen Austritt aus der Gemeinschaft erreichen. In einem Fall erzählte eine Schwester, wie sie ihren Austritt selber plante und dass sie vor dem bereits implizierten Wiedereintritt in dieselbe Gemeinschaft den «Blick von aussen» benötigte. ${ }^{385}$ Eine weitere Schwester bekundete Mühe, für die Gemeinschaft und das Gebetsleben allgemein gültige Regelungen in die eigenen Denk- und Lebensstrukturen hineinzunehmen. Sie habe sich andere Gebets- und Meditationsformen gewünscht. Innerhalb dieser Entwicklung habe sie die Ratsschwestern um eine religiöse Weiterbildung gebeten, die gleichzeitig einer Auszeit von zehn Monaten gleichkam, die sie selber vorschlug. Diese habe man ihr bewilligt. Nach Ablauf dieser Zeit habe sie Mühe gehabt, sich wieder in die Gemeinschaft einzugliedern. ${ }^{386}$

Das Konzil bewirkte in den spirituellen und liturgischen Traditionen der Gemeinschaften Veränderungen, die den einen Schwestern zu wenig progressiv, den anderen zu weit oder zu wenig im traditionellen Sinn bewahrend waren. Dezidierte Äusserungen zu Umsetzungen eigener Vorstellungen zu diesem Themenkreis tauchten in den Lebenserzählungen eher seitens der Schwestern, die sich als «fortschrittlich» denkend einstuften, auf: «Ich habe mich dann auch ein wenig von den Normen vom eigenen Orden weg entwickelt. Ich habe wieder daran geglaubt, dass man die «konziliaren» Beschlüsse eigentlich auch hätte umsetzen können, dann habe ich eine schwierige Phase gehabt, da ich nicht mehr so in bestehende Systeme hineingepasste.» ${ }^{387}$ Innerhalb der Aufbruchstimmung in nachkonziliarer Zeit kam es auch vor, dass Schwestern den Mut hatten, sich gegenüber ihren Vorgesetzten zu äussern, etwa, wenn sie sich mit den

382 Interview 052, Z. 291-300.

383 Interview 007, 289-292.

384 Zum Beispiel: Interview 007.

385 Interview 049, Z. 103-113.

386 Interview 022, Z. 33-35.

387 Interview 022, Z. 127-132. 
gemeinsamen Gebetsformen nicht identifizieren konnten. Eine Schwester berichtete hier, in diesem Fall die Erlaubnis erhalten zu haben, teilweise selbstentworfene Formen umsetzen zu dürfen. ${ }^{388}$ Manche Schwestern mit diesen Vorstellungen von spiritueller Erneuerung probierten andere Meditationsformen aus, die teilweise von der Zen-Methode aus dem von Jesuiten geleiteten «Lassalle-Haus» in Edlibach bei Zug inspiriert waren. ${ }^{389}$ In diesem Zusammenhang äusserte ein Schwester eigene Pläne, die einen Missionsaufenthalt beinhalteten, um dort freiere Gebetsformen leben zu können. ${ }^{390}$

In diese Gruppe von Schwestern, die versuchten eigenen Interpretationen des geistlichen Auftrags einer religiösen Schwester umzusetzen. gehört ebenfalls eine Schwester, die den Berufungsgedanken in der Gassenarbeit mit Drogenabhängigen umsetzte und ihre konkrete Planung dieses Vorhabens eingehend darlegte, dies entgegen den Vorstellungen des grössten Teils ihrer Schwesterngemeinschaft. ${ }^{391}$ Sie habe dieses Verständnis des Evangeliums zu leben versucht, bei dem insbesondere das Armutsverständnis ernst genommen werde und habe das in der Nächstenliebe mit der Adaption des ärmlichen «Gassenstils» in Kleidung und Sprache umgesetzt. Im «Sinn des Gründers» ihrer religiösen Gemeinschaft habe sie versucht, in der Betreuung von randständigen Menschen, der Not der Zeit zu begegnen. Trotz komplementär anderem Lebensentwurf zur Mehrheit der Mitschwestern ihrer Gemeinschaft sei sie dieser treu geblieben. ${ }^{392}$

Ab 1980 kam innerhalb der Lebensverläufe von nach dem Konzil eingetretenen Ordensschwestern der Anspruch eines mehr selbstbestimmten Lebens zum Tragen. So waren sich ältere Schwestern der Bedeutung dieser Dynamik bezüglich des Gemeinschaftszusammenhalts bewusst, indem einzelne die Motivation später eingetretener Schwestern, die eigene Entfaltung im Kloster leben zu können, infrage stellten. Jüngere Jahrgänge verfolgten nicht mehr diesen geradlinigen, vorgegebenen Lebensentwurf der «typischen Schwester, die schon früh gewusst hatte, dass sie ins Kloster eintreten wollte und damit ihr Schicksal gewissermassen in die Hände der Oberinnen legte. Die Schwester, die dort im Grunde genommen

388 Interview 022, Z. 85-87.

389 Interview 022, Z. $263 \mathrm{f}$.

390 Interview 022, Z. 462-487.

391 Interview 040.

392 Interview 040, Z. 395-420. 
zufrieden war, weil sie zugunsten eines gemeinsamen Ideals «einfach etwas durchgestanden» hatte. Die jüngeren Schwestern unterstanden vielmehr einem Leben mit Reflektionsmustern, das eine teilweise autonome Lebensplanung auch in einer religiösen Gemeinschaft einschloss. Der Einfluss des Pluralismus in spirituellen Fragen und Lebensmodellen, der sich im letzten Drittel des 20. Jahrhunderts stark abzeichnete, machte sich hier bemerkbar.

\subsection{Erzählstrukturen}

Welche Inhalte wurden wie erzählt? Zwei grosse Themen überwiegen die Erzählungen, wenn die Kriterien der Häufigkeit, Prägnanz und Ausführlichkeit angeschaut werden. Beinahe alle Schwestern erzählten eingangs ihrer Darlegungen über weite Strecken und meist detailreich zu Erlebnissen ihrer Kindheit. ${ }^{393}$ Quantitativ gesehen machen die Kindheitserzählungen in der Regel bis zu einem Drittel der erzählten Lebensgeschichte aus. Das zweite, in breiter Darlegung erzählte Thema erstreckt sich über die Erlebnisse in den Tätigkeits- oder Berufsausübungen der Schwestern. Darin enthalten sind Erzählungen zu den vielen Standort- und Tätigkeitswechsel, die zum Lebensverlauf der meisten Schwestern gehörten, ${ }^{394}$ sowie zu u. a. auch emotional wiedergegebenen Begebenheiten in den verschiedenen Arbeitssituationen in Schulen, Kinderheimen oder Spitälern. ${ }^{395}$ Dazu gehörten häufig eingehende Schilderungen zu Schicksalen von Patienten, Angehörigen von Heimen oder insbesondere zu sozial benachteiligten Kindern, bei denen die eigene Betreuungsleistung ein Element sein konnte. ${ }^{396}$ Ein weiterer innerhalb des Berufslebens vielfach ausgeführter Themenkreis war das in mehreren Zusammenhängen wiederholt geäusserte «strenge und viele Arbeiten», welches die Lebenserfahrung der meisten Schwestern bzw. einer ganzen Generation an Schwestern bis in die 1990er Jahre eingehend prägte. ${ }^{397}$

393 Unter den 53 erfassten und hier untersuchten Interviews sind nur zwei bis drei darunter, die keine oder nur eine knappe Erzählung der eigenen Kindheit beinhalten.

394 Zum Beispiel: Interview 042, Z. 304-696.

395 Zum Beispiel: Interviews 017, Z. 1-267; 031, Z. 380-641.

396 Zum Beispiel: Interviews 015, Z. 315-386; 019, Z. 279-407.

397 Zum Beispiel: Interview 023. 
Aus dem beruflichen Umfeld aufgetretene Schwierigkeiten personeller oder struktureller Art erwähnten die Schwestern selten oder nur am Rande. Grundsätzlich ist hier der entsprechende Erzählduktus dahingehend ausgerichtet, möglichst viele Unebenheiten oder Unzulänglichkeiten innerhalb des Lebensverlaufs als zu bewältigende Elemente darzustellen. Die Konstruktion dieses Teils der aus der Retrospektive betrachteten Lebensgeschichte ist somit gleichzeitig eine Darstellung der Strategien, welche die Schwestern zur Lebensbewältigung heranzogen. Gleichzeitig sind diese Darstellungen ein Konstrukt einer entschiedenen Loyalitätsbekundung der gewählten Klostergemeinschaft gegenüber, die sich durch das ganze Leben im Kloster hindurch zog. So sind Erzähltopoi wie «dass es schon gegangen sei» oder «man trotzdem im Kloster geblieben sei», etwa nach erzählten Schwierigkeiten mit Vorgesetzten oder mit Mitschwestern, häufige Elemente, die selbst unzulänglichen Lebensphasen im Nachhinein eine positive Sicht verleihen oder auch schwierigen Einzelsituationen etwas Gutes abverlangen konnten. ${ }^{398}$ Immer wieder integrieren die Schwestern hier weitere entsprechende Erzählmuster wie «man muss etwas durchstehen können» oder «man musste sich in allen Situationen zurecht finden». ${ }^{399}$ Ebenfalls zogen viele Schwestern innerhalb dieser Erzählsequenzen das Bewusstsein als hilfreiches Denkmuster herbei, dass es «Konflikte überall gebe, auch in jeder Familie». Hin und wieder wurde dieses Element auch als abschwächende Komponente gegenüber erzählten Krisensituationen verwendet. ${ }^{400}$

Die Religiosität kommt hier abschliessend, wenn auch im Übrigen selten, in der direkten Thematisierung, ausgesprochen dezidiert als zusätzlich erklärendes Element in krisenbehafteten Lebensabschnitten zum Tragen. Innerhalb dieser erwähnten wiederkehrenden Erzählmuster, subsummieren die Schwestern das Geschehene unter den «Willen Gottes».401 Für die Bewältigung von Krisen hilfreiche Wendungen wie «mit der Hilfe Gottes werde ich versuchen weiterzumachen» oder «so schwer es auch war, der Herrgott hat aus allem Negativen immer wieder etwas sehr Positives gemacht» nehmen in diesem Sinn einen beinahe stereotypen Charakter an, da sie stets an die Sequenzen zu schwierigen Lebenssituationen

398 Zum Beispiel: Interviews 014, Z. 354-375; 013, Z. 726-734; 023, Z. 176-178.

399 Zum Beispiel: Interviews 023, Z. 441-443; 004, Z. 182.

400 Zum Beispiel: Interview 013, Z. 272-275.

401 Interview 012, Z. $29 \mathrm{f}$. 
gekoppelt sind. ${ }^{402}$ Überdurchschnittlich häufige Hilfs- oder Verarbeitungsstrategien berufen sich auf den als Gelübde geleisteten Gehorsam wie: «Bei Schwierigem habe ich gedacht, im Gehorsam leistet man viel.» ${ }^{403}$

Momente des eigenen Scheiterns werden durchwegs erzählt, tauchen aber weniger oft auf als ausführliche Darstellungen zu den erbrachten persönlichen Leistungen. ${ }^{404}$ Diese Lebensumstände, zu denen sowohl Brüche als auch Glücksmomente nach überwundener Krise gehören, stellen die Schwestern aus der eigenverantworteten Perspektive dar. Hier sind auch die im Rückblick auf das Leben, meistens am Schluss des selbst strukturierten Erzählflusses, geäusserten Erzählmuster zu nennen, die wiederum trotz nicht linearen Phasen eine Zufriedenheit mit dem eigenen Leben gegenüber, besonders mit der Wahl des Lebens im Kloster, beinhalten: «Und ich muss Ihnen sagen, ich habe eigentlich nie bereut, den Schritt ins Kloster gemacht zu haben» oder «dass es ein schönes Leben im Kloster» gewesen sei. ${ }^{405}$

Die am häufigsten und vergleichsweise ausführlichsten religiös konnotierten Erzählstrukturen verwendeten die Schwestern als Fazit oder als Abrundung am Schluss ihrer dargelegten Lebensgeschichte: Hier wurde der geistliche Bezugsrahmen zur erlebten und erzählten Lebensgeschichte geschaffen, in den die Schwestern die eigene Lebensführung eingebetteten und auch verantworteten: «Ich wurde so gut von Gott geführt». ${ }^{406}$ Die älteren Schwestern äussern in diesem Zusammenhang explizit eine Dankbarkeit der Gnade Gottes gegenüber, die der Schwester «einen Boden» vermittelte, in der sie die Verbindung mit Gott spürte. ${ }^{407}$

Wie wurden die Erzählungen strukturiert? Allgemein beinhalten die Lebenskonstruktionen einen assoziativen und wenig selbst strukturierten Erzählstil. So verhältnismässig selten die direkte Rede von religiösem Erleben war, so oft dienten religiöse Ereignisse als Eckpfeiler zur Strukturierung der Erzählung. Nebst der in jeder Erzählung erwähnten Profess setzten die Schwestern sehr oft auch katholische Initiationsfeste wie die Erstkommunion oder die Firmung als Elemente zur Zeiteinordung von Geschehnissen ein. ${ }^{408}$ Dass die Schwestern eine weitere, etwa inhaltliche

402 Zum Beispiel: Interviews 012, Z. 29 f.; 042, Z. 696 f.

403 Interview 012, Z. 337.

404 Zum Beispiel: Interviews 013, Z. 726-734; 041, Z. 117; 012, Z. 337.

405 Zum Beispiel: Interviews 013, Z. 228 f.; 049, Z. 447-451.

406 Zum Beispiel: Interview 044, Z. $170 \mathrm{f}$.

407 Zum Beispiel: Interview 026, Z. 245-250.

408 Interview 040, Z. 17-27. 
Strukturierung ihrer Erzählung vornahmen, war eher selten. Allgemein folgten auf die Kindheitsphase lange Erzählphasen zu äusseren Abläufen in den beruflichen Tätigkeiten. Gewöhnliche Alltagsabläufe wurden dabei nur in Ansätzen berichtet. In der Regel legten die Schwestern vorab besondere Ereignisse dar, die sie meist entlang chronologisch aufgestellter Erinnerungsmomente aneinanderreihten. Dies konnte beispielsweise den Bericht von Erlebnissen als Schwester in einem Kinderheim bedeuten. ${ }^{409}$

Eine explizit geäusserte Orientierung an Muster-Lebensläufen von bestimmten ordensintern als vorbildlich geltenden Schwestern kam nicht vor. Die in den internen Organen reich gepflegte Nachrufkultur dürfte indessen bei älteren Schwestern in den selbst strukturierten Lebenserzählungen implizit eine beachtliche Rolle gespielt haben ${ }^{410}$ Insofern zeigten sich die Erzählungen für sich einzeln betrachtet zwar authentisch und enthielten selten von aussen beeinflusste Erzählmomente. Hingegen weisen sie klare Prägungen nach im Kloster geltenden Gebrauchs- und Umgangsregeln sowie nach den Satzungen auf, welche die Schwestern als einen verbindlich-normativen, und nicht als einen individuell gestaltbaren Bezugsrahmen darstellten. Insofern stimmten die erzählten Handlungen mit den Deutungsmustern überein. Auch kamen im Vergleich verschiedener Schwesternerzählungen dieser Generation kaum nennenswerte unterschiedliche Wahrnehmungen gleicher Inhalte zum Vorschein.

Hingegen sind deutliche Unterschiede festzustellen innerhalb der Erzählweise älterer Schwestern mit Jahrgängen zwischen 1920 bis ca. 1950 mit Eintritten bis unmittelbar nach dem Konzil im Vergleich mit den nach 1970 ins Kloster eingetreten Schwestern. Wie eine Erzählung strukturiert und welche Inhalte erzählt wurden, war wiederum eine Frage der Generation, der die jeweilige Schwester angehörte. Jüngere Schwestern erzählten ihre Lebensgeschichte verstärkt auf der Basis einer spirituellen Auseinandersetzung im Hinblick auf eine sorgfältig abgewogene Wahl des richtigen Lebensentwurfs. ${ }^{411}$ So nahm hier die Selbstreflexion und die explizit autonom und authentisch Strukturierung von Lebensabläufen in den Erzählungen grundsätzlich einen breiteren Raum ein. Ein zentraler

409 Interview 036, Z. 41-314.

410 Siehe zum Nachlass der einzelnen Schwester am Beispiel aus dem Archiv Institut Menzingen (AIM), Nachlass von Sr. Alba Dörig, o. Signatur; Esther Vorburger-Bossart, Ordensschwestern in der Ostschweiz im 20. Jahrhundert, Zürich 2018, S. 46 f.

411 Zum Beispiel: Interviews 038, Z. 68-403; 035. 
Teil innerhalb dieser Lebenserzählungen bildete die subjektive Sinn- oder Gottsuche, die mit der Frage nach einem Klostereintritt bzw. auch nach einem Klosterverbleib verbunden war. $^{412}$

\subsection{Unerzählte Elemente}

Die Schwestern gestalteten ihre Lebenserzählungen selber. Damit bestimmten sie, was sie wie und wie lange erzählten oder nicht erzählten. Die erzählten Inhalte wurden bereits dargelegt. Hier interessiert die Frage, ob es in den erzählten Lebensgeschichten Leerstellen oder Ausklammerungen gab bzw. was wurde nicht erzählt?

Äussere mögliche Inhalte, die über den klosterinternen Kosmos hinausgreifen wie die Vernetzung im religiösen und weltlichen Umfeld oder allfällige Abwehr- bzw. Akklimatisationsmechanismen im profanen Lebens- oder Berufsumfeld wurden kaum in die Lebenserzählungen einbezogen, obwohl sie vielfältig existierten. Dazu gehörte auch das Verhältnis zu protestantischen Glaubensangehörigen, insbesondere zu den Diakonissen, die als evangelischen Schwestern zur selben Zeit beinahe dieselben Tätigkeiten absolvierten. Dennoch wurde die Koexistenz mit den protestantischen Schwestern, die in zahlreichen Niederlassungen in paritätischen Gemeinden zum Alltag der Ordensschwestern gehörte, nicht erwähnt. Bezugnahmen zu Zeitereignissen in politischer, gesellschaftlicher oder wirtschaftlicher Hinsicht wurden ausserhalb des Klosters praktisch keine genannt. Diese wurden im eingehenden Stil einzig von deutschen Schwestern über Berichte zu Kriegs- und Fluchterfahrungen einbezogen. Einzelne Schwestern kontextualisierten ihre Wahrnehmungen oder Erlebnisse innerhalb bedeutender Ereignisse der Weltkirche wie besonders das Zweite Vatikanische Konzil.

Auch innere Inhalte wie die eigene Beziehung zu Vorbildern, auch zu ordensintern verehrten Gründern und Gründerinnen, wurden nicht erzählt. Als unbedingte Teile der Subjektkonstruktion wurden weiter rein persönliche, etwa auch unerfüllte Wünsche kaum erwähnt. Diese äusserten die Schwestern in der Erzählung hingehen relativ häufig und u. U. dezidiert, wenn es sich - wie oben bereits dargelegt - um Wünsche 
oder Vorstellungen des beruflichen Umfelds handelte, etwa, wenn eine Schwester «sicher nicht noch einmal ins Mutterhaus in die Küche zurück wollte.» ${ }^{413}$ Auch auf die vielschichtigen Aspekte des tagtäglichen sozialen Zusammenlebens in einer Gemeinschaft traten die Schwestern nur selten ein.

Nicht «nicht erwähnt», aber nur selten oder am Rande erzählt bzw. nicht der lebensgeschichtlichen Bedeutung entsprechend ausgeführt, wurden zahlreiche Themenkreise, die offenbar als selbstverständlich und nicht erzählwürdig eingestuft wurden. In den Erzählkonzepten der Schwestern müssen sie deshalb dennoch als wohl unbewusste Ausklammerungen bezeichnet werden. Das Reden von Religiosität bildet - vermutlich aufgrund des grundlegenden Charakters innerhalb des Ordenslebens - eine der grossen Leerstellen. Demnach taucht das freie und direkte Erzählen von religiösen Erlebnissen oder der im Kloster praktizierten Frömmigkeit in Ansätzen eingangs der Erzählungen im Zusammenhang mit der Entscheidungsfindung für eine klösterliche Gemeinschaft als «Gottsuche» auf, ist aber in den Berichten zum eigentlichen Klosterleben kaum präsent. ${ }^{414}$ Die Sequenzen zur Suche nach einem geeigneten Kloster wurden meist auf die äusserlichen und praktischen Kriterien ausgerichtet und beinhalten weniger ausgeprägt die geistlichen Inhalte. Auf Nachfrage der Interviewerin im dritten Teil des narrativen und frei strukturierten Interviews, ob die Schwester zur eigenen Religiosität etwas erzählen wolle, wurden tendenziell eher religiöse Strukturen als Inhalte oder Praktiken angesprochen. ${ }^{415}$ So sprachen die Schwestern die gemeinschaftliche Spiritualität in der Regel nicht von sich aus an oder machten sie nicht zu einem nennenswerten Erzählthema, obwohl sie durchwegs zentrale und die Schwestern prägende Inhalte waren. Vereinzelt wurden diese erst ausführlicher, als die Interviewerin danach fragte. ${ }^{416}$ Wohl aufgrund der langen Absenz von Neueintritten in die Klostergemeinschaften, die mittlerweile bis zu einer ganzen Generation andauert, sprachen die Schwestern selten vom Noviziat wie es sich in der heutigen Zeit gestaltet. ${ }^{417}$

413 Interview 016, Z. 188-192.

414 Zum Beispiel: Interview 001, Z. $449 \mathrm{f}$.

415 Zum Beispiel: Interview 037, Z. 147-261.

416 Interview 037, Z. 668-684.

417 Interview 001, Z. 1288-1353. 
Weiter zeigte sich, dass das prägendste Gelübde des Gehorsams als weitgehend aktiv unerzähltes Element taxiert werden muss, obwohl es sich in jeder Lebensgeschichte wie ein roter Faden durch die meisten Ereignisse hindurch erwies.

Aufgrund des subjektiven Ausgangspunkts der Lebensberichte integrierten die Schwestern weniger Elemente des allgemeinen Gemeinschaftslebens im Kloster, obwohl die gesamte Erzählperspektive auf das Kollektiv ausgerichtet wurde. Dazu gehört die in allen Gemeinschaften intensiv geführte Diskussion um die Neuerungen am Erscheinungsbild des Ordenskleides. Das 〈Kleid` wurde nur wenige Male aktiv erwähnt. Es wurde stets im Zusammenhang mit der Identitätsfrage in dem Sinn verknüpft, dass das Ordenskleid zu einer «echten Schwester gehöre». ${ }^{418}$ Auch die Frage nach der Rolle, welche die Geistlichen im Beziehungsumfeld der Schwestern übernahmen, gehörte zu den nicht aktiv erzählten Elementen. ${ }^{419}$ Weitere, die einzelne Schwester prägende Inhalte wie das Mutterhaus, die Filialstruktur oder das Alter wurden kaum als eigene Erzählmomente explizit ausgeführt. Über die Narrative der vielerzählten Berufstätigkeit wurden sie dennoch thematisch eingebracht. Sie gaben das wohl prägendste Beziehungsgeflecht innerhalb des Klosterlebens jeder Schwester wieder, das die drei zentralen Eckpunkte 〈Mutterhaus〉, 〈Berufstätigkeit〉 und «R̈̈ckkehr von Aussenstationen` im Leben der Schwestern verband. Das verhältnismässig wenig thematisierte «Alter` wurde in den Erzählungen als weiterführende Anschlussphase des Berufslebens stillschweigend subsummiert. Dieser aktuell erlebte, letzte Lebensabschnitt hat in der Rekonstruktion der Lebensgeschichte nur insofern eine Bedeutung, als die Schwestern in jüngeren Jahren als Berufstätige in den meisten Fällen auswärts waren und erwähnten, «nachher ins Mutterhaus heimgekehrt zu sein». Das «Mutterhaus` selber wiederum bildete nur über die Wiederspiegelung durch das berufliche Leben auf den Aussenstationen eine wahrnehmbare soziale Einheit.

Ebenso bildeten die sozialen Beziehungen und Freundschaften unter den Schwestern weitgehende Auslassungen, obwohl sie trotz statutarischer Weisung zu den "partiellen Freundschaften» praktiziert wurden. ${ }^{420}$ Dies gilt auch für die Erwähnung von persönlichen Strategien, die not-

418 Interview 001, Z. 904-946, Z. 28 f.

419 Ein Beispiel einer kurzen Ausführung, das auf Rückfrage der Interviewerin zustande kam: Interview 014, Z. 384-433.

420 Interviews 014, Z. 847-870; 018, Z. 457 f. 
wendig wurden, wenn eine Schwester entweder Mühe mit klosterinternen Strukturen oder mit religiösen Formen hatte. Auch Erkrankungen psychischer Art, die Schwestern gegenüber ihren Mitschwestern nicht ansprechen wollten, gehören weitgehend zu den Ausklammerungen in den für diese Studie erfassten Lebenserzählungen. ${ }^{421}$

Verständlicherweise wurden innerhalb einer subjektiv ausgerichteten Erzählperspektive zur eigenen Lebensgeschichte weitere gemeinschaftsinterne Strukturen wie die Zusammenarbeit mit den zu den Klöstern gehörenden Provinzen ${ }^{422}$ oder ökonomische Aspekte der Gemeinschaft ${ }^{423}$ nur sehr selten erwähnt. Entsprechend wurden die zum Ordensleben selbstverständlich dazugehörenden Leitbilder oder Satzungen in den Erzählungen nicht als eigene Themenfelder, hie und da wohl als Referenzgrössen zur Einordnung von einzelnen Erzählelementen, angesprochen. So kann nichts Konkretes darüber ausgesagt werden, wie sie durch die Schwestern interpretiert, wahrgenommen und umgesetzt wurden. Implizit kamen die Satzungen als Fundament des klösterlichen Lebensverständnisses dennoch oft als Erzählinhalte vor. Weiter gaben die Schwestern nur marginal oder kaum ausführlichere Reflexionen zu Kontinuitäten oder Brüchen innerhalb der zahlreichen, von den Gemeinschaften geführten Institutionen an. ${ }^{424}$ Auch ereignislose oder alltäglich wiederkehrende Lebensphasen wurden selten erzählt.

\subsection{Fazit}

Wie konnte die Subjektgeschichte einer religiösen Schwester über die Methode der befragten Geschichte erfasst werden?

Ausgangspunkt dieser Studie war die Erkenntnis, dass sich das Individuum der einzelnen Schwester, und damit der Analysebereich «subjektive Identität» gegenüber dem weitaus besser dokumentierten Kollektiv der Schwesterngemeinschaft in den schriftlichen Quellen kaum niederschlug. Mit der Methode der Oral History konnten nun Aspekte des Subjekts von

421 Interview 022, Z. 624-628.

422 Interview 023, Z. 190-233.

423 Interview 012, Z. 1019-1024.

424 Interview 023, Z. 1045-1076. 
Ordensschwestern aus alltags-, religions- und kulturgeschichtlicher Perspektive aufgezeigt werden.

Da das Forschungsverständnis dieser Studie nicht nur methodisch, sondern auch inhaltlich von einer Rekonstruktion der eigenen Lebensgeschichte ausging, die zeithistorisch kontextualisiert und interpretativ verdichtet wurde, mussten die beiden Kategorien «Biografie» und «Identität» einbezogen werden. Dabei erwiesen sich die vier Narrative «Herkunft», «Kloster», «Konfession» und «Profession» als nützlich, um aus quantitativer und qualitativer Sicht die erzählten Inhalte greifbar zu machen.

Die dieser Studie vorausgesetzte Annahme, das Erzählen von religiöser Erfahrung und Frömmigkeit bilde eine der Leerstellen, wurde bestätigt. Nicht die bei geistlichen Schwestern naheliegende Religiosität, sondern der Beruf und die in diesem Kontext erzählte Berufung waren die breit entfalteten Erzählthemen. Das Nicht-Erzählen dieses zentralen Bereichs war eines der Grundmuster innerhalb der freien Erzählung wie auch des stimulierten Gesprächs. Das zeigte sich im Erzählen über die kollektive Religionspraxis wie in der persönlichen Religiosität.

Eine Orientierung an ordensinternen Leitfiguren mit vorbildlichen Lebensentwürfen kam auch als Teil der Rekonstruktion des eigenen Lebens - entgegen der vorgängigen Annahme - in den Erzählungen nicht vor. Weitere Elemente, die das Gemeinschaftsleben, und damit die einzelne Schwester in zentraler Weise prägten (wie interne Geistliche, Mutationen beim Ordenskleid oder Leitungsstrukturen und Ratsentscheide, auch aktuelle Seligsprechungsprozesse), wurden kaum aufgegriffen. Hier erwies sich das methodische Instrument, auch Leerstellen und Lücken zu interpretieren, als hilfreich. Über diesen Zugriff wird das unerzählte Element 〈Religiosität〉 dennoch zu einem zentralen Bestandteil der erzählten Geschichte. Dazu gehört ebenfalls das häufig miterzählte, aber nicht eigentlich ausgeführte Erzählfeld «klösterliche Gemeinschaft».

Die drei Erinnerungsbereiche «Kindheit〉, 〈Berufung〉 und 〈Beruf〉 wurden erwartungsgemäss ausführlich in die Lebensgeschichte integriert. Detailreiches Erzählen sowie assoziative Geschichten mit szenischer oder episodenhafter Form gehörten zu den faktengestützten Teilen der erzählten Lebensgeschichte.

Hingegen konnte der vorgängig nicht erwartete, frei konstruierte Erzählinhalt der persönlichen Lebensgeschichte als Erfolgsgeschichte wahrgenommen werden. Mit der mehrheitlich positiv dargestellten Identität einer Ordensschwester zog sich ein zuweilen ausgeprägtes Selbstbe- 
wusstsein als wiederkehrender Duktus in den Erzählungen durch, die der öffentlichen Wahrnehmung des selbstlosen Charakters einer geistlichen Schwester entgegensteht. Insbesondere der meist prononciert gestaltete Abschluss der Erzählung bildete praktisch ausnahmslos ein Gefäss, um das eigene Leben als Ordensschwester aus der Retrospektive nicht nur als durchwegs gelungen, sondern vor allem auch als erfolgreich darzustellen. Die Einschränkungen durch historische Fakten, chronologische Strukturen oder durch unangenehme Empfindungen im Lebensverlauf konnten hier ausgeblendet werden.

Ebenso verhielt es sich mit dem zweiten, hier zum Voraus nicht prognostizierten Narrativ der Umsetzung des Gehorsamsgelübdes, das sich als bedeutungsvollster Inhalt erwies. Explizit wurde dieser zwar nur zweimal als eigener Erzähltopoi aufgegriffen. Somit war der Gehorsam zwar als Erinnerungstopoi auf der latenten Gedächtnisebene vorhanden, wurde aber nicht als eigenes Erzählmoment aufgenommen. Implizit gehörte das Gelübde des Gehorsams mit all seinen alltäglichen Ausfaltungen über die eingehenden Schilderungen zur Berufstätigkeit zum prägendsten Element innerhalb des Lebens dieser Ordensschwestern. Damit hat die Analyse der gut 50 erzählten Lebensgeschichten nun von der subjektgeschichtlichen Seite die früheren Thesen bestätigt, dass das Modell der tätigen religiösen Frauengemeinschaften auf der Einforderung bzw. Leistung von Gehorsam beruhte und dadurch über 150 Jahre erfolgreich war. Weiter hat sich gezeigt, dass das Verständnis des Gehorsams gegen Ende des 20. Jahrhunderts aufgrund veränderter gesellschaftlicher Strömungen neu interpretiert und ausgerichtet werden musste. Mit dem Wegfall des traditionell gelebten Gehorsamsgelübdes funktionierte das religiöse Gemeinschafts- und Leistungsmodell nicht mehr. Dies äusserte sich aus interner Sicht auf struktureller Ebene in den zurückgegangenen Schwesternzahlen sowie dem markanten Abbau an klostereigenen Institutionen. Gesellschaftlich oder klosterextern gesehen, bedeutete das nachlassende Interesse an einem klösterlichen Lebensentwurf die $\mathrm{Zu}$ nahme individueller Lebensmuster, begleitet von einem Trend hin zu geringerer Bereitschaft, das eigene Leben durch Bindungen und Regulierungen zu gestalten.

Damit ist die klosterinterne Generationenfrage angesprochen, die in den Erzählungen zwar selten selbstthematisiert auftaucht, aber sich durch viele Darstellungen zumindest partiell hindurchzieht. Die Generationenfrage erweist sich innerhalb der Konstruktion eines Gruppenporträts als erheblich. Es bietet sich somit zusammen mit dem zweiten, hier generier- 
ten Analysebereich «Gehorsam» eine Zweiteilung der Schwesternporträts an. Einerseits gibt es die Gruppe von Schwestern mit Jahrgängen zwischen 1920 bis ca. Mitte der 1950er Jahre, die der «typischen〉 Ordensschwester mit ausgeprägtem Gehorsamsverständnis entspricht. Anderseits ist die innerhalb der Klostergemeinschaften nur noch marginal vorhandene Gruppe mit Jahrgängen ab 1960 auszumachen. Die Motivation zu einem Klostereintritt unterscheiden sich bei den beiden Gruppen. Die ältere Gruppe trat vorwiegend aus Gründen eines karitativ geprägten Lebensmodells in eine klösterliche Gemeinschaft ein. Die jüngere Gruppe suchte vermehrt aus spirituellen Motiven den Anschluss in einer Klostergemeinschaft, um ein religiöses Leben verwirklichen zu können. Dem Zeitgeist entsprechende pluralistische Lebensmodelle, denen auch religiöse Frauen unterworfen sind und waren, liess diese Lebensentwürfe teilweise fragil verlaufen. Dementsprechend weisen die älteren Schwestern Lebensläufe mit langen Kontinuitäten, mit 40 bis 50 Jahre dauernder Berufstätigkeit, mit bis zu 60 und mehr Jahren an Lebenszeit im Kloster in derselben Gemeinschaft auf. Damit bildete das Kloster für diesen Typus an Schwestern einen eigenen Kosmos, der für die Schwestern von Ausbildung, Berufsausübung, Familienanschluss über geregelte Strukturen für Ferien, Krankheit, Alter und Tod geeignete interne Angebote und Institutionen bot. So ist es nur konsequent, wenn die mehrheitlich hier vorkommenden Erzähltopoi in den einzelnen Interviews der Jahrgänge von 1920 bis ca. 1955 über grosse Strecken ähnlich bis fast kongruent erscheinen. Die Narrative folgen oft dem Muster eines durch Gott geführten Lebens, in dem aufgetretene Krisen nur am Rande erwähnt oder nicht als solche gedeutet wurden. Übergeordnet gesehen interpretierten diese Schwestern ihren Lebensverlauf als «in der Hand Gottes geborgen und getragen» und als somit sinnvollen Verlauf.

Diese subjektive Konstruktion entsprach der kollektiven Sicht auf das Leben als tätige Ordensschwester. Damit kann der grundsätzliche Fragestrang um das Verhältnis von Subjekt und Kollektiv aus der Gesamtsicht angegangen werden. Die Frage, ob sich Unterschiede zwischen dem subjektiven und dem kollektiven Gedächtnis zeigten, erwies sich als nicht relevant. Zur gegenseitigen Beeinflussung der beiden Forschungsfelder kann ausgeführt werden, dass das kollektive Gedächtnis in erheblichem Mass das Erinnern der einzelnen Respondentin prägte.

Unter dem zugrunde gelegten methodischen Zugriff, der die Interviews als Rekonstruktion eines nachträglich hergestellten Sinnzusammenhangs vergangener Ereignisse und Erfahrungen begreift, konnte 
weiter das Vergessen und Verdrängen als eigenen Prozess der lebensgeschichtlichen Konstruktion begriffen werden. Entgegen der Annahme betraf dies nicht das Erzählen von schwierigen Lebenssituationen innerhalb des Erzählverlaufs, die durchwegs, teilweise sogar eingehend dargestellt wurden. Dabei hat sich auch von dieser Seite her bestätigt, dass die erzählte Lebensgeschichte bereits Produkt einer Interpretation durch die erzählende Schwester ist. Die Transformation von Erinnerung wurde zu einem Teil der historischen Wirklichkeit hinzugefügt. Gleichzeitig konnten über diese Methode die Grenzen von Erinnerung und Gedächtnis erfasst werden.

Mit der Präsentation von erzählten und nicht erzählten Inhalten, wurde gleichzeitig versucht, sich der Frage zu nähern, wie die Schwester ihre individuelle Lebensgeschichte in der Erzählung konstruierte. Vielleicht wurde mit dieser singulären Situation oder auch Möglichkeit, einer externen Person, hier der Historian, die eigene Lebensgeschichte in unbeschränkter inhaltlicher oder zeitlicher Limite frei erzählen zu dürfen, ein eigenes Konstruktionsfeld erzeugt? Der oben ausgeführte Befund, der in fast ausnahmslos jeder Erzählung ein positiv gestaltetes Fazit als Abrundung der Erzählung des eigenen Lebens zeigt, ist aus dieser Perspektive wohl nicht nur der Form des Erzählabschlusses geschuldet. Es ist zumindest denkbar, dass unter dem Schutz einer in diesen Interviews zugesicherten Anonymität die Äusserung eines im katholischen Milieu für Frauen nicht üblichen Selbstbewusstseins durch den Erzählmodus hervorgerufen wurde. Entgegen der tolerierten Identität der selbstlosen geistlichen Schwester darf sich ganz zu Recht - zumindest am Lebensende die eigene Person und das eigene Können, hier im Erzählen, präsentieren. Es sind und waren mit den religiösen Schwestern Frauen, die über 150 Jahre lang Ideale der katholischen Kirche und Ideen von geistlichen Männern engagiert umsetzten und den langfristigen Erfolg dieser Institutionen gewährleisteten. Dieser durchwegs beachtlichen und für eine breite Öffentlichkeit bislang praktisch nicht wahrgenommenen, gesellschaftlich aber durchwegs relevanten Lebensleistung konnte mit diesen Erzählungen eine Plattform und mit der Publikation der Ergebnisse eine Sichtbarkeit verschaffen werden.

Die Relevanz des Vorhabens liegt damit auch nach Abschluss der Forschung einerseits in der Erhebung und Sicherung lebensgeschichtlicher und nicht schriftlich dokumentierter Inhalte zu einem weiblichen Lebensmodell der religiösen Schwester, das vom Aussterben gekennzeichnet ist. Die daraus erschlossene Realität hat eine soziale Bedeutung. Anderseits 
ermöglicht es die Einordnung von Sichtweisen der einzelnen Schwester auf Forschungsergebnisse und Perspektiven der bisherigen katholischen Kirchengeschichtsschreibung. Dabei steht die subjektive Einschätzung der Schwester nicht vollumfänglich parallel zur These, die den Wandel der Ordensgemeinschaften in der zweiten Hälfte des 20. Jahrhunderts von der patriarchalen Familiengemeinschaft zu einer religiösen Lebens- und Dienstgemeinschaft konstatiert. Aufgrund der Altersstruktur und der spirituell motivierten Gemeinschaftsbeteiligung nach 1970 nur vereinzelt eingetretener Schwestern weisen die Gemeinschaften einen schwindenden ökonomischen Dienstcharakter auf.

Die Verortung der Lebensläufe im Kontext des christlich ausgerichteten Schwesternwesens konnte belegt werden. Zusätzlich können mit der Präsentation der Lebensgeschichten von Ordensschwestern Denkmodelle und Handlungsspielräume katholischer Frauen im 20. Jahrhundert sichtbar gemacht und damit ein Stück religionsgeschichtlicher Schweizer Katholizimus der Nachkriegszeit. Es handelt sich hier um die geschlechtsspezifische Ausprägung eines Lebensmodells innerhalb des Katholizismus, das nur über weibliche normierte Lebensformen möglich war.

Innerhalb der kulturhistorischen Einordnung lautete die These in Bezug auf das Verhältnis von Beruf und Religion, dass die einzelne Schwester sich innerhalb des vorgegebenen Rasters der jeweiligen Gemeinschaft nach dessen Vorgaben bewegte. Ebenso ging diese These davon aus, dass eine eigene Subjektkonstruktion grundsätzlich nur in Ansätzen möglich war, ohne dabei individuelle Merkmale zu verlieren. Beide Annahmen konnten bestätigt werden. Ein thesenartig entworfenes Gruppenporträt dieser Generation von Schwestern der zweiten Hälfte des 20. Jahrhunderts verdeutlicht somit, dass die Präsentation der Lebensgeschichte das Resultat von sozio-religiösen Deutungsangeboten und Sinnbildungsprozessen ist. 



\section{Anhang}

\section{Bildnachweis}

Bilder von Sr. Margrit Bösch, S. 137-S. 147, Privatarchiv Sr. Margrit Bösch, St. Anna-Schwestern, Luzern

\section{Interviews}

53 Interviews von Schwestern aus acht Gemeinschaften, aufgenommen zwischen April 2015 und Oktober 2016.

Die Ton- und Transkriptdokumente befinden sich in den unten aufgeführten Kloster- bzw. Gemeinschaftsarchiven. Die Dossiers sind abgelegt unter der Bezeichnung: «SNF-Projekt zur Oral-History-Forschung: Diakonissen und Ordensschwestern im 20. Jahrhundert, Laufzeit 20152018 (Schwestern erzählen aus ihrem Leben)». Eine Zuweisung ermöglicht der Auflösungsschlüssel, der den Dossiers in den Klosterarchiven beiliegt.

Baldegg, Klosterarchiv Baldegger Schwestern, Baldegg:

7 Interviews

Interview mit Sr. B.

Interview mit Sr. C.

Interview mit Sr. C.

Interview mit Sr. L.

Interview mit Sr. T.

Interview mit Sr. T.

Interview mit Sr. Y.

Basel, Gemeinschaftsarchiv Katharina-Werk, Basel:

7 Interviews

Interview mit Sr. B. 
Interview mit Sr. E.

Interview mit Sr. F.

Interview mit Sr. R.

Interview mit Sr. S.

Interview mit Sr. K.

Interview mit Sr. L.

Cham, Klosterarchiv Olivetaner Benediktinerinnen,

Cham-Heiligkreuz:

4 Interviews

Interview mit Sr. A.

Interview mit Sr. A.

Interview mit Sr. E.

Interview mit Sr. M.

Ilanz, Klosterarchiv Ilanzer Dominikanerinnen, Ilanz:

13 Interviews

Interview mit Sr. A.

Interview mit Sr. A.

Interview mit Sr. A.

Interview mit Sr. A.

Interview mit Sr. A.

Interview mit Sr. B.

Interview mit Sr. B.

Interview mit Sr. C.

Interview mit Sr. E.

Interview mit Sr. E.

Interview mit Sr. G.

Interview mit Sr. J.

Interview mit Sr. R.

Ingenbohl. Provinzarchiv Ingenbohler Schwestern, Ingenbohl:

5 Interviews

Interview mit Sr. C.

Interview mit Sr. B.

Interview mit Sr. C.

Interview mit Sr. S.

Interview mit Sr. W. 
Luzern, Gemeinschaftsarchiv St. Anna-Schwestern, Luzern:

3 Interviews

Interview mit Sr. M.

Interview mit Sr. M.

Interview mit Sr. M.

Menzingen, Institutsarchiv Menzinger Schwestern, Menzingen:

9 Interviews

Interview mit Sr. A.

Interview mit Sr. J.

Interview mit Sr. E.

Interview mit Sr. M.

Interview mit Sr. T.

Interview mit Sr. T.

Interview mit Sr. U.

Interview mit Sr. M.

Interview mit Sr. B.

Niederuzwil/Bernhardzell, Gemeinschaftsarchiv der

Missionsschwestern vom Katholischen Apostolat (Pallottinerinnen),

Pallotti-Haus, Delegatur, Niederuzwil:

5 Interviews

Interview mit Sr. A.

Interview mit Sr. D.

Interview mit Sr. $\mathrm{H}$.

Interview mit Sr. M.

Interview mit Sr. R. 


\section{Biografische und soziodemografische Daten}

Jahrgänge:

- 1920-1930: 7 Schwestern

- 1931-1940: 25 Schwestern

- 1941-1950: 18 Schwestern

- 1951-1970: 3 Schwestern

Alter anlässlich der Ewigen Profess ${ }^{425}$ :

- 18-20 Jahre: 1 Schwester

- 21-25 Jahre: 30 Schwestern

- 26-30 Jahre: 14 Schwestern

- 31-35 Jahre: 3 Schwestern

- 36-40 Jahre: 4 Schwestern

- 41-45 Jahre: -

- 46-50 Jahre: -

- 51-55 Jahre: -

- 56-60 Jahre: 1 Schwester

Berufstätigkeit während der Klosterzeit ${ }^{426}$ :

- Lehrerin: Kindergärtnerin, Primar-, Real- und Sekundarstufe, Fachlehrerin:

17 Schwestern

- Krankenschwester, Operationsschwester, Krankenpflegerin, Hebamme, Schwesternhilfe:

15 Schwestern

- Kindererzieherin, Familien- und Haushalthelferin:

14 Schwestern

- Theologin:

4 Schwestern

- Damenschneiderin:

3 Schwestern

425 Das Klostereintrittsdatum fand entsprechend ca. 3 Jahre früher als das Datum der Profess statt.

426 Manche Schwestern gaben zwei Berufe an; die Berufsbezeichnungen richten sich nach den Angaben der Schwestern und wurden nicht den heutigen Bezeichnungsnormen angepasst. 
- Köchin:

2 Schwestern

- Bäuerin: 2 Schwestern

- Hauswirtschaftliche Betriebsleiterin: 2 Schwestern

- Sozialarbeiterin: 2 Schwestern

- Sekretärin, kaufmännische Tätigkeiten: 1 Schwester

- Medizinische Laborantin: 1 Schwester

- Physiotherapeutin: 1 Schwester

- Arztgehilfin: 1 Schwester

- Mesmerin: 1 Schwester

Leitungsfunktionen im Kloster:

- Provinz- und Generaloberin, Leitung von mehreren Hundert Schwestern:

5 Schwestern

- Hausoberin, Leitung von mehr als 10 Schwestern: 7 Schwestern

- Hausoberin, Leitung von bis zu 10 Schwestern: 10 Schwestern

Familiäre Herkunft:

- Ländliche Umgebung und kleine Ortschaften, einige Hundert bis wenige Tausend Einwohner:

42 Schwestern

- Kleinstädtische Umgebung und grössere Ortschaften über 5000 bis 10000 Einwohner: 11 Schwestern

\section{Anzahl Geschwister:}

- 1 bis 5 Geschwister:

31 Schwestern 
- 6 bis 10 Geschwister:

19 Schwestern

- 11 bis 15 Geschwister:

3 Schwestern 


\section{Beispiel einer transkribierten Lebensgeschichte ${ }^{427}$}

Sr. Margrit Bösch, Gemeinschaft der St. Anna-Schwestern, Luzern Interviewaufnahme am 4. Oktober $2016 \mathrm{im}$ Gemeinschaftszentrum der St. Anna-Schwestern, Luzern

Ich bin am 10. April 1947 in Grosswangen/Kt. Luzern auf einem Bauernhof geboren als drittes Kind meiner Eltern: Walter Bösch-Rieg und Viktoria Bösch-Rieg. Dort besuchte ich auch zwei Jahre die Primarschule.

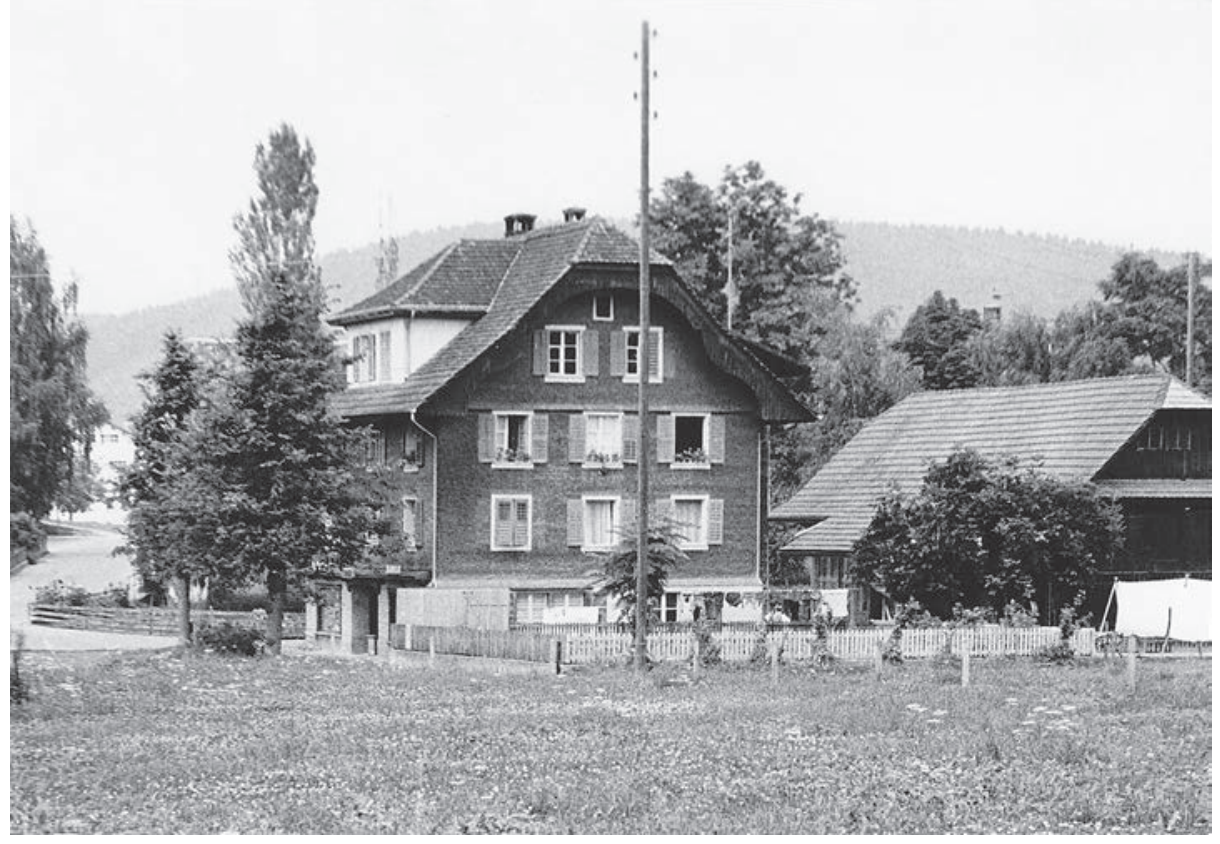

Meine Eltern haben beide sehr viel gearbeitet und waren sehr arm. Trotzdem denke ich gerne an meine Jugendzeit zurück. Meine Schwester war drei, der Bruder acht Jahre älter als ich. Im Alter von zwei Jahren durfte

427 Die Grundlage zu dieser von Sr. Margrit Bösch verfassten Lebensgeschichte bildet das innerhalb des im SNF-Projekt «Lebensgeschichten von Diakonissen und Ordensschwestern» im Oktober 2016 im Gemeinschaftszentrum der St. Anna-Schwestern in Luzern erstellte Interview, das Sr. Margrit Bösch anschliessend selber redigierte. Die Dauer des Interviews beträgt rund zwei Stunden. 
ich zusammen mit meinen Eltern und den Geschwistern das erste Mal nach Deutschland. Die Eltern hatten sich das Geld für das Billet lange zusammengespart. Der jüngste Bruder meines Vaters, er war ledig, hat meine Eltern dazu finanziell unterstützt. Onkel Franz war Sakristan in Buttisholz, (mein Bürgerort) am Wohnort meiner Grosseltern.

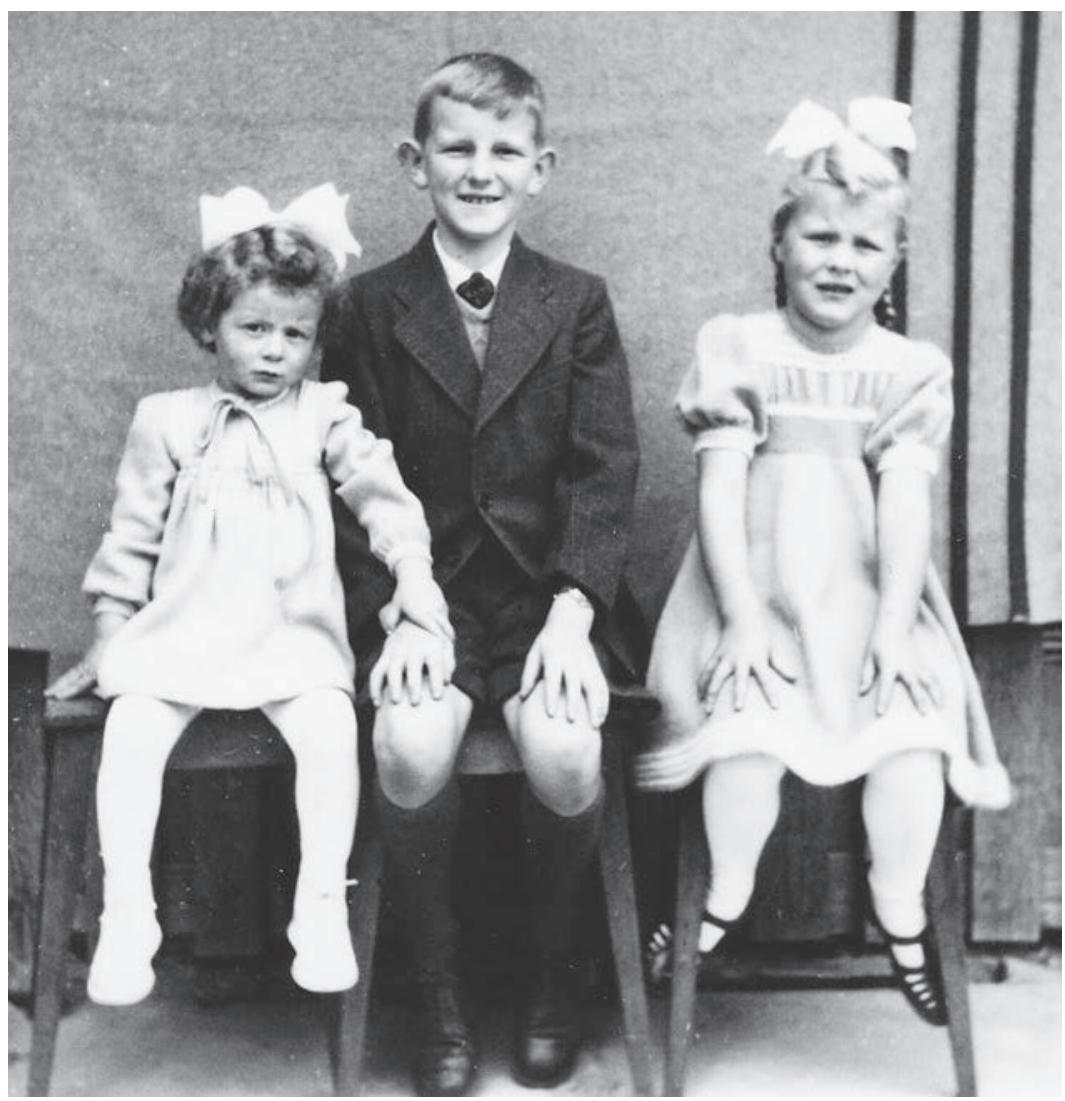

Meine Grosseltern und Tanten in Mutlangen haben mich zum ersten Mal gesehen. Später, mit sieben Jahren reiste ich alleine mit meiner Schwester, mit dem Zug.

Der Grossvater erzählte uns viel aus dem früheren Leben, viele Geschichten vom Krieg und wie er sich retten konnte. Seine erste Frau verbrannte als das Haus Feuer fing. Sie waren frisch verheiratet und hatten noch keine Kinder. So heiratete er ihre Zwillingsschwester, meine Grossmutter. Grossen Eindruck machte mir das Ehebett, das er bis zu seinem 
Tod mit 89 Jahren behalten hat. Unten am Fussende an der Bettstatt konnte man noch Einschüsse sehen. Immer wieder betonte er, dass ihm sein Bett, diese massive Holzbettstatt, das Leben gerettet habe. Dasselbe auch an der Mauer der Pfarrkirche in Mutlangen. Auf der Westseite kann man heute noch die vielen Einschuss-Löcher sehen. Diese Seite wurde bei jeder Renovation ausgelassen, um der Nachwelt die «echte» Aussenmauer zu zeigen. Ein unvergessliches Erlebnis war auch die goldene Hochzeit der Grosseltern1960, an der wir wiederum als ganze Familie daran teilgenommen haben. Das war ein Fest fürs ganze Dorf. Die Dorfmusik begleitete uns vom Wohnhaus der Grosseltern bis in die Dorfkirche.

Darum war dann auch für unsere Eltern, für mich und meine Geschwister auch die goldene Hochzeit unserer Eltern 1987 sehr wichtig. Diese feierten wir in der Muttergottes-Kapelle in Maria Dreibrunnen in Wil, SG. Den 60. Hochzeitstag feierten meine Eltern im «Sonnenhof» im Alterszentrum in Wil. Eine «richtige» Hochzeit, mit Hl. Messe und allen Fragen des Priesters, bis hin zur Segnung der Ringe/Hände. Ein Brautstrauss, der für meinen Vater sehr wichtig war, weil er bei der Hochzeit vor 60 Jahren kein Geld dazu hatte.

Bis im Frühling 1956, bis 14 Tage vor meiner Erstkommunion, ging ich in Grosswangen in die Schule. Dann sind meine Eltern in die Ostschweiz, nach Wil/St. Gallen gezogen, wo ich die Primarschule beendete. Der Grund des Wegzuges war der Gesundheitszustand meines Vaters. Er hatte einen sehr langen Arbeitstag. Mein Vater war Melker auf einem kleineren Betrieb. Am Morgen früh musste er die Kühe melken, tagsüber in der Sägerei arbeiten und am Abend wieder auf den Bauernhof zurück, Gras mähen, die Kühe füttern ... Das Wasser für die Kühe musste er zuerst am Brunnen vor der Scheune heraufpumpen und in den Stall schleppen. Er hatte keine freien Tage und nur einen ganz kleinen Lohn. Da sagte die Mutter, so geht es nicht weiter, so haben wir keine Zukunft.

Für mich war der Wegzug sehr einschneidend und schwierig. In der Ostschweiz wurde ja ein ganz anderer Dialekt gesprochen als in Grosswangen. Der Umzug fand am 9. März 1956, 14 Tage vor meiner Erstkommunion statt. Meinen Kommunion-Gespanen von Grosswangen konnte ich ja nicht nach Wil mitnehmen. In Wil kannte ich niemanden.

Zum Glück war dann noch ein Mädchen, das auch noch keinen Kommunion-Gespanen hatte. Es stammte aus einer Familie mit fünf Kindern. Ihr Vater arbeitete als Wäscher in der psychiatrischen Klinik in Wil. Auch 

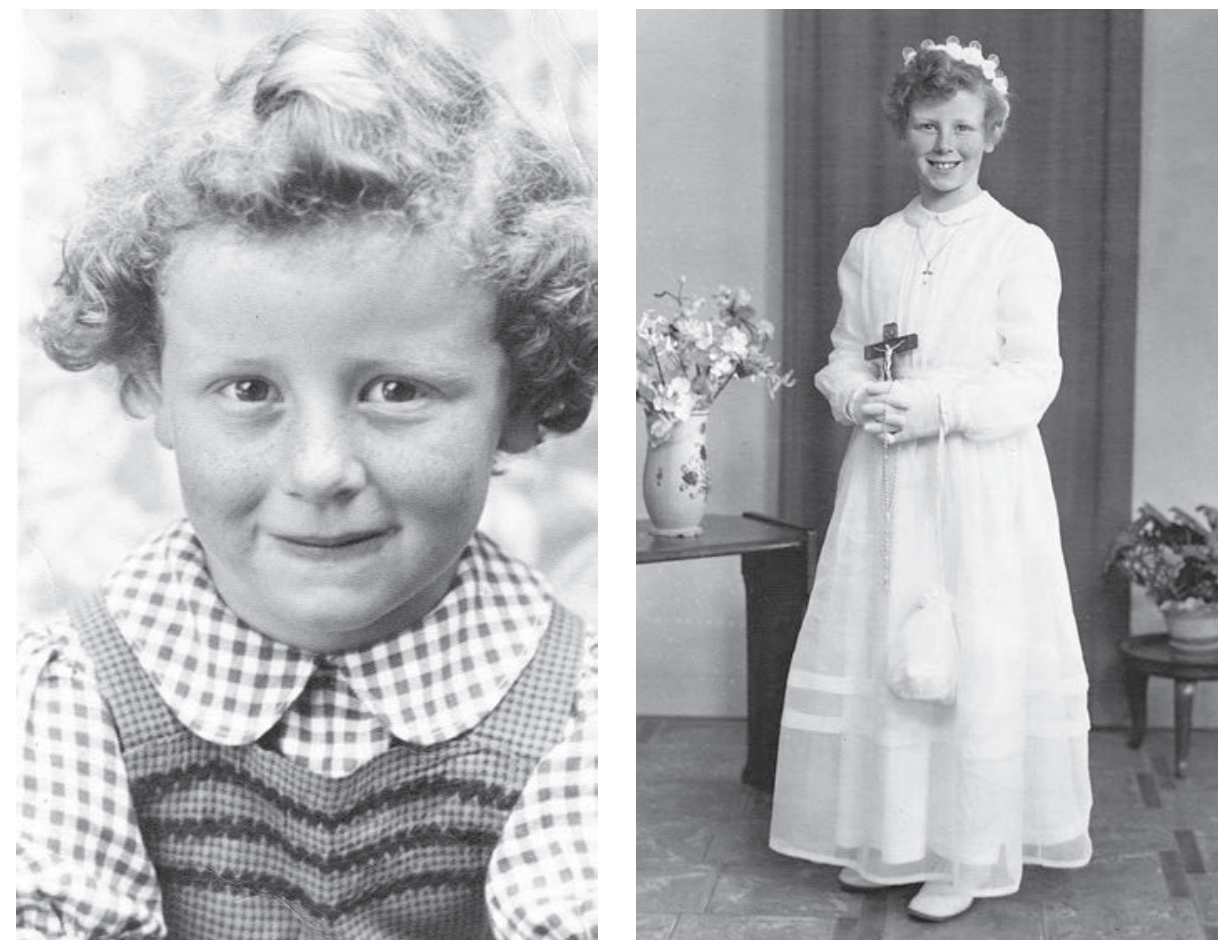

er arbeitete streng. Für mich war das sehr gut. In der Schule bin ich in der ersten Woche zwei, drei Mal weggelaufen. Ich wollte nach Hause. Obwohl ich das erste Mal den Heimweg nicht gefunden habe. Ich habe diese Kinder (Ostschweizer Dialekt!) nicht verstanden.

Ich hatte schon als kleines Kind Heimweh. Ich durfte einmal zu meiner Patin nach Luzern in die Ferien. Meine Eltern aber mussten mich wieder heimholen, weil ich sagte, es sei so weit in die Stadt und es habe kein "Gülleloch»! Der Grund war aber der, dass mir meine Patin die Stadt Luzern zeigen wollte und mich das sehr weit dünkte.

In Wil waren Mädchen und Knaben in der Primarschule und Sekundarschule getrennt. Also Knaben und Mädchen wurden in separaten Schulhäusern unterrichtet. Die Mädchen wurden von den Klosterfrauen vom «St. Katharina» unterrichtet. Nach der Aufnahmeprüfung für die Sekundarschule, besuchte ich diese an der Töchterschule St. Katharina, im gleichnamigen Kloster in Wil. Auch meine Schwester ging hier drei Jahre in die Sekundarschule. Diese Schule hatte einen sehr guten Ruf. 
In der ersten Sekundarklasse 1960 unterrichteten die ersten freien Lehrerinnen (also Lehrerinnen, die nicht Klosterfrauen waren) in der Chemie, im Französisch und im Rechnen. Alle anderen Fächer wurden von den Klosterfrauen erteilt. Auch Handarbeit, Hauswirtschaft. Nach drei Jahren Sekundarschule bereitete ich mich auf die Ausbildung als Kinderkrankenschwester vor. Schon in der Primarschule habe ich in der Freizeit oder den Schulferien sehr gerne kleine Kinder gehütet. Kinder, die im gleichen Haus gewohnt haben oder Nachbarskinder. Ich wollte KinderKrankenschwester werden.

Ich habe dann auch die Aufnahmeprüfung gemacht für die Kinderpflegerinnenschule «Birnbäumen» in St. Gallen. Diese Schule war damals noch nicht anerkannt vom Roten Kreuz. Bei der Anmeldung musste ich auch ein Leumundszeugnis einreichen, das mir mein Religionslehrer, Kaplan Fidelis Scherrer, ausgestellt hatte. Das Couvert aber war verschlossen. Wie gerne hätte ich gewusst, was er geschrieben hatte! Auch für diese Schule war es Bedingung, dass man eine Fremdsprache sprechen konnte.

Meine erste Stelle hatte ich in Fribourg in einer Familie mit 5 kleinen Kindern, keines ging in die Schule. Der Monsieur war Lehrer im St. Michel. Niemand sprach Deutsch!

So absolvierte ich von 1963 bis 1964 das Haushaltlehrjahr bei einer jungen Familie. Rickenbach b. Wil. In drei Monaten kehrte ich wieder heim. Das Heimweh war zu gross. Ihr drittes Kind wurde mitten in meiner Lehrzeit geboren. Die Lehrmeisterin überliess mir zu einem grossen Teil die Pflege des Neugeborenen. Für mich war es eine sehr glückliche Zeit. Ich fuhr jeden Morgen mit dem Velo, manchmal schon vor 07.00 Uhr hin und am Abend wieder heim.

Nach dem Hauhaltlehrjahr, das ich mit sehr guten Noten abgeschlossen habe, arbeitete ich im Winterhalbjahr von 1964 bis 1965 als Schwesternhilfe im Spital Wattwil.

$\mathrm{Da}$ auf der Kinderabteilung keine Stelle frei war, wurde ich auf der Männerabteilung eingesetzt und entdeckte dort meine Fähigkeiten zum Pflegeberuf. Um die vorgeschriebenen Kenntnisse der französischen oder italienischen Sprache nachzuholen, wagte ich es noch einmal ins Welschland.

In einer Kinderarztfamilie in Villars sur Glânes/Fribourg, mit fünf Kleinkindern, vier davon noch nicht schulpflichtig. Ich lernte die französische Sprache beinahe perfekt! Die Madame war eine ehemalige Hebamme, der Monsieur Kinderarzt. Ich arbeitete dort vom Frühling 1965 bis 1966. 
In den Sommerferien war ich zwei Wochen zu Hause und bin einmal in der Stadt der Berufsberaterin begegnet. In der dritten Sekundarklasse hatten wir damals schon (1963!) eine Berufsberaterin, die in die Klasse kam. Sie kannte mich also und fragte mich, wie es mir gehe und was ich zurzeit mache. Ich erzählte ihr, dass ich die Schule in St. Gallen beginnen werde und zurzeit noch mein Französisch verbessere im Welschland Aufenthalt. Dann sagte sie zu mir: Weisst du Margrit, ich kann das nicht verstehen, dass du mit deiner guten Schulbildung, nicht die «grosse» Schule machst. Früher war, die Kinderpflegerinnenschule die «kleine» Schule und die Krankenschwesternschule nannte man die "grosse» Schule. Anschliessend habe ich das meiner Mutter erzählt. Meiner Mutter war es sehr wichtig, dass ihre Kinder eine gute Ausbildung machen konnten. Darum zogen wir ja auch nach Wil.

Meine Mutter, sowie auch der Vater konnte nur die Primarschule besuchen. Nachher mussten sie schon in die Fremde um zu verdienen. Dafür kam meine Mutter als 16-Jährige von Mutlangen, Schwäbisch Gmünd Deutschland, in die Schweiz. Ihr Vater war Schneider. Sie hatte drei Brüder (alle sind im Krieg gefallen) und drei Schwestern.

Sie hat meinen Vater auf einem Bauernhof in Meggen, wo sie als Magd gedient hat, kennengelernt. Mein Vater war "Charrer» und Melker. Er stammte aus einer Grossfamilie mit 10 Kindern, aus Buttisholz, Luzern. Sein Vater war Schreiner. Zwei Brüder und eine Schwester gingen ins Kloster.

Ich erzählte meiner Mutter von der Begegnung mit der Berufsberaterin. Sie sagte mir, aber weisst du, wenn die Berufsberaterin das gesagt hat, dann würde ich auf sie hören, denn das ist so eine kluge Frau. Die Berufsberaterin hatte mir verschiedene Krankenpflege-Schulen in der Schweiz aufgezählt, wo es diese Ausbildung gibt. Ja, und dann habe ich eigentlich ziemlich etwas gewagt. Ich musste mich ja bei der Kinderpflegerinnenschule wieder abmelden, damit ich die eingereichten Unterlagen/Dokumente, die es zur Anmeldung brauchte, wieder zurück erhielt. Ich brauchte diese ja um mich in der anderen Schule neu zu bewerben. Ich erinnere mich noch gut, dass ich mich gefreut habe, somit konnte ich das Leumund-Zeugnis doch noch lesen, das ja geöffnet an mich zurückkam. Das weiss ich noch sehr gut. Ich habe mich dann an verschiedenen Schulen beworben. In Zürich, St. Gallen und in Luzern.

Sr. Martha Röllin, die damalige Schulleiterin der Krankenschwestern-Schule der St. Anna-Schwestern in der Klinik St. Anna Luzern, war die erste, die mir zurückgeschrieben hat. «Liebes Fräulein Bösch ...»Ich 
habe diese Karte immer noch. Sie hat mich eingeladen, doch einmal vorbeizukommen, das würde sie sehr freuen. Ich habe diese Post zuerst noch auf die Seite gelegt und wollte noch die Unterlagen der anderen Schulen abwarten. Dann hat es aber der Zufall gewollt, dass meine Schwester, die bei der FHD war, zu der Zeit in Luzern einen WK absolvierte. Meine Mutter sagte mir dann: «... wenn Marie-Theres schon in Luzern ist, könnte sie dich doch begleiten. Dann sähe sie auch noch, ob das etwas ist für dich oder nicht!» Meine Eltern kannten das «St. Anna» als Klinik. Meine Grossmutter (die Mutter des Vaters) ist 1959 in der Klinik gestorben.

Das haben wir dann auch so gemacht. Meine Schwester ist mitgekommen. Viele meinten sie sei eine Politesse, weil sie die Militäruniform trug. Sr. Martha Röllin hat uns dann das ganze Haus gezeigt, die Schule und die Kapelle, das Esszimmer usw. Aber viel anderes weiss ich nicht mehr. Sie gab mir dann die Anmelde-Formulare für die Schule mit. Ich habe diese ausgefüllt, mich angemeldet.

Aber, dabei habe ich überhaupt nicht gemerkt, dass ich mich damit gleichzeitig auch als Kandidatin für die Schwesterngemeinschaft angemeldet habe!

Am 28. März 1966 habe ich die Lehre als Krankenschwester angefangen. Gleichzeitig trat ich in die Gemeinschaft der St. Anna-Schwestern ein.

Die Ausbildung zur Krankenschwester beendete ich 1969 mit dem Diplomabschluss AKP.

Der Unterschied zwischen den «freien Schülerinnen» so wurden diese damals genannt und den Kandidatinnen für die Gemeinschaft bestand nur in der Form der Schwesternhaube und der Länge der weissen Berufsschürze. Das erste Jahr in der Kandidatur waren wir in der Freizeit noch zivil gekleidet.

Ich erinnere mich noch sehr gut an diesen Eintrittstag. Der 14-er Bus fuhr damals nur etwa $4 \mathrm{x}$ am Tag. Wir waren drei junge Frauen, die mit Koffer beladen eingestiegen sind. Beim Ausladen an der Haltestelle Klinik St. Anna, meinte der Bus- Chauffeur: «So, so, fängt im St. Anna wieder die Rekrutenschule an!!» Beim Hauptportal der Klinik, damals war die Klinik auch gleichzeitig das «Mutterhaus» der St. Anna-Schwestern, stand eine Schwesternhilfe, die schon länger in der Klinik arbeitete. Sie hatte den Auftrag, uns den Weg zur Schule und dann ins Schwesternhaus «Rosenhalde» zu zeigen. Dort waren die Kandidatinnen im untersten Geschoss in kleinen Zweierzimmern einquartiert. Heute, 2019, sind da Gästezimmer, die provisorische Cafeteria, Drehscheibe. 
In meinem Zimmer stand schon ein Koffer mit einer ausländischen Adresse drauf. Das war der Koffer von meiner «Zimmer-Kollegin». Sr. Elisabeth aber kam erst am anderen Tag, weil ihre Grossmutter gerade an diesem Eintrittstag beerdigt wurde.

Beim Anprobieren «der Uniform», der weissen Schwesternschürzen und der Haube, bemerkte ich erst den eigentlichen Unterschied. Es war die Länge der Schürze und das Häubchen war anders geformt. AlLE Krankenschwestern mussten eine Haube tragen und die Haare nach hinten kämmen, dies aus hygienischen Gründen. Das war eine Vorschrift des Roten Kreuzes. Für mich war dies sehr schwierig. Ich hatte ganz kurze, gekrauste, widerspenstige Haare. Doch es musste sein. Andere Schwestern «kämpften» ja auch. Es war Vorschrift und das Einzige, was ich wollte, das war: Krankenschwester werden - und ich wollte eine gute Krankenschwester werden.

Alle Schülerinnen hatten die gleichen Unterlagen, das gleiche Lehrmaterial erhalten. Sogar das Brevier (Stundenbuch) lag auf dem Pult. Die Schürzen, das Schulmaterial musste bezahlt werden. Alle mussten wir am Morgen in die Messe und auch den Rosenkranz beten. Das war damals üblich, dass die ganze Klasse alles mitmachen musste. Das war ein weiterer Grund, warum ich am Anfang nicht realisiert habe, dass ich mich als Kandidatin angemeldet hatte.

Was uns Schwester Martha Röllin noch einprägte, das die Bezeichnung SCHWESTER. Im ersten Lehrjahr durften wir uns nicht als Schwester bezeichnen, sondern als Kandidatin. Ich habe einer ehemaligen Schulkameradin gesagt, ich sei nun: cand. med. (Ärztin in Ausbildung!), weil sie das Wort Kandidatin nicht begriff!

Nach dem ersten Jahr, am Josef-Tag 1967, bekamen wir unser Schwesternkleid.

Wir waren die letzten Schwestern, die noch das alte, fischgratgemusterte Kleid mit Manschetten an den Armen bekamen. Ab 1968 erhielten alle Schwestern die neue Ausgabe!!

Wir hatten von Kaplan Amrein, der unser geistlicher Begleiter war, ein kleines Bildchen erhalten, das war so gross etwa wie eine Jasskarte. Hintendrauf hatte er uns von Hand aufgeschrieben, wie man betrachtet (meditiert). Dazu haben wir noch die Satzungen bekommen; das war ein Büchlein, in dem wir alles nachlesen konnten, wer die Oberin ist, wie sie gewählt wird, welche Aufgaben sie wahrnehmen muss usw. Das war alles, was wir als Unterlagen zur spirituellen Ausbildung bekamen. Im Vordergrund stand eindeutig die Ausbildung zur Krankenschwester. Wir hatten 


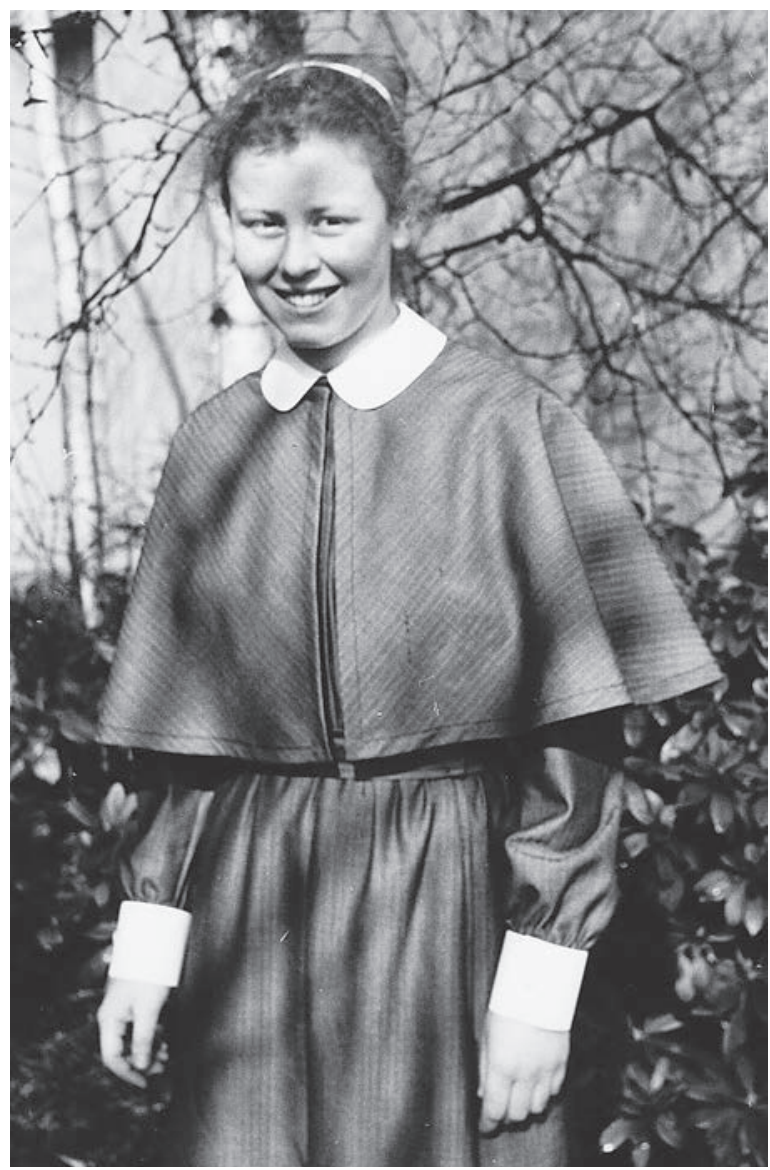

jeden Morgen um 06.00 Uhr, manchmal schon um 05.30 Uhr Heilige Messe. Am Nachmittag war der Rosenkranz und am Abend das Nachtgebet und nach dem Nachtgebet stand Frau Mutter aussen an der Tür bei der Treppe und hat jeder Schwester die Hand gegeben und Gute Nacht gewünscht.

Während diesen drei Jahren der Ausbildung mussten wir verschiedene Fachgebiete, auf verschiedenen Abteilungen durchlaufen. So auch im Gebärsaal. Ich wollte über längere Zeit Hebamme werden.

Da war noch etwas, das mich sehr betroffen machte, was ich zuerst gar nicht recht begriffen habe. Nach der dreijährigen Ausbildung und den anschliessenden Prüfungen, Theorie und praktisch, erhielten die «welt- 


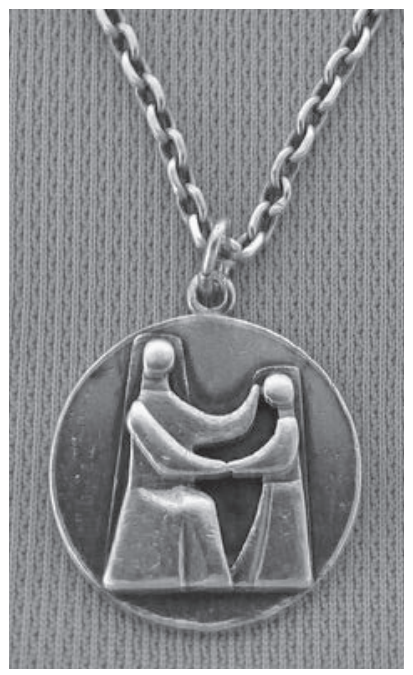

lichen» Schwestern in einer Feier in der Kapelle die Brosche, als Zeichen dafür, dass sie nun diplomierte Krankenschwester AKP sind.

Wir waren drei Kandidatinnen, also angehende St. Anna-Schwestern. Wir haben KeIne Brosche erhalten und das Diplom (schriftlich, A4-Format) auch nicht.

Wir haben keine Brosche bekommen, weil wir dann am ersten Mai-Sonntag unsere ersten Versprechen (für drei Jahre) abgelegt haben. Das Diplom wurde in unserer persönlichen Dokumentenmappe abgelegt.

An unserem Aufnahmetag, dem zeitlichen Versprechen für drei Jahre, erhielten wir die Kette mit der Medaille der Mutter Anna.

Zu diesem Fest durfte ich die Eltern, meine Geschwister, meine Taufpatin Tante Anna und Onkel Hans und meinen Religionslehrer aus Wil, Kaplan Fidelis Scherrer, einladen.

Was mir SEHR in Erinnerung geblieben ist, das sind Gespräche mit meiner Mutter, wenn ich ab und zu daheim war. Sie sagte mir, dass es ihr wehgetan habe, dass sie nicht so geschätzt, beachtet wurde an meinem Treueversprechen-Fest. Als ich sie fragte: Was, wieso meinst du denn das?, dann sagte sie, die Begrüssung von den anderen, den «mehrbesseren» Leuten und den Gönnern der Mission, die war dann schon ganz anders. Diese wurden bei der Feier am Mittagessen besonders erwähnt und geehrt. Das hat mich lange, lange, immer wieder beschäftigt. Ich muss sagen, dass war aber wirklich so. Meine Mutter hatte es wohl stärker empfunden als ich. Ich habe dann wie mitgelitten mit meiner Mutter. Meine Mutter war eine sehr starke Frau. Sie hat mich auch immer wieder darauf angesprochen, dass ich immer dünner werde, zu wenig schlafe, viel arbeiten müsse. Sie mahnte mich immer wieder: «Lass dich nicht ausnützen.» Vielleicht waren die Erfahrungen in ihrem eigenen Leben zu stark und unverarbeitet da. Sie wusste aber auch, dass ich sehr gerne Krankenschwester war und grosse Freude an allem hatte, was ich neu lernen durfte.

Ich habe sehr, sehr viele Jahre unter Migräne gelitten. Im Nachhinein weiss ich auch warum. Ich war oft todmüde, dann das unregelmässige Essen, ja und das waren manchmal Arbeitstage von 14 und 16 Stunden. Dazu kamen die Notfälle wie zum Beispiel Kaiserschnitt dazu. Wir hatten damals keine Notfallequipe, wenn ein Kaiserschnitt mitten in der Nacht 


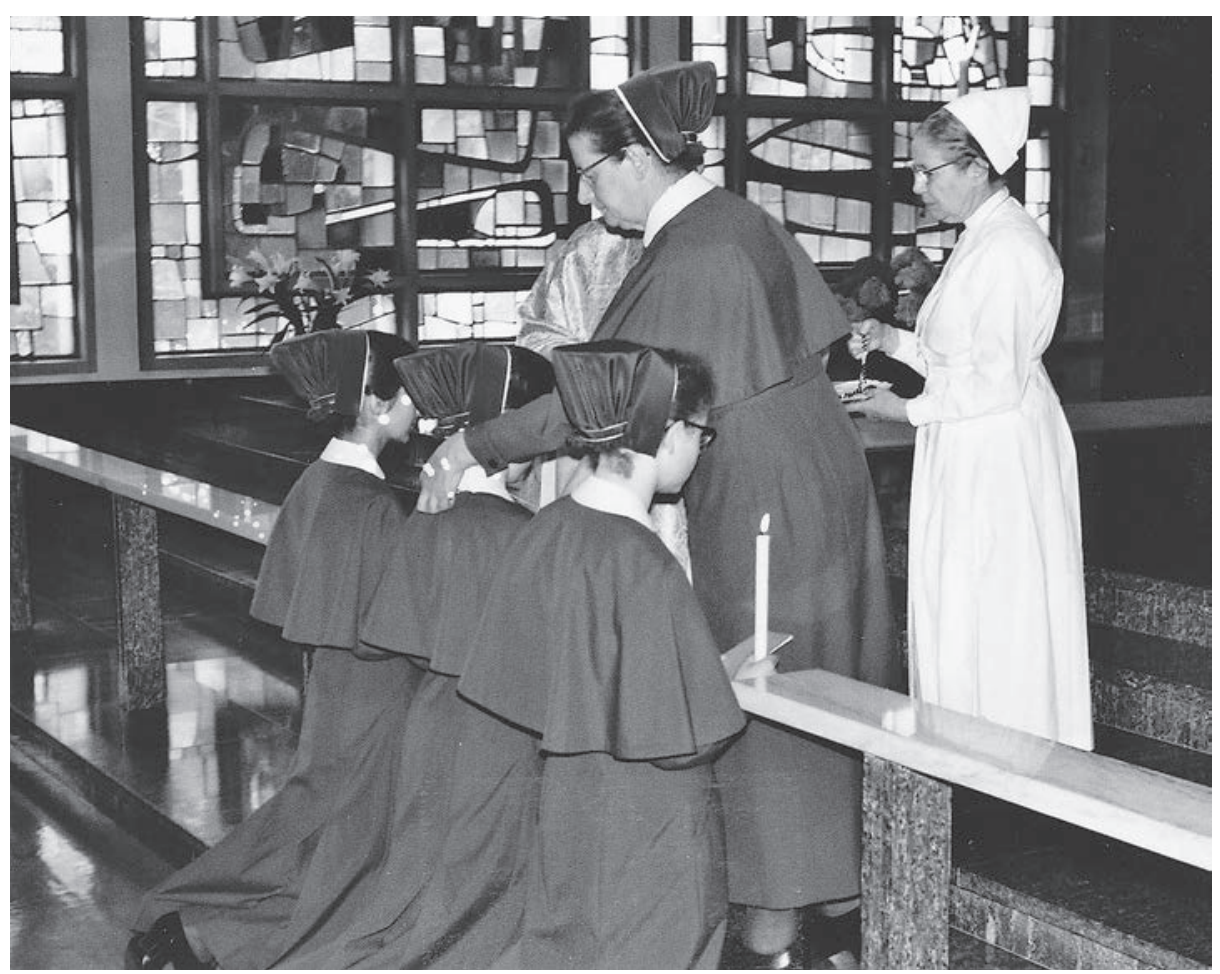

angemeldet wurde, mussten wir aufstehen und gehen. Das merke ich heute noch mit der Schlafqualität. Ich habe einen sehr oberflächlichen Schlaf. Das kommt wohl daher, dass ich über Jahre immer bereit sein musste, im Schlaf noch mit einem Ohr hören ob jemand an die Zimmertüre klopft. Damals hatten wir noch kein Telefon im Zimmer. Die Nachtwache weckte jeweils die Schwestern, die aufstehen mussten, das heisst sie kamen ins Zimmer und weckten uns, indem sie das volle Licht angezündet haben. Trotz allem, ich habe diese Arbeit sehr geliebt und habe dabei auch viel gelernt. Und: ich wollte immer noch eine gute Krankenschwester sein. Wenn du viel arbeiten konntest und gut gearbeitet hast, nie krank und immer am Morgen in der Kirche warst, dann warst du eine gute Schwester. Das war einfach der Massstab damals. Das war aber nicht nur bei den St. Anna-Schwestern so. Das haben mir auch Schwestern aus anderen Gemeinschaften erzählt.

Nach der Diplomierung arbeitete ich 6 Wochen auf der Nachtwache und anschliessend dann vor allem in den Operationssälen der Klinik 
St. Anna Luzern. Wir hatten ja auch noch Kliniken in Fribourg und Sorengo im Tessin, die ich aber nur von Besuchen her kannte.

Ich habe zuerst die vielen spezifischen Arbeiten im Operationssaal gelernt, wie zum Beispiel das Kennenlernen und Pflegen der Instrumente. Ich war damals schon Perfektionistin, was sich aber für diese Arbeit positiv auswirkte. Ich durfte «zudienen» und sehr bald schon bei grösseren oder kleineren Eingriffen assistieren. Ich hatte sehr grosse Freude an dieser Arbeit. Es war aber auch sehr, sehr streng. Oft mussten wir ja schon morgens um 04.30 Uhr mit der Arbeit beginnen, weil wir die Wäsche und alle Instrumente, alles selber einpacken und sterilisieren mussten. Damals war Zentralsterilisation ein Fremdwort! Nebst dem Instrumentieren lernte ich auch Infusionen stecken, das Vorbereiten und das Überwachen der Patienten. Meine Arbeit, mein Da-Sein für die Patienten wurde auch von einigen Ärzten sehr geschätzt. Das spürte ich auch und gab mir grosse innere Zufriedenheit und Ansporn für noch mehr Einsatz. Einige Ärzte haben meine Talente erkannt und gefördert.

$\mathrm{Zu}$ unsrer Arbeit gehörte auch das Vorbereiten der Kinder. Immer am Samstag hat die damals noch junge Kinder-Chirurgin Frau Dr. Margrit Stockmann operiert.

Grosses Vertrauen wurde mir als junge Schwester auch geschenkt, wenn ich ganz selbstständig auf die Neugeborenen-Abteilung gehen durfte. Dort musste ich alles vorbereiten (sterile Instrumente, die nötigen Blut-Flaschen) und dann mit dem zuständigen Kinderarzt einen Blutaustausch vornehmen. Auch das Neugeborene überwachen gehörte dazu. Das waren Kinder mit einer Rhesus-Faktor-Unverträglichkeit. Heute unvorstellbar!

Erst mit den Jahren und der grossen Entwicklung auf allen Fachgebieten mussten wir uns entscheiden, welchen Fachausweis wir wollten, welcher besser geeignet war.

Entweder Anästhesie- oder Instrumentier-Schwester (Technische Operationsassistentin heisst das heute). Das verlangten das Rote Kreuz und der Berufsverband SBK.

1973 entschloss ich mich für die Anästhesie. Diese konnten wir im Haus absolvieren, aber für die Theorie mussten wir ins Kantonsspital, ebenso das Praktikum auf der IPS und im Notfall. Das war noch zusätzlich streng. Die Theorie war erst am Nachmittag und nach diesen Schulstunden mussten wir daheim noch helfen, im OPS zu putzen oder für den anderen Tag vorzubereiten. Das war einfach so. Ich habe mich nicht weiter daran gestört. 
1974 habe ich diese Ausbildung mit Fachausweis abgeschlossen.

Immer wieder lernte ich Neues hinzu. Weiterbildung war mir wichtig. Nebst dieser anspruchsvollen Arbeit engagierte ich mich auch im Berufsverband SBK und war aktives Gründungsmitglied der Interessengruppe Anästhesie - Zentralschweiz.

1988, bei einem zweitägigen Ausflug mit dieser Interessengruppe, der auch Anästhesieärzte angehörten, bin ich beim Aufstieg zum Chaiserstock in den Urner Alpen (ab Liderenhütte) verunglückt. Die REGA musste mich bergen. Ich hatte eine Trimalleolar-Fraktur am rechten Fuss. Der Fuss schaute hinten hinaus! Es folgte mein erster Flug mit der REGA und dann meine ersten Erfahrungen in der Klinik ... als Patientin!

Trotzdem habe ich die Freude am Wandern nicht verloren. Gerne erholte ich mich auch beim Velofahren oder Schwimmen und beim Fotografieren. Einige Jahre amtete ich als Hausfotografin.

1985, nach dem Einzug in die renovierten und neuen Operationssäle, da war wochenlang ein Techniker im OPS, der uns immer begleitet hat. Die neuen Narkose-Apparate waren computerisiert. Wir mussten alle umgeschult werden, sonst konnte man gar nicht mit diesen Geräten arbeiten. Aber das war dann gleichzeitig auch so, dass wir immer weniger mit dem Patient zu tun hatten.

Ich erinnere mich so gut an ein Kind. Im TV gab es damals eine Sendung die «Die Schwarzwaldklinik» geheissen hat. Dieser Bub hat das scheinbar jeweils auch geschaut. Ich musste ihn vorbereiten für eine Leistenbruch-Operation. Er hatte grosse Angst und wollte jede Handlung genau erklärt haben. Ich habe ihm dann sitzend drei Elektroden fürs EKG aufgeklebt. Das fanden die Kinder meistens interessant. Das habe ich darum auch zuerst gemacht, weil das die Kinder interessierte und gleichzeitig auch ablenkte.

Ich sagte dann zu den Kindern: «Jetzt kannst du schauen wie dein Herzli «gumpet!»

Sie haben sich so auf den Monitor konzentriert. Das lenkte sie ab und ich konnte weiter vorbereiten. Das habe ich bei diesem Buben auch gemacht. Nach einer Weile hat er sich immer wieder ein bisschen bewegt. Ich habe ihn dann wieder zugedeckt und habe mit ihm gesprochen. Auf einmal ist er in einem Ruck aufgesprungen und hat auf den Monitor geschaut und geschrien:

«Bin ich jetzt tot?» Er sah nur einen Strich auf dem Monitor, weil er die Elektroden mit dem Händchen abgerissen hatte. Vom Film der 
Schwarzwaldklinik her wusste er, wenn ein gerader Strich kommt, dann ist der Mensch tot!

Dieses Erlebnis mit diesem Kind kommt mir immer wieder in den Sinn. Immer wieder dann, wenn es irgendwelche Neuerungen, Verbesserungen der Technik gibt.

Früher hat man das Kind auf den Arm genommen und dann hat der Narkosearzt ein bisschen Lachgas in die Nähe des Gesichtes des Kindes gegeben und dann sind diese Kinder ruhig eingeschlafen Manchmal hat das auch mich müde gemacht, nach acht oder zehn Kindern.

Auch die Chirurgen/die Operationsmethoden haben sich geändert. Ich erinnere mich gut an die ersten Hirnoperationen hier in der Klinik. Es kam dafür extra ein Professor vom Ausland. Das heisst, es brauchte auch neue Operationsmikroskope und für die Anästhesie noch mehr, noch feinere Überwachungsgeräte. Auch wurden nun die ersten Operationen mit der «Schlüsselloch-Technik» begonnen. Es kam ganz viel Neues.

Auch ein sogenannter Schönheitschirurg eröffnete in der Stadt eine Praxis und hat in unserer Klinik operiert. Er hat auch ganz viel Neues gebracht, das wir sonst im St. Anna gar nicht gekannt haben. Zum Beispiel hat er einer kriegsverletzten Vietnamesin, die ein völlig verunstaltetes Gesicht durch eine Schussverletzung hatte, ein «neues Gesicht» gestaltet. Die OP wurde von jemandem finanziert. Er kam mir vor wie der liebe Gott in Person. Es war ein eindrückliches Kunstwerk. Er hat ihr ein wunderschönes Gesicht gemacht. Dabei erklärte er uns auch, dass er das nur kann, weil er die Technik, die Übung durch das Operieren von z.B. FaceLifting, gelernt hat. Das war eine unvergessliche Erfahrung für mich. Das nahm mir den negativen Ruf von Schönheitsoperationen.

Ja das waren Meilensteine für mich, auch zu sehen, was es da alles gibt.

Patienten, die ein Face-Lifting bekamen, mussten wir stundenlang überwachen. Der Eingriff wurde in Lokalanästhesie ausgeführt und dauerte 6 bis 7 Stunden!

Ich war einmal bei einer Frau zugeteilt, die sehr schwierig war. Schon beim Eintritt, bei den Vorbereitungen hat sie immer wieder reklamiert. Ihre Face-Lifting-Operation dauerte sieben Stunden oHNE Narkose, in Lokalanästhesie. Und ich musste diese Frau überwachen. Ich bin fast verzweifelt. Meine Gedanken wanderten immer wieder in die Stadt, ins Krankenzimmer für Obdachlose, KFO. Mein Herz war dort, dort wäre meine Arbeit gefragt - und auch notwendig! Not wendend! 
Ich spürte immer häufiger, dass ich meine Arbeit im OPS aufhören wollte, aufhören musste. Auch Sonderbehandlungen reicher Patienten störten mich mehr und mehr.

Ich habe niemandem von meinem Wunsch erzählt. Ich hätte es auch nie gewagt, das jetzt einer Oberin oder der Frau Mutter zu sagen, denn das waren ja auch Patienten, die uns Geld brachten, und sie waren oft auch Gönner von der Mission.

Der Auftrag unseres Gründers, der Gründergedanke lautet: «Der Not der Zeit zu begegnen!»

Vor diesem Hintergrund wurde ja unserer Gemeinschaft auch gegründet. Das war für mich immer der Leitsatz. Lange Zeit vielleicht auch unbewusst. Aber es wurde dann immer wichtiger. Ich war damals noch nicht ganz 50 Jahre alt.

Mehrmalige Aufenthalte in Taizé hatten mich geprägt, machten mich noch hellhöriger für die Frage des «Lebensnotwendigen», eben für die Not der Zeit. 1979 verbrachte ich die ganze Karwoche/Ostern in Taizé und feierte am Dienstag meinen Geburtstag an diesem wunderschönen Ort. Das Thema ARMUT war allgegenwärtig. Was ist lebensnotwendig? Es sind Wasser und Luft! Auch wenn ich kein Bett oder keine Kleider habe, sterbe ich nicht. Wie viele Dinge haben sich auch in meinem Leben angehäuft, die ich gar nicht brauchte. Kleider, Bücher, die ich seit Jahren nicht mehr angezogen oder angeschaut habe. Die Taizé-Lieder begleiten mich noch heute in meinem Leben. Ich singe oder summe sie, wenn mir die Kraft zu anderen Gebeten, Gedanken fehlt oder auch, wenn ich sehr glücklich bin.

«Dans nos obscurités allume le feu qui ne séteint jamais, qui ne s'éteint jamais ..."

«Meine Hoffnung, meine Freude mein Licht, Christus meine Zuversicht. Auf dich vertrau ich und fürchte mich nicht.»

Oder:

«Das Magnifikat» in verschiedenen Melodien.

Immer wieder dachte ich nach, was könnte ich denn sonst noch machen? Es ging so weit, es hat mich so beschäftigt, dass ich unten in der Stadt zu einer Berufsberaterin ging. Das sagte ich niemandem. Sie hat mir ein paar Berufe aufgezeigt, Berufe, die auch mit den Menschen zu tun haben. Die Pflege am Krankenbett habe ich ja nicht praktiziert. Spitex kam also nicht 
infrage. Ich war nach dem Diplom sechs Wochen auf der Nachtwache und bin dann nachher direkt in den OPS gekommen.

Ich habe dann einmal einen Tag lang bei einer Podologin geschnuppert. Aber das war mir wie zu weit weg. Damals hatte ich noch das Gefühl, ja Fingernägel und Zehennägel anstreichen, das ist Luxus, das ist kein Beruf! «Kommissar Zufall» half mir weiter!!

Im Herbst 1994 war in der in der Stadt Luzern eine Abstimmung. Das Gefängnis am Löwengraben war sehr alt. Um der Bevölkerung die Notwendigkeit eines Neubaus aufzuzeigen, veranstalteten sie vor der Abstimmung einen «Tag der offenen Tür».

Das interessierte mich sehr. Ein «Tag der offenen Tür» in einem Gefängnis, das ist einmalig. Ich ging hin und liess mir alles erklären, ich schaute in jede Ecke! Da fiel mir auch ein Plakat an der Wand auf: Sie suchten eine Krankenschwester für Nachtwache. Eine Krankenschwester im Gefängnis? Ich habe mich gleich näher erkundigt. Sie erklärten mir, dass ich zur Vorbereitung zuerst im Frauengefängnis Hindelbank einen sechswöchigen Einführungskurs besuchen müsse. In Hindelbank war gerade der Direktionswechsel. Darum empfahlen sie mir mit dem Praktikum bis Anfang Jahr 1995 zu warten. Ich hatte aber die Zusage.

Die Arbeit im OPS ging weiter, aber auch mein Suchen. Ich begleitete eine Sozialarbeiterin zu Fuss durch die Stadt, durch die Gassen. Mit dem Beatmungsbeutel im Rucksack. Nach über dreissig Jahren im Operationssaal drängt es mich immer mehr hinaus aus der Klinik. Es drängt mich hin zu den Bedürftigen am Rande in der Stadt. Damals bestand die Eisengasse noch mit der ganzen, offenen Drogenszene. So bin ich dann das erste Mal in Kontakt gekommen mit dem Krankenzimmer KFO. Um uns aufzuwärmen, begaben wir uns an die Murbacherstrasse 20, wo das Krankenzimmer war. Das hat mich dann so fasziniert, dass es dort schwer kranke Menschen gab, junge Menschen. Ein Mann, der mich sehr beeindruckt hat, sein Blick, seine Atemnot, abgemagert auf die Knochen. Das hatte ich noch nie gesehen. Er ist zwei Tage später gestorben. Ich hatte von Drogen und von AIDS null Ahnung. Das war wie auf einem anderen Planeten für mich und auch wie Tag und Nacht zur Arbeit in der Klinik.

Ich erinnere mich gut an jenen Morgen, wo ich am Tag zuvor bis spät in der Nacht auf der Gasse war. Ich musste am morgen früh einen Patienten mit einem Hirntumor vorbereiten. Das gibt ja sehr viele Vorbereitungen mit technischen Apparaturen. Ich sehe es noch vor mir, ich spüre es fast noch, wie es mir war. Ich habe gemerkt, nein, das geht nicht zusam- 
men. Meine Seele hat es nicht geschafft, am anderen Tag wieder in den OPS zu gehen und ganz bei dieser Arbeit mich zu konzentrieren.

Ich habe mich dann bei der damals zuständigen Oberin gemeldet. Sie hatte sehr grosses Verständnis. Wir sind dann so verblieben, dass ich in der Klinik noch $50 \%$ und in der Gassenarbeit $40 \%$ gearbeitet habe. Das war dann besser - ABER nach einigen Monaten habe ich die Klinik ganz verlassen. Ich war mit Leib und Seele Anästhesieschwester, Krankenschwester und es war eine unvergessliche, sehr lehrreiche und beglückende Zeit, über 30 Jahre im OPS.

Dennoch habe ich den Weggang NIE bereut. Es begann ein neuer Lebensabschnitt.

Ich habe dann angefangen an meinen Freitagen ein paar Stunden am Tag hinzugehen, um zu helfen. Bald schon habe ich dann auch Nachtwache gemacht. Am Anfang nicht alleine, sondern als Mithilfe. Dass ich da Nachwache machte, habe ich daheim geheim gehalten. das ist mir auch gelungen.

Anfangs 1995 stellte ich mich dieser neuen beruflichen Herausforderung. Das Krankenzimmer für Obdachlose (getragen von einem Verein), das KFO, hatte mein Herz erobert. In diesem Zimmer gab es vier Betten, die Kranken wurden rund um die Uhr betreut. Drogenkranke, HIV-Positive, AIDS-Kranke und alkoholabhängige Menschen fanden hier Betreuung und Pflege. Es war eine mir unbekannte Welt! Berufsbegleitend absolvierte ich 1996, während eines Jahres, die vom Berufsverband angebotene Zusatzausbildung: Begleitung und Pflege von Menschen mit HIV und AIDS.

1996 übernahm der Verein Kirchliche Gassenarbeit von Luzern das Krankenzimmer. Es wurde als medizinisches Ambulatorium weitergeführt. Dort arbeitete ich während acht Jahren. Regelmässig vertiefte und erweiterte ich meine Fachkenntnisse in verschiedenen Weiterbildungen. Ich wurde Mitglied der IG HIV und AIDS. 2002 habe ich das NDS an der Uni Bern besucht: Kirche im Strafvollzug. Umgang mit psychisch auffälligen Gefängnisinsassinnen/Gefängnisinsassen.

Ich machte ein Praktikum in der Strafanstalt Wauwilermoos und in der Strafanstalt Grosshof Kriens. Unvergesslich sind die vielen Besuche, die ich in verschiedenen Gefängnissen machte, wie zum Beispiel in Zug oder im Torberg BE. Ich wurde Mitglied der Gefangenenseelsorge Schweiz und nahm regelmässig an den Tagungen und Weiterbildungen teil.

Es waren sinnvolle, spannende und bereichernde Jahre. Mehrere intensive Lebensbegleitungen bis zum Tode erlebte ich als Geschenk und 
Bereicherung für mein eigenes Leben. Ich wurde konfrontiert mit Verarmung, Verwahrlosung, Einsamkeit und Not, mit Krankheit und Tod.

Im Krankenzimmer für Obdachlose musste ich auch eine neue Sprache lernen. Ich hatte ja keine Ahnung von Drogen und dem Umgang mit diesen Menschen, ihren Gewohnheiten, ihren Zwängen und Krankheiten.

Das hat mich so fasziniert. Diese Menschen sind mir so ans Herz gewachsen, weil sie so echt waren, so direkt. Es war für mich als Ordensschwester überhaupt kein Problem.

Im Gegenteil! Was macht denn eine gute Schwester aus? Nur das Äussere? Das Tragen eines Ordenskleides, einer weissen Berufsschürze und die Haube? Ganz klar NEIN! Durch diese Menschen habe ich es gelernt.

Als ich am 28.03.1966 eingetreten bin, war ich noch nicht ganz 19 Jahre alt und bin heute immer noch bei den «Jüngsten»! Auch mit 40, 50, wenn die älteren Schwestern sagten, ja die Jungen sollen das jetzt machen, hat mich das damals schon gestört. Ich habe es immer vermisst, dass ich meine Begeisterung, meine Ideen nicht mit jüngeren Schwestern teilen konnte. Darum war ich wahrscheinlich umso glücklicher als ich mich dann im Beruf, in den verschiedenen Weiterbildungen voll entfalten konnte.

Ab 1992 konnten wir zwischen dem grauen Schwesternkleid oder zivilen Kleider wählen. Zum Arbeiten im OPS war es ohnehin klar, dass wir uns umziehen mussten.

In der weissen Schürze und mit dem Häubchen in diese Gassenarbeit gehen ... unmöglich!

Das war für mich ganz klar, dass ich zivil gekleidet gehe, schon aus hygienischen Gründen. So war ich auch glaubwürdiger, auf der gleichen Ebene: niederschwellig. Ohne Distanz, ohne Hindernis, das heisst für mich, gar keine Schwelle. Ich bin auf dem gleichen Boden und auf der gleichen Ebene wie diese Menschen. Das gab auch viel Nähe und unvergessliche Erlebnisse. Ich habe dann bald gemerkt, dass ich mit ihnen in ihrer Sprache reden musste um gehört zu werden.

So habe ich auch ab und zu geflucht und ihre Wörter/Ausdrücke übernommen und gesagt. Einmal habe ich wirklich ganz «wüescht» geredet, aber es ging nicht anders. Dieser Mann hat einfach nicht auf mich gehört. Es kam ein anderer Mann dazu. Auch er war ein schwer kranker, schwerst drogen- und alkoholabhängiger Mann. Er stand vor mich hin und sagte: ... also Margrit, du darfst doch nicht fluchen, du bist doch eine Klosterfrau. Und?, sagte ich, wo in der Bibel steht denn das geschrieben? 
Solche Rückmeldungen waren oft die Grundlage zu sehr tiefen und ganz persönlichen Gesprächen, die grosses gegenseitiges Vertrauen schafften. Es war sehr faszinierend mit diesen Menschen über ganz ernste Probleme zu reden. Also über ihren eigenen Tod, über ihr Leben oder was es ihnen wert ist. Über ihre Kindheit, ihre Erziehung, ihre Eltern. Tiefsinnige Gespräche, wie ich es mit meinen Mitschwestern ganz selten führen konnte.

Mein Beruf als Krankenschwester und als Anästhesieschwester erleichterte mir den Zugang sehr. Ich wusste vieles über die Drogen, über die Drogen als Heilmittel, wenn sie richtig dosiert wurden. Das hat mir sehr geholfen. Ich hatte auch von verschiedenen Ärzten die Kompetenz weiterhin, also ausserhalb der Klinik, Medikamente zu spritzen. Zum Beispiel das Gegenmittel (Narcan) bei einer Überdosis. Dieses Medikament darf man als «normale» Krankenschwester nicht spritzen, nur wenn man die Ausbildung als Anästhesieschwester hat. Dieses Antidot hat auch Nebenwirkungen und diese muss man auch erkennen und wenn nötig darauf reagieren können. Diese Menschen hatten oft aufgrund des Drogenkonsums epileptische Anfälle. Ich erinnere mich sehr gut an jenen jungen Mann, der vor meinen Augen kopfvoran die Treppe hinunterstürzte. Ich konnte nichts tun als bei ihm bleiben, bis der Krampf sich gelöst hatte.

Das hat jeweils allen, die das miterleben mussten, grossen Eindruck gemacht. Ich habe solche Momente auch immer wieder dazu benutzt, mit ihnen über den Tod, den plötzlichen Tod zu sprechen. Das öffnete oft ihre Herzen um auch einfache Probleme, die sie schon lange beschäftigen, Konflikte mit den Eltern usw. anzusprechen. Einmal sagte ein sehr junger Mann zu mir: «Du redest wie meine Mutter.» Das gab mir die Gelegenheit nachzufragen, was denn seine Mutter zu ihm gesagt habe, es gab einen ganz neuen Zugang. Sie hatten absolutes Vertrauen in mein medizinisches Können. Das hat mir wie ein Vorschussvertrauen gegeben auch für andere Themen.

Am Anfang musste ich mich auch mit mir sehr ungewöhnlichen Schwierigkeiten auseinandersetzen. Ein Rauchverbot in öffentlichen Räumen, das war kein Thema. Da habe ich, wenn ich nach Hause kam, so richtig gestunken! Der Rauch in unseren Räumen war oft so dicht, dass wir die Leute kaum gesehen haben. Das war einfach so, es hat dazugehört. Das war ja auch sehr ungesund. Oft liefen mir die Tränen über die Wangen, meine Augen waren so ausgetrocknet und gereizt. Ich weiss noch ganz gut, wie mich einmal eine Mitschwester zurechtgewiesen hat. Ich 
kam nach Hause, ging kurz ins Zimmer und nachher zum Abendessen. Sie wies mich sehr ungehalten und unhöflich drauf hin, ich solle zuerst duschen gehen, bevor ich ins Esszimmer käme.

Es war auch verboten am Sonntag in Hosen!! in die Kirche zu gehen. Ich ging trotzdem hin. Ich sagte mir, ich gehe wegen dem lieben Gott in die Kirche und nicht wegen den Schwestern! Ja, das war für mich immer auch ein bisschen ein «Reizpunkt».

Immer wieder habe ich mich dann auch am Rande gefühlt, am Rand der eigenen Gemeinschaft. Ich bin dankbar, dass ich diese Erfahrungen, selbst die schmerzlichen Erfahrungen machen durfte. Auch die Erfahrungen mit dem Geld - oder ohne Geld!!

Ich hatte ja gleich viel Taschengeld wie alle anderen Schwestern. Die Schwestern, die zivile Kleider tragen, erhalten gleich viel Taschengeld wie die Schwestern, die sich für das Ordenskleid entschieden haben. Wir mussten die zivilen Kleider von Anfang an selber waschen. Die anderen konnten sie in die Wäscherei geben. Auch das Waschpulver mussten wir kaufen. Das waren Beträge, die sich dann eben doch summiert haben. Aber auch durch diese Ungerechtigkeit habe ich viel gelernt. Doch was ist Armut?

In unserer Gemeinschaft geht die Vorstellung von Armut weit auseinander. Für mich ist es immer wieder ein wichtiges Thema, denn die Armut gehört ja schliesslich zu unseren evangelischen Räten.

Oft werde ich auch darauf angesprochen, auf diese «ewige Bettlerei» am Bahnhof. Dabei kommt auch immer wieder die Frage: Sollen wir etwas geben oder sollen wir nichts geben? Darauf sage ich immer die gleiche Antwort: Wenn ich etwas gebe, dann beschäftigt es mich nachher und wenn ich nichts gebe, dann beschäftigt es mich nämlich auch. Das ist seit 20 Jahren so. Das Wichtigste ist einfach, dass man es ihnen wenigstens anständig sagt, erklärt, dass man nichts geben kann oder dass man jetzt nichts geben möchte.

Ich bin überzeugt, dass ich gerade deshalb diese Menschen verstehen, ihnen nachfühlen kann, weil ich es selber erfahren habe was es heisst, wenn das Taschengeld aufgebraucht und das Portemonnaie leer ist.

Ich habe sehr, sehr viel gelernt von diesen Menschen und immer und immer wieder versuche ich zu hören, was Gott mir durch diese Menschen sagen will.

Ich lernte neu, was es heisst, Mensch sein dürfen, arm sein ... Ich lernte umzugehen mit Machtlosigkeit, Hilflosigkeit, lernte Ekel überwinden, Distanz und Nähe richtig zu dosieren. Mich betroffen machen, nicht 
mitleiden, sondern betroffen sein, betroffen vom Schmerz, der Angst, der Not des anderen, der jetzt da ist, so wie er es erlebt, wie er heimgesucht wird, ihn ernst nehmen. Ohne Erwartungen für ein bestimmtes Verhalten oder Reagieren, absichtslos in einer Echtheit und Offenheit. Dienend werden, nicht gönnerhaft, das wäre verletzend. Das gibt ihnen auch das Gefühl, die Gewissheit, angenommen zu sein.

Aus diesem echten und auch gefühlsmässigen Mitgehen erwächst dann auch die Kraft zum Aushalten.

Es geht ja nur darum, diese Menschen zu begleiten. Alle, alle wollen sie ja nur als Menschen angenommen und geliebt werden.

Nebst meiner Arbeit im medizinischen Ambulatorium, engagierte ich mich in der «Spur-Gruppe», in der Projektgruppe, aus der der Treffpunkt Stutzegg entstand. Das ist ein Ort der Begegnung und der Gastfreundschaft, ein Projekt des Vereins HÔTEL DIEU in Luzern. Frauen und Männer aus verschiedenen christlichen Konfessionen und aus Ordensgemeinschaften hatten sich zusammengefunden. Ab 1998 arbeitete ich regelmässig im «Stutzegg». Von 2003 bis 2007 als stellvertretende Leiterin. Im Auftrage dieses Vereins betreute, begleitete und pflegte ich auch vereinsamte, ausgegrenzte, nicht integrierte Menschen, in ihrem Umfeld, dort wo sie leben und wohnen. Darum konnte ich mich wiederum einer neuen Herausforderung stellen. Um meine langjährige Erfahrung noch professioneller, fachlich fundiert und den heutigen Anforderungen entsprechend anwenden zu können, habe ich mich 2003 für einen Studienplatz an der Schule für Sozialbegleitung in Zürich beworben. Diese Schule beendete ich 2006 erfolgreich mit dem Diplom.

In einer schriftlichen Arbeit während meiner Ausbildung zur Sozialbegleiterin habe ich meine Grundhaltungen formuliert und schriftlich festgehalten.

Meine Grundhaltungen:

Menschlichkeit und Herzlichkeit über jede Art von beruflicher Fachkompetenz hinaus.

Vertrauen als Fundament jeder echten Begegnung zwischen Menschen.

VERLÄsSLICHKEIT, die sich ausdrückt im Mitgehen, im Halt Geben, Mittragen und Dranbleiben.

GeDULD, Suchbereitschaft, nicht vorschnell Antwort geben, auch auf schwere Fragen,

Aggressionen und Enttäuschungen AUSHALTEN.

Spirituelle Offenheit, OffenheIt für die Möglichkeit eines Trostes. 
Immer wieder waren es gerade diese Erinnerungen, Erlebnisse mit der Armut, die mich näher zu den Armen und Ausgegrenzten der Stadt gebracht haben.

Es genügt nicht, nach Feierabend auf der Strasse dem einen oder der anderen ein gutes Wort mit auf den Weg zu geben oder einen, zwei Fränkler in die Tasche zu schieben.

Aufsuchende Sozialbegleitung heisst für mich auch mit wachem Herzen und offenen Augen durch die Strassen und Gassen der Stadt zu gehen.

Es war Anfang Sommer, ich wartete auf einen Bus am Kasernenplatz, doch da zog es mich zu Fuss über die Brücke auf die andere Seeseite. In einem Lied von Peter Maffay heisst es: «Über sieben Brücken musst du gehen.» In meinem Herzen summt es: über diese Brücke musst du gehen! Auf der einzigen Bank auf der Brücke lag ein obdachloser Mann (... und das seit Monaten!). Immer wieder ging ich an den folgenden Tagen und Wochen über diese Brücke. Hinsehen, sich nicht an den Anblick gewöhnen. Trotz der vielen Hilfsangebote gibt es kein Patentrezept. Viele Obdachlose fühlen sich verfolgt, hören Stimmen. Sie brauchen Hilfe um Hilfe annehmen zu können.

Ist die Obdachlosigkeit, die Isolation der Grund oder umgekehrt? Was war zuerst? Wir werden es nie erfahren! Das Herz muss entscheiden und mich zum Handeln bewegen!

Auf dieser Brücke wollte er ruhen, um den endlos langen Tag überhaupt zu überstehen ..., um in den eisig kalten Nächten nicht zu erfrieren oder an den heissen Sommertagen nicht zu verdursten. Auf dieser harten Bank, ausgesetzt dem Wind und Wetter, den verachtenden Blicken der Menschen, als Störfaktor der Touristen ... Sein soziales Netz waren die Menschen, die vorübergingen. Sein Dach über dem Kopf der Sternenhimmel, sein Schlaflied das Wasser, das unter ihm durchrauschte. «Über diese Brücke musst du gehen!»

Aufsuchende Sozialarbeit im wahrsten Sinne des Wortes! Auch Worte sind Brücken, Brücken zum Herzen, Brücken, um zurückzufinden zu den Menschen, zu sich selbst. Viele Menschen unserer Stadt, die Behörden, die Polizei, das Personal im Spital, alle haben sie mitgebaut an dieser «Brücke» bei diesem obdachlosen und kranken Mann. Mit grosser Achtung und Menschenwürde suchten wir gemeinsam ein neues Daheim für diesen Menschen. Es war kurz vor Weihnachten. Er lebt nun in einer Institution. Ich bin seine Bezugsperson und besuche und begleite ihn weiterhin regelmässig. Eine wunderbare, wahre Weihnachtsgeschichte. 
Ich sah den Mann auf der Brücke zum ersten Mal. Ich brachte ihm Kaffee und versuchte mich zu nähern und seine Abwehrhaltung zu durchbrechen. Er hatte nur noch einen Schuh, den zweiten warf jemand in die Reuss. Ich weiss nicht warum, aber ich packte den Schuh mitsamt dem dreckigen Fusslumpen in einen Sack, irgendwie als «Beweismittel» für diese Person. Ich machte mich auf den Weg um im nahen Schuhgeschäft neue Sandalen für seine kranken Füsse kaufen. Dabei begegnete ich dem Leiter der SIP. Er kannte die Situation dieses Mannes und dass bei Kontrollgängen jeder Uniformierte in grossem Abstand an dem Mann vorbeigehen musste, um ihn nicht zu verunsichern. Er hat grosse Angst vor Amtspersonen und möchte nicht irgendwo zwangseingewiesen werden.

Später sehe ich noch eine Polizistin, die Parkbussen schreibt und schildere auch ihr den Fall und zeige ihr den Schuh! Sie kennt den Mann und macht Meldung bei der Polizei. Es läuft gegen ihn eine Anzeige wegen Verschmutzung des öffentlichen Raumes!!

Das glaub ich jetzt nicht. Das konnte ich nicht zulassen Ich melde mich bei der Vormundschaftsbehörde und erhalte die Kompetenz, den Mann in eine Klinik einweisen zu lassen, wenn es mir gelingt ihn zu überzeugen. Aufgrund des Anhörungsrechtes geht der Chef der Vormundschafts-Behörde persönlich zu dem Mann auf die Brücke, spricht einfühlsam mit ihm und kann ihn zu einem freiwilligen Eintritt in die Psychiatrische Klinik überreden. Nun kam die Frage: Wer bezahlt alle anfallenden Kosten? Die KESB findet heraus, dass der Mann vier Jahre, unschuldig, in Italien in Haft sass und nach seiner Freilassung zu Fuss in die Schweiz heimging. Man findet auch seine letzte Wohngemeinde, die zahlungspflichtig wird.

Was wäre wohl aus ihm geworden, wenn ich meinem Inneren Drängen nicht gefolgt und den Heimweg nicht über die Brücke gegangen wäre?

Gott sei Dank hat ihn nach dem Klinikaufenthalt das Pflegeheim Steinhof aufgenommen. Auch schwer kranke, pflegebedürftige Menschen von der Gasse fanden Aufnahme. Das war nicht selbstverständlich. Drogen- und alkoholabhängige Menschen halten sich oft nicht an die Abmachungen. Ein Altersheim/Pflegeheim ist keine Entzugsstation, das Personal nicht speziell ausgebildet in der Betreuung von drogenabhängigen und suchtkranken Menschen. Nicht der Kranke, vor allem das Umfeld ist schwierig oder wenn Kolleginnen und Kollegen zu Besuch kommen. Darum bin ich noch heute Ansprechperson, Bezugsperson. Eine grosse Hilfe war der Abschluss eines Zusatzvertrages zum eigentlichen Heimvertrag. Ganz individuell angepasst. Also zum Beispiel: kein Besuch von 
der Gasse oder keinen Aufenthalt im Garten mit drogenabhängigen Kollegen usw., was es dann einfach brauchte.

Dadurch war ich sehr viel im Steinhof. 2011 haben mich die SteinhofBrüder um Mithilfe im Seelsorge-Team gefragt. Es war den Brüdern ein Anliegen, dass eine Frau, das Brüderteam ergänzte.

Ab 2007 hatte ich immer wieder grössere Operationen, alle Jahre wieder! Beide Hüften bekamen neue Gelenke, Totalprothesen, ebenfalls beide Knie. Ein Fuss musste versteift werden, um eine Schmerzfreiheit zu erlangen. Ich musste auch schon mehrere Operationen an den Händen machen lassen. Durch die Kortison-Therapie gegen meine entzündliche rheumatische Erkrankung, stieg der Augendruck in beiden Augen. Der Augendruck war auf sehr hohe Werte gestiegen, es drohte mir die Erblindung. Es folgte eine sehr intensive Zeit in der Augenklinik im Kantonsspital. Dr. med. Frank Bochmann hat mich sehr erfolgreich (Glaukom) operiert.

In dieser Zeit wurde für mich das Thema Organspende sehr wichtig. Aktuell damals die Hornhautspende. Ich habe mich jahrelang immer wieder neu informiert und oft auch ganz konkret damit auseinandergesetzt. Ich bin heute noch Expertin in diesem Thema. Dazu gehörte auch das Thema: Patientenverfügung/Menschenrechte.

Ich habe einmal die Frage gestellt: Wo deponiert ein obdachloser Mensch seine Patientenverfügung? Er hat ja keinen Nachttisch, wo er sie versorgen kann. Das war hochinteressant. Weder die Caritas, die Kurse über diese Themen leitete, noch sonst jemand hat an diese Situation gedacht. Ich habe mit einigen Menschen die Verfügungen selber geschrieben. Also zum Beispiel mit einem dreissigjährigen Mann, der hatte abgefaulte Finger (AIDS) Ich habe seine Hand geführt, damit er seine Wünsche aufschreiben konnte. Seine Eltern wollten etwas ganz anderes. ER wollte, dass ich ihm Musik der Rolling Stones abspiele an seiner Beerdigung. Er wollte unbedingt eine Erdbestattung. Eine Mitarbeiterin der Gassenarbeit übernahm die Pflege und Bepflanzung des Grabes.

Ich bin sehr glücklich, dass heute die Palliativpflege zur Standardpflege gehört und auch allgemein versicherte Menschen sicher sein dürfen, dass ihnen diese Pflege gewährt wird. Niemand will Schmerzen haben und niemand will verdursten

Ich habe auch zwei, drei Menschen erlebt, die mithilfe von Exit ihr Leben beendet haben. So etwas Eindrückliches. Exit ist eine sehr seriöse, gute Institution. (Dignitas kenne ich nicht.)

Unvergesslich ist für mich ein älterer Mann, der mich und Sepp Riedener in sein Zimmer in einem Altersheim bestellt hat. Er wollte Abend- 
mahl feiern mit uns. Nach dem Vaterunser, das er deutlich und laut gebetet hatte, gab er mir, für mich persönlich, einen Abschiedsbrief, einen Dankesbrief, samt Foto von ihm. Dann händigte er mir 6 Briefe aus an Menschen auf der Gasse, bei denen er sich nicht verabschieden konnte oder nicht wusste, wo sie sich befanden. Er hat sich so mit allen versöhnt. Er bat mich unter Tränen, diese Menschen zu suchen. Anschliessend wurde er zu Exit nach Zürich gefahren. Die Verantwortlichen im Heim haben dies erst im Nachhinein erfahren. Ich habe alle Empfänger der Briefe gefunden, einen davon im Gefängnis. Alle diese Erfahrungen haben mein persönliches Leben sehr geprägt.

Ich gehe mit grossem Vertrauen in die Zukunft. Bruder Benedikt, Generaloberer der Barmherzigen Brüder, hat mir folgenden Text eines irischen Weihnachtsliedes geschenkt:

"Wenn das Lied der Engel wieder verstummt ist, wenn die Sterne am Himmel verschwunden sind, wenn die Könige und Fürsten nach Hause zurückgekehrt und die Hirten wieder bei den Herden sind, dann beginnt die Arbeit von Weihnachten: die zu finden, die verloren gegangen sind, $z u$ heilen, deren Herz zerbrochen ist, die Hungrigen zu speisen, die Unterdrückten zu befreien, und allen Völkern den Frieden zu bringen ... ... und ein wenig Musik zu machen in unseren Herzen!»

Ich freue mich weiterhin auf die "Arbeit von Weihnachten", die ja das ganze Jahr hindurch andauert. «Und ein wenig Musik zu machen in unseren Herzen!»

Ich hoffe und bete darum, dass mich meine Gesundheit nicht daran hindert. 


\section{Annexe zur Durchführung der Interviews (Teil des Samplings)}

\section{A Personalblatt befragte Schwester}

Kloster-Name:

Name und Ort des Klosters/der Klostergemeinschaft:

Adresse, wenn Wohnort ausserhalb des Klosters:

Ziviler Nach- und Vorname:

Geburtsdatum:

Heimatort(e)/Kanton:

Geburtsort/Kanton:

Konfession:

Schulbildung:

Berufsbildung vor dem Klostereintritt:

Ausgeübte(r) Beruf(e)/Tätigkeiten vor dem Klostereintritt: 
Datum Profess:

Ev. Übertritt aus einem anderen bzw. in ein anderes Kloster: Wo? Wann?

Aus-, Zusatz- und Weiterbildungen nach dem Klostereintritt:

Tätigkeiten in Aussenstationen des Mutterhauses:

Wo, welche, von wann bis wann?

Wo, welche, von wann bis wann?

Wo, welche, von wann bis wann?

Wo, welche, von wann bis wann?

Wo, welche, von wann bis wann?

Wo, welche, von wann bis wann?

Name der Eltern:

Geburtsjahr der Eltern:

Mutter:

Vater:

Todesjahr der Eltern:

Mutter:

Vater: 
Ausbildung der Eltern:

Mutter:

Vater:

Beruf/Tätigkeit der Eltern:

Mutter:

Vater:

Name/Anzahl und Alter der Geschwister: 


\section{B Einverständniserklärung}

(Steht nicht zu Forschungszwecken zur Verfügung und bleibt nach Abschluss der Forschung als Original im Mutterhaus der befragten Schwester)

A) Befragte Schwester

Die Schwester erklärt sich mit der Anonymisierung des Namens einverstanden.

Die Schwester erklärt sich mit dem gemeinsam für das Gespräch gewählten Pseudonym einverstanden.

Die Schwester erklärt sich mit der Transkription des Interviews einverstanden.

Die Schwester erklärt sich mit der zwischen der Klosterleitung und der Interviewerin vereinbarten Archivierung der (beiden gleichzeitig aufgenommenen) Tonbandaufnahmen, des transkribierten Interviews sowie des Personalblattes einverstanden.

Die Schwester erklärt sich einverstanden, gemeinsam vereinbarte Auszüge des transkribierten Interviews zu Publikationszwecken unter anonymisierter Form zur Verfügung zu stellen.

B) Interviewerin:

Die Interviewerin verpflichtet sich auf die Anonymisierung des Klosternamens zu Archivierungs- und Publikationszwecken.

Die Interviewerin verpflichtet sich auf die Verwendung des gemeinsam festgelegten Pseudonyms zu Archivierungs- und Publikationszwecken. 
Die Interviewerin verpflichtet sich auf die Durchführung des gemeinsam mit der Klosterleitung festgelegten Archivierungsmodus der (beiden gleichzeitig aufgenommenen) Tonbandaufnahmen, des transkribierten Interviews sowie des Personalblattes.

Die Interviewerin verpflichtet sich, ausschliesslich die gemeinsam mit der Schwester vereinbarten Auszüge des transkribierten Interviews zu Publikationszwecken unter anonymisierter Form zu verwenden.

Name der Schwester/Respondentin; Unterschrift, Ort, Datum:

Name der Interviewerin; Unterschrift, Ort, Datum:

\section{Fragebogen}

(Tritt erst in Kraft, wenn die befragte Schwester statt des offenen Narrativs die strukturierte Form des Interviews durch vorgefasste Fragen wünscht)

\section{A) Personalien}

(kurz erfragt als Einstieg ins Gespräch im Sinn der ersten Kontaktaufnahme durch die Interviewerin mit der Schwester, obwohl sie bereits auf dem Personalblatt angegeben sind)

Name (zivil und Kloster):

Geboren am:

Profess: 
B) Klostereintritt:

Wann traten Sie ins Kloster ein?

Was bewog Sie für Ihren Klostereintritt?

C) Ausbildung und Beruf

Konnten Sie eine Ausbildung oder Weiterbildung im Kloster machen?

Welche?

Brachten Sie beim Klostereintritt bereits eine Ausbildung mit?

D) Beschreibung der Zeit der Tätigkeit im Mutterhaus/in einer Aussenstation

Wo waren Sie tätig?

Von wann bis wann?

Entsprach diese Tätigkeit Ihren Neigungen?

Genügte Ihre Ausbildung den Anforderungen im Beruf?

Wie waren die Arbeitsstrukturen?

(Personal, Infrastruktur, Arbeitsstunden, Freizeit)

War die Arbeitszeit vertraglich geregelt? 
Wie konnten Sie Ihre Fähigkeiten einbringen bzw. sich entfalten?

Gab es auch Schwierigkeiten?

Welche?

Bei Konflikten: standen Ihnen Lösungs-Strukturen zur Verfügung?

Fühlten Sie sich dann unterstützt?

Konnten Sie bei negativen Zumutungen Dritter auf Aussenstationen Hilfestellungen oder Schutzmassnahmen entgegennehmen?

Durch wen?

Fühlten Sie sich auch ungerechtfertigt behandelt?

Von wem?

Waren Sie auf weiteren Aussenstationen tätig?

E) Beziehung zum Mutterhaus

Wie empfanden Sie die Beziehung zum Mutterhaus während Ihrer externen, ev. auch internen Wirkungszeit? 
F) Religiosität

Konnten Sie Ihrem Bedürfnis nach Gebet und Stille während Ihrer externen Zeit nachkommen?

Konnten Sie eine persönliche Religiosität oder Frömmigkeit leben?

Wollen Sie dazu Ausführungen machen?

Von wem wurden Sie dabei begleitet?

G) Beruf und Religion

Wie standen die beiden Bereiche zueinander?

Beeinflusste der eine Bereich den anderen?

H) Gemeinschaft

Wie erlebten Sie die Gemeinschaft unter Schwestern im Mutterhaus?

Wie erlebten Sie diese auf den Aussenstationen?

I) Kontakt nach aussen

Gestaltete sich dieser in der Praxis gemäss den Satzungen oder Konstitutionen? 
Wie konnten Sie sich als Ordensschwester ausserhalb der Schwesterngemeinschaft einbringen?

Wie wurden Sie als Ordensschwestern wahrgenommen?

J) Sie als Individuum

Möchten Sie etwas zu Ihrer Person als Ordensschwester sagen?

Möchten Sie noch etwas zu Ihrer Berufungsgeschichte sagen? 


\section{Abkürzungsverzeichnis}

$\begin{array}{ll}\text { AB } & \text { Klosterarchiv Baldegg } \\ \text { AIM } & \text { Institutsarchiv Menzingen } \\ \text { HF } & \text { Helvetia Franciscana (Collectanea Helvetico-Franciscana), Luzern } \\ & \text { 1932 ff. } \\ \text { HS } & \text { Helvetia Sacra } \\ \text { IAI } & \text { Institutsarchiv Ingenbohl } \\ \text { ZSKG } & \text { Zeitschrift für Schweizerische Kirchengeschichte, Stans/Freiburg } \\ & \text { 1907-2003 (1.-97. Jahrgang) }\end{array}$




\section{Quellenverzeichnis}

\section{Klosterarchiv Baldegg (AB)}

C VII 2 1/a, Gründungsvertrag des Hilfsvereins 1831.

EI 1, 4, Empfang des Ordenskleides in Ribeauvillé, 23.9.1841.

D IV $4,2$.

Fc 36.1, Fc 36.2, Regeln und Verordnungen für die armen Dienst- und Lehrschwestern von der göttlichen Vorsicht in der Arbeits-Erziehungsanstalt bei St. Jost zu Baldegg, 1836 (Fc 36.1) und 1842/44 (Fc 36.2).

Statuten der Armen- und Waisenhausschwestern der Göttlichen Vorsehung, Baldegg 1862, gedruckt 1867, I. Abschnitt, Allgemeine Bestimmungen, $3 \mathrm{f}$.

Statuten der Lehr- und Waisenschwestern der göttlichen Vorsehung vom III. Orden des hl. Franziskus v. Assis, Luzern 1877, 3.

Sc 1-Sc 3, Statuten/Konstitutionen von 1859, 1862, 1877.

Fc 36, Zur Geschichte unserer Konstitutionen (Generalkapitel 1981).

Fc 36; dort die weitere Entwicklung zur Benennung der heutigen Schwestern von der Göttlichen Vorsehung aus dem Regulierten Orden des hl. Franziskus von Assisi, der Baldegger Schwestern.

A III 2, 4; Aufhebungsdekret vom 3.5.1848

A III 2, 5; Aufhebungsdekret vom 23.3.1849.

A III 2, 5; Aufhebungsdekret vom 8.4.1853.

IV 1, 1; Gesuch um Genehmigung des Instituts und um Staatsschutz: Ottilia Kaufmann an Herrn Landammann und Regierungsräte von Zug vom 3.5.1858; Anerkennung des Instituts in Heiligkreuz: Regierungsratsprotokoll vom 13.5.1858 Ziff. 9, Ziff. 12. Grundzüge der neuen vom Bischöflichen Ordinariate zu beschliessenden Statuten des Lehr- und WaisenschwesternInstitutes von Baldegg-Cham vom 16.10.1858, signiert Bischof Karl Arnold von Basel; Dekan Jakob Buck (am 16.10.1858 von Bischof Karl ernannter geistlicher Vater des Schwesterninstituts Baldegg-Cham) an Dekan und bischöflichen Kommissar Melchior Schlumpf vom 20.10.1858 (Kommissariatsarchiv Zug).

Statuten der Lehr- und Waisenschwestern der göttlichen Vorsehung vom III. Orden des hl. Franciscus v. Assis (sic.), Solothurn 1859, 16 f.

A III 1, 8 Trennungsurkunde von Bischof Carl Arnold-Obrist vom 24.8.1862. Vgl. weiter die Verzeichnisse der Schwestern, die sich (1862 anlässlich der Trennung) für Cham bzw. für Baldegg entschieden, AB EI 1, 6.

B IV $1,1,-1,4$. 


\section{Klosterarchiv Heiligkreuz Cham}

Statuten der Lehr- und Waisenschwestern der Göttlichen Vorsehung vom III. Orden des hl. Franziskus von Assisi, Solothurn 1859; vgl. die mit der formellen Aufnahme der Schwestern von Heiligkreuz in den Verband der Benediktinerkongregation von Monte Oliveto von 1892 angepassten Statuten: Statuten für die Schwesterngemeinschaft der Olivetaner-Kongregation OSB von Heiligkreuz bei Cham, Kanton Zug, o. O. 1892.

\section{Klosterarchiv Ilanz}

Grundverfassung, 5.

\section{Institutsarchiv Ingenbohl, Brunnen (IAI)}

Cornelia Göcking, Canonizationis Servae Dei Mariae Theresiae Scherer positio super virtutibus, 22-28.

Constitutionen der barmherzigen Schwestern vom heiligen Kreuze aus dem dritten Orden des heiligen Franziskus von Assis (sic.), Ingenbohl 1860.

\section{Archiv Institut Menzingen (AIM)}

Menzingen, Constitutionen des Institutes der Lehrschwestern vom III ${ }^{\text {ten }}$ Orden des hl. Franciscus von Assisi unter dem besonderen Titel: «Schwestern vom hl. Kreuze», Approbation, Chur, 26.10.1845, I. Abschnitt, 4. Kapitel.

IV. 1848/74 Th. 58, Constitutionen des Institutes der Lehrschwestern vom III ${ }^{\text {ten }}$ Orden des hl. Franciscus von Assisi unter dem besonderen Titel: «Schwestern vom hl. Kreuze», Approbation, Chur, 26.10.1845, I. Abschnitt, 1. Kapitel.

Constitutionen des Institutes der Lehrschwestern vom III ${ }^{\text {ten }}$ Orden des hl. Franciscus von Assisi unter dem besonderen Titel: «Schwestern vom hl. Kreuze», Approbation, Solothurn, 2. Oktober 1851, Einsiedeln 1852, V. Abschnitt, 1. Kapitel.

Mappe II, 1. Fasz. 1.1., Protokoll von der heutigen Conferenz zur Einführung der Schulschwestern im Pfarrhaus zu Menzingen. 8.8.1844.

IV. 1848/74 Th. 58, Constitutionen des Institutes der Lehrschwestern vom III ${ }^{\text {ten }}$ Orden des hl. Franciscus von Assisi unter dem besonderen Titel: «Schwestern vom hl. Kreuze», Approbation, Chur, 26.10.1845, I. Abschnitt, 1. Kapitel.

\section{Archiv der Missionsschwestern vom Katholischen Apostolat, Pallottinerinnen, Delegatur Niederuzwil}

«Die Sendung der Pallottinerinnen in die Schweiz. Schwierigkeiten und Aufgaben», 1.7.1932.

«Das «alte Klösterli» in Bernhardzell ist nicht mehr», Akten Gründung Schwesternhaus «St. Wiborad» 1944, o. D. (April 1944). 


\section{Bibliografie}

Teil A

Schweizer Katholizismus mit Schwerpunkt weibliche Ordensgeschichte der

Schweiz

A1. Allgemeiner Katholizismus und Protestantismus 19./20. Jahrhundert

A2. Allgemeine (religiöse) Frauengeschichte

A3. Schweizerische religiös-konfessionelle Frauengeschichte

A4. Weibliche Diakonie und allgemeine religiöse Frauengeschichte

A5. Religiöse Kulturgeschichte

A6. Helvetia Sacra

A7. Mutterhausspezifische Literatur

A8. Konfessionelles Bildungs-/Erziehungs- und Gesundheitswesen in der Schweiz

Teil B

Oral History: Theorie und Anwendung

\section{Teil A: Schweizer Katholizismus mit Schwerpunkt weibliche Ordensgeschichte der Schweiz}

\section{A1. Allgemeiner Katholizismus und Protestantismus 19./20. Jahrhundert}

Urs Altermatt, Katholizismus und Moderne. Zur Sozial- und Mentalitätsgeschichte der Schweizer Katholiken im 19. und 20. Jahrhundert, Zürich ${ }^{2} 1991$.

Urs Altermatt/Catherine Bosshart-Pfluger/Francis Python, Katholiken und Katholizismus im 19. und 20. Jahrhundert, in: Boris Schneider/Francis Python (Hg.), Geschichtsforschung in der Schweiz. Bilanz und Perspektiven - 1991, Basel 1992, 304-322.

Urs Altermatt (Hg.), Schweizer Katholizismus im Umbruch 1945-1990, Freiburg 1993.

Urs Altermatt (Hg.), Schweizer Katholizismus zwischen den Weltkriegen 19201940, Freiburg 1994.

Urs Altermatt/Franziska Metzger, Milieu, Teilmilieus und Netzwerke. Das Beispiel des Schweizer Katholizismus, in: Urs Altermatt (Hg.), Katholische Denk- und Lebenswelten. Beiträge zur Kultur- und Sozialgeschichte des Schweizer Katholizismus im 20. Jahrhundert, Freiburg 2003, 15-36.

Gregor Beuret, Die katholisch-soziale Bewegung in der Schweiz 1848-1919, Winterthur 1959.

Franz Xaver Bischof/Markus Ries (Hg.), Kirche zwischen Aufbruch und Verweigerung. Ausgewählte Beiträge zur Kirchen- und Theologiegeschichte des 19. 
und 20. Jahrhunderts. Festgabe für Manfred Weitlauff zum 65. Geburtstag, Stuttgart 2001.

Heidi Borner, Zwischen Sonderbund und Kulturkampf. Zur Lage der Besiegten im Bundesstaat von 1848, Luzern/Stuttgart 1981.

Norbert Busch, Katholische Frömmigkeit und Moderne. Zur Sozial- und Mentalitätsgeschichte des Herz-Jesu-Kultes zwischen Kulturkampf und Erstem Weltkrieg, Bielefeld 1995.

Roland J. Campiche, Die zwei Gesichter der Religion, Faszination und Entzauberung, Zürich 2004.

Victor Conzemius, Schweizer Katholizismus (1933-1945). Eine Konfessionskultur zwischen Abkapselung und Solidarität, Zürich 2001.

Gisela Fleckenstein/Joachim Schmiedl (Hg.), Ultramontanismus. Tendenzen der Forschung, Paderborn 2003.

Martin Friedrich/Norbert Friedrich, u. a. (Hg.), Sozialer Protestantismus im Vormärz, Münster 2001.

Karl Gabriel, Katholizismus und katholisches Milieu in den fünfziger Jahren der Bundesrepublik: Restauration, Modernisierung und beginnende Auflösung, in: Franz-Xaver Kaufmann/Arnold Zingerle (Hg.), Vatikanum II und Modernisierung. Historische, theologische und soziologische Perspektiven, Paderborn/München/Wien/Zürich 1996, 67-83.

Irmtraud Götz von Olenhusen, Klerus und abweichendes Verhalten. Zur Sozialgeschichte katholischer Priester im 19. Jahrhundert: Die Erzdiözese Freiburg, Göttingen 1994.

Friedrich Wilhelm Graf, Der Protestantismus. Geschichte und Gegenwart, München 2006.

Urs Hoffmann, Innenansichten eines Niedergangs. Das protestantische Milieu in Basel 1920 bis 1970, Baden 2013.

Lucian Hölscher, Geschichte der protestantischen Frömmigkeit in Deutschland, München 2005.

Karl-Joseph Hummel (Hg.), Zeitgeschichtliche Katholizismusforschung. Tatsachen, Deutungen, Fragen. Eine Zwischenbilanz, Paderborn/München/Wien/ Zürich 2004.

Marco Jorio, Der Untergang des Fürstbistums Basel (1792-1815). Der Kampf der beiden letzten Fürstbischöfe Joseph Sigismund von Roggenbach und Franz Xaver von Neveu gegen die Säkularisation, Freiburg 1982.

Marco Jorio (Red.), Historisches Lexikon der Schweiz, Stiftung Historisches Lexikon der Schweiz (Hg.), Basel 2002 ff.

Martin H. Jung, Der Protestantismus in Deutschland von 1870 bis 1945, Berlin ${ }^{2} 2002$.

Hermann Kocher, Rationierte Menschlichkeit. Schweizer Protestantismus im Spannungsfeld von Flüchtlingsnot und öffentlicher Flüchtlingspolitik der Schweiz 1933-1948, Zürich 1996. 
Matthias Krieg/Gabrielle Zangger-Derron, Die Reformierten. Suchbilder einer Identität, Zürich ${ }^{2} 2003$.

Frank-Michael Kuhlemann/Hans-Walter Schmuhl (Hg.), Beruf und Religion im 19. und 20. Jahrhundert, Stuttgart 2003.

Claudia Lepp/Harry Oelke/Detlef Pollak (Hg.), Religion und Lebensführung im Umbruch der langen 1960er Jahre, Göttingen, 2016.

Aram Mattioli/Gerhard Wanner (Hg.), Katholizismus und «soziale Frage». Ursprünge und Auswirkungen der Enzyklika «Rerum novarum» in Deutschland, Liechtenstein, Vorarlberg und St. Gallen, Zürich 1995.

Henning Pahl, Die Kirche im Dorf. Religiöse Wissenskulturen im gesellschaftlichen Wandel des 19. Jahrhunderts, Berlin 2006.

Markus Ries, Die Neuorganisation des Bistums Basel am Beginn des 19. Jahrhunderts (1815-1828), Stuttgart 1992.

Heinz Rüegger/Christoph Sigrist, Diakonie - eine Einführung. Zur theologischen Begründung helfenden Handelns, Zürich 2011.

Christoph Sigrist, Reflections on the paradigm shift in voluntary work, with reference to Switzerland, diaconia 2/1 (2011), 80-89.

Christoph Sigrist (Hg.), Kirchen Macht Raum. Beiträge zu einer kontroversen Debatte, Zürich 2010.

Peter Stadler, Der Kulturkampf in der Schweiz. Eidgenossenschaft und katholische Kirche im europäischen Umkreis 1848-1888, Zürich ${ }^{2} 1996$.

Alfred Stoecklin, Schweizer Katholizismus. Eine Geschichte der Jahre 1925-1975 zwischen Ghetto und konziliarer Öffnung, Zürich/Einsiedeln/Köln 1978.

Lukas Vischer/Lukas Schenker, u.a. (Hg.), Ökumenische Kirchengeschichte der Schweiz, Freiburg/Basel ${ }^{2} 1998$.

Rolf Weibel, Schweizer Katholizismus heute. Strukturen, Aufgaben, Organisationen der römisch-katholischen Kirche, Zürich 1989.

Paul Wernle, Der schweizerische Protestantismus in der Zeit der Helvetik 17981803, 2 Bde., Zürich 1938-1942.

Benjamin Ziemann, Der deutsche Katholizismus im späten 19. und 20. Jahrhundert. Forschungstendenzen auf dem Weg zu sozialgeschichtlicher Fundierung und Erweiterung, in: Archiv für Sozialgeschichte, 40 (2000), 402-422.

Hellmut Zschoch (Hg.), Protestantismus und Kultur. Wirkungen, Spannungen, Perspektiven, Wuppertal 2002.

\section{A2. Allgemeine (religiöse) Frauengeschichte}

Silvan Abicht/Beat Dittli, Gotteslob und Mädchenschule. Kapuzinerinnenkloster Maria Opferung Zug 1611-2011, hg. vom Historischen Verein des Kantons Zug (2011) Bd. 16.

Ursula Baumann, Protestantismus und Frauenemanzipation in Deutschland 1850 bis 1920, Frankfurt a. M./New York 1992. 
Ursula Baumann, Religion und Emanzipation: Konfessionelle Frauenbewegung in Deutschland 1900-1933, in: Irmtraud Götz von Olenhusen u.a. (Hg.), Frauen unter dem Patriarchat der Kirchen. Katholikinnen und Protestantinnen im 19. und 20. Jahrhundert, Stuttgart 1995, 89-119.

Lydia Bendel-Maidl (Hg.), Katholikinnen im 20. Jahrhundert. Bilder, Rollen, Aufgaben, Berlin 2007.

Norbert Busch, Die Feminisierung der ultramontanen Frömmigkeit, in: Irmtraud Götz von Olenhusen (Hg.), Wunderbare Erscheinungen. Frauen und katholische Frömmigkeit im 19. und 20. Jahrhundert, Paderborn/München/ Wien/Zürich 1995, 203-219.

Annett Büttner, «Nachricht aus der Stadt des grossen Elends». Die Pflege von Cholerakranken in Hamburg im Jahr 1892 durch Kaiserswerther Diakonissen, in: Sabine Braunschweig (Hg.), Pflege - Räume, Macht und Alltag. Beiträge zur Geschichte der Pflege, Zürich 2006, 261-270.

Michela De Giorgio, Das katholische Modell, in: Georges Duby/Michelle Perrot (Hg.), Geschichte der Frauen, Bd. 4, Frankfurt a. M. 1994, 187-220.

Brigitte Degler-Spengler, «Katholizismus auf weiblich», in: Rottenburger Jahrbuch für Kirchengeschichte, 6 (1987), 239-251.

Vera Deissner, Gottes Mägde oder christliche Kommunardinnen? Zum Selbstbild von Frauen im Nonnenkloster, in: Ulrike Krasberg (Hg.), Religion und weibliche Identität. Interdisziplinäre Perspektiven auf Wirklichkeiten, Marburg 1999, 19-34.

Annette Drees, Profession, Konfession und Geschlecht: Profilierungsbestrebungen katholischer Lehrerinnen Anfang des 20. Jahrhunderts, in: FrankMichael Kuhlemann/Hans-Walter Schmuhl (Hg.), Beruf und Religion im 19. und 20. Jahrhundert, Stuttgart 2003, 112-128.

Ruth Felgentreff, Das Diakoniewerk Kaiserswerth 1836-1966, Kaiserswerth 1998.

Ruth Felgentreff, Die Diakonissen. Beruf und Religion im 19. und 20. Jahrhundert, in: Frank-Michael Kuhlemann/Hans-Walter Schmuhl (Hg.), Beruf und Religion im 19. und 20. Jahrhundert, Stuttgart 2003, 195-209.

Norbert Friedrich, Überforderte Engel? Diakonissen als Gemeindeschwestern im 19. und 20. Jahrhundert, in: Sabine Braunschweig (Hg.), Pflege - Räume, Macht und Alltag. Beiträge zur Geschichte der Pflege, Zürich 2006, 85-94.

Siri Fuhrmann/Irmgard Pahl u. a. (Hg.), Soziale Rollen von Frauen in Religionsgemeinschaften. Ein Forschungsbericht, Münster 2003.

Birgit Funke, Gehorsam als «diakonische Gesinnung»? Kaiserswerther Schwestern erzählen von ihrer Probezeit, in: Siri Fuhrmann/Irmgard Pahl u. a. (Hg.), Soziale Rollen von Frauen in Religionsgemeinschaften. Ein Forschungsbericht, Münster 2003, 105-118.

Ute Gause, Geschlecht als Kategorie. Was leistet eine feministische Perspektive für die Kirchengeschichte? Ein Diskussionsbeitrag, in: Anselm Doering- 
Manteuffel/Kurt Nowak (Hg.), Kirchliche Zeitgeschichte. Urteilsbildung und Methoden, Stuttgart 1996, 164-179.

Ute Gause, Frauen und Frömmigkeit im 19. Jahrhundert: Der Aufbruch in die Öffentlichkeit, in: Hermann Ehmer/Udo Sträter (Hg.), Beiträge zur Geschichte des württembergischen Pietismus, Göttingen 1998, 309-327.

Ute Gause/Julia Paulus, Evangelische und katholische Gender-Forschung im Überblick, in: Ute Gause/Barabara Heller/Jochen Christoph Kaiser (Hg.), Starke fromme Frauen? Eine Zwischenbilanz konfessioneller Frauenforschung heute, Hofgeismar 2000, 5-23.

Ute Gause/Barabara Heller, u. a. (Hg.), Starke fromme Frauen? Eine Zwischenbilanz konfessioneller Frauenforschung heute, Hofgeismar 2000.

Ute Gause, Frauen entdecken ihren Auftrag! Neue Erträge diakonischer Frauenforschung, in: Cornelia Coenen-Marx (Hg.), Ökonomie der Hoffnung. Impulse zum 200. Geburtstag von Theodor und Friederike Fliedner, Düsseldorf 2001, 75-92.

Ute Gause, Bürgerliches Frauenideal und christliche Frauenemanzipation, in: Hermann Wilmes (Hg.), Materialien Handbuch Geschichte, Bd. 4: Staat und Nation im 19. Jahrhundert, Köln 2001, 64-71.

Ute Gause, Friederike Fliedner und die «Feminisierung des Religiösen» im 19. Jahrhundert, in: Martin Friedrich/Norbert Friedrich, u. a. (Hg.), Sozialer Protestantismus im Vormärz, Münster 2001, 123-128.

Ute Gause, Protestantismus und Frauenfrage, in: Hermann Wilmes (Hg.), Materialien Handbuch Geschichte, Bd. 4: Staat und Nation im 19. Jahrhundert, Köln 2001, 79-86.

Ute Gause, Dienst und Demut. Diakoniegeschichte als Geschichte christlicher Frauenleitbilder, in: Siri Fuhrmann/Irmgard Pahl/Erich Geldbach (Hg.), Soziale Rollen von Frauen in Religionsgemeinschaften, Münster 2003, 65-83.

Ute Gause, Kirchengeschichte und Genderforschung, Tübingen 2006.

Ute Gause, Aufbruch der Frauen - Das vermeintlich «Weibliche〉 der weiblichen Diakonie, in Jochen-Christoph Kaiser/Rajah Scheepers (Hg.), Dienerinnen des Herrn - Beiträge zur weiblichen Diakonie des 19. Und 20. Jahrhunderts, Leipzig 2010, 57-71.

Ute Gause/Cordula Lissner (Hg.), Kosmos Diakonissenmutterhaus. Geschichte und Gedächtnis einer protestantischen Frauengemeinschaft, Leipzig 2005.

Ute Gause, Kirchengeschichte und Genderforschung, Tübingen 2006.

Ute Gerhard, Verhältnisse und Verhinderungen, Frauenarbeit, Familie und Rechte der Frauen im 19. Jahrhundert, Frankfurt a. M. 1978.

Irmtraud Götz von Olenhusen (Hg.), Wunderbare Erscheinungen. Frauen und katholische Frömmigkeit im 19. und 20. Jahrhundert, Paderborn/München/ Wien/Zürich 1995. 
Irmtraud Götz von Olenhusen u. a. (Hg.), Frauen unter dem Patriarchat der Kirchen. Katholikinnen und Protestantinnen im 19. und 20. Jahrhundert, Stuttgart 1995.

Irmtraud Götz von Olenhusen, Die Feminisierung von Religion und Kirche im 19. und 20. Jahrhundert: Forschungsstand und Forschungsperspektiven (Einleitung), in: Irmtraud Götz von Olenhusen u. a. (Hg.), Frauen unter dem Patriarchat der Kirchen. Katholikinnen und Protestantinnen im 19. und 20. Jahrhundert, Stuttgart 1995, 9-21.

Heinrich Grosse/Hans Otte/Joachim Perels (Hg.), Erinnerungen an die Zukunft? Die 1960er/70er Jahre und hannoversche Landeskirche, Hannover 2010. (im Druck)

Maria E. Gründig, Weibliche Ordensgemeinschaften an der Schwelle zum 21. Jahrhundert. Herausforderungen - Chancen - Perspektiven. Ergebnisse der Podiumsdiskussion, in: Rottenburger Jahrbuch für Kirchengeschichte, Bd. 27 (2008), $239 \mathrm{f}$.

Rebekka Habermas, Weibliche Religiosität - oder: Von der Fragilität bürgerlicher Identitäten, in: Klaus Tenfelde/Hans-Ulrich Wehler (Hg.), Wege zur Geschichte des Bürgertums. Vierzehn Beiträge, Göttingen 1994, 125-148.

Elisabeth Hartlieb/Jutta Koslowski/Ulrike Wagner-Rau (Hg.), Das neue Kleid. Feministisch-theologische Perspektiven auf geistliche und weltliche Gewänder, Sulzbach/Taunus 2010.

Angelica Hilsebein/Gisela Fleckenstein/Bernd Schmies (Hg.), Unser Kloster in der Welt. Franziskanisches Wirken vom 19. Jahrhundert bis in die Gegenwart. Begleitband zur Ausstellung im Franziskaner Kloster Paderborn vom 9. Dezember 2011 bis zum 6. Mai 2012, Münster 2012.

Walburga Hoff, «Kirche ... ist irgendwo so ein geschützter Raum». Weiblichkeitskonstruktionen in den Berufsstrukturen der katholischen Kirche, in: Ingrid Lukatis/Regina Sommer/Christof Wolf(Hg.), Religion und Geschlechterverhältnis, Opladen 2000, 181-192.

Lucian Hölscher, «Weibliche Religiosität»? Der Einfluss von Religion und Kirche auf die Religiosität von Frauen im 19. Jahrhundert, in: Margret Kraul/Christoph Lüth (Hg.), Erziehung der Menschengeschlechter. Studien zur Religion, Sozialisation und Bildung in Europa seit der Aufklärung, Weinheim 1996, $45-62$.

Anna-Katharina Höpflinger/Ann Jeffers/Daria Pezzoli-Olgiati (Hg.), Handbuch Gender und Religion, Göttingen 2008.

Gertrud Hüwelmeier, Närrinnen Gottes. Lebenswelten von Ordensfrauen, Münster 2004.

Katrin Irle, «Durch so viel, viel Segen mir der Herr beschert hat». Leben und Werk Caroline Fliedners, der zweiten Vorsteherin der Diakonissen-Anstalt Kaiserswerth, in: Siri Fuhrmann/Irmgard Pahl u. a. (Hg.), Soziale Rollen von 
Frauen in Religionsgemeinschaften. Ein Forschungsbericht, Münster 2003, 89-104.

Katrin Irle, Leben und Werk Caroline Fliedners geb. Berthau, der zweiten Vorsteherin der Diakonissenanstalt Kaiserswerth, Diss. Siegen 2003.

Jochen-Christoph Kaiser, Überlegungen zur Neuinterpretation des Sozialen Protestantismus, in: Diakonisches Werk der Evangelischen Kirche von Westfalen (Hg.), Traditionsbruch, Wandlung, Kontinuitäten. Diakonie Forum 23 (2000). Beiträge zur Diakonie- und Zeitgeschichte, 5-14.

Jochen-Christoph Kaiser/Rajah Scheepers (Hg.), «Dienerinnen des Herrn». Beiträge zur Weiblichen Diakonie im 19. und 20. Jahrhundert, Leipzig 2010.

Uwe Kaminsky, Erinnerungsmuster und Krankenpflegegeschichte in der Zeit des Nationalsozialismus. Das Beispiel der Kaiserswerther Diakonissen, in: Sabine Braunschweig (Hg.), Pflege - Räume, Macht und Alltag. Beiträge zur Geschichte der Pflege, Zürich 2006, 223-231.

Elke Kleinau/Claudia Opitz (Hg.), Geschichte der Mädchen- und Frauenbildung, 2 Bde., Frankfurt a. M./New York 1996.

Silke Köser, Friederike Fliedner als Leitbild der Kaiserswerther Frauendiakonie, in: Ute Gause/Barabara Heller, u. a. (Hg.), Starke fromme Frauen? Eine Zwischenbilanz konfessioneller Frauenforschung heute, Hofgeismar 2000, 137143.

Silke Köser, Denn eine Diakonisse darf kein Alltagsmensch sein. Kollektive Identitäten Kaiserswerther Diakonissen 1836-1914, Leipzig 2006.

Ulrike Krasberg (Hg.), Religion und weibliche Identität. Interdisziplinäre Perspektiven auf Wirklichkeiten, Marburg 1999.

Maria Regina Kuhn, Die Benediktinerinnenabtei Kellenried am Beginn des 21. Jahrhunderts, in: Rottenburger Jahrbuch für Kirchengeschichte, Bd. 27 (2008), $241 \mathrm{f}$.

Cordula Lissner, Macht und Alltag im Interview. Ein Oral-History-Projekt zur Pflegegeschichte, in: Sabine Braunschweig (Hg.), Pflege - Räume, Macht und Alltag. Beiträge zur Geschichte der Pflege, Zürich 2006, 193-201.

Hugh McLeod, Weibliche Frömmigkeit - männlicher Unglaube? Religion und Kirchen im bürgerlichen 19. Jahrhundert, in: Ute Frevert (Hg.), Bürgerinnen und Bürger. Geschlechterverhältnisse im 19. Jahrhundert, Göttingen 1988, 134-156.

Relinde Meiwes, «Arbeiterinnen des Herrn». Katholische Frauenkongregationen im 19. Jahrhundert, Frankfurt a. M. 2000.

Relinde Meiwes, Von Ostpreussen in die Welt. Die Geschichte der ermländischen Katharinenschwestern (1772-1914), Paderborn 2011.

Gisela Muschiol (Hg.), Katholikinnen und Moderne. Katholische Frauenbewegung zwischen Tradition und Emanzipation, Münster 2003. 
Gisela Muschiol, Versorgung, Unterdrückung, Selbstbestimmung? Religiöse Frauengemeinschaften als Forschungsfeld?, in: Rottenburger Jahrbuch für Kirchengeschichte, Bd. 27 (2008), 13-25.

Catherine M. Prelinger, Die deutsche Frauendiakonie im 19. Jahrhundert. Die Anziehung des Familienmodells, in: Ruth-Ellen Joeres/Annette Kuhn (Hg.), Frauenbilder und Frauenwirklichkeiten. Interdisziplinäre Studien zur Frauengeschichte in Deutschland im 18. und 19. Jahrhundert, Düsseldorf 1985, 268-285.

Hermann Schauer, Frauen entdecken ihren Auftrag. Weibliche Diakonie im Wandel eines Jahrhunderts, Göttingen 1960.

Rajah Scheepers, Das Jahr 1968 und die Diakonissen. Ein Beitrag zur Geschichte der Inklusion evangelischer Frauen in Kirche und Theologie sowie zur gleichzeitigen Erosion konfessioneller Frauenberufe, in: Heinrich Grosse/ Hans Otte/Joachim Perels (Hg.), Erinnerungen an die Zukunft? Die 1960er/70er Jahre und die hannoversche Landeskirche, Hannover 2010 (im Druck, ca. 25 S.).

Jochen-Christoph Kaiser/Rajah Scheepers, Einführung oder: Weibliche Diakonie nach 1945 im Kontext der Kirchen- und Theologiegeschichte. Weichenstellungen und Herausforderungen, in: Jochen-Christoph Kaiser/Rajah Scheepers (Hg.), «Dienerinnen des Herrn». Beiträge zur weiblichen Diakonie im 19. und 20. Jahrhundert, Leipzig 2010, 11-35.

Rajah Scheepers, Fossilized fashion. Vom Ehrenkleid zum boundary marker. Die Tracht der Diakonisse im Wandel der Jahrhunderte, in: Elisabeth Hartlieb/ Jutta Koslowski/Ulrike Wagner-Rau (Hg.), Das neue Kleid. Feministischtheologische Perspektiven auf geistliche und weltliche Gewänder, Königstein 2010. (im Druck)

Rajah Scheepers, Frauen Gestalten Geschichte. Kirchengeschichte und Genderforschung, in: Thomas Braun/Cornelia Richter (Hg.), Junge Marburger Theologie, Marburg 2010. (im Druck)

Rajah Scheepers, «Ich bin genau der gleiche Mensch, ob ich Tracht oder zivil trage.» Zum gewandelten Selbst- und Fremdverständnis der Diakonissen im Spiegel der sich verändernden Diakonissentracht und ihrer Bedeutung, in: Jochen-Christoph Kaiser/Rajah Scheepers (Hg.), «Dienerinnen des Herrn». Beiträge zur Weiblichen Diakonie im 19. und 20. Jahrhundert, Leipzig 2010, 212-230.

Rudolf Schlögl, Sünderin, Heilige oder Hausfrau? Katholische Kirche und weibliche Frömmigkeit um 1800, in: Irmtraud Götz von Olenhusen (Hg.), Wunderbare Erscheinungen. Frauen und katholische Frömmigkeit im 19. und 20. Jahrhundert, Paderborn/München/Wien/Zürich 1995, 13-50.

Bernhard Schneider, Feminisierung der Religion im 19. Jahrhundert. Perspektiven einer These im Kontext des deutschen Katholizismus, in: Trierer Theologische Zeitschrift 111 (2002), 123-147. 
Michaela Sohn-Kronthaler/Andreas Sohn, Frauen im kirchlichen Leben. Vom 19. Jahrhundert bis heute, Kevelaer 2008.

Christian Sorrel, Romanisation et expansation internationle: les Sœurs de SaintJoseph de Chambéry de 1843 à 1914, in: Schweizerische Zeitschrift für Religions- und Kulturgeschichte (2011), 117-139.

Friedrich Thiele, Diakonissenhäuser im Umbruch der Zeit. Strukturprobleme im Kaiserswerther Verband deutscher Diakonissenhäuser als Beitrag zur institutionellen Diakonie, Stuttgart 1963.

Barbara Welter, «Frauenwille ist Gottes Wille». Die Feminisierung der Religion in Amerika, 1800-1860, in: Claudia Honegger/Bettina Heintz (Hg.), Listen der Ohnmacht. Zur Sozialgeschichte weiblicher Widerstandsformen, Frankfurt a. M. 1981, 326-355.

\section{A3. Schweizerische religiös-konfessionelle Frauengeschichte}

Seraphin Arnold, Vom Abenteuer christlicher Kultur. Die soziale Tätigkeit von Menzingen und Ingenbohl im Kanton Uri, 1852-1991, Luzern 1992.

Ivo Berther, Die «schwarze Lawine» und der Bauch der Frau: Frauenrollen in der katholischen Surselva 1870-1970 und ihr ideologischer Hintergrund, in: Ursula Jecklin/Silke Redolfi/Silvia Hofmann (Hg.), FrauenKörper. Beiträge zur Frauen- und Geschlechtergeschichte Graubündens im 19. und 20. Jahrhundert, Bd. 2, Zürich 2005, 67-149.

Marlis Betschart, Sozialarbeit um Gottes Lohn? Die Ingenbohler Schwestern an Anstalten im Kanton Luzern, in: Helvetia Franciscana, 31/2 (2002), 121-183.

Sophia Bietenhard/Rudolf Dellsperger, u. a. (Hg.), Zwischen Macht und Dienst. Beiträge zur Geschichte und Gegenwart von Frauen im kirchlichen Leben der Schweiz, Bern 1991.

Catherine Bosshart-Pfluger/Elisabeth Castellani Zahir, u.a., Religiöses Engagement von Freiburgerinnen 1848-1900, in: Femmes Tour (Hg.), Mit Geld, Geist und Geduld. Frauen und ihre Geschichte zwischen Helvetik und Bundesstaat, Bern 1998, 87-112.

Doris Brodbeck/Yvonne Domhardt, u. a. (Hg.), Siehe, ich schaffe Neues. Aufbrüche von Frauen in Protestantismus, Katholizismus, Christkatholizismus und Judentum, Bern 1998.

Doris Brodbeck, Hunger nach Gerechtigkeit. Helene von Mülinen (1850-1924) eine Wegbereiterin der Frauenemanzipation, Zürich 2000.

Doris Brodbeck (Hg.), Unerhörte Worte. Religiöse Gesellschaftskritik von Frauen im 20. Jahrhundert, Bern 2003.

Doris Brodbeck (Hg.), Dem Schweigen entronnen. Religiöse Zeugnisse von Frauen des 16. bis 19. Jahrhunderts, Würzburg 2006.

Romano Broggini, Contributo sulle organizzazioni scolastiche religiose ticinesi. Lopera della congregazione delle suore insegnanti di S. Croce di Menzingen, in: Risveglio, 89 (1984), 219-229. 
Angelika Bucher, Pater Theodosius Florentini und der Plan der «Antichristlichen Schulbildung mittels einer christ-katholischen Erziehung zu begegnen». Aspekte und Überlegungen zum Erziehungskonzept des Kapuzinerpaters unter besonderer Berücksichtigung der Frauen als zu Erziehende und als Erzieherinnen, Seminararbeit Bern 1988.

Nathalie Büsser, Die widerspenstigen Nonnen - «In unordentlichem Wesen der Fleischeslust erlegen», in: Verein Frauenstadtrundgang Zürich (Hg.), Fadegrad. 13 denkwürdige Geschichten von Frauen aus Zürich mit einer fast wahren Chronik, Zürich 2001, 34-39.

Victor Conzemius, Schweizer Katholizismus weiblich. Die Kongregationen von Menzingen und Ingenbohl im Kontext ihrer Entstehung, in: Stimmen der Zeit, 207 (1989), 181-192.

Mireille Courbat, Les Ursulines de Porrentruy au XIX ${ }^{\text {e }}$ siècle, Lizentiatsarbeit Freiburg 2000.

Brigitte Degler-Spengler, Schwestern vom Kostbaren Blut, Löwenberg, in: Patrick Braun (Hg.), Die Kongregationen in der Schweiz 19. und 20. Jahrhundert, HS VIII/2, Basel 1998, 410-420.

Brigitte Degler-Spengler, Schwestern vom Kostbaren Blut, Steinerberg, in: Patrick Braun (Hg.), Die Kongregationen in der Schweiz 19. und 20. Jahrhundert, HS VIII/2, Basel 1998, 421-436.

Brigitte Degler-Spengler, Die Entstehung des benediktinischen Anbetungsklosters Maria Rickenbach, Kanton Nidwalden, Schweiz, in: Studien und Mitteilungen zur Geschichte des Benediktinerordens und seiner Zweige, Bd. 118 (2008), 405-478.

Brigitte Degler-Spengler, St. Anna in Steinerberg, Filiale des Klosters Maria Rickenbach, und ihre Gründerin Vinzentia Gretener, in: Der Geschichtsfreund. Mitteilungen des Historischen Vereins Zentralschweiz, 162. Band (2009), 209-286.

Thomas Dürr/Doris Kellerhals u.a. (Hg.), Evangelische Ordensgemeinschaften in der Schweiz, Zürich 2003.

Iwona Eberle, Sr. Augusta Clara (Rosa Schönbächler) 1917, in: Susann BosshardKälin/Elena Hinshaw-Fischli (Hg.), spruchreif. Frauenleben im Kanton Schwyz im 20. Jahrhundert. Zeitzeuginnen erzählen, Einsiedeln ${ }^{2} 2007,196-$ 207.

Frauenklöster der Schweiz, Vereinigungen der Ordensfrauengemeinschaften der deutschsprachigen Schweiz (Hg.), Freiburg 1984.

Uta Teresa Fromherz/Maria Raphaela Rast u. a., Schwester werden - Schwester sein. Klöster, Kongregationen und Säkularinstitute in der Schweiz, Zürich 1970.

Uta Teresa Fromherz, Autonome Frauen. Frauenbildung in Zuger Frauenklöstern, in: Zug erkunden. Bildessays und Historische Beiträge zu 16 Zuger Schauplätzen. Jubiläumsband Zug 650 Jahre eidgenössisch, Zug 2002, 258-279. 
Albert Gasser, Jenseitsfrömmigkeit und Sozialengagement im 19. Jahrhundert. Das Beispiel der sozialen Schwesterngemeinschaften des Theodosius Florentini, in: Katholische Soziallehre in neuen Zusammenhängen, Einsiedeln 1985 (Theologische Berichte 14), 89-103.

Marthe Gosteli (Hg.), Vergessene Geschichte. Illustrierte Geschichte der Frauenbewegung 1914-1963, 2 Bde., Bern 2000.

Marianne-Franziska Imhasly, Aspekte zu den Anfängen der höheren Mädchenund Frauenbildung im 19. Jahrhundert bei den Schwesternkongregationen Baldegg, Menzingen und Ingenbohl, in: Helvetia Franciscana, $27 / 2$ (1998), 283-321.

Zoe Maria Isenring, Die Frau in den apostolisch tätigen Ordensgemeinschaften. Eine Lebensform am Ende oder an der Wende? Freiburg ${ }^{3} 1996$.

Marco Jorio, Das Blutwunder von Frauenthal 1708. Glaube, Aberglaube und Inquisition am Vorabend des zweiten Villmergerkrieges, in: Schweizerische Zeitschrift für Religions- und Kulturgeschichte (2007), 313-322.

Elisabeth Joris/Heidi Witzig (Hg.), Frauengeschichte(n). Dokumente aus zwei Jahrhunderten zur Situation der Frauen in der Schweiz, Zürich ${ }^{4} 2001$.

Anne-Marie Käppeli, Religiosität und tätiges Leben: protestantische Pädagoginnen der französisch-sprachigen Schweiz Ende des 19. und Anfang des 20. Jahrhunderts, in: Margret Kraul/Christoph Lüth (Hg.), Erziehung der Menschengeschlechter. Studien zur Religion, Sozialisation und Bildung in Europa seit der Aufklärung, Weinheim 1996, 121-138.

Amadea Mathieu Anthamatten, Ein Jahrhundert Katholische Arbeiterinnenbewegung 1899-1999, Kriens 1999.

Beatrix Mesmer, Ausgeklammert - Eingeklammert. Frauen und Frauenorganisationen in der Schweiz des 19. Jahrhunderts, Basel 1989.

Carlo Moos, Zukunft aus dem Glauben. Bernarda Heimgartner und die Gründung des Menzinger Lehrschwesterninstituts im historischen Kontext, Kriens 2002.

Sibylle Omlin, Bernarda (Maria Anna) Heimgartner (1822-1863). Aufstieg eines Landmädchens zur Ordensmutter, in: Der Kanton Zug zwischen 1798 und 1850. 23 Lebensgeschichten. Alltag und Politik in einer bewegten Zeit, Zug 1998, 230-239.

Susanne Perren, Edith Kopf-Schwestermann, Brig/Paris. Klosterfrau, Lehrerin, Gattin, in: Susanne Perren (Hg.), Rosenkranz und Fasnachtstanz. Walliser Frauenleben - Dreizehn Porträts, Zürich ${ }^{32005}$, 169-182.

Markus Ries, Gebetsleben und religiöse Ausstrahlung der Kapuzinerinnen in Luzern, in: Helvetia Franciscana, 27 (1998), 123-135.

Markus Ries, Religion als Herausforderung für die frühe Bürgergesellschaft. Theodosius Florentini als Beispiel, in: Christian Schweizer/Markus Ries (Hg.), Theodosius Florentini (1808-1865) - Vir famosus. Festschrift zum 200. Geburtstag, Helvetia Franciscana 38/1 (2009), 11-24. 
Markus Ries/Valentin Beck (Hg.), Fürsorge und Gewalt in kirchlich geführten Erziehungsanstalten im Kanton Luzern, Zürich 2013.

Verena Rothenbühler, Beruf und Berufung. Die Töchterfortbildungs- und Haushaltungsschule Santa Maria in Zug, in: Verein Stadtrundgang Zug (Hg.), Rechtschaffen. Beiträge zur Zuger Frauen- und Geschlechtergeschichte 1800-1930, Zug 2001, 77 f.

Valeria Sievi/Regula Gerspacher, «Hochverehrte liebe theure würdige Mutter!» Sr. Eugenia Welz (1833-1899) von der Kongregation der Schwestern vom hl. Kreuz, Ingenbohl. Ihr Leben und ihre Briefe während den Sammelreisen in der Schweiz, in Ungarn, Siebenbürgen und Slavonien für das Kreuzspital in Chur, Beiheft Nr. 7 zum Bündner Monatsblatt, Chur 1997.

Kathrin Spring, Sie arbeitete und betete und wurde reichlich mit Kindern gesegnet. Schwester Possenta Ritter, geboren 1916, Klosterfrau, Lehrerin, Baldegg, in: Christina Niederer/Kathrin Spring/Jutta Vogel (Hg.), Der Rede wert. Frauenleben im letzten Jahrhundert. 15 Porträts aus dem Kanton Luzern, Zürich 2002, 111-123.

Sabine Stüssi, Das Band der Vollkommenheit ist die Liebe (Kol. 3,14) - Diakonie: Weg zur Emanzipation? In: Sophia Bietenhard/Rudolf Dellsperger (Hg.), Zwischen Macht und Dienst, Bern 1991, 153-182.

Mathilde Tobler, Klosterarbeiten, in: Ernst Halter/Dominik Wunderlin (Hg.), Volksfrömmigkeit in der Schweiz, Zürich 1999, 81-97.

Vereinigungen der Ordensfrauen-Gemeinschaften der deutschsprachigen Schweiz (Hg.), Frauenklöster in der Schweiz, Freiburg 1984.

Esther Vorburger-Bossart, «Was Bedürfnis der Zeit ist ...». Identitäten in der katholischen Frauenbildung. Die Innerschweizer Lehrschwesterninstitute Baldegg, Cham, Ingenbohl und Menzingen 1900-1980, Fribourg 2008.

Esther Vorburger-Bossart, Innerschweizer Lehrschwesterninstitute als Konstruktionsorte weiblicher katholischer Identitäten und Vernetzungsorte laikaler Katholikinnen - Theoretisches zur Konzeption, in: Urs Altermatt/Jan de Maeyer/Franziska Metzger (Hg.), Religious Institutes and Catholic Culture in 19th and 20th Century Europe, Leuven 2010.

Esther Vorburger-Bossart, Spiritualität, Gemeinschaft der St. Anna-Schwestern (Hg.), Die St.Anna-Schwestern. Geschichte einer Gemeinschaft, Luzern/ Dallenwil 2015, 64-101.

Esther Vorburger-Bossart, Ordensschwestern in der Ostschweiz im 20. Jahrhundert, Zürich 2018.

Mirjam Weiss, Schwester Maria Regula, Menzingen, Ordensfrau, 1925, in: Mirjam Weiss/Felicitas Oehler Weiss u. a. (Hg.), Zugehört. Elf Lebensgeschichten von Zuger Frauen, Zürich 2007, 137-153. 


\section{A4. Weibliche Diakonie und allgemeine religiöse Frauengeschichte}

Alfred Aeppli/Hans Corrodi u.a. (Hg.), Kirche im Miteinander von Ortsgemeinde, Kommunitäten und Bewegungen, Zürich 2011.

Alexa A. Becker, Die Kongregation der Barmherzigen Schwestern vom Heiligen Vinzenz von Paul an den klinischen Einrichtungen der Universität München und ihre Begegnung mit dem Nationalsozialismus, Braubach 2008.

Susann Bosshard-Kälin/Daniela Schwegler, Unter der Haube. Diakonissen erzählen aus ihrem Leben, Frauenfeld 2011.

Diakonissenhaus Bern (Hg.), Ich würde schon gehen. Berner Diakonissen erzählen, Bern 2011.

Diakoniewerk Bethanien (Hg.), 100 Jahre - aktueller denn je, Zürich 2011.

Diakonissenhaus Siloah (Hg.), 75 Jahre - Eine Festschrift, Gümligen 1993; Diakonieverband Ländli (Hg.), ... mit Gott unterwegs, 75 Jahre Diakonieverband Ländli, Oberägeri 1998.

Walter Eglin, 100 Jahre Schwesternheim Wilchingen, Schaffhausen 2004.

Ingunn Elstadt, District nursing between the local and the international. Northern Norway 1890-1940, in: Astri Andresen/Groenlie Tore u.a. (Hg.), Science, Culture and Politics. European perspectives on Medicine, Sickness and health. Conference proceedings. Bergen 2006, 173-186.

Hermann Findeisen/Gisela Staib (Hg.), Leben ungeschminkt. Diakonissen erzählen, Marburg an der Lahn 2009.

Norbert Friedrich/Martin Wolff (Hg.): Diakonie in der Gemeinschaft. Perspektiven gelingender Mutterhausdiakonie, Neukirchen 2011.

Gerhard Fürstler, Der Glaube, der durch die Liebe tätig ist, Gallneukirchen 2007.

Ute Gause, Kirchengeschichte und Genderforschung. Eine Einführung in protestantischer Perspektive, Tübingen 2006.

Ute Gause, Aufbruch der Frauen - Das vermeintlich «Weibliche〉 der weiblichen Diakonie, in Jochen-Christoph Kaiser/Rajah Scheepers (Hg.), Dienerinnen des Herrn - Beiträge zur weiblichen Diakonie des 19. und 20. Jahrhunderts, Leipzig 2010, 57-71.

Ute Gause, die Diakonisse - Veränderungen des Berufsbildes zwischen dem 19. Und dem 21. Jahrhundert, in: Norbert Friedrich/Martin Wolff (Hg.), Diakonie in Gemeinschaft. Perspektiven gelingender Mutterhausdiakonie, Göttingen 2011, 191-201.

Geschichtswelten. Abstractband zur wissenschaftlichen Tagung der Pflege- und Gesundheitsberufe, 24.05.2013 bis 25.05.2013, im Deutschen HygieneMuseum in Dresden. Geschichte der Pflege- und Gesundheitsberufe, lehren und lernen: Ambulante Versorgung, Dresden 2013.

Jochen-Christoph Kaiser/Rajah Scheepers (Hg.), «Dienerinnen des Herrn». Beiträge zur Weiblichen Diakonie im 19. und 20. Jahrhundert, Leipzig 2010.

Jochen-Christoph Kaiser/Rajah Scheepers, Einführung: Weibliche Diakonie nach 1945 im Kontext der Kirchen- und Theologiegeschichte. Weichenstel- 
lungen und Herausforderungen, in: Jochen-Christoph Kaiser/Rajah Scheepers (Hg.), «Dienerinnen des Herrn». Beiträge zur Weiblichen Diakonie im 19. und 20. Jahrhundert, Leipzig 2010, 11-35.

Silvia Käppeli, Vom Glaubenswerk zur Pflegewissenschaft. Geschichte des MitLeidens in der christlichen, jüdischen und freiberuflichen Krankenpflege, Bern 2004.

Susanne Kreutzer, Nursing Body and Soul in the Parish. Lutheran Deaconess Motherhouses in Germany and the United States, in: Nursing History Review, Jg. 18 (2010), 134-150.

Susanne Kreutzer, Freude und Last zugleich. Zur Arbeits- und Lebenswelt evangelischer Gemeindeschwestern in Westdeutschland, in: Hähner-Rombach, Sylvelyn (Hg.), Alltag in der Krankenpflege. Geschichte und Gegenwart/ Everyday Nursing Life. Past and Present, Stuttgart 2009, S. 81-99.

Susanne Kreutzer, Gemeindepflege in Westdeutschland. Alltag und soziale Praxis am Beispiel des Diakonissenmutterhauses der Henriettenstiftung, in: Thiekötter, Andrea u.a. (Hg.), Alltag in der Pflege. Wie machten sich Pflegende bemerkbar? Beiträge des 8. Internationalen Kongresses zur Geschichte der Pflege 2008, Frankfurt a. M. 2009, S. 161-176.

Susanne Malchau Dietz, Nursing and history. Proceedings. First Danish History of Nursing Conference, Aarhus, 2009.

Susanne Malchau Dietz, "Angels in nursing: Images of nursing sisters in a Lutheran context in the nineteenth and twentieth centuries». Nursing Inquiry 2007, 14(4), 289-298.

Camen Mangion, «Good Teacher» or «Good Religious»?: The Professional Identity of Catholic Women Religious in nineteenth-century England and Wales, Women's History Review, 14:2 (2005), 223-242.

Camen Mangion, «To console, to nurse, to prepare for eternity». The Catholic sickroom in late nineteenth-century England, Women's History Review, 21:4 (2012), 657-678.

Camen Mangion Carmen: «Give them practical lessons». Catholic women religious and the transmission of nursing knowledge in late nineteenth-century England, in: Martin Dinges/Robert Jütte (Hg.), The Transmission of Health Practices (c. 1500 to 2000), Stuttgart 2011, 89-104.

Camen Mangion, Women, Religion and Medical Care in Victorian Britain, Manchester 2008.

Karen Nolte Karen, Einführung: Pflegegeschichte - Fragestellungen und Perspektiven, in: Medizinhistorisches Journal (47) 2012, 115-128.

Karen Nolte, Local missionaries. Community deaconesses in early nineteenth century health care, in: Martin Dinges/Robert Jütte (Hg.), The transmission of health practices (c. 1500 to 2000), Medizin, Gesellschaft und Geschichte, Beiheft (39), Stuttgart 2011, 105-116. 
Karen Nolte, Pflegende und ihre Kranken im 19. Jahrhundert, in: Atzl Isabel (Hg.): Who cares? Geschichte und Alltag der Krankenpflege, Frankfurt a. M. 2011, 33-42.

Karen Nolte, Relationship between doctors and nurses in Agnes Karll's Letters around 1900, in: Women's History Magazine 65/2011, 9-17.

Karen Nolte, Pflege von Sterbenden im 19. Jahrhundert - eine ethikgeschichtliche Annäherung, in: Susanne Kreutzer (Hg.): Transformationen im Verhältnis Pflegende- Patienten. Konzepte - Praxis - Erfahrungen vom 19. bis 21. Jahrhundert, Göttingen 2010, 87-108.

Karen Nolte/Susanne Kreutzer, Seelsorgerin «im Kleinen» - Krankenseelsorge durch Diakonissen im 19. und 20. Jahrhundert, in: Zeitschrift für medizinische Ethik 56/2010, 45-56.

Karen Nolte, Eine «heilige Schar einheimischer Missionarinnen» - Diakonissen in der Gemeindepflege im 19. Jahrhundert, in: Schoska M. Rechen/Andrea Thiekötter (Hg.): Alltag in der Pflege. Wie mach(t)en sich Pflegende bemerkbar?, Frankfurt a. M. 2009, 139-160.

Cathrine M. Prelinger, Religious dimension of the mid-nineteenth-century womens movement in Germany, New York 1994.

Hannelore Reiner, Das Amt der Gemeindeschwester am Beispiel der Diözese Oberösterreich. Entstehung, Funktion und Wandel eines Frauenberufs in der Kirche, Wien 1992.

Carole G. Rogers, Habits of Change: An Oral History of American Nuns. New York: Oxford University Press, 2011.

Heinz Rüegger/Christoph Sigrist, Diakonie eine Einführung. Zur theologischen Begründung helfenden Handelns, Zürich 2011.

Tobias Sarx/Rajah Scheepers, u. a. (Hg.), Protestantismus und Gesellschaft. Beiträge zur Geschichte von Kirche und Diakonie im 19. und 20. Jahrhundert, Stuttgart 2013.

Rajah Scheepers, Die transnationalen Zusammenhänge zwischen Innerer und Äusserer Mission - niedersächsische Kirchengeschichte in Übersee. Die Auslandstationen der Henriettenstiftung im 20. Jahrhundert, in: Jahrbuch der Gesellschaft für niedersächsische Kirchengeschichte 105 (2007), 167-201.

Rajah Scheepers, Mütterlich und kinderlos von Amts wegen - Konzeption von Mütterlichkeit in der weiblichen Diakonie nach 1945, in: Mütterliche Macht und väterliche Autorität - Elternbilder im deutschen Diskurs: Tel Aviver Jahrbuch für deutsche Geschichte (Tel Aviv Yearbook of German History) XXXVI (2008), 236-253.

Rajah Scheepers, Ökonomie und Theologie. Die Entwicklung des Unternehmens Diakonie in den Scharnierjahrzehnten 1960 bis 1980, in: Zeitschrift für Unternehmensgeschichte 54/2009, 25-49.

Rajah Scheepers, Fossilized fashion. Vom Ehrenkleid zum boundary marker. Die Tracht der Diakonisse im Wandel der Jahrhunderte, in: Elisabeth Hartlieb/ 
Jutta Koslowski/Ulrike Wagner-Rau (Hg.), Das neue Kleid. Feministischtheologische Perspektiven auf geistliche und weltliche Gewänder, Königstein 2010, 69-88.

Rajah Scheepers, «Ich bin genau der gleiche Mensch, ob ich Tracht oder zivil trage.» Zum gewandelten Selbst- und Fremdverständnis der Diakonissen im Spiegel der sich verändernden Diakonissentracht und ihrer Bedeutung, in: Jochen-Christoph Kaiser/Rajah Scheepers (Hg.), «Dienerinnen des Herrn». Beiträge zur Weiblichen Diakonie im 19. und 20. Jahrhundert, Leipzig 2010.

Rajah Scheepers, Frauen Gestalten Geschichte. Kirchengeschichte und Genderforschung, in: Thomas Braun/Cornelia Richter (Hg.), Junge Marburger Theologie, Marburg 2011, 111-136.

Rajah Scheepers, Das Jahr 1968 und die Diakonissen. Ein Beitrag zur Geschichte der Inklusion evangelischer Frauen in Kirche und Theologie sowie zur gleichzeitigen Erosion konfessioneller Frauenberufe, in: Heinrich Grosse/Hans Otte/Joachim Perels (Hg.), Erinnerungen an die Zukunft? Die 1960er/70er Jahre und die hannoversche Landeskirche, Hannover 2011, 465-487.

Regula Schär, «Der Wunsch Diakonisse zu werden schlummerte schon lange in mir». Diakonissen und ihr Mutterhaus in Riehen 1852-1872, Lizentiatsarbeit Universität Bern, 2008.

Christoph Sigrist (Hg.): Ökumenie und Diakonie. Orientierungen im Europa des Wandels, Zürich 2006.

Barbara Wall, American Catholic Nursing. An historical analysis, in: Medizinhistorisches Journal (47) 2012, 160-175; Wall Mann, American Catholic Hospitals. A Century of Changing Markets and Missions, New Brunswick 2011.

Barbara Wall Mann, American Catholic Nursing. An historical Analysis, in, Medizinhistorisches Journal (47), 2012, S. 160-175.

Lisa Zerull, Nursing out of the parish. A history of the Baltimore Lutheran Deaconesses 1893-1911, Umi 2011.

\section{A5. Religiöse Kulturgeschichte}

Urs Altermatt (Hg.), Katholische Denk- und Lebenswelten. Beiträge zur Kulturund Sozialgeschichte des Schweizer Katholizismus im 20. Jahrhundert, Freiburg 2003.

Urs Altermatt, Plädoyer für eine Kulturgeschichte des Katholizismus, in: KarlJoseph Hummel (Hg.), Zeitgeschichtliche Katholizismusforschung. Tatsachen, Deutungen, Fragen. Eine Zwischenbilanz, Paderborn/München/Wien/ Zürich 2004, 169-187.

Ute Daniel, Kompendium Kulturgeschichte. Theorien, Praxis, Schlüsselwörter, Frankfurt a. M. 2001.

Michael N. Ebertz, Erosion der Gnadenanstalt? Zum Wandel der Sozialgestalt von Kirche, Frankfurt a. M. 1998. 
Karl Gabriel, Christentum zwischen Tradition und Postmoderne, Freiburg i. Br./ Basel/Wien ${ }^{4} 1994$.

Burkhard Gladigow, Symbole und Symbolkontrolle als Ergebnis einer Professionalisierung von Religion, in: Rudolf Schlögl/Bernhard Giesen u. a. (Hg.), Die Wirklichkeit der Symbole. Grundlagen der Kommunikation in historischen und gegenwärtigen Gesellschaften, Konstanz 2004, 159-172.

Friedrich Wilhelm Graf, Die Wiederkehr der Götter. Religion in der modernen Kultur, München ${ }^{2} 2004$.

Wolfgang Hardtwig/Hans-Ulrich Wehler (Hg.), Kulturgeschichte Heute, Göttingen 1996.

Herbert Kühr, Katholische und evangelische Milieus. Vermittlungsinstanzen und Wirkungsmuster, in: Dieter Oberndörfer/Hans Rattinger/Karl Schmitt (Hg.), Wirtschaftlicher Wandel, religiöser Wandel und Wertwandel, Berlin 1985, 245-261.

Antonius Liedhegener, Katholizismusforschung in der Erweiterung: Internationaler Vergleich, konfessioneller Vergleich, neue methodische Zugänge. Kommentar, in: Karl-Joseph Hummel (Hg.), Zeitgeschichtliche Katholizismusforschung. Tatsachen, Deutungen, Fragen. Eine Zwischenbilanz, Paderborn/ München/Wien/Zürich 2004, 215-230.

Markus Ries, «Gilt für das literarische Schaffen Religion und Moral?» Katholische Kultur im Schatten der Modernismuskrise, in: Michael Graetz/Aram Mattioli (Hg.), Krisenwahrnehmungen im Fin de siècle. Jüdische und katholische Bildungseliten in Deutschland und der Schweiz, Zürich 1997, 231-243.

Rudolf Schlögl/Bernhard Giesen, u.a. (Hg.), Die Wirklichkeit der Symbole. Grundlagen der Kommunikation in historischen und gegenwärtigen Gesellschaften, Konstanz 2004.

Wolfgang Tischner, Neue Wege in der Katholizismusforschung: Von der Sozialgeschichte einer Konfession zur Kulturgeschichte des Katholizismus in Deutschland?, in: Karl-Joseph Hummel (Hg.), Zeitgeschichtliche Katholizismusforschung. Tatsachen, Deutungen, Fragen. Eine Zwischenbilanz, Paderborn/München/Wien/Zürich 2004, 197-213.

A6. Helvetia Sacra $(H S)^{428}$

Patrick Braun (Hg.), Die Kongregationen in der Schweiz 16.-18. Jahrhundert, HS VIII/1, Basel/Frankfurt a. M. 1994.

428 Neben den beiden Bänden zu den Kongregationen der Schweiz sind für dieses Forschungsvorhaben weitere nützliche Bände dieser Reihe zu nennen; hier insbesondere zu den Benediktinerinnen, Dominikanerinnen, Kapuzinerinnen, Prämonstratenserinnen und Zisterzienserinnen sowie zu den Erzbistümern und Bistümern. Zur Literaturübersicht der in der Reihe der HS erschienenen Bände seit 1972 siehe: www.helvetiasacra.ch. 
Patrick Braun, Religiöse Männer- und Frauenkongregationen des 16. und 18. Jahrhunderts (Einleitung), in: Patrick Braun (Hg.), Die Kongregationen in der Schweiz 16.-18. Jahrhundert, HS VIII/1, Basel/Frankfurt a. M. 1994, 19-68.

Patrick Braun (Hg.), Die Kongregationen in der Schweiz 19. und 20. Jahrhundert, HS VIII/2, Basel 1998.

Patrick Braun, Die religiösen Kongregationen im 19. und 20. Jahrhundert (Einleitung), in: Patrick Braun (Hg.), Die Kongregationen in der Schweiz 19. und 20. Jahrhundert, HS VIII/2, Basel 1998, 19-71.

\section{A7. Mutterhausspezifische Literatur ${ }^{429}$}

Baldegger Schwestern:

Matthäa Vock, Das Schwestern-Institut Baldegg, 1830-1930, Hochdorf 1930.

Josef Hartmann, Schwestern-Institut Baldegg, in: Die katholischen Orden und Kongregationen der Schweiz, Immensee 1937, 410-418.

Josef Strebel, Kaplan Leonz Blum. Gründer des Schwestern-Institutes Baldegg, Hochdorf 1969.

Matthäa Vock, Kleine Geschichte von Baldegg, Baldegg 1969.

Maria Martine Rosenberg, Baldegger Schwestern, in: Patrick Braun, Die Kongregationen in der Schweiz 19. und 20. Jahrhundert, HS VIII/2, Basel 1998, 72-93. Hilda-Maria Steiner, Baldegger Schwestern 1830-1980, Hochdorf 1980.

\section{Ilanzer Dominikanerinnen:}

Maria Magna Monssen, Die Ilanzer Schwesternkongregation, Ilanz 1950.

125 Jahre Ilanzer Dominikanerinnen. Festschrift zum 125-Jahr-Jubiläum der Kongregation, Ilanz 1990.

\section{Ingenbohler Schwestern:}

Hildburg Baumgartner/Markus Ries/Christian Schweizer u.a., Von der Not der Zeit getrieben. Maria Theresia Scherer - Theodosius Florentini: Briefe und Schriften, in: Helvetia Franciscana 45 (2016).

Cornelia Fürer, Geschichte des Institutes der Barmherzigen Schwestern vom hl. Kreuze in Ingenbohl (Kt. Schwyz), von dessen ersten Ursprunge an bis zum Jahre 1870. Mit einem Anhange: Programme und Verzeichnisse der Schwestern und Anstalten. Aus authentischen Quellen zusammengestellt. Mit mehreren Bildern, Ingenbohl 1870.

Cornelia Fürer, Geschichte des Institutes der Barmherzigen Schwestern vom hl. Kreuze in Ingenbohl (Kt. Schwyz), von dessen Gründung bis zum Jahre 1888, Ingenbohl 1888.

429 Nachfolgend eine Auswahl zu grösseren Gemeinschaften, die in der Ostschweiz Niederlassungen unterhielten oder immer noch unterhalten. 
Josef Hartmann, Die Kreuzschwestern von Ingenbohl, in: Die katholischen Orden und Kongregationen der Schweiz, Immensee 1937, 453-474.

Max Heimbucher, Die Orden und Kongregationen der katholischen Kirche, 2 Bde., Paderborn ${ }^{3} 1932-1934,42-44$.

Zoe Maria Isenring, Franziskanischer Lebensweg für Frauen. Die Zugehörigkeit der Barmherzigen Schwestern vom heiligen Kreuz Ingenbohl zur franziskanischen Ordensfamilie - Beitrag zum 150-jährigen Jubiläum der Ingenbohler Schwestern, in: Helvetia Franciscana, 34/2 (2005), 169-252.

Zoe Maria Isenring, P. Theodosius Florentini (1808-1865). «Den Strom nicht stauen, sondern ihm ein Bett anweisen».

Markus Ries, Gedanken aus einer anderen Welt. Maria Theresia Scherer und Theodosius Florentini in ihren Briefen, in: Helvetia Franciscana 41/2 (2012), S. 165-175.

Barmherzige Schwestern vom heiligen Kreuz Ingenbohl (Hg,), Hoffnung leben. 150 Jahre Barmherzige Schwestern vom heiligen Kreuz Ingenbohl (18562006), Ingenbohl 2006.

Ethelred Steinacher, Ingenbohl 1856-1956, Ingenbohl 1958.

Renata Pia Venzin, Ingenbohler Schwestern, in: Patrick Braun (Hg.), Die Kongregationen in der Schweiz 19. und 20. Jahrhundert, HS VIII/2, Basel 1998, 184-212.

\section{Menzinger Schwestern:}

Finbarr Coffey, Geist der Gründung - Auftrag für heute. Schwestern vom Hl. Kreuz, Kriens 2003.

Max Heimbucher, Die Orden und Kongregationen der katholischen Kirche, 2 Bde., Paderborn ${ }^{3} 1932-1934,42-44$.

Josef Hartmann, Die Lehrschwestern von Menzingen, in: Die katholischen Orden und Kongregationen der Schweiz, Immensee 1937, 431-452.

Rudolf Henggeler, Das Institut der Lehrschwestern vom hl. Kreuze in Menzingen (Kt. Zug) 1844-1944, Menzingen 1944.

Uta Teresa Fromherz, Menzinger Schwestern, in: Patrick Braun (Hg.), Die Kongregationen in der Schweiz 19. und 20. Jahrhundert, HS VIII/2, Basel 1998, 278-315.

Uta Fromherz/Josef Grünenfelder, Institut Menzingen Kanton Zug, hg. von der Gesellschaft für Schweizerische Kunstgeschichte GSK in Zusammenarbeit mit dem Institut der Schwestern vom Heiligen Kreuz, Menzingen, Bern 2011.

Carlo Moos, Zukunft aus dem Glauben. Bernarda Heimgartner und die Gründung des Menzinger Lehrschwesterninstituts im historischen Kontext, Kriens 2002.

Schwestern vom hl. Kreuz. Festschrift zur 150-Jahrfeier, Strasbourg 1994. 
Olivetaner-Benediktinerinnen Heiligkreuz, Cham:

Josef Hartmann, Die Schwesternkongregation Heiligkreuz, in: Die katholischen

Orden und Kongregationen der Schweiz, Immensee 1937, 419-430

Johannes Invernizzi, 100 Jahre Schwestern-Institut Heiligkreuz Cham, Zug 1962.

Patrick Braun, Olivetaner-Benediktinerinnen von Heiligkreuz, Cham, in: Pat-

rick Braun, Die Kongregationen in der Schweiz 19. und 20. Jahrhundert, HS VIII/2, Basel 1998, 338-356.

Festschrift 125 Jahre Kloster Heiligkreuz Cham, 1862-1987, Zug 1987.

\section{Pallottinerinnen:}

Vreni Merz, Vinzenz Pallotti. Ein leidenschaftliches Leben, München 2012.

\section{St. Anna-Schwestern Luzern:}

Gemeinschaft der St. Anna-Schwestern (Hg.), Die St. Anna-Schwestern. Geschichte einer Gemeinschaft, Luzern/Dallenwil 2015.

Gemeinschaft der St. Anna-Schwestern, Luzern, (Hg.), 100 Jahre Gemeinschaft der St. Anna-Schwestern 1909-2009. Weltoffen, weitblickend und nahe bei den Menschen, Baar 2009.

Raimund Netzhammer, Regens Wilhelm Meyer. Lebensbild des Gründers der St. Anna-Schwestern (1870-1912), Stans 1930.

St. Katharina-Werk:

Katharina-Werk (Hg.), Mut zum Wandel. 100 Jahre Katharina-Werk, Basel 2013.

A8. Konfessionelles Bildungs-/Erziehungs- und Gesundheitswesen in der Schweiz

Barbara Alzinger/Remi Frei, Die katholischen Erziehungsheime im 19. Jahrhundert in der deutschsprachigen Schweiz, Brugg/Zürich 1987.

Thomas Binotto, Durch alle Stürme. Bernarda Heimgartner - Ordensgründerin und Kämpferin für die Bildung der Frauen, Luzern 2003.

Rudolf Bolzern, Das höhere katholische Bildungswesen der Schweiz im Ancien Régime (16.-18. Jahrhundert): Eine Zeit ohne eigene Universität, in: Zeitschrift für Schweizerische Kirchengeschichte, 83 (1989), 7-38.

Georg Boner, Aus der älteren Geschichte des Mädchenschulwesens in der Schweiz, in: Schweizer Schule, 47/3 (1960), 89-95.

Sabine Braunschweig (Hg.), Pflege - Räume, Macht und Alltag. Beiträge zur Geschichte der Pflege, Zürich 2006.

Caroline Bühler, «Die Pflegi». Ein Spital für Frauen - von Frauen geschaffen und geprägt, Zürich 2007.

Adalhelm Bünter, Die industriellen Unternehmungen von P. Theodosius Florentini 1808-1865. Eine sozial-ethische Studie über Voraussetzungen und Grenzen der Sozialreform, Diss. Freiburg 1962. 
Adalhelm Bünter, P. Theodosius Florentini (1808-1865). Sozialreformer im Ordensgewand, in: Verein für wirtschaftshistorische Studien Zürich (Hg.), Schweizer Pioniere der Wirtschaft und Technik 17, Zürich 1966, 9-36.

Adalhelm Bünter, Pater Theodosius Florentini. Wegbereiter aus christlicher Leidenschaft, Freiburg 1985.

Maria-Crucis Doka, Das Schulwesen der Lehrschwestern vom Hl. Kreuz in Menzingen im Kt. Zug, 1844-1874. Ein Beitrag zur Bildungsgeschichte der Schweiz im 19. Jahrhundert, Diss. Freiburg 1963.

Melchior Estermann, Abriss einer Geschichte der Lehr- und Waisenhausschwestern der deutschen Schweiz, Separatdruck aus den «katholischen SchweizerBlätter», Luzern 1888.

Alfred Fritschi, Schwesterntum. Zur Sozialgeschichte der weiblichen Berufskrankenpflege in der Schweiz (1850-1930), Zürich 2006.

Alfons Fuchs, Im Dienste der Caritas. Handbuch der katholischen und geschlossenen Fürsorge, Luzern 1952.

Albert Gasser, Jenseitsfrömmigkeit und Sozialengagement im 19. Jahrhundert. Das Beispiel der sozialen Schwesterngemeinschaften des Theodosius Florentini, in: Katholische Soziallehre in neuen Zusammenhängen, Einsiedeln 1985 (Theologische Berichte 14), 89-103.

Wunibald Grüninger, Mut zum Wagnis. P. Theodosius Florentini als Reformer in Schule, Karitas und Sozialpolitik, Paderborn 1965.

Das «Katholische Handbuch der Schweiz», bearb. von Hermann Seiler, Luzern 1943.

Josef Hartmann (Hg.), Kirche und Leben. Jahrbuch der katholischen Schweiz 1931, Immensee 1931.

Josef Hartmann, Die katholischen Orden und Kongregationen der Schweiz, Immensee 1937.

Brigitte Haselböck, «Eine treue Dienstmagd im Weinberg des Herrn ...». Das Schwesterninstitut Baldegg 1830-1880, Lizentiatsarbeit Zürich, Luzern 1991.

Gisela Hauss/Béatrice Ziegler (Hg.), Helfen, Erziehen, Verwalten. Beiträge zur Geschichte der Sozialen Arbeit in St. Gallen, Zürich 2010.

Urs F.A. Heim, Leben für Andere. Die Krankenpflege der Diakonissen und Ordensschwestern in der Schweiz, Basel 1998.

Max Heimbucher, Die Orden und Kongregationen der katholischen Kirche, 2 Bde., Paderborn ${ }^{3} 1932-1934$, Neudruck: Aalen 1965.

Andreas Henkelmann, Caritasgeschichte zwischen katholischem Milieu und Wohlfahrtsstaat. Das Seraphische Liebeswerk (1889-1971), Paderborn 2008. Marianne-Franziska Imhasly, Aspekte zu den Anfängen der höheren Mädchenund Frauenbildung im 19. Jahrhundert bei den Schwesternkongregationen Baldegg, Menzingen und Ingenbohl, in: Helvetia Franciscana, 27/2 (1998), 283-321. 
Juliane Jacobi, Religiosität und Mädchenbildung im 19. Jahrhundert, in: Margret Kraul/Christoph Lüth (Hg.), Erziehung der Menschengeschlechter. Studien zur Religion, Sozialisation und Bildung in Europa seit der Aufklärung, Weinheim 1996, 45-62.

Ein Jubiläum der schweizerischen Caritas. Die schweizerischen caritativen Mutterhäuser: Die Institute Baldegg, Menzingen, Ingenbohl, Heiligkreuz in Cham, u. a., Caritas-Bulletin (1930).

Anne-Marie Käppeli, Religiosität und tätiges Leben: protestantische Pädagoginnen der französischsprachigen Schweiz Ende des 19. und Anfang des 20. Jahrhunderts, in: Margret Kraul/Christoph Lüth (Hg.), Erziehung der Menschengeschlechter. Studien zur Religion, Sozialisation und Bildung in Europa seit der Aufklärung, Weinheim 1996, 121-138.

Ulrich Knellwolf, Lebenshäuser. Vom Krankenasyl zum Sozialunternehmen 150 Jahre Diakoniewerk Neumünster, Zürich 2007.

Wilhelm Kissling (Hg.), Die katholischen Anstalten der Schweiz, Küssnacht 1932.

Linda Mantovani Vögeli, Fremdbestimmt zur Eigenständigkeit. Mädchenbildung gestern und heute, Chur/Zürich 1994.

Albert Müller, Für Gott und die Caritas. Zur Geschichte des Vereins für Kranken- und Wochenpflege im Kanton Zug und der Gemeinschaft der Liebfrauenschwestern, Zug 2005.

Sabina Neumayer, «Gerne dem wahren Fortschritt gefolgt». Schwesterngemeinschaften des Kantons Zug im Dienste höherer Töchterbildung: Maria Opferung in Zug, Institut Menzingen, Heiligkreuz Cham, in: Tugium, Jahrbuch des Staatsarchivs des Kantons Zug, 19 (2003), 61-88.

Paul Pflüger, Der Krankenschwesternstand in der Schweiz, Zürich/Leipzig 1929.

Dora Schlatter, Barmherzige Kirche. Geschichte der Diakonissenhäuser in der Schweiz, Bern 1944.

Urban Schwegler, Das Schwesterninstitut Baldegg und seine Institutsschule, 1830-1903, Lizentiatsarbeit Freiburg 1997.

Christian Schweizer/Markus Ries (Hg.), Theodosius Florentini (1808-1865) Vir famosus. Festschrift zum 200. Geburtstag, Helvetia Franciscana 38/1 (2009).

Nicole Stadler, Das Theresianum als Sozialisationsinstanz. Schulalltag und Wertevermittlung in einer Innerschweizer Mädchenschule, Lizentiatsarbeit Zürich 2005.

Josefa Stäger, Die pädagogischen Grundsätze des Pater Theodosius Florentini und die Pädagogik seiner Zeit, Manuskript, Ingenbohl 1973.

Pia Venzin, Theresianum Ingenbohl 1857-1997. 140 Jahre Werden und Wachsen einer Mittelschule für Mädchen, Schwyz 2002. 
Esther Vorburger-Bossart, «Was Bedürfnis der Zeit ...». Identitäten in der katholischen Frauenbildung. Die Innerschweizer Lehrschwesterninstitute Baldegg, Cham, Ingenbohl und Menzingen 1900-1980, Freiburg 2008.

Esther Vorburger-Bossart, Theodosius und die pädagogische Idee: Das Beispiel von Ingenbohl, in: Helvetia Franciscana, 38/1 (2009), 191-220.

Hedwig Wolff, Frauendienst in der Kraft Gottes. Geschichte der weiblichen Diakonie, Basel 1951.

Ursula Zürcher (Hg.), 100 Jahre Schweizerischer Hebammenverband 1894-1994, Bern 1994.

\section{Teil B: Oral History: Theorie und Anwendung}

Lynn Abrmas, Oral history theory, New York 2010.

Martina Althoff/u. a. (Hg.), Feministische Methodologien und Methoden. Traditionen, Konzepte, Erörterungen, Opladen 2001.

Martina Akermann/Markus Furrer u. a., Zwischenbericht Untersuchung Kinderheime im Kanton Luzern (1930-1970), Luzern 2011.

Martina Akermann/Markus Furrer u. a., Bericht Kinderheime im Kanton Luzern im Zeitraum von 1930-1970, Luzern 2012.

Susan H. Armitage/Patricia Hart u.a. (Hg.), Women's Oral History. The Frontier's Reader, London 2002.

Aleida Assmann, Wie wahr sind Erinnerungen?, in: Harald Welzer, Das soziale Gedächtnis. Geschichte, Erinnerung, Tradierung, Hamburg 2001, 103-122.

Jan Assmann, Kollektives Gedächtnis und kulturelle Identität, in: Jan Assmann/ Tonio Hölscher (Hg.), Kultur und Gedächtnis, Frankfurt a. M. 1988, 9-19.

Jan Assmann, Das kulturelle Gedächtnis. Schrift, Erinnerung und politische Identität in frühen Hochkulturen, München 1992.

Ruth Becker/Beate Kortendiek (Hg.), Handbuch Frauen- und Geschlechterforschung. Theorie, Methoden, Empirie, Wiesbaden 2004.

Cornelia Behnke/Michael Meuser (Hg.), Geschlechterforschung und qualitative Methoden, Opladen 1999.

Lydia Bendel-Maidl, Sr. Basilissa Hürtgen OSB, «Wer aus der Hoffnung lebt, tanzt ohne Musik.», in: Lydia Bendel-Maidl (Hg.), Katholikinnen im 20. Jahrhundert. Bilder, Rollen, Aufgaben, Berlin 2007, 261-286.

Sherna Berger Gluck/Daphne Patai (Hg.), Women's Words. The Feminist Practice of Oral History, New York/London 1991.

Ralf Bohnsack, Dokumentarische Methode und die Analyse kollektiver Biographien, in: Gerd Jüttemann/Hans Thomae (Hg.), Biographische Methoden in den Humanwissenschaften, Weinheim/Basel 1999, 213-230.

Ralf Bohnsack/u.a. (Hg.), Hauptbegriffe Qualitativer Sozialforschung, Opladen 2003.

Ralf Bohnsack, Rekonstruktive Sozialforschung, Opladen ${ }^{5} 2003$. 
Susann Bosshard/Daniela Schwegler, Unter der Haube. Diakonissen erzählen aus ihrem Leben, Frauenfeld 2011.

Roswitha Breckner, Von den Zeitzeugen zu den Biographen. Methoden der Erhebung und Auswertung lebensgeschichtlicher Interviews, in: Berliner Geschichtswerkstatt (Hg.): Alltagskultur, Subjektivität und Geschichte. Zur Theorie und Praxis von Alltagsgeschichte, Münster 1994, 199-222.

May M. Broda, Erfahrung, Erinnerungsinterview und Gender. Zur Methode der Oral History, in: Maguérite Bos/Bettina Vincenz u.a. (Hg.), Erfahrung: Alles nur Diskurs? Zur Verwendung des Erfahrungsbegriffes in der Geschlechtergeschichte. Beiträge der 11. Schweizerischen Historikerinnentagung 2002, Zürich 2004, 159-171.

Heinz Bude, Lebenskonstruktion als Gegenstand der Biographieforschung, in: Gerd Jüttemann/Hans Thomae (Hg.), Biographische Methoden in den Humanwissenschaften, Weinheim/Basel 1999, 247-258.

Barbara Dätwyler/Jürg Baillod: Mit-Leidenschaft. Krankenschwestern sprechen über ihren Beruf, Bern u. a.: Hans Huber 1995.

Barbara Dätwyler, Professionalisation in Nursing: The Swiss Case. PhD thesis, University of Nottingham: URL http://etheses.nottingham.ac.uk/528/, 2008.

Bettina Dausien, «Biographie» als rekonstruktiver Zugang zu «Geschlecht» Perspektiven der Biographieforschung, in: Doris Lemmermöhle/Dietlind Fischer u.a. (Hg.), Lesarten des Geschlechts. Zur De-Konstruktionsdebatte in der erziehungswissenschaftlichen Geschlechterforschung, Opladen 2000, 96-115.

Bettina Dausien, Erzähltes Leben - erzähltes Geschlecht? Aspekte der narrativen Konstruktion von Geschlecht im Kontext der Biographieforschung, in: Feministische Studien 2 (2001), 57-73.

Vera Deissner, Gottes Mägde oder christliche Kommunardinnen? Zum Selbstbild von Frauen im Nonnenkloster, in: Ulrike Krasberg (Hg.), Religion und weibliche Identität. Interdisziplinäre Perspektiven auf Wirklichkeiten, Marburg 1999, S. 19-34.

Angelika Diezinger (Hg.), Erfahrung mit Methode. Wege sozialwissenschaftlicher Frauenforschung (Forum Frauenforschung), Bd. 8, Freiburg i. Br. 1994.

Maria Ecker, «Tales of Edification and Redemption». Oral/Audiovisual Holocaust Testimonies and American Public Memory 1945-2005, Salzburg 2006.

Michael von Engelhardt, Biographie und Identität. Die Rekonstruktion und Präsentation von Identität im mündlichen und autobiographischen Erzählen, in: Walter Sparn (Hg.), Wer schreibt meine Lebensgeschichte. Biographie, Autobiographie, Hagiographie und ihre Entstehungszusammenhänge, Gütersloh 1990, 197-247.

Ruth Felgentreff, Ist verpflichtet den Judenstern zu tragen. Eine Dokumentation über die Diakonissen Johannae und Erna Aufricht. Kaiserswerth-Theresienstadt-Ausschwitz, o. O. (Düsseldorf) o. J. ${ }^{32003) ~[1973] . ~}$ 
Uwe Flick/u. a. (Hg.), Handbuch qualitative Sozialforschung, Weinheim ${ }^{3} 2012$.

Edith Franke/Gisela Matthiale u.a. (Hg.), Frauen Leben Religion. Ein Handbuch empirischer Forschungsmethoden, Stuttgart 2002.

Frauenforschungsprojekt zur Geschichte der Theologinnen Göttingen (Hg.), «Darum wagt es, Schwestern ...». Zur Geschichte evangelischer Theologinnen in Deutschland, Neukirchen/Vluyn 1994.

Frauenforschungsprojekt zur Geschichte der Theologinnen Göttingen (Hg.), Querdenken. Beiträge zur feministisch-befreiungstheologischen Diskussion. Festschrift für Hannelore Erhart zum 65. Geburtstag, Pfaffenweiler 1992.

Norbert Friedrich, Gedächtnisorte der Mutterhauskolonie. Die Archive und historischen Sammlungen in den Mutterhäusern, in: Der weite Raum 2 (2004), 47-50.

Norbert Friedrich, «Man wusste immer erst war, wenn man gerufen wurde»Die Institution als Schicksal, in: Werner Fuchs, Biographische Forschung. Eine Einführung in Praxis und Methode, Opladen 1984, 265-267.

Birgit Funke, «Gehorsam als diakonische Gesinnung〉? Kaiserswerther Schwestern erzählen von ihrer Probezeit, in: Siri Fuhrmann/Erich Geldbach u.a. (Hg.), Soziale Rollen von Frauen in Religionsgemeinschaften. Ein Forschungsbericht mit Beiträgen von Ute Gause, u. a., Münster 2003, 105-118.

Birgit Funke, Wahlfamilien - Rekonstruktion der Erinnerung an die Arbeit in Kinderheimen und Kindergärten, in: Ute Gause/Cordula Lissner (Hg.), Kosmos Diakonissenmutterhaus. Geschichte und Gedächtnis einer protestantischen Frauengemeinschaft, Leipzig 2005, 174-195.

Manfred Gabriel (Hg.), Paradigmen der akteurszentrierten Soziologie, Wiesbaden 2004.

Ute Gause/Cordula Lissner (Hg.), Kosmos Diakonissenmutterhaus. Geschichte und Gedächtnis einer protestantischen Frauengemeinschaft, Leipzig 2005.

Barney Glaser/Anselm Strauss, The Discovery of Grounded Theory. Strategies for qualitative research, Chicago 1967/dies., Grounded Theory. Strategien qualitativer Forschung, Bern 1998.

Roland Girtler, Methoden der Feldforschung, Wien 2001.

Kathrin Gisbert, Das autobiographische Gedächtnis in der psychologischen Biographieforschung, BIOS 14 (2001), 26-36.

Silke Göttsch/Albrecht Lehmann (Hg.), Methoden der Volkskunde, Berlin 2001. Arnd Götzelmann, Frauendiakonie und Krankenpflege. Im Gespräch mit Diakonissen in Speyer, Heidelberg 2009.

Ronald J. Grele, Methodologische und theoretische Probleme der Oral History, in: Lutz Niethammer (Hg.), Lebenserfahrung und kollektives Gedächtnis. Die Praxis der Oral History, Frankfurt a. M. 1985, 195-220.

Martina Gugglberger, «Ich wollte immer nach Afrika». Lebensgeschichten deutschsprachiger Missionsschwestern nach 1945, in: Ingrid Böhler/Eva 
Pfanzelter u.a. (Hg.), 7. Österreichischer Zeitgeschichtetag 2008, Innsbruck/ Wien/Bozen, 551-559.

Martina Gugglberger, «Ich wollte immer nach Afrika». Lebensgeschichten deutschsprachiger Missionsschwestern nach 1945 (Diss. Uni Salzburg 2009).

Martina Gugglberger, Abenteuer Mission. Lebensgeschichten von Missionarinnen als Beitrag zur Expatriate-Forschung», in: ÖZG, (2/2013), 139-158.

Martina Gugglberger, Reguliertes Abenteuer. Missionarinnen in Südafrika nach 1945, L'Homme (22), Wien 2014.

Karen Hagemann, «Ich glaub nicht, dass ich Wichtiges zu erzählen hab ...». Oral History und historische Frauenforschung, in: Herwart Vorländer (Hg.), Oral History. Mündlich erfragte Geschichte, Göttingen 1990, 29-48.

Karin Hartewig, «Wer sich in Gefahr begibt, kommt [nicht] darin um» - sondern macht eine Erfahrung!», in: Berliner Geschichtswerkstatt (Hg.), Alltagskultur, Subjektivität und Geschichte. Zur Theorie und Praxis von Alltagsgeschichte, Münster 1994, 110-124.

Andreas Heller/Theres Weber/u.a. (Hg.), Religion und Alltag. Interdisziplinäre Beiträge zu einer Sozialgeschichte des Katholizismus in lebensgeschichtlichen Aufzeichnungen, Wien/Köln 1990.

Andreas Heller, Zur Sozialgeschichte des Katholizismus in lebensgeschichtlichen Erinnerungen, in: ders./Theres Weber/u. a. (Hg.), Religion und Alltag. Interdisziplinäre Beiträge zu einer Sozialgeschichte des Katholizismus in lebensgeschichtlichen Aufzeichnungen, Wien/Köln 1990, 287-300.

Thomas Heinze, Qualitative Sozialforschung. Einführung, Methodologie und Forschungspraxis, München/Wien 2001.

Peter Hersche, Agrarische Religiosität. Landbevölkerung und traditionaler Katholizismus in der voralpinen Schweiz 1945-1960, Baden 2013.

Christa Hoffmann-Riem, Die Sozialforschung einer interpretativen Soziologie. Der Datengewinn. In Kölner Zeitschrift für Sozilogie und Sozialpsychologie 32 (1980), 339-373.

Christel Hopf/Elmar Weingarten, Hg.), Qualitative Sozialforschung, Stuttgart 1979.

Gertrud Hüwelmeier, Närrinnen Gottes. Lebenswelten von Ordensfrauen, Münster 2004.

Ulrike Jureit, Erinnerungsmuster. Zur Methodik lebensgeschichtlicher Interviews mit Überlebenden der Konzentrations- und Vernichtungslager, Hamburg 1999.

Gerd Jüttemann/Hans Thomae (Hg.), Biographische Methoden in den Humanwissenschaften, Weinheim/Basel 1999.

Veronika Jüttemann, Im Glauben vereint. Männer und Frauen im protestantischen Milieu Ostwestfalens 1845-1918, L'Homme (Bd. 16), Köln 2008.

Uwe Kaminsky, «Frontverkürzung» - Krankenpflege in der Zeit des Nationalsozialismus, in: Ute Gause/Cordula Lissner (Hg.), Kosmos Diakonissenmutter- 
haus. Geschichte und Gedächtnis einer protestantischen Frauengemeinschaft, Leipzig 2005, 217-242.

Uwe Kaminsky, Erinnerungskultur und Krankenpflegegeschichte in der Zeit des Nationalsozialismus. Das Beispiel der Kaiserswerther Diakonissen, in: Sabine Braunschweig (Hg.), Pflege - Räume, Macht und Alltag. Beiträge zur Geschichte der Pflege, Zürich 2006, 223-231.

Waltraud Kannonier-Finster/Meinrad Ziegler, Frauen-Leben im Exil. Biographische Fallgeschichten, Wien 1996.

Anne Kitsch/u. a. (Hg.), «Wir sind so frei». Biographische Skizzen von Diakonissen, Bielefeld-Bethel 2001.

Stephanie Klein, Theologie und empirische Biographieforschung. Methodische Zugänge zur Lebens- und Glaubensgeschichte und ihre Bedeutung für eine erfahrungsbezogene Theologie, (Praktische Theologie heute 19), Stuttgart/ Berlin/Köln 1994.

Sabine Kowal/Daniel C. O'Connell, Zur Transkription von Gesprächen, in: Uwe Flick/u.a. (Hg.), Handbuch qualitative Sozialforschung, Weinheim 3/2012, 437-447.

Susanne Kreutzer, Vom «Liebesdienst» zum modernen Frauenberuf. Die Reform der Krankenpflege nach 1945, Frankfurt a. M. 2005.

Susanne Kreutzer, Hierarchien in der Pflege. Zum Verhältnis von Eigenständigkeit und Unterordnung im westdeutschen Pflegealltag, in: Sabine Braunschweig, (Hg.), Pflege, Räume, Macht und Alltag. Beiträge zur Geschichte der Pflege, Zürich 2006, 203-211.

Susanne Kreutzer, Fürsorglich-Sein. Zur Praxis evangelischer Gemeindepflege nach 1945, in: L'Homme 19 (2008), H. 1, 61-79.

Susanne Kreutzer, Gemeindepflege in Westdeutschland. Alltag und soziale Praxis am Beispiel des Diakonissenmutterhauses der Henriettenstiftung, in: Andrea Thiekötter/u. a. (Hg.), Alltag und Pflege. Wie machten sich Pflegende bemerkbar? Beiträge des 8. Internationalen Kongresses zur Geschichte der Pflege 2008, Frankfurt a. M. 2009, 161-176.

Susanne Kreutzer, Freude und Last zugleich. Zur Arbeits- und Lebenswelt evangelischer Gemeindeschwestern in Westdeutschland, in: Sylvelyn HähnerRombach (Hg.), Alltag in der Krankenpflege. Geschichte und Gegenwart/ Everyday Nursing Life. Past und Present (=Medizin, Gesellschaft und Geschichte, Beiheft 32), Stuttgart 2009, 81-99.

Susanne Kreutzer, Arbeit mit Quellenvielfalt. Zu den Chancen einer Verknüpfung von mündlichen und schriftlichen Quellen am Beispiel von Diakonissenbiographien, in: Hans-Georg Soeffner (Hg.), Unsichere Zeiten. Herausforderungen gesellschaftlicher Transformationen. Verhandlungen des 34 . Kongresses der Deutschen Gesellschaft für Soziologie in Jena. Wiesbaden 2010 (CD-Rom). 
Andreas Kruse/Eric Schmitt, Halbstrukturierte Interviews, in: Gerd Jüttemann/ Hans Thomae (Hg.), Biographische Methoden in den Humanwissenschaften, Weinheim/Basel 1999, 161-174.

Udo Kuckartz, Einführung in die computergestützte Analyse qualitativer Daten, Wiesbaden ${ }^{2} 2007$.

Annette Kuhn, Oral History und Erinnerungsarbeit: Zur mündlichen Geschichtsschreibung und historischen Erinnerungskultur, in: Ruth Becker/Beate Kortendiek (Hg.), Handbuch Frauen- und Geschlechterforschung. Theorie, Methoden, Empirie, Wiesbaden 2004, 311-313.

Siegfried Lamnek, Qualitative Sozialforschung, Bd. 2, Methoden und Techniken, Weinheim ${ }^{3} 1995$.

Siegfried Lamnek, Qualitative Sozialforschung, Weinheim 4/2005.

Heidemarie Lauterer-Pirner, Liebestätigkeit für die Volksgemeinschaft. Der Kaiserswerther Verband deutscher Diakonissenmutterhäuser in den ersten Jahren des NS-Regimes, Göttingen 1994.

Heidemarie Lauterer, «Ja, das haben wir miterlebt, aber wir konnten dagegen ja nichts machen.» Diakonische Werke und Verbände in der Konsolidierungsphase des NS-Gewaltregimes am Beispiel des Kaiserswerther Verbands, in: Gerhard Besier (Hg.), Zwischen «nationaler Revolution und militärischer Aggression». Transformationen in Kirche und Gesellschaft 1934-1939, München 2000, 103-120.

Albert Lichtblau, «Keeping Distance», in: Philippe Denis/James Worthington (Hg.), The power of Oral History. Healing and Development, Pieterrmaritzburg 2002, 814-824.

Cordula Lissner, Migration ohne Migrationserfahrungen? Kaiserswerther Schwestern im Auslandeinsatz, in: Ute Gause/Cordula Lissner (Hg.), Kosmos Diakonissenmutterhaus. Geschichte und Gedächtnis einer protestantischen Frauengemeinschaft, Leipzig 2005, 243-274.

Cordula Lissner, Macht und Alltag im Interview. Ein Oral-History-Projekt zur Pflegegeschichte, in: Sabine Braunschweig (Hg.), Pflege - Räume, Macht und Alltag. Beiträge zur Geschichte der Pflege, Zürich 2006, 193-201.

Cordula Lissner, «Alles konnten wir Ihnen natürlich nicht erzählen» - Oral History als Forschungsmethode in der Diakoniegeschichte, in: Jochen-Christoph Kaiser/Rajah Scheepers (Hg.), «Dienerinnen des Herrn». Beiträge zur Weiblichen Diakonie im 19. und 20. Jahrhundert, Leipzig 2010, 83-101.

Gabriele Lucius-Hoene/Arnulf Deppermann, Rekonstruktion narrativer Identität. Ein Arbeitsbuch zur Analyse narrativer Interviews, Opladen 2002.

Gabriele Lucius-Hoene, Rekonstruktion narrativer Identität, Wiesbaden 3/2009. Alf Lüdtke, Geschichte und Eigensinn, in: Berliner Geschichtswerkstatt (Hg.), Alltagskultur, Subjektivität und Geschichte, Alltagskultur, Subjektivität und Geschichte. Zur Theorie und Praxis von Alltagsgeschichte, Münster 1994, 139-153. 
Hans J. Markowitsch, Bewusste und unbewusste Formen des Erinnerns. Befunde aus der neurowissenschaftlichen Gedächtnisforschung, in: Harald Welzer (Hg.), Das soziale Gedächtnis. Geschichte, Erinnerung, Tradierung, Hamburg 2001, 219-239.

Hans J. Markowitsch/Harald Welzer, Das autobiographische Gedächtnis. Hirnorganische Grundlagen und biosoziale Entwicklung, Stuttgart 2005.

Philipp Mayring, Qualitative Inhaltsanalyse. Grundlagen und Techniken, Weinheim ${ }^{7} 2000$

Ines Meder/Dietmar Meder, Sr. Dr. Hildegardis Wulff OSB (1896-1961) - eine deutsche Katholikin im schwäbischen Banat, in: Lydia Bendel-Maidl (Hg.), Katholikinnen im 20. Jahrhundert. Bilder, Rollen, Aufgaben, Berlin 2007, 131-157.

Jens Murken, Erinnerungskultur und Biographie. Zur kommunikativen Praxis der Geschichte, in: Aus evangelischen Archiven 43 (2003), 37-45.

Christine Müller-Botsch. Der Lebenslauf als Quelle. Fallrekonstruktive Biographieforschung anhand personenbezogener Akten, in: ÖZG 19/2008/2, 38-63.

Anette Neff, Mündliche Lebensberichte im Zentralarchiv der EKHN. Methoden der Erfassung, Aufbewahrung und Benutzung, in: Aus evangelischen Archiven 43/2003, 55-71.

Anette Neff (Hg.), Oral History und Landeskirchengeschichte: Religiosität und kirchliches Handeln zwischen Institution und Biographie, Darmstadt 2004.

Vera Niemann, Nicht der Rede wert. Die Privatisierung der Kriegsfolgen in der frühen Bundesrepublik. Lebensgeschichtliche Erinnerungen, Münster 1999.

Lutz Niethammer (Hg.), Lebenserfahrung und kollektives Gedächtnis. Die Praxis der Oral History, Frankfurt a. M. 1985.

Julia Obertreis (Hg), Oral History. Basistexte Geschichte, Stuttgart 2012.

Ulrich Oevermann, Die objektive Hermeneutik als unverzichtbare methodologische Grundlage für die Analyse von Subjektivität. Zugleich eine Kritik der Tiefenhermeneutik, in: Thomas Jung/Stefan Müller-Doohm (Hg.), Wirklichkeit im Deutungsprozess. Verstehen und Methoden in den Kultur- und Sozialwissenschaften, Frankfurt a. M. 1993, 106-189.

Robert Perks/Alistair Thomson (Hg.), The Oral History Reader. Second Edition, London/New York 2006.

Alexander von Plato, Oral History als Erfahrungswissenschaft. Zum Stand der mündlichen Geschichte in Deutschland, in: BIOS. Zeitschrift für Biographieforschung und Oral History 1991, Heft 1. $97 \mathrm{ff}$.

Alexander von Plato, Erfahrungsgeschichte - von der Etablierung der Oral History, in: Gerd Jüttemann/Hans Thomae (Hg.), Biographische Methoden in den Humanwissenschaften, Weinheim/Basel 1999, 60-74.

Alexander von Plato, "Janus als Zeuge»? Zeitzeugen-Erinnerung und das Problem der «Verdrängung», in: Horch und Guck (2006), Nr. 2, 1-5. 
Alessandro Portelli, What makes Oral History different, in: Robert Perks/Alistair Thomson (Hg.), The Oral History Reader. Second Edition, London/New York 2006, 32-42.

Chamberlayne Prue/u.a. (Hg.), The turn to biographical methods in social science. Comparative issues an examples, London 2000.

Aglaja Przyborski/Monika Wohlrab-Sahr, Qualitative Sozialforschung, 4, München 2013.

Margrit Reiter, Die Generation danach. Der Nationalsozialismus im Familiengedächtnis, Innsbruck/Wien/Bozen 2006.

Gerhard Riemann, Narratives Interview, in: Ralf Bohnsack/u. a. (Hg.), Hauptbegriffe Qualitativer Sozialforschung, Opladen 2003, 120-122.

Markus Ries/Valentin Beck (Hg.), Fürsorge und Gewalt in kirchlich geführten Erziehungsanstalten im Kanton Luzern, Zürich 2013.

Gabriele Rosenthal, Erlebte und erzählte Geschichte. Gestalt und Struktur biographischer Selbstbeschreibungen, Frankfurt a. M. 1995.

Gabriele Rosenthal, Interpretative Sozialforschung. Eine Einführung, Weinheim $2 / 2008$.

Alfred Schütz, Wissenschaftliche Interpretation und Alltagsverständnis menschlichen Handelns, in: ders., Gesammelte Aufsätze I, Den Haag 1971, 3-54.

Fritz Schütze, Zur Hervorlockung und Analyse von Erzählungen thematisch relevanter Geschichten im Rahmen soziologischer Feldforschung, in: Arbeitsgruppe Bielefelder Soziologen (Hg.), Kommunikative Sozialforschung, München 1976, 159-260.

Fritz Schütze, Technik des narrativen Interviews in Interaktionsfeldstudien, Bielefeld 1977.

Fritz Schütze, Biographieforschung und narratives Interview, in: Neue Praxis 13 (1983), 283-292.

Fritz Schütze, Kognitive Figuren des autobiographischen Stegreiferzählens, in: Martin Kohli/Günther Robert (Hg.), Biographie und soziale Wirklichkeit. Neue Beiträge und Forschungsperspektiven, Stuttgart 1984. 78-117.

Hugo Slim, Ways of Listening, in: Robert Perks/Alistair Thomson (Hg.), The Oral History Reader. Second Edition, London/New York 2006, 143-154.

Kerstin Söderblom/Andrea Bieler, Erinnerungsarbeit und Biographieforschung. Anknüpfungspunkte für die Aufarbeitung der Geschichte protestantischer Theologinnen, in: Frauenforschungsprojekt zur Geschichte der Theologinnen Göttingen (Hg.), «Darum wagt es, Schwestern ...». Zur Geschichte evangelischer Theologinnen in Deutschland, Neukirchen/Vluyn 1994, 4-25.

Regina Sommer, Lebensgeschichte und gelebte Religion von Frauen. Eine qualitativ-empirische Studie über den Zusammenhang von biographischer Struktur und religiöserOrientierung, Stuttgart 1998.

Walter Sparn (Hg.), Wer schreibt meine Lebensgeschichte. Biographie, Autobiographie, Hagiographie und ihre Entstehungszusammenhänge, Gütersloh 1990. 
Kathrin Spring, Sie arbeitete und betete und wurde reichlich mit Kindern gesegnet. Schwester Possenta Ritter, geboren 1916, Klosterfrau, Lehrerin, Baldegg, in: Christina Niederer/Kathrin Spring u. a. (Hg.), Der Rede wert. Frauenleben im letzten Jahrhundert. 15 Porträts aus dem Kanton Luzern, Zürich 2002, 111-123.

Jörg Stolz/Edmée Ballif, Die Zukunft der Reformierten. Gesellschaftliche Megatrends - kirchliche Reaktionen, Zürich ${ }^{2} 2010$.

Jürgen Straub, Historisch-psychologische Biographieforschung, Heidelberg $1989,150 \mathrm{f}$.

Anselm Strauss/Juliet Corbin, Grounded Theory. Grundlagen Qualitativer Sozialforschung, Weinheim 1996.

Malte Thiessen, Gedächtnisgeschichte. Neue Forschungen zur Entstehung und Tradierung von Erinnerungen, in: Archiv für Sozialgeschichte, 48 (2008), 607-634.

Angela Treiber, «Diakonie ist kein Handwerk, sondern ein Dienewerk». Weiblichkeitsideale und gelebte Frömmigkeit. Zur Identitätsbildung evangelischer Feierabendschwestern in Lebensgeschichten, in: Bayrisches Jahrbuch für Volkskunde 2000, 111-128.

Esther Vorburger-Bossart, Tomasina Färber (1897-1983), Marina Guntli (geboren 1930), Martina Hässig (1912-1999). Der Posten Sargans, in: Marina Widmer/Heidi Witzig (Hg.), St. Galler Frauen - 200 Porträts. Blütenweiss bis rabenschwarz, Zürich 2003, $119 \mathrm{f}$.

Herwart Vorländer, (Hg.), Oral History, Göttingen 1990.

Harald Welzer, Das gemeinsame Verfertigen von Vergangenheit im Gespräch, in: ders. (Hg.), Das soziale Gedächtnis. Geschichte, Erinnerung, Tradierung, Hamburg 2001, S. 160-178.

Harald Welzer, Die Medialität des menschlichen Gedächtnisses, in: BIOS. Zeitschrift für Biographieforschung, Oral History und Lebensverlaufsanalysen, 1/2008, 15-27.

Harald Welzer, Das kommunikative Gedächtnis. Eine Theorie der Erinnerung, München ${ }^{3} 2011$.

Dorothee Wierling, Oral History, in: Maurer, Michael (Hrg.), Neue Themen und Methoden der Geschichtswissenschaft, Stuttgart 2003, 81-151.

Clemens Wischermann (Hg.), Vom kollektiven Gedächtnis zur Individualisierung der Erinnerung, Stuttgart 2002.

\section{Zeitschriften}

BIOS. Zeitschrift für Biographieforschung und Oral History (seit 2001, für Biographieforschung. Oral History und Lebensverlaufsanalysen).

Traverse. «Oral history» 1 (1994). 